Aus dem Institut für Pflanzenpathologie und Pflanzenschutz der Georg-August-Universität Göttingen

\title{
Untersuchungen zur Schadwirkung von Sclerotinia sclerotiorum \\ (Lib. de Bary) und Verticillium longisporum (comb. nov. Karapapa) \\ in Winterraps (Brassica napus)
}

\author{
Dissertation \\ zur Erlangung des Doktorgrades \\ der Fakultät für Agrarwissenschaften \\ der Georg-August-Universität Göttingen
}

\author{
vorgelegt von \\ Sarah Dunker \\ geboren in Helmstedt
}

Göttingen, im Dezember 2005 
D7

1. Referent: Prof. Dr. Andreas von Tiedemann

2. Korreferent: Prof. Dr. Petr Karlovsky

Tag der mündlichen Prüfung: 02.02.2006 


\section{Inhaltsverzeichnis}

\section{Abkürzungen und Symbole}

$\begin{array}{lr}\text { 1. Einleitung } & 1\end{array}$

2. Material und Methoden 6

$\begin{array}{lr}2.1 \text { Chemikalien } & 6\end{array}$

2.2 Medien, Puffer und Trenngele $\quad 7$

2.2.1 Nährmedien für die Pilzkultivierung 8

2.2.2 Nährmedien für die Bakterienkultivierung 9

2.2.3 Puffer und Lösungen für den ELISA-Test 10

2.2.4 Puffer und Lösungen für die molekularen Untersuchungen $\quad 11$

$\begin{array}{ll}2.3 \text { Pilze, Bakterien und Plasmide } & 15\end{array}$

2.3.1 Herkunft und Anzucht der verwendeten Pilzisolate 15

2.3.2 Verwendete Bakterien und Plasmide $\quad 15$

2.4 Feldversuche zur Schadwirkung von Pathogenen an Winterraps 17

$\begin{array}{ll}\text { 2.4.1 Versuchsstandort und Versuchsanlage } & 17\end{array}$

$\begin{array}{ll}2.4 .2 \text { Versuchsfaktoren } & 19\end{array}$

2.4.2.1 Sorten 19

2.4.2.2 Inokulationstermin 20

2.4.2.3 Anbautechnische Maßnahmen $\quad 21$

2.4.2.4 Simulierung von Pflanzenverlusten 22

2.5 Witterungsverlauf und Pflanzenentwicklung in den Jahren 2001 bis $2005 \quad 23$

$\begin{array}{ll}2.6 \text { Inokulationsmethoden } & 27\end{array}$

$\begin{array}{ll}\text { 2.6.1 Sclerotinia-Inokulation } & 27\end{array}$

2.6.1.1 Produktion von Sclerotinia-Inokulum 27

2.6.1.2 Zahnstocher-Inokulation mit S. sclerotiorum 29

2.6.1.3 Gewächshausversuche zur Optimierung der Zahnstochermethode 29

2.6.1.4 Sclerotinia-Inokulation mit der

Zahnstochermethode im Feldversuch $\quad 30$

2.6.2 Verticillium-Inokulation im Feld 31

$\begin{array}{ll}2.7 \text { Befallsermittlung } & 32\end{array}$ 
2.7.1 Sclerotinia-Bonitur im Feld

32

2.7.2 Verticillium-Bonitur im Labor 32

2.7.3 Berechnung des Befallsindex für $V$. longisporum 32

2.7.4 Erfassung weiterer Schaderreger im Feld 33

2.8 Quantifizierung des bodenbürtigen Inokulums von Verticillium spp. 33

2.9 Erhebung der Ertragsparameter 34

2.10 Nachweis von $V$. longisporum in Pflanzenmaterial mittels ELISA 35

2.10.1 Probenahme und -aufbereitung 35

2.10.2 Durchführung des ELISA-Tests 36

2.11 Statistische Verrechnung der Daten 36

2.12 Validierung der Wirtschaftlichkeit von Fungizidmaßnahmen gegen

$\begin{array}{ll}\text { S. sclerotiorum von 1991-2003 } & 37\end{array}$

$\begin{array}{ll}2.12 .1 \text { Datensammlung } & 37\end{array}$

2.12.2 Kostenfaktoren 38

2.13 Entwicklung einer artspezifischen PCR zum in vitro-Nachweis von

$\begin{array}{ll}V . \text { longisporum } & 38\end{array}$

2.13.1 Isolierung von Nukleinsäuren $\quad 38$

2.13.1.1 Isolierung genomischer DNA aus filamentösen Pilzen 38

2.13.1.1.1 DNA-Extraktion mit dem DNeasy Plant Mini/

Maxi Kit 38

2.13.1.1.2 DNA-Extraktionsmethode nach MöLLER et al. (1992)

2.13.1.1.3 DNA-Extraktion für die Verwendung im Southern-Blot

40

2.13.1.2 Isolierung von Plasmiden aus E. coli $\quad 40$

2.13.1.3 Isolierung von DNA-Fragmenten aus Agarosegelen 41

2.13.1.4 Isolierung von DNA-Fragmenten aus

Polyacrylamidgelen $\quad 41$

2.13.2 Quantifizierung der extrahierten DNA 42

2.13.3 Aufreinigung von Nukleinsäuren 43

2.13.3.1 Phenol-Chloroform-Extraktion 43

2.13.3.2 Ethidiumbromid-Phenolextraktion $\quad 43$

2.13.4 Fällung von Nukleinsäuren $\quad 44$

2.13.4.1 Ammoniumacetat-Isopropanol-Fällung $\quad 44$ 
2.13.4.2 Ammoniumacetat-Ethanol-Fällung 44

2.13.5 Enzymatische Modifikation der DNA 44

2.13.5.1 Spaltung der DNA durch Restriktionsendonukleasen $\quad 44$

2.13.5.2 Dephosphorylierung linearisierter Plasmide 44

2.13.5.3 Phosphorylierung von Fragmenten zur Klonierung 45

2.13.5.4 Generierung von DNA-Fragmenten mit glatten Enden 45

2.13.5.5 Ligationsreaktion 46

2.13.5.6 Markierung von DNA-Sonden durch PCR 46

2.13.6 Transformation chemokompetenter E. coli-Stämme 47

2.13.7 Nachweis der Integration klonierter DNA-Fragmente 47

2.13.7.1 Selektion rekombinanter Plasmide 47

2.13.7.2, „colony-PCR“ 48

2.13.7.3 Restriktionsspaltung mit $P v u I I \quad 49$

2.13.8 DNA-Transfer mittels Vakuum-Blot 49

2.13.9 DNA-DNA-Hybridisierung und Stringenzwaschung 50

2.13.10 Detektion markierter DNA-Sonden $\quad 50$

2.13.11 Amplifikation der DNA mittels PCR-fingerprinting 51

2.13.12 DNA-Sequenzierung 52

2.13.13 In vitro-Nachweis von $V$. longisporum mittels PCR 53

2.13.13.1 Primer Design $\quad 53$

2.13.13.2 Amplifikationsbedingungen $\quad 54$

2.13.14 Geldokumentation $\quad 54$

2.13.14.1 Dokumentation der Agarosegele $\quad 54$

2.13.14.2 Dokumentation der Polyacrylamidgele $\quad 54$

3. Ergebnisse

3.1 Einfluss unterschiedlicher Methoden der Inokulumproduktion auf die S. sclerotiorum Befallshäufigkeit im Gewächshaus 55

3.2 Auftreten von Krankheiten und Schädlingen im Feld 57

3.2.1 Einfluss von Jahr, Sorte, Inokulationstermin und Bestandesdichte auf die S. sclerotiorum Befallshäufigkeit 57

3.2.2 Auftreten weiterer Krankheiten und Schädlinge $\quad 60$

3.3 Befalls-Verlust-Relationen von S. sclerotiorum an Winterraps 61 
3.3.1 Einfluss des Inokulationstermins auf die Schadwirkung von S. sclerotiorum

3.3.2 Einfluss von Aussaattermin und Bestandesdichte auf die Schadwirkung von $S$. sclerotiorum

3.3.3 Einfluss der Sorte auf die Schadwirkung von S. sclerotiorum $\quad 73$

3.4 Ertragswirkung der mechanischen Pflanzenreduktion

3.5 Wirtschaftlichkeit von Fungizidmaßnahmen gegen S. sclerotiorum

in den Jahren 1991 - 2003

3.5.1 Ertragswirkung von Fungizidapplikationen im Winterraps in den Jahren 1991 bis 2003

3.5.2 Wirkungsgrad von Fungiziden gegen S. sclerotiorum 82

3.5.3 Beurteilung der Wirtschaftlichkeit

3.6 Entwicklung ökonomischer Schadensschwellen für S. sclerotiorum in Winterraps

3.7 Eingliederung der Schadensschwelle in das Prognosemodell SkleroPro

3.8 Befalls-Verlust-Relationen von $V$. longisporum an Winterraps

3.81 Bodenbürtiges Inokulum von Verticillium spp. in

Abhängigkeit von der ausgebrachten Inokulummenge

3.8.2 Befallsparameter in Abhängigkeit von der ausgebrachten Inokulummenge

3.8.3 Einfluss von $V$. longisporum auf Ertrag und Qualität des Erntegutes

3.9 Befallsverlauf von $V$. longisporum in Winterraps im Feld

3.10 In vitro-Nachweis von $V$. longisporum mittels artspezifischer PCR

$\begin{array}{ll}\text { 3.10.2 Spezifität der DNA-Sonden } & 102\end{array}$

3.10.3 Artspezifischer in vitro-Nachweis von $V$. longisporum 103

3.10.3.1 Eigenschaften der artspezifischen Primer 103

3.10.3.2 Optimierung der PCR-Reaktion

3.10.3.3 Ergebnisse der Spezifitätsuntersuchungen des Primerpaares pV1O2/3-6

3.10.3.4 Nachweisgrenzen für den in vitro-Nachweis von 
4.1 Schadwirkung pilzlicher Pathogene an Winterraps

4.1.1 Befalls-Verlust-Relationen für S. sclerotiorum an Winterraps

4.1.2 Befalls-Verlust-Relation für $V$. longisporum an Winterraps

4.2 Wirtschaftlichkeit von Fungizidmaßnahmen zur Bekämpfung von

S. sclerotiorum in Winterraps

4.3 Wirtschaftliche Schadensschwellen für S. sclerotiorum an Winterraps

5. Zusammenfassung 


\section{Abkürzungen und Symbole}

$\begin{array}{ll}{ }^{\circ} & \text { Prozent } \\ { }^{\circ} \mathrm{C} & \text { Grad Celsius } \\ \mu & \text { mikro } \\ \mu 1 & \text { Mikroliter } \\ € & \text { Euro } \\ \mathrm{Abb} . & \text { Abbildung } \\ \mathrm{AK} & \text { Antikörper } \\ \mathrm{b} & \text { Regressionskoeffizient }\end{array}$

BBCH Codierung der phänologischen Entwicklungsstadien von Winterraps

$\mathrm{BN} \quad$ Boniturnote

BSA Bundessortenamt

cfu colony forming units

dNTP Desoxy-Nucleotidtriphosphat

dpi days post inoculation

dt Dezitonne

$\mathrm{E}_{592} \quad$ Extinktion bei einer Wellenlänge von $592 \mathrm{~nm}$

ELISA enzyme linked immunosorbent assay

ERIC Enterobacterial repetitive intergenic consensus

g Gramm

$g \quad$ Erdbeschleunigung

$\mathrm{H}_{2} \mathrm{O}_{\text {bidest }} \quad$ doppelt destilliertes Wasser

h Stunden

ha Hektar

Kap. Kapitel

Kö. Körner

$1 \quad$ Liter

M Mol

mg Milligramm

$\min \quad$ Minuten

ml Milliliter

$\mathrm{mm} \quad$ Millimeter 


\begin{tabular}{|c|c|}
\hline $\mathrm{mM}$ & Millimol \\
\hline MS & Mikrosklerotien \\
\hline $\mathrm{nm}$ & Nanometer \\
\hline $\mathrm{Nm}$ & Nährmedium \\
\hline OD & optische Dichte \\
\hline $\mathrm{p}$ & Irrtumswahrscheinlichkeit \\
\hline PCR & Polymerase-Kettenreaktion \\
\hline PDA & Potato Dextrose Agar \\
\hline PDB & Potato Dextrose Broth \\
\hline Pfl. & Pflanzen \\
\hline Pfu-Pol. & Pfu-Polymerase \\
\hline pg & Picogramm \\
\hline pNPP & 4-Nitrophenylphosphat \\
\hline PPK & Phosphatgepufferte physiologische Kochsalzlösung \\
\hline ppm & parts per million \\
\hline PVP & Polyvinylpyrrolidone \\
\hline$r^{2}$ & Bestimmtheitsmaß \\
\hline RAPD & Random amplification of polymorphic DNA \\
\hline rpm & Umdrehungen pro Minute \\
\hline RSA & Rinderserumalbumin \\
\hline RT & Raumtemperatur \\
\hline SD & Standardabweichung \\
\hline SE & Standardfehler \\
\hline $\sec$ & Sekunden \\
\hline StrAp & Streptavidin-alkalische Phosphatase \\
\hline $\mathrm{t}$ & Tonne \\
\hline Tab. & Tabelle \\
\hline Taq-Pol. & Taq-Polymerase \\
\hline $\mathrm{TKG}$ & Tausendkorngewicht \\
\hline $\mathrm{U}$ & Unit \\
\hline VNTR & Variable number of tandem repeats \\
\hline Vol. & Volumen \\
\hline Wdh. & Wiederholung \\
\hline $\mathrm{w} / \mathrm{v}$ & Gewichtsanteil zu Volumenanteil \\
\hline
\end{tabular}




\section{Einleitung}

In den letzten Jahrzehnten ist eine zunehmende Intensivierung in der Landwirtschaft zu verzeichnen. Vor allem die Produktionsfläche von Winterraps wies in den vergangenen Jahren einen stetigen Anstieg auf. Während im Jahr 1998 auf einer Fläche von rund 1.220.000 ha Winterraps angebaut wurde, ist diese für das Jahr 2005 auf geschätzte 1.267.000 ha angestiegen (UFOP, 2005a; STATISTISCHES BUNDESAMT, 2005). In der EU nimmt Deutschland mit rund 29\% der EU-weiten Rapsproduktion die führende Stellung ein, gefolgt von Frankreich mit rund 25\% und Großbritannien und Polen mit jeweils rund 13\% (UFOP, 2005b). Die Ursachen für eine stetig steigende Rapsanbaufläche sind zum einen in der erhöhten Nachfrage nach ernährungsphysiologisch hochwertigen Rapsspeiseölen (REUTER, 2003) zu suchen, zum anderen nimmt die Produktion von Raps auf Stilllegungsflächen als nachwachsender Rohstoff eine wichtige Stellung ein (BOCKEY, 2003). Rund 322.000 ha Stilllegungsfläche wurden im Jahr 2005 mit Raps bestellt (FACHAGENTUR NACHWACHSENDE ROHSTOFFE, 2005). Als nachwachsender Rohstoff wird ein großer Anteil des Rapsöls für die Produktion von Biodiesel eingesetzt, die in den letzten Jahren eine starke Zunahme von $5.000 \mathrm{t}$ in 1993 auf rund 650.000 t im Jahr 2003 verzeichnete (FACHAGENTUR NACHWACHSENDE ROHSTOFFE, 2005).

Neben der hohen Bedeutung der Verarbeitungsprodukte von Raps, weist diese Kulturpflanze auch sehr gute agronomische Eigenschaften auf. Durch die lange Bodenbedeckung und die intensive Durchwurzelung des Bodens führt der Rapsanbau zu einer Verbesserung des Bodengefüges und zur Unterdrückung von Unkräutern (GEISLER, 1988; HONERMEIER et al., 2002) und hat somit einen hohen Vorfruchtwert (Christen \& Siebling, 1999).

Einhergehend mit einer Intensivierung des Rapsanbaus und der dadurch bedingten Verkürzung der Fruchtfolge ist ein verstärktes Auftreten pilzlicher Pathogene zu verzeichnen. Hierbei sind vor allem die bodenbürtigen Erreger Sclerotinia sclerotiorum und Verticillium longisporum zu nennen (AMELUNG et al., 1996), die neben dem Erreger der Wurzelhals- und Stängelfäule Phoma lingam (HALL et al., 1993; BARBETTI \& KHANGURA, 1999; ZHOU et al., 1999; PAUL, 2003) von besonderer wirtschaftlicher Bedeutung sind. Weitere Rapskrankheiten, wie die Kohlhernie (Plasmodiophora brassicae), Rapsschwärze (Alternaria brassicae), Cylindrosporiose (Cylindrosporium concentricum), Falscher Mehltau (Peronospora parasitica) oder Botrytis cinerea 
(Grauschimmel) treten nur vereinzelt in deutschen Rapsanbaugebieten auf und sind von vergleichsweise geringerer Bedeutung.

S. sclerotiorum und $V$. longisporum produzieren mit den (Mikro-) Sklerotien Dauerorgane, die im Boden bis zu 15 Jahre überdauern können (HEALE \& KARAPAPA, 1999) und somit die Inokulumquelle für die Infektion nachfolgend angebauter Rapsbestände darstellen. Hierdurch sind auch langfristig erhöhte Infektionswahrscheinlichkeiten für diese Pathogene gegeben.

Das Auftreten und die Ausbreitung von S. sclerotiorum sind maßgeblich abhängig von Witterungsparametern, so dass erhebliche Unterschiede in der Befallshäufigkeit in unterschiedlichen Jahren auftreten können. Für die durch S. sclerotiorum hervorgerufene Weißstängeligkeit wurden in verschiedenen Jahren Ertragsausfälle von bis zu 50\% berichtet (KRÜGER, 1973; POPE et al., 1989; LAMEY, 1998; LANDSCHREIBER, 2004).

Da im deutschen Rapssortiment zurzeit nur eine sehr geringe Variabilität hinsichtlich der Anfälligkeit der Sorten gegenüber S. sclerotiorum $\mathrm{zu}$ finden ist, stellt die Applikation chemischer Fungizide oder des biologischen Fungizids Contans (VON TiEdemanN et al., 2000) die einzige Bekämpfungsmöglichkeit dar. In der Praxis werden vielfach prophylaktische Fungizidapplikationen zur Vermeidung hoher Ertragsausfälle durch S. sclerotiorum durchgeführt. Aufgrund der starken Begrenzung von Infektionen auf die Blütezeit des Rapses sowie der geringen kurativen Wirkung der Fungizide ist das zeitliche Behandlungsfenster auf die Blütephase eingeschränkt. Erste Symptome sind häufig jedoch erst ab Ende der Blüte $\mathrm{zu}$ finden und können somit nicht als Entscheidungshilfe für eine Fungizidapplikation herangezogen werden. Wirtschaftlichkeitsuntersuchungen auf Basis von Feldversuchen der amtlichen Pflanzenschutzdienste der Länder aus dem Zeitraum 1981 bis 1990 ergaben, dass lediglich $27 \%$ der durchgeführten Fungizidmaßnahmen wirtschaftlich waren (WAHMHOFF, 2000). Die Ursache für den großen Anteil unwirtschaftlicher Fungizidbehandlungen ist in den witterungsbedingten starken Schwankungen in der Befallshäufigkeit der verschiedenen Jahre zu suchen.

Eine Möglichkeit zur Vermeidung unwirtschaftlicher Fungizidapplikationen stellt die Anwendung eines schadensbezogenen Prognosemodells dar. Ein Beispiel hierfür ist das Modell MEVA-PLUS für Mehltau in Winterweizen (BRUNS, 1996). Im Bereich der 
Unkraut- und Schädlingsbekämpfung ist die Anwendung von Schadensschwellen eine gebräuchliche Methode der Entscheidungshilfe. Durch die Anwendung des Göttinger Schadensschwellenmodells (CeBrUs, WERNER et al., 2002) zur gezielten Unkrautbekämpfung im Winterraps konnten in der Validierungsphase rund $21 \%$ unwirtschaftliche Herbizidanwendungen eingespart werden (WERNER, 1996).

Für eine gezielte Bekämpfungsentscheidung für $S$. sclerotiorum wird vielfach die Notwendigkeit eines Prognosemodells in der Literatur geäußert (STEINBACH \& Broschewitz, 1997; Krostitz, 1998; Garbe, 1999). In Deutschland wurden bereits verschiedene Modelle zur Abschätzung der Gefährdung eines Sclerotinia-Befalls auf Basis von Witterungsparametern und schlagspezifischen Daten von AHLERS \& HINDORF (1987), AHLERS (1989) und FRIESLAND (2000) entwickelt. Auch in anderen Ländern wurden auf Basis von Witterungsparametern, Apothezienentwicklung, Blütenblattbefall sowie schlagspezifischen Faktoren Prognoseansätze für S. sclerotiorum entwickelt (Nordin et al., 1992; KÖPPL \& SCHMIDT, 1993; TURKINGTON \& MORRALL, 1993; Twengström et al., 1998; BOM \& BOLAND, 2000). Der entscheidende Baustein für eine wirtschaftliche Entscheidungshilfe, eine wirtschaftliche Schadensschwelle, fehlt diesen Modellen jedoch. Schadensschwellen und Befalls-Verlust-Relationen stellen die essentiellen Grundlagen für eine wirtschaftlich und ökologisch sinnvolle Bekämpfungsentscheidung dar (JAMES, 1974; MADDEN ET AL., 1981; MADDEN, 1983; WALKER, 1983; CAMPBell \& MAdDen, 1990; Freier et al., 1994). Im Jahr 2002 wurde deshalb ein Projekt mit dem Ziel der Erarbeitung eines schlagspezifischen, schadensbezogenen Prognosemodells für die Bekämpfung von S. sclerotiorum im Winterraps gestartet. Aufbauend auf dem von FrIESLAND (2000) entwickelten Modell SKLERO, wurde das neue Prognosemodell SkleroPro erarbeitet. Neben der Berechnung des SclerotiniaBefalls aus Witterungsparametern kann auf Basis einer integrierten wirtschaftlichen Schadensschwelle durch Eingabe schlagspezifischer Faktoren eine schlagspezifische Bekämpfungsentscheidung errechnet werden (KOCH \& VON TIEDEMANN, 2005a, b). Im Rahmen der vorliegenden Arbeit wurden in dreijährigen Feldversuchen Befalls-VerlustRelationen für S. sclerotiorum in Abhängigkeit der Parameter Inokulationstermin, Aussaattermin, Bestandesdichte und Sorte erarbeitet. Basierend auf diesen Ergebnissen sowie der wirtschaftlichen Auswertung eines Datensatzes aus den offiziellen Feldversuchen der Pflanzenschutzdienste der Länder aus den Jahren 1991-2003 wurden die in SkleroPro integrierten wirtschaftlichen Schadensschwellen entwickelt. 
Im Gegensatz zu der seit bereits vielen Jahren in Deutschland auftretenden Weißstängeligkeit (S. sclerotiorum), gewinnt die Rapswelke, hervorgerufen durch V. longisporum, in Deutschland erst seit Mitte der achtziger Jahre zunehmend an Bedeutung. Besonders in den intensiven Rapsanbaugebieten MecklenburgVorpommerns und Schleswig-Holsteins ist ein zum Teil rapider Anstieg im Befallsauftreten zu verzeichnen (DAEBELER et al., 1988; GÜNZELMANN \& PAUL, 1990; Zeise \& Seidel, 1990; Zeise \& Steinbach, 2004). In Teilen Schwedens war ein vermehrtes Auftreten von $V$. longisporum an Raps bereits in den 60er Jahren zu beobachten (SVENSSON \& LERENIUS, 1987).

Die durch $V$. longisporum verursachten Ertragsausfälle werden auf 10 bis $50 \%$ geschätzt (DAebeler et al., 1988; GünZelmann \& PAUl, 1990; PAul, 2003). An Einzelpflanzen konnte sogar ein maximaler Ertragsverlust von $70 \%$ durch einen starken Befall mit $V$. longisporum festgestellt werden (WOLF \& WEINERT, 2003; ZEISE \& STEINBACH, 2004). Durch mögliche Kompensationseffekte im Feld können diese Ergebnisse jedoch nicht auf die Feldebene übertragen werden. Um genauere Informationen über die Schadwirkung im Feld zu erlangen, wurden in zweijährigen Feldversuchen Befalls-Verlust-Relationen für $V$. longisporum erarbeitet.

Im Gegensatz zu S. sclerotiorum sind zur Bekämpfung von $V$. longisporum weder resistente Sorten noch Fungizide auf dem Markt erhältlich. Da Infektionen ausschließlich über Myzel aus den Mikrosklerotien ausgehen, wird eine direkte Bekämpfung von $V$. longisporum durch Fungizide zusätzlich erschwert. Eine Erweiterung der Fruchtfolge stellt somit die einzige Möglichkeit dar, die Infektionswahrscheinlichkeit mit $V$. longisporum zu minimieren (ALSTRÖM, 2000; ZEISE \& STEINBACH, 2004).

Die Diagnose dieses Erregers im Feld stellt sich aufgrund der zum Teil sehr unspezifischen Symptome als schwierig dar (DAEBELER et al., 1985; KRÜGER, 1986; ZEISE \& SteINBACH, 2004; STEINBACH et al., 2005). Streifenförmige Stängelverbräunungen und halbseitige Vergilbung der Laubblätter mit beginnender Abreife sind die ersten Symptome, die jedoch auch durch natürliche Seneszenz hervorgerufen werden können (SVENSSON \& LERENIUS, 1987). Erst die im weiteren Verlauf der Symptomentwicklung gebildeten Mikrosklerotien im befallenen Gewebe lassen eine sichere Diagnose zu (DAEBeler et al., 1988; ZeISE \& SEIDEL, 1990; Zeise \& STEINBACH, 2004). In der Literatur beschriebene Ergebnisse weisen jedoch darauf hin, 
dass schon $\mathrm{zu}$ sehr frühen Entwicklungsstadien der Pflanzen Infektionen mit V. longisporum stattfinden können (ZEISE \& SEIDEL, 1990; ZHOU et al., 2006). Im Rahmen dieser Arbeit wurden ELISA-Untersuchungen von im Verlauf der Vegetationsperiode entnommen Pflanzenproben durchgeführt, um Aufschluss über den Infektionsverlauf von $V$. longisporum im Feld zu erhalten. Durch die Entwicklung artspezifischer Primer sollte weiterhin die Grundlage für eine sensitive PCR-Methode zum in planta-Nachweis von $V$. longisporum geschaffen werden, um eine frühzeitige Diagnose zu ermöglichen. Eine artspezifische Detektionsmethode ermöglicht außerdem die Abgrenzung von $V$. longisporum zu anderen Verticillium-Arten, was besonders im Hinblick der Diskussion um den Verursacher der Rapswelke von Bedeutung ist.

Viele Jahre wurde der Erreger $V$. dahliae als Verursacher der Rapswelke angesehen. Vergleichende Untersuchungen von Isolaten aus Raps mit denen anderer Kulturpflanzen zeigten, dass diese Verticillium-Isolate deutlich längere Konidien aufwiesen. Bereits im Jahr 1961 konnte STARK von Meerrettich ein $V$. dahliae-Isolat mit ungewöhnlich langen Konidien isolieren, welches als $V$. dahliae var. longisporum bezeichnet wurde. In verschiedenen Untersuchungen konnten neben der Konidienlänge noch weitere Merkmale gefunden werden, durch die eine klare Abgrenzung der langsporigen $V$. dahliae-Isolate zu den kurzsporigen $V$. dahliae-Isolaten ermöglicht wurde. Aufgrund der Unterschiede in Wirtsspezifität, Morphologie, Physiologie und molekulargenetischen Merkmalen schlugen KARAPAPA et al. (1997) vor, die langsporige Varietät als eigene Art $V$. longisporum anzuerkennen. Anders als $V$. dahliae weist $V$. longisporum eine enge Wirtsspezifität für Kruziferen auf (ZEISE \& VON TIEDEMANN, 2002b).

Ableitend aus den geschilderten Problemstellungen ergaben sich als Ziele dieser Arbeit die Erstellung wirtschaftlicher Schadensschwellen für S. sclerotiorum auf Basis von Befalls-Verlust-Relationen und Wirtschaftlichkeitsuntersuchungen von Fungizidmaßnahmen gegen dieses Pathogen, die Erarbeitung von Befalls-Verlust-Relationen zur Abschätzung des Schadpotentials und Untersuchungen zur Befallsdynamik von $V$. longisporum, sowie die Entwicklung artspezifischer Primer als Grundlage einer sensitiven PCR-Nachweismethode. 


\section{Material und Methoden}

\subsection{Chemikalien}

Sämtliche hier aufgeführten Chemikalien stammen, soweit nicht anders erwähnt, aus Deutschland. Nicht aufgeführte Chemikalien stammen von der Firma Merck, Darmstadt, Deutschland. Soweit nicht anders angegeben, stammen alle verwendeten Enzyme von der Firma Fermentas, St. Leon-Rot.

Agar

Agarose NEEO

Ameisensäure

Anti-Digoxigenin-AP

Bacto-Trypton

Blocking-Reagenz

CDP-Star

Chloramphenicol

Chloroform

Chlortetracyclin

Cetyltrimethylammoniumbromid (CTAB)

Czapek-Dox-Broth

Diethanolamin

Diethylether

DIG-11-dUTP, alkali-labil

DIG Easy Hyb

DNeasy Plant Mini/Maxi Kit

dNTP-Mix

EDTA

Ethidiumbromid

Glyzerin

Hefe Extrakt

Isopropanol

Loading Dye Solution

MacConkey Agar

Maleinsäure
Serva, Heidelberg

Roth, Karlsruhe

Roth, Karlsruhe

Roche, Mannheim

Fluka, Neu-Ulm

Roche, Mannheim

Roche, Mannheim

Roth, Karlsruhe

AppliChem, Darmstadt

Serva, Heidelberg

Roth, Karlsruhe

Scharlau, Barcelona, Spanien

Fluka, Neu-Ulm

Roth, Karlsruhe

Roche, Mannheim

Roche, Mannheim

Qiagen, Hilden

Fermentas, St. Leon-Rot

amresco, Solon, USA

Fluka, Neu-Ulm

Roth, Karlsruhe

Roth, Karlsruhe

AppliChem, Darmstadt

Fermentas, St. Leon-Rot

Difco, Detroit, Michigan, USA

Fluka, Neu-Ulm 
$\mathrm{MgCl}_{2}, 25 \mathrm{mM}$

PCR-Puffer, 10x

PDB-Medium

$P f u$-Polymerase

Phenol

pNPP (4-Nitrophenylphosphat)

Polyacrylamid

Polyethylenglycol (PEG)

Polygalacturonsäure Na-Salz

Polyvinylpyrrolidone 25

Proteinase $\mathrm{K}$

Rinderserumalbumin

RNaseA

SDS (Natriumdodecyl Sulfat)

Streptavidin-AP-Konjugat

TEMED

Tergitol NP 10

TRIS

Triton X 100

Tween 20

Vent-Polymerase
Fermentas, St. Leon-Rot

New England Biolabs, Frankfurt/Main;

Fermentas, St. Leon-Rot

Scharlau, Barcelona, Spanien

Sigma, Steinheim

Fermentas, St. Leon-Rot

AppliChem, Darmstadt

Serva, Heidelberg

AppliChem, Darmstadt

AppliChem, Darmstadt

Sigma, Steinheim

Serva, Heidelberg

Roth, Karlsruhe

Roche, Mannheim

Serva, Heidelberg

AppliChem, Darmstadt

Roche, Mannheim

Fluka, Neu-Ulm

Sigma, Steinheim

Roth, Karlsruhe

AppliChem, Darmstadt

Scharlau, Barcelona, Spanien

New England Biolabs, Frankfurt/Main

\subsection{Medien, Puffer und Trenngele}

Alle aufgeführten Medien und Puffer wurden mit doppelt destilliertem Wasser angesetzt. Die Bestandteile wurden zunächst in einer geringen Menge Wasser gelöst und anschließend auf das Endvolumen aufgefüllt. Zur Sterilisierung wurden die Medien für $15 \mathrm{~min}$ bei $120^{\circ} \mathrm{C}$ autoklaviert.

Soweit nicht anders angegeben wurden die Antibiotika aus einer 1000fach konzentrierten sterilfiltrierten Stammlösung nach dem Autoklavieren in das auf ca. $50^{\circ} \mathrm{C}$ abgekühlte Medium gegeben. Die Stammlösungen wurden in doppelt destilliertem Wasser angesetzt und bei $-20^{\circ} \mathrm{C}$ gelagert. 


\subsubsection{Nährmedien für die Pilzkultivierung}

PDB-Medium:

$\begin{array}{ll}\text { PDB } & 24 \mathrm{~g} \\ \mathrm{H}_{2} \mathrm{O}_{\text {bidest }} & \text { ad } 1000 \mathrm{ml}\end{array}$

PDA-Medium:

PDB

Agar

$\mathrm{H}_{2} \mathrm{O}_{\text {bidest }}$

Czapek-Dox-Medium:

Czapek-Dox Broth

Agar

$\mathrm{H}_{2} \mathrm{O}_{\text {bidest }}$
$24 \mathrm{~g}$

$15 \mathrm{~g}$

ad $1000 \mathrm{ml}$

$33,5 \mathrm{~g}$

$15 \mathrm{~g}$

ad $1000 \mathrm{ml}$

Selektivmedium für Verticillium spp. (STEINBACH et al., 2002, verändert nach HARRIS et al., 1993):

Bodenextrakt

Czapek-Dox-Mineralsalzmischung

Polygalacturonsäure Na-Salz

Tergitol NP 10

Chloramphenicol

Chlortetracyclin

Streptomycinsulfat

$\mathrm{H}_{2} \mathrm{O}_{\text {bidest }}$
24,0 ml

$5,0 \mathrm{~g}$

$2,5 \mathrm{~g}$

$0,5 \mathrm{ml}$

$50,0 \mathrm{mg}$

$50,0 \mathrm{mg}$

$50,0 \mathrm{mg}$

ad $1000 \mathrm{ml}$

Bodenextrakt:

- $1000 \mathrm{~g}$ humosen Boden in $1000 \mathrm{ml} \mathrm{H}_{2} \mathrm{O}$ schütteln

- Boden sedimentieren lassen

- Überstand dekantieren und bei 1500 rpm 10 min zentrifugieren

- Überstand als Bodenextrakt verwenden 
Czapek-Dox-Mineralsalzmischung:

$\begin{array}{ll}\mathrm{NaNO}_{3} & 3 \mathrm{~g} \\ \mathrm{~K}_{2} \mathrm{HPO}_{4} & 1 \mathrm{~g} \\ \mathrm{KCl} & 0,5 \mathrm{~g} \\ \mathrm{MgSO}_{4} \cdot 7 \mathrm{H}_{2} \mathrm{O} & 0,5 \mathrm{~g} \\ \mathrm{FeSO}_{4} \cdot 7 \mathrm{H}_{2} \mathrm{O} & 0,01 \mathrm{~g}\end{array}$

\subsubsection{Nährmedien für die Bakterienkultivierung}

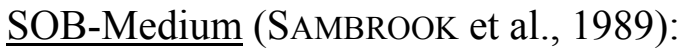

$\begin{array}{ll}\text { Bacto-Trypton } & 20 \mathrm{~g} \\ \text { Hefe-Extrakt } & 5 \mathrm{~g} \\ \mathrm{NaCl} & 0,5 \mathrm{~g}\end{array}$

Die Komponenten wurden in $\mathrm{H}_{2} \mathrm{O}_{\text {bidest }}$ gelöst, bevor $10 \mathrm{ml}$ einer $250 \mathrm{mM} \mathrm{KCl-Lösung}$ addiert wurden. Dann wurde der $\mathrm{pH}-$ Wert mit $5 \mathrm{~N} \mathrm{NaOH}$ auf $\mathrm{pH}$ 7,0 eingestellt und auf 11 aufgefüllt. Das Nährmedium wurde im Autoklaven sterilisiert. Vor Gebrauch wurden $5 \mathrm{ml}$ einer separat autoklavierten $2 \mathrm{M} \mathrm{MgCl}_{2}$-Lösung addiert.

SOC-Medium (SAMBROOK et al., 1989):

Für die Herstellung des SOC-Mediums wurde das oben beschriebene SOB-Medium nach dem Erkalten mit $20 \mathrm{ml}$ einer $1 \mathrm{M}$ sterilen Glukoselösung versehen.

Terrific-Broth (TARTOF \& HOBBS, 1987):

$\begin{array}{ll}\text { Bacto-Trypton } & 12,0 \mathrm{~g} \\ \text { Hefe-Extrakt } & 24,0 \mathrm{~g} \\ \text { Glyzerin } & 4,0 \mathrm{ml}\end{array}$

Die Medien-Komponenten wurden in $\mathrm{H}_{2} \mathrm{O}_{\text {bidest }}$ gelöst und das Volumen anschließend auf $900 \mathrm{ml}$ aufgefüllt. Das Medium wurde im Autoklaven sterilisiert und nach dem Erkalten mit $100 \mathrm{ml}$ einer separat autoklavierten $0,17 \mathrm{M} \mathrm{KH}_{2} \mathrm{PO}_{4}, 0,72 \mathrm{M} \mathrm{K}_{2} \mathrm{HPO}_{4}$ Lösung versehen. 
LB-Medium (Luria-Bertani Medium) (SAMBROOK et al., 1989):

$\begin{array}{ll}\text { Bacto-Trypton } & 10 \mathrm{~g} \\ \mathrm{Hefe}-\text { Extrakt } & 5 \mathrm{~g} \\ \mathrm{NaCl} & 10 \mathrm{~g} \\ \mathrm{H}_{2} \mathrm{O}_{\text {bidest }} & \text { ad } 1000 \mathrm{ml}\end{array}$

Der $\mathrm{pH}$-Wert wurde mit einer $5 \mathrm{~N} \mathrm{NaOH}$ auf $\mathrm{pH}$ 7,0 eingestellt.

MacConkey-Agar:

MacConkey Agar $\quad 50 \mathrm{~g}$

$\mathrm{H}_{2} \mathrm{O}_{\text {bidest }} \quad$ ad $1000 \mathrm{ml}$

Nach dem Autoklavieren und Abkühlen auf $50^{\circ} \mathrm{C}$ wurden dem Medium zusätzlich $10 \mathrm{~g}$ Laktose sowie zur Selektion rekombinanter Plasmide 100 ppm Ampicillin zugegeben.

\subsubsection{Puffer und Lösungen für den ELISA-Test}

Extraktionspuffer $(\mathrm{pH} \mathrm{7,4):}$

PPK 20x

Tween 20

$0,05 \%$

PVP

$0,2 \%$

$\mathrm{NaN}_{3}(10 \%$ ig)

$0,2 \%$

PPK 20x $(\mathrm{pH} 7,4)$ :

$\begin{array}{ll}\mathrm{NaCl} & 160 \mathrm{~g} \\ \mathrm{KH}_{2} \mathrm{PO}_{4} & 4 \mathrm{~g} \\ \mathrm{Na}_{2} \mathrm{HPO}_{4} \times 12 \mathrm{H}_{2} \mathrm{O} & 58 \mathrm{~g} \\ \mathrm{KCl} & 4 \mathrm{~g} \\ \mathrm{H}_{2} \mathrm{O}_{\text {bidest }} & \text { ad } 1000 \mathrm{ml}\end{array}$

$\underline{\text { Substratpuffer }}(\mathrm{pH} 9,8)$ :
$\mathrm{H}_{2} \mathrm{O}_{\text {bidest }}$
$600 \mathrm{ml}$
Diethanolamin
$97 \mathrm{ml}$ 
Der $\mathrm{pH}$-Wert wurde mit $2 \mathrm{~N} \mathrm{HCl}$ auf $\mathrm{pH}$ 9,8 eingestellt und anschließend mit $\mathrm{H}_{2} \mathrm{O}_{\text {bidest }}$ auf $1000 \mathrm{ml}$ aufgefüllt.

Waschpuffer:

$\begin{array}{ll}\text { PPK 20x } & 50 \mathrm{ml} \\ \mathrm{H}_{2} \mathrm{O}_{\text {bidest }} & 1950 \mathrm{ml} \\ \text { Tween } 20 & 0,05 \% \\ \mathrm{NaN}_{3}(10 \% \text { ig) } & 0,02 \%\end{array}$

Beschichtungspuffer ( $\mathrm{pH} 9,6)$ :

$\begin{array}{ll}\mathrm{Na}_{2} \mathrm{CO}_{3} & 1,59 \mathrm{~g} \\ \mathrm{NaHCO}_{3} & 2,93 \mathrm{~g} \\ \mathrm{NaN}_{3} & 0,2 \mathrm{~g} \\ \mathrm{H}_{2} \mathrm{O}_{\text {bidest }} & \text { ad } 1000 \mathrm{ml}\end{array}$

Verdünnung biotinylierter Antikörper:

(Die biotinylierten AK $(200 \mu \mathrm{l})$ wurden vor Gebrauch mit $800 \mu 1$ der angegebenen

Lösung verdünnt.)

$\begin{array}{ll}\text { PPK 20x } & 100 \mu \mathrm{l} \\ \mathrm{H}_{2} \mathrm{O}_{\text {bidest }} & 1900 \mu \mathrm{l} \\ \mathrm{NaN}_{3}(10 \% \text { ig) } & 4 \mu \mathrm{l} \\ \text { RSA } & 0,02 \mathrm{mg}\end{array}$

\subsubsection{Puffer und Lösungen für die molekularen Untersuchungen}

TBE-Puffer 10x (TRIS-Borat-EDTA-Puffer):

$108 \mathrm{~g}$

Borsäure $55 \mathrm{~g}$

0,5 M EDTA $\quad 40 \mathrm{ml}$

$\mathrm{H}_{2} \mathrm{O}_{\text {bidest }} \quad$ ad $1000 \mathrm{ml}$

Agarose-Trenngel (1\%ig):

$\begin{array}{ll}\text { Agarose } & 1 \mathrm{~g} \\ \text { TBE-Puffer } & \text { ad } 100 \mathrm{ml}\end{array}$


Polyacrylamid-Gel (10\%):

Polyacrylamid $10 \mathrm{ml}$

TBE-Puffer 10x $6 \mathrm{ml}$

$\mathrm{H}_{2} \mathrm{O}_{\text {bidest }}$ $17 \mathrm{ml}$

TEMED $10 \mu 1$

APS $200 \mu 1$

TE-Puffer:

Tris, $\mathrm{pH} \mathrm{8,0}$

$0,1 \mathrm{M}$

EDTA

$10 \mathrm{mM}$

TES-Puffer:

$\begin{array}{ll}\text { TRIS, } \mathrm{pH} 8,0 & 0,1 \mathrm{M} \\ \text { EDTA } & 10 \mathrm{mM} \\ \text { SDS } & 2 \%(\mathrm{w} / \mathrm{v})\end{array}$

CTAB: $10 \%(\mathrm{w} / \mathrm{v}), \mathrm{CTAB}$ in $0,7 \mathrm{M} \mathrm{NaCl}$ und $1 \mathrm{x}$ TE-Puffer

Proteinase K:

$20 \mathrm{mg} / \mathrm{ml} \mathrm{H}_{2} \mathrm{O}_{\text {bidest }}$, Lagerung bei $-20^{\circ} \mathrm{C}$

$\underline{\text { RNaseA: }}$

$10 \mathrm{mg} / \mathrm{ml} \mathrm{H}_{2} \mathrm{O}_{\text {bidest }}$, Lagerung bei $-20^{\circ} \mathrm{C}$

Wasch-Puffer für die Gelextraktion:

$\begin{array}{ll}\mathrm{NaCl} & 400 \mathrm{mM} \\ \text { TRIS } & 20 \mathrm{mM} \\ \text { EDTA } & 2 \mathrm{mM} \\ \text { Ethanol } & \\ \mathrm{H}_{2} \mathrm{O}_{\text {bidest }} & 50 \% \\ & \text { ad } 200 \mathrm{ml}\end{array}$

Binding-Puffer für die Gelextraktion:

$\begin{array}{ll}\text { Natrium Perchlorat } & 73,44 \mathrm{~g}(6 \mathrm{M}) \\ \text { Tris } 1 \mathrm{M} & 5 \mathrm{ml} \\ \text { EDTA } 0,5 \mathrm{M} & 2 \mathrm{ml} \\ \mathrm{H}_{2} \mathrm{O}_{\text {bidest }} & \text { ad } 100 \mathrm{ml}\end{array}$


Prep-A-Gene-Matrix:

$20 \mathrm{ml}$ Quantum prep Matrix (Bio-Rad) werden mit $100 \mathrm{ml}$ sterilem Wasser versetzt und 10 min leicht geschüttelt. Das Granulat wird anschließend für $30 \mathrm{~min}$ bei Raumtemperatur sedimentiert und der Überstand verworfen. Dieser Waschschritt wird viermal wiederholt. Das Pellet wird anschließend 1:1 in sterilem Wasser aufgenommen und jeweils $500 \mu \mathrm{l}$ in $2 \mathrm{ml}$ Reaktionsgefäßen bei $4^{\circ} \mathrm{C}$ gelagert

DNA-Elutionspuffer:

Tris-HCl, $\mathrm{pH} 7,4$ $50 \mathrm{mM}$

Natriumacetat

$0,5 \mathrm{M}$

EDTA $1 \mathrm{mM}$

STET-Puffer:

Saccharose $8 \%(\mathrm{w} / \mathrm{v})$

Triton X 100 $0,5 \%$

Natrium-EDTA $50 \mathrm{mM}$

TRIS, $\mathrm{pH} 8,0$ $10 \mathrm{mM}$

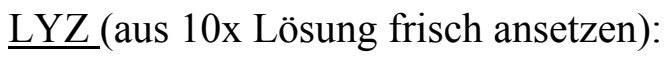

SDS $1 \%$

$\mathrm{NaOH} \quad 0,2 \mathrm{M}$

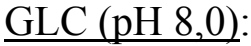

$\begin{array}{ll}\text { Glucose } & 50 \mathrm{mM} \\ \text { EDTA } & 10 \mathrm{mM} \\ \text { Tris } \mathrm{HCl} & 50 \mathrm{mM}\end{array}$

Kurz vor der Verwendung Lysozym auf eine Endkonzentration von 0,5 mg/ml zugeben.

HS:

Kaliumacetat $147 \mathrm{~g}$

Ameisensäure (98-100\%) $19 \mathrm{ml}$

$\mathrm{H}_{2} \mathrm{O}_{\text {bidest }}$ ad $500 \mathrm{ml}$ 


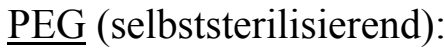

Polyethylenglykol 6000 $30 \mathrm{~g}$

$\mathrm{NaCl}$ $10,5 \mathrm{~g}$

$\mathrm{H}_{2} \mathrm{O}_{\text {bidest }}$ ad $100 \mathrm{ml}$

Denaturierungslösung:

$\begin{array}{lr}\mathrm{NaOH} & 0,5 \mathrm{M} \\ \mathrm{NaCl} & 1,5 \mathrm{M}\end{array}$

$\underline{\text { 20x SSC }}(\mathrm{pH} \mathrm{7,5):}$

$\mathrm{NaCl} \quad 3 \mathrm{M}$

Natrium-Citrat $\quad 0,3 \mathrm{M}$

Äquilibrierungspuffer ( $\mathrm{pH} 9,5)$ :

$\begin{array}{ll}\text { Tris } \mathrm{HCl} & 0,1 \mathrm{M} \\ \mathrm{NaCl} & 0,1 \mathrm{M}\end{array}$

Grundpuffer $(\mathrm{pH} 7,5)$ :
Maleinsäure
$0,1 \mathrm{M}$
$\mathrm{NaCl}$
$0,15 \mathrm{M}$

Waschpuffer:

Grundpuffer versetzt mit $0,3 \%(\mathrm{v} / \mathrm{v})$ Tween 20

Blocking-Stammlösung:

Blocking Reagenz $\quad 10 \%(\mathrm{w} / \mathrm{v})$ gelöst im Grundpuffer

Blocking-Puffer:

Blocking-Stammlösung 1:10 verdünnt im Grundpuffer 


\subsection{Pilze, Bakterien und Plasmide}

\subsubsection{Herkunft und Anzucht der verwendeten Pilzisolate}

Alle in dieser Arbeit verwendeten Pilzisolate sind in Tab. 2.2 aufgeführt. Die verwendeten S. sclerotiorum-Isolate wurden zur Erhaltung in Erdröhrchen bei $4^{\circ} \mathrm{C}$ aufbewahrt. Die Anzucht der S. sclerotiorum-Isolate erfolgte auf PDA bei Raumtemperatur. Sobald sich Sklerotien bildeten (nach ca. 10 Tagen) wurden die Isolate mit einem Agarstück aus dem Randbereich neu überimpft. Die verwendeten $V$. longisporum und $V$. dahliae-Isolate wurden zur Erhaltung als Sporenlösung in Glycerinkultur (Sporensuspension versetzt mit 25\% autoklavierten Glycerin) mit einer Sporendichte von $10^{6} \mathrm{Sporen} / \mathrm{ml}$ bei $-70^{\circ} \mathrm{C}$ aufbewahrt. Die Anzucht erfolgte auf PDA bzw. als Schüttelkultur in PDB. Alle weiteren verwendeten Isolate wurden als Lyophilisate aufbewahrt. Zur Anzucht der Pilze für die DNA-Extraktion wurden Schüttelkulturen in PDB verwendet.

\subsubsection{Verwendete Bakterien und Plasmide}

Der für die Transformation verwendete E. coli-Stamm und das verwendete Plasmid sind mit den relevanten Merkmalen in Tabelle 2.1 aufgeführt.

Tab. 2.1: Verwendeter E. coli-Stamm und Plasmid

\begin{tabular}{ccc}
\hline $\begin{array}{c}\text { Stamm/ } \\
\text { Plasmid }\end{array}$ & relevante Merkmale & Referenz \\
\hline DH5 & $\begin{array}{r}r e c A 1, \text { end } A 1, \text { hsdR17(rk-, mk+), } \\
\text { lacZ } \Delta \mathrm{M} 15, \Delta(\text { lacZYAA-argF), U169 }\end{array}$ & HANAHAN (1983) \\
pBluescript SK- & $2,96 \mathrm{kBp}, \mathrm{Amp}^{\mathrm{R}}$, lacPOZ $^{\prime}$ & $\begin{array}{c}\text { Firma Stratagene } \\
\text { (San Diego, USA) }\end{array}$ \\
\hline
\end{tabular}


Tab. 2.2: Bezeichnung und Herkunft der verwendeten Pilzisolate

\begin{tabular}{|c|c|c|c|c|c|}
\hline Art & Bezeichnung & Herkunft & Land & Jahr & Wirt/Habitat \\
\hline \multirow{3}{*}{$\begin{array}{c}\text { Sclerotinia } \\
\text { sclerotiorum }\end{array}$} & Ss 1.1 & Petschow & $\mathrm{D}$ & 1997 & Brassica napus \\
\hline & Ss 1.5 & Biestow & $\mathrm{D}$ & 1997 & Brassica napus \\
\hline & Ss 1.6 & Diedrichshagen & $\mathrm{D}$ & 1997 & Brassica napus \\
\hline \multirow{9}{*}{$\begin{array}{l}\text { Verticillium } \\
\text { longisporum }\end{array}$} & V1 18 & Mecklenburg & $\mathrm{D}$ & 1989 & Brassica napus \\
\hline & $\mathrm{V} 132$ & Mecklenburg & $\mathrm{D}$ & 1988 & Brassica napus \\
\hline & $\mathrm{Vl} 40$ & Mecklenburg & $\mathrm{D}$ & 1990 & Brassica napus \\
\hline & V1 43 & Mecklenburg & $\mathrm{D}$ & 1991 & Brassica napus \\
\hline & V1 59 & Kalifornien & USA & 1997 & B. oleracea var. botrytis \\
\hline & V1 60 & Kalifornien & USA & 1997 & B. oleracea var. botrytis \\
\hline & V1 82 & Mecklenburg & $\mathrm{D}$ & 1997 & Brassica napus \\
\hline & V1 83 & Mecklenburg & $\mathrm{D}$ & 1997 & Brassica napus \\
\hline & V1 84 & Mecklenburg & $\mathrm{D}$ & 1997 & Brassica napus \\
\hline \multirow{7}{*}{$\begin{array}{l}\text { Verticillium } \\
\text { dahliae }\end{array}$} & $\mathrm{Vd} 3$ & Münsterland & $\mathrm{D}$ & 1997 & Fragaria $x$ ananassa \\
\hline & Vd 13 & Cordoba & ESP & 1987 & Gossypium hirsutum \\
\hline & $\mathrm{Vd} 16$ & Mecklenburg & $\mathrm{D}$ & 1988 & Solanum tuberosum \\
\hline & $\mathrm{Vd} 49$ & Burgenland & $\mathrm{A}$ & n.b. & Capsicum annuиm \\
\hline & Vd 52 & Burgenland & $\mathrm{A}$ & n.b. & Capsicum annuum \\
\hline & $\mathrm{Vd} 57$ & Mecklenburg & $\mathrm{D}$ & 1995 & Fragaria $x$ ananassa \\
\hline & $\mathrm{Vd} 76$ & n.b. & USA & n.b. & Gossypium hirsutum \\
\hline $\begin{array}{l}\text { Verticillium } \\
\text { albo-atrum }\end{array}$ & Vaa 1.0 & Wisconsin & USA & 1989 & Solanum tuberosum \\
\hline $\begin{array}{c}\text { Verticillium } \\
\text { tricorpus }\end{array}$ & $\mathrm{Vt}$ & \multicolumn{4}{|c|}{ n.b. } \\
\hline $\begin{array}{c}\text { Fusarium } \\
\text { graminearum }\end{array}$ & Fg 35 & Göttingen & $\mathrm{D}$ & 1975 & Triticum aestivum \\
\hline $\begin{array}{l}\text { Fusarium } \\
\text { culmorum }\end{array}$ & Fc 33 & Italien & I & & Triticum aestivum \\
\hline $\begin{array}{l}\text { Fusarium } \\
\text { oxysporum }\end{array}$ & Fo 36 & \multicolumn{4}{|c|}{ nicht bekannt } \\
\hline $\begin{array}{c}\text { Alternaria } \\
\text { alternata }\end{array}$ & $\mathrm{Aa}$ & n.b. & $\mathrm{D}$ & 1983 & Triticum aestivum \\
\hline $\begin{array}{l}\text { Rhizoctonia } \\
\text { solani }\end{array}$ & Rs & \multicolumn{4}{|c|}{ n.b. } \\
\hline \multirow[t]{4}{*}{ Phoma lingam } & P1 IB 2 & Deutschland & $\mathrm{D}$ & n.b. & Brassica napus \\
\hline & P1 IB 23 & Polen & $\mathrm{P}$ & n.b. & Brassica napus \\
\hline & P1 IB 39 & Deutschland & $\mathrm{D}$ & n.b. & Brassica napus \\
\hline & P1 IB 42 & Frankreich & $\mathrm{F}$ & n.b. & Brassica napus \\
\hline
\end{tabular}

n.b. $=$ nicht bekannt 


\subsection{Feldversuche zur Schadwirkung von Pathogenen an Winterraps}

\subsubsection{Versuchsstandort und Versuchsanlage}

Die Versuche wurden von August 2001 bis August 2005 an den Standorten „Dragoneranger“ (2001/02 und 2004/05), „Große Breite“ (2002/03) und „Große Lage“ (2003/04) in Göttingen-Weende auf Versuchsflächen des Versuchsgutes Marienstein der Universität Göttingen durchgeführt (Abb. 2.1). Die Versuchsflächen liegen in der Talaue des Leinegrabens im nord-westlichen Stadtgebiet Göttingens. Die Versuchsflächen weisen nur eine geringe Hangneigung auf. Der vorherrschende Bodentyp ist toniger Lehm mit einer Bodenpunktzahl von 80. Die Versuchsflächen unterliegen einer dreigliedrigen Fruchtfolge in der W-Weizen - W-Gerste - Zwischenfrucht Ölrettich Zuckerrüben angebaut werden. Innerhalb dieser betriebsüblichen Fruchtfolge wurde abweichend davon in den Versuchsjahren das Fruchtfolgeglied Zuckerrüben durch Winterraps ersetzt. Auf allen Flächen wurde seit mehr als 10 Jahren kein Raps angebaut, so dass das Risiko einer natürlichen Infektion mit S. sclerotiorum und V. longisporum minimiert werden konnte.

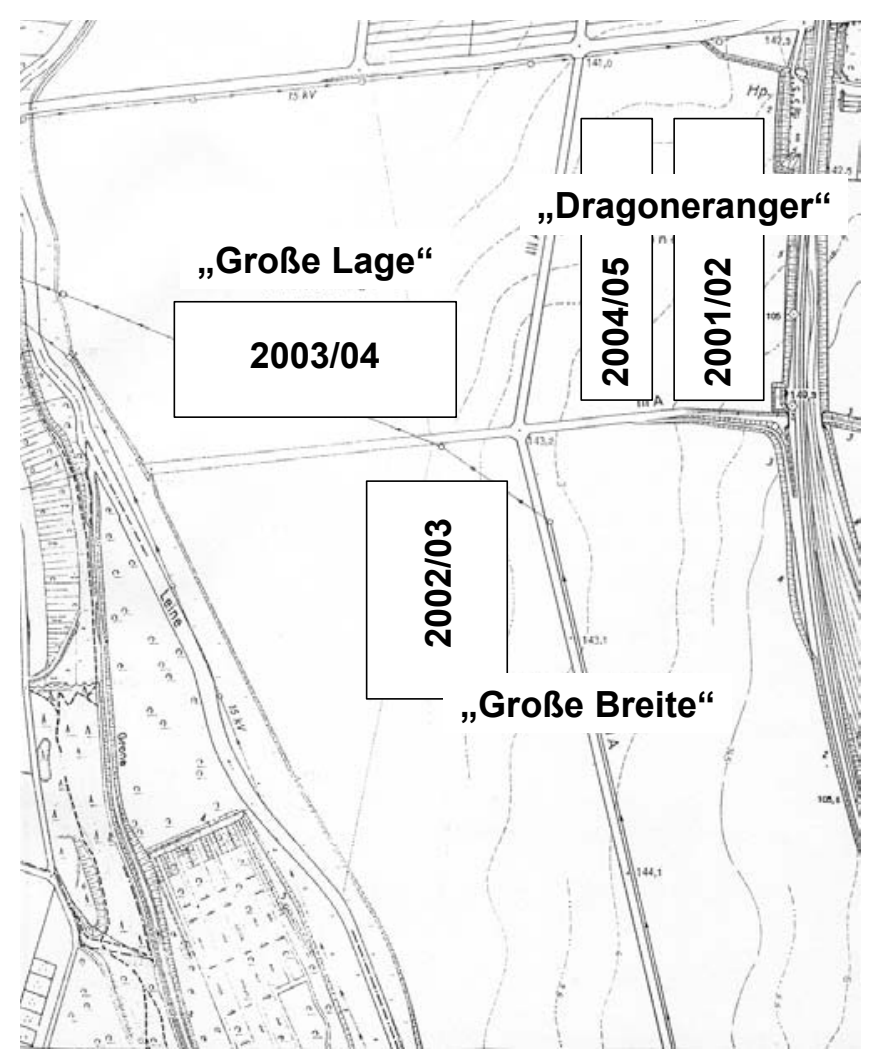

Abb. 2.1: Lage der Versuchsstandorte in den Versuchsjahren 2001/02 bis 2004/05 in Göttingen-Weende. 
Die auf den Flächen ackerbaulich durchgeführten Maßnahmen sind im Anhang aufgeführt (Tab. Ala-d).

Die Versuche zur Schadwirkung von S. sclerotiorum in Abhängigkeit von Inokulationstermin, Aussaatstärke und Aussaattermin sowie zum Kompensationspotential wurden in zwei Blockanlagen (ein Block je Sorte) mit vier Wiederholungen angelegt.

Die Versuche zum Kompensationspotential von Raps und zum Einfluss des Inokulationstermins wurden im Versuchsjahr 2001/02 mit einer Praxisdrillmaschine ausgesät. Die Parzellengröße betrug in diesen Versuchen $2 \mathrm{~m}$ x $10 \mathrm{~m}=20 \mathrm{~m}^{2}$. Der Feldversuch zum Einfluss verschiedener Anbaumaßnahmen sowie alle Versuche in den folgenden Versuchsjahren wurden mit einer Parzellendrillmaschine (Firma Hege) ausgesät. Die Parzellengröße betrug im Jahr 2001/02 $10 \mathrm{~m} \mathrm{x} \mathrm{1,25} \mathrm{m=12,5} \mathrm{m}^{2}$ und in den folgenden Jahren $12 \mathrm{~m} \times 1,2 \mathrm{~m}=14,4 \mathrm{~m}^{2}$.

Um genaue Befallshäufigkeiten in den Parzellen einstellen zu können wurde die Bestandesdichte im Frühjahr zu BBCH 31-33 bestimmt. Mit einem 1/4 $\mathrm{m}^{2}$-Zählrahmen wurde an vier Stellen pro Parzelle die Bestandesdichte gezählt. Über den Mittelwert der vier Zählungen wurde die Bestandesdichte pro Parzelle ermittelt.

Um in allen Parzellen dieselben Bedingungen zu schaffen, wurde die Bestandesdichte durch Entfernen überschüssiger Pflanzen auf die geforderte Anzahl Pflanzen/Parzelle eingestellt.

Die Feldversuche zur Befalls-Verlust-Relation von $V$. longisporum an Winterraps in den Jahren 2002/03 und 2003/04 wurden in einem Lateinischen Rechteck mit vier Wiederholungen angelegt (Tab. 2.3). Die Parzellengröße betrug 2,50 m x $10 \mathrm{~m}\left(25 \mathrm{~m}^{2}\right)$. Die Parzellen wurden in eine Beprobungsparzelle (2,50 m x $2 \mathrm{~m}$ ) und eine Ernteparzelle $(2,50 \mathrm{~m} \times 8 \mathrm{~m})$ aufgeteilt. Zwischen den Wiederholungen wurde eine Arbeitsbreite $(2,50 \mathrm{~m})$ und hinter jeder Parzelle drei Meter freigelassen, um eine Verschleppung des Inokulums in Nachbarparzellen zu verhindern.

Die Aussaat wurde mit einer Praxisdrillmaschine mit einer Aussaatstärke von $63 \mathrm{Kö} / \mathrm{m}^{2}$ durchgeführt. 
Tab. 2.3: Versuchsanlage zur Untersuchung der Schadwirkung von $V$. longisporum an Winterraps in den Vegetationsperioden 2002/03 und 2003/04

\begin{tabular}{|c|c|c|c|c|c|c|c|}
\hline 5 & \multirow{8}{*}{ 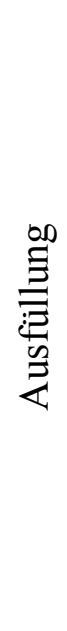 } & 1 & \multirow{8}{*}{ 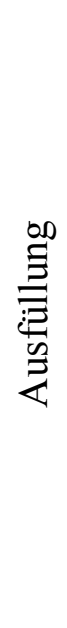 } & 2 & \multirow{8}{*}{ 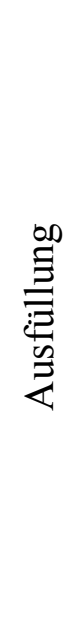 } & 4 & Inokulummenge \\
\hline & & & & & & & 1: Kontrolle \\
\hline \multirow[t]{2}{*}{4} & & 5 & & 3 & & 2 & $2: 300 \mathrm{~g}$ \\
\hline & & & & & & & $3: 600 \mathrm{~g}$ \\
\hline \multirow[t]{2}{*}{3} & & 2 & & 1 & & 5 & 4: $900 \mathrm{~g}$ \\
\hline & & & & & & & 5: $1200 \mathrm{~g}$ \\
\hline 2 & & 3 & & 4 & & 1 & \\
\hline 1 & & 4 & & 5 & & 3 & \\
\hline Wdh & & $\underset{\text { Wdh }}{2 .}$ & & $\begin{array}{c}3 . \\
\text { Wdh }\end{array}$ & & $\begin{array}{r}4 . \\
\text { Wdh }\end{array}$ & \\
\hline
\end{tabular}

\subsubsection{Versuchsfaktoren}

\subsubsection{Sorten}

In den Versuchsjahren 2001/02, 2002/03 und 2003/04 wurden jeweils eine Hybride (Talent in 2001/02 und 2002/03, Maja in 2003/04) und eine Liniensorte (Prince) angebaut, um mögliche Unterschiede zwischen den Sortentypen zu erfassen. Im Versuchsjahr 2004/05 wurden acht verschiedene Sorten (Tab. 2.4), jeweils vier Hybridund Liniensorten angebaut, um sortenspezifische Befalls-Verlust-Relationen zu erarbeiten. Die in Tab. 2.4 aufgeführten Sorten wurden aufgrund ihrer in der Bundessortenliste aufgeführten Eigenschaften ausgewählt. Ausschlaggebend war eine hohe Anfälligkeit gegen S. sclerotiorum, eine geringe Anfälligkeit gegen P. lingam sowie eine hohe Vermehrungsfläche als Kennzeichen für eine hohe Anbauintensität in der Praxis.

Zur Ermittlung der sortenspezifischen Befalls-Verlust-Relationen im Versuchsjahr 2004/05, wurden für alle Sorten Befallshäufigkeiten von $0-70 \%$ in einfacher Wiederholung eingestellt (Tab. 2.5). Die Inokulation (siehe Kap. 2.6.1.4) wurde zu BBCH 65-67 durchgeführt.

Die Aussaatdichte betrug $55 \mathrm{Kö.} / \mathrm{m}^{2}$. Die Bestandesdichte wurde im Frühjahr ausgezählt und auf $50 \mathrm{Pfl} . / \mathrm{m}^{2}$ eingestellt. 
Tab. 2.4: Auszug zur Sortenbeschreibung von Winterraps aus der Bundessortenliste (ANONYM, 2004).

\begin{tabular}{ccccc}
\hline Sorte & Sortentyp* & \multicolumn{2}{c}{$\begin{array}{c}\text { Anfälligkeit gegen } \\
\text { S. sclerotiorum }\end{array}$} & $\begin{array}{c}\text { Permehrungs- } \\
\text { fläche }{ }^{\mathrm{a}} \text { [ha] }\end{array}$ \\
\hline Prince & F & 6 & 4 & $35^{\mathrm{b}}$ \\
Talent & H & 6 & 3 & $444^{\mathrm{b}}$ \\
Maja & H & 7 & 6 & $276^{\mathrm{c}}$ \\
Viking & F & 6 & 5 & 215 \\
Oase & F & 5 & 4 & 275 \\
Trabant & H & 5 & 4 & 197 \\
Elektra & H & 6 & 6 & 556 \\
Smart & F & 5 & 5 & 145 \\
\hline
\end{tabular}

* = F: freiabblühende Sorte, Liniensorte; H: Hybridsorte; ${ }^{\mathrm{a}}=$ Vermehrungsfläche im Jahr 2004, ${ }^{\mathrm{b}}=$ Vermehrungsfläche im Jahr 2001, ${ }^{\mathrm{c}}=$ Vermehrungsfläche im Jahr 2002

Tab. 2.5: Versuchsanlage zur Untersuchung sortenspezifischer Befalls-VerlustRelationen von S. sclerotiorum im Versuchsjahr 2004/05.

\begin{tabular}{|l|l|l|l|l|l|l|l|}
\hline $\mathbf{8 . 8}$ & $\mathbf{2 . 3}$ & $\mathbf{5 . 7}$ & $\mathbf{6 . 1}$ & $\mathbf{8 . 4}$ & $\mathbf{2 . 7}$ & $\mathbf{5 . 3}$ & $\mathbf{6 . 5}$ \\
\hline $\mathbf{7 . 7}$ & $\mathbf{4 . 5}$ & $\mathbf{3 . 5}$ & $\mathbf{1 . 4}$ & $\mathbf{7 . 3}$ & $\mathbf{4 . 1}$ & $\mathbf{3 . 1}$ & $\mathbf{1 . 8}$ \\
\hline $\mathbf{6 . 6}$ & $\mathbf{1 . 2}$ & $\mathbf{8 . 2}$ & $\mathbf{7 . 2}$ & $\mathbf{6 . 2}$ & $\mathbf{1 . 6}$ & $\mathbf{8 . 6}$ & $\mathbf{7 . 6}$ \\
\hline $\mathbf{5 . 5}$ & $\mathbf{3 . 4}$ & $\mathbf{2 . 4}$ & $\mathbf{4 . 7}$ & $\mathbf{5 . 1}$ & $\mathbf{3 .} .8$ & $\mathbf{2 . 8}$ & $\mathbf{4} .3$ \\
\hline $\mathbf{4 . 4}$ & $\mathbf{7 . 8}$ & $\mathbf{6 . 8}$ & $\mathbf{2 . 5}$ & $\mathbf{4 . 8}$ & $\mathbf{7 . 4}$ & $\mathbf{6 . 4}$ & $\mathbf{2 . 1}$ \\
\hline $\mathbf{3 . 3}$ & $\mathbf{5 . 6}$ & $\mathbf{1 . 3}$ & $\mathbf{8 . 3}$ & $\mathbf{3 . 7}$ & $\mathbf{5 . 2}$ & $\mathbf{1 . 7}$ & $\mathbf{8 . 7}$ \\
\hline $\mathbf{2 . 2}$ & $\mathbf{8 . 1}$ & $\mathbf{7 . 1}$ & $\mathbf{3 . 6}$ & $\mathbf{2 . 6}$ & $\mathbf{8 . 5}$ & $\mathbf{7 . 5}$ & $\mathbf{3 . 2}$ \\
\hline $\mathbf{1 . 1}$ & $\mathbf{6 . 7}$ & $\mathbf{4 . 6}$ & $\mathbf{5 . 8}$ & $\mathbf{1 . 5}$ & $\mathbf{6 . 3}$ & $\mathbf{4 . 2}$ & $\mathbf{5 . 4}$ \\
\hline
\end{tabular}

Sorten: $\quad$ Befallshäufigkeit:

1 Prince 1: Kontrolle

2 Viking 2: $10 \%$

3 Smart 3: $20 \%$

4 Trabant $\quad 4: 30 \%$

5 Talent 5: $40 \%$

6 Elektra 6: $50 \%$

7 Maja $\quad 7: 60 \%$

8 Oase $\quad 8: 70 \%$

\subsubsection{Inokulationstermin}

Zur Untersuchung des Einflusses von Befallsstärke und Befallszeitpunkt auf die Schadwirkung von S. sclerotiorum wurde zu zwei Terminen inokuliert. Die frühe Inokulation wurde zu BBCH 61-65, die späte Inokulation zu BBCH 71 durchgeführt. Es wurden Befallshäufigkeiten von $0-70 \%$ in den Parzellen eingestellt (Tab. 2.6). 
Die Aussaatdichte betrug $60 \mathrm{Kö.} / \mathrm{m}^{2}$ für die Liniensorte und $48 \mathrm{Kö.} / \mathrm{m}^{2}$ für die Hybridsorte. Die Bestandesdichte wurde auf $50 \mathrm{Pfl} . / \mathrm{m}^{2}$ für die Liniensorte und 40 $\mathrm{Pfl} . / \mathrm{m}^{2}$ für die Hybridsorte eingestellt.

Tab. 2.6: Versuchsanlage zur Untersuchung der Schadwirkung von S. sclerotiorum in Abhängigkeit von Befallsstärke und Befallszeitpunkt in den Vegetationsperioden $2001 / 02$ bis $2003 / 04$.

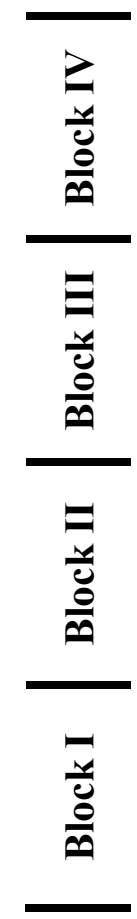

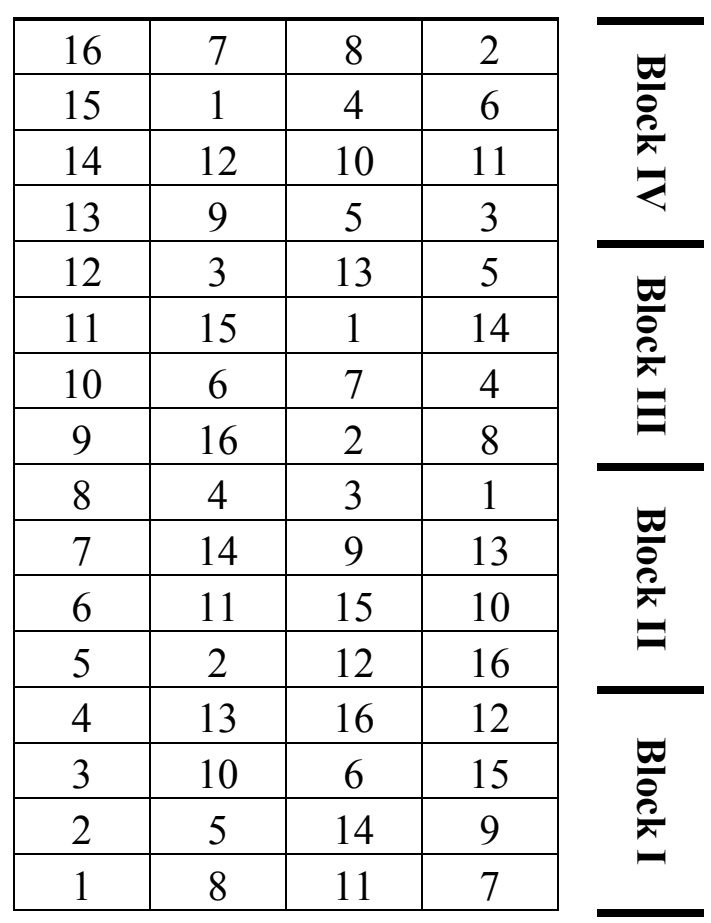

Befallshäufigkeit:

1/9: Kontrolle

2/10: $10 \%$

3/11: $20 \%$

4/12: $30 \%$

5/13: $40 \%$

6/14: $50 \%$

7/15: $60 \%$

8/16: $70 \%$

1. $2 . \quad 3.4$. 4.

Wdh. Wdh. Wdh. Wdh.

\subsubsection{Anbautechnische Maßnahmen}

In einem weiteren Versuch wurde der Einfluss der anbautechnischen Parameter Aussaattermin und Bestandesdichte auf die Schadwirkung von $S$. sclerotiorum untersucht. Es wurde jeweils ein Versuch pro Sorte zu einem frühen (10.-15.08.) und ein zweiter Versuch zu einem für die Region Göttingen normalen Termin (20.-25.08.) gesät. Für jede Sorte wurden zwei Aussaatdichten/Bestandesdichten gewählt. Die Hybridsorte wurde mit 60 und $42 \mathrm{Kö.} / \mathrm{m}^{2}$, die Liniensorte mit 72 und $54 \mathrm{Kö.} / \mathrm{m}^{2}$ ausgesät. Die Bestandesdichten wurden auf 50 und $35 \mathrm{Pfl} . / \mathrm{m}^{2}$ für die Hybride und 60 und $45 \mathrm{Pfl} . / \mathrm{m}^{2}$ für die Liniensorte im Frühjahr eingestellt. 
Die Inokulation wurde zur abgehenden Blüte (BBCH 65-69) mit Befallshäufigkeiten von $0-50 \%$ durchgeführt (Tab. 2.7).

Tab. 2.7: Versuchsanlage zur Untersuchung des Einflusses anbautechnischer Maßnahmen auf die Befalls-Verlust-Relationen von $S$. sclerotiorum in den Vegetationsperioden 2001/02 bis 2003/04.

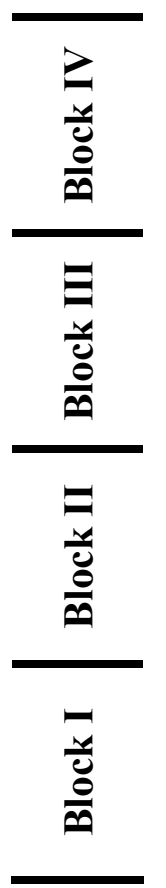

\begin{tabular}{|l|l|l|l|}
\hline 12 & 4 & 6 & 2 \\
\hline 11 & 3 & 9 & 5 \\
\hline 10 & 7 & 1 & 8 \\
\hline & 1 & 12 & 4 \\
\hline
\end{tabular}

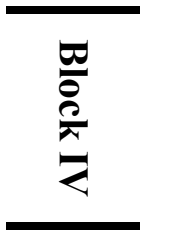

Befallshäufigkeit:

1/7: Kontrolle

2/8: $10 \%$

3/9: $20 \%$

4/10: $30 \%$

5/11: $40 \%$

6/12: $50 \%$

\begin{tabular}{|c|c|c|c|}
\hline 6 & 9 & 8 & 12 \\
\hline 5 & 10 & 7 & 3 \\
\hline 4 & 2 & 11 & 1 \\
\hline 3 & 8 & 5 & 11 \\
\hline 2 & 6 & 4 & 7 \\
\hline 1 & 12 & 10 & 9 \\
\hline
\end{tabular}

1.

2.

3.

4.

Wdh. Wdh. Wdh. Wdh.

\section{Aussaatstärken:}

1-6: niedrig

7-12: hoch

\subsubsection{Simulierung von Pflanzenverlusten}

$\mathrm{Zu}$ Beginn der Schotenbildung (BBCH 71) wurden durch eine mechanische Bestandesdichteregulierung späte Pflanzenausfälle, wie sie z. B. durch einen Sclerotinia-Befall entstehen, simuliert. Die Pflanzenstängel wurden in 30-40 cm Höhe mit einer Rosenschere durchtrennt, die Pflanzenreste wurden in der Parzelle belassen. Mit dieser Methode wurden Pflanzenreduktionen von $0-70 \%$ durchgeführt (Tab. 2.8).

Der Versuch wurde mit einer Aussaatmenge von $60 \mathrm{Kö.} / \mathrm{m}^{2}$ für die Liniensorte und 48 Kö./m² für die Hybridsorte ausgesät. Zu BBCH 31-33 wurde die Bestandesdichte auf 50 $\mathrm{Pfl} . / \mathrm{m}^{2}$ für die Liniensorte und $40 \mathrm{Pfl} . / \mathrm{m}^{2}$ für die Hybridsorte eingestellt. 
Tab. 2.8: Versuchsanlage zur Untersuchung des Kompensationspotentials von Winterraps in den Vegetationsperioden 2001/02 bis 2003/04.

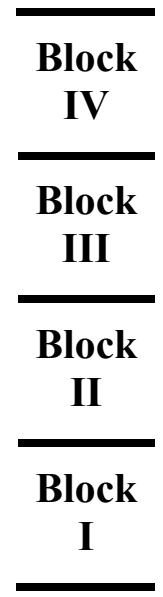

\begin{tabular}{|l|l|}
\hline 8 & \\
\hline 7 & \\
\hline 6 & \\
\hline 5 & \\
\hline 4 & \\
\hline 3 & \\
\hline 2 & \\
\hline 1 & \\
\hline
\end{tabular}

1.

2.

2.

3.

Wdh. Wdh. Wdh. Wdh.
Pflanzenreduktion:

1: Kontrolle

2: $10 \%$

3: $20 \%$

4: $30 \%$

5: $40 \%$

6: $50 \%$

7: $60 \%$

$8: 70 \%$

\subsection{Witterungsverlauf und Pflanzenentwicklung in den Jahren 2001 bis 2005}

Der Witterungsverlauf in den vier Versuchsjahren ist in Abb. 2.2 dargestellt. Die Vegetationsperiode 2001/02 war gekennzeichnet durch überdurchschnittlich hohe Niederschlagsmengen in den Monaten September, Februar und Mai. Durch die bis in den Oktober reichenden Temperaturen über $10^{\circ} \mathrm{C}$ gingen die Pflanzen gut entwickelt in den Winter. Aufgrund sehr milder Temperaturen traten keine nennenswerten Auswinterungsschäden auf. Im Februar 2002 waren überdurchschnittlich hohe Temperaturen zu verzeichnen. Durch ausreichend Niederschlag und Wärme konnten sich die Pflanzen optimal entwickeln. Bedingt durch die guten Wachstumsbedingungen wurden deutliche Unterschiede in der Pflanzenentwicklung zwischen der Früh- und der Normalsaat deutlich.

In der Vegetationsperiode 2002/03 gingen die Pflanzen gut entwickelt (BBCH 17) in den Winter. Der Winter war gekennzeichnet durch einen sehr kalten Februar mit Schneefällen und anhaltenden Frostperioden bis in den März. Im Frühjahr folgten nach einer Woche mit warmer, wüchsiger Witterung eine Woche mit starken Nachtfrösten (bis $-9^{\circ} \mathrm{C}$ ). Auswinterungen waren jedoch nur in der Hybridsorte Talent vereinzelt zu finden. Das Frühjahr und der Sommer waren durch sehr hohe Temperaturen und anhaltende Trockenheit gekennzeichnet. Durch die niedrigen Temperaturen im frühen Frühjahr und fehlende Niederschläge wurde die Pflanzenentwicklung im März bis Mitte 
April deutlich gehemmt, was sich in einer sehr geringen Pflanzenlänge niederschlug. Durch einsetzende vereinzelte Niederschläge und warme Temperaturen Mitte April bekamen die Pflanzen einen Wachstumsschub, der die fehlende Pflanzenlänge jedoch nicht kompensieren konnte. Die Blüte war im Jahr 2003 sehr kurz (24.04. bis ca. 10.05.) und es waren keine Unterschiede in der Pflanzenentwicklung zwischen der Hybrid- und Liniensorte sowie zwischen den beiden Aussaatterminen erkennbar.

In der Vegetationsperiode 2003/04 setzte sich die Sommertrockenheit bis in den Herbst fort. Durch die starke Trockenheit zum Zeitpunkt der frühen Aussaat, liefen nur ca. 10\% der Pflanzen auf. Die restlichen Pflanzen liefen erst zeitgleich mit den Pflanzen des späteren Aussaattermins Ende August auf. Der Winter im Jahr 2003/04 war sehr mild und es traten keine Auswinterungsschäden auf. Das Frühjahr 2004 war gekennzeichnet durch sehr kühle Temperaturen und relativ geringe Niederschläge bis Anfang Mai. Auch die Sommermonate Juni und Juli waren im Vergleich zu vorhergehenden Jahren sehr kühl, und der Monat Juli sehr feucht. Bedingt durch die schlechten Witterungsbedingungen zur Aussaat und das sehr ungleichmäßige Auflaufen der Pflanzen des frühen Aussaattermins war der Bestand in diesen Parzellen bis zum Beginn der Blüte sehr ungleichmäßig. Unterschiede zwischen den Sorten und Aussaattermine waren auch in diesem Versuchsjahr nicht ersichtlich.

In der Vegetationsperiode 2004/05 konnte ein zügiger Pflanzenaufgang nach der Aussaat und eine gute Pflanzenentwicklung vor Winter beobachtet werden. Trotz zum Teil sehr geringer Temperaturen während der Wintermonate traten keine Auswinterungsschäden auf. Die Frühjahrsniederschläge waren vergleichbar dem vorhergehendem Jahr. Der Pflanzenbestand war in allen Sorten sehr gleichmäßig. Aufgrund der relativ geringen Temperaturen zur Blüte zeigte sich eine über ca. vier Wochen ausgedehnte Blütephase von Ende April bis Ende Mai. Die Sortenunterschiede im Blühzeitpunkt waren nur gering. Die Sorte Prince wurde am 15.09.2004, zwölf Tage nach der normalen Aussaat, nachgesät. Aufgang und Pflanzenentwicklung vor Winter waren sehr schlecht. Auch im Frühjahr war die Entwicklung dieser Sorte sehr stark verzögert und wurde zum Teil durch gut entwickelte Nachbarparzellen unterdrückt. Die einzelnen Pflanzen zeigten ein stark eingeschränktes Höhenwachstum und die Pflanzenstängel blieben sehr dünn. Aufgrund der schlechten Pflanzenentwicklung ging diese Sorte nicht in die Versuchsauswertung ein. 
Temperatur $\left[{ }^{\circ} \mathrm{C}\right]$
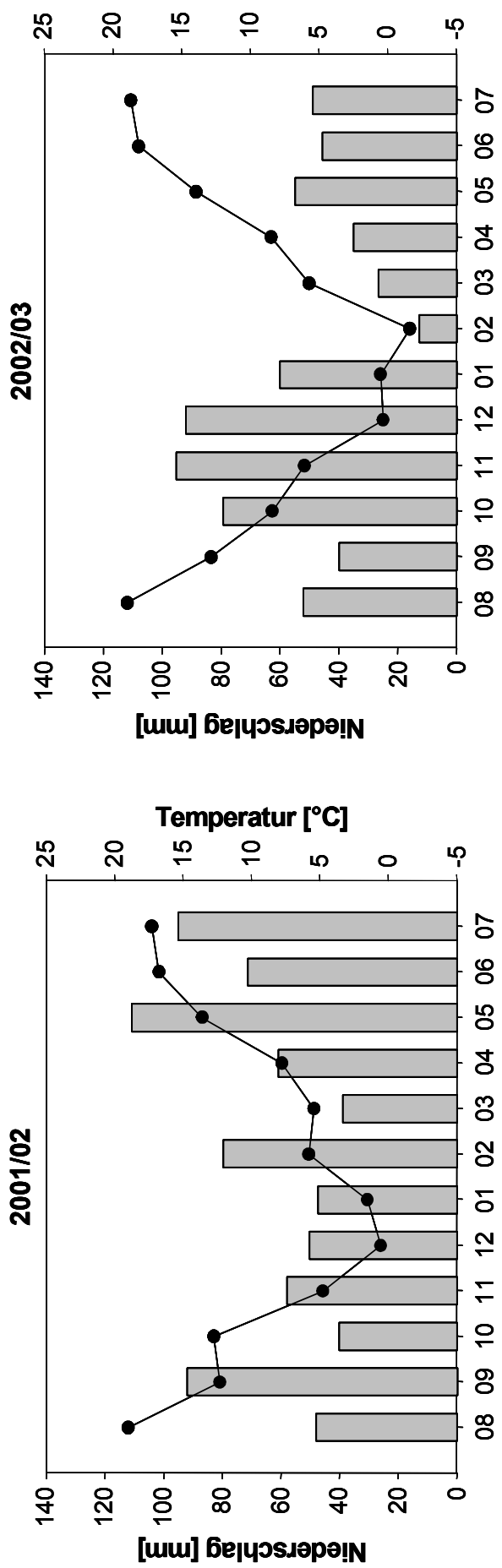

Temperatur $\left[{ }^{\circ} \mathrm{C}\right]$
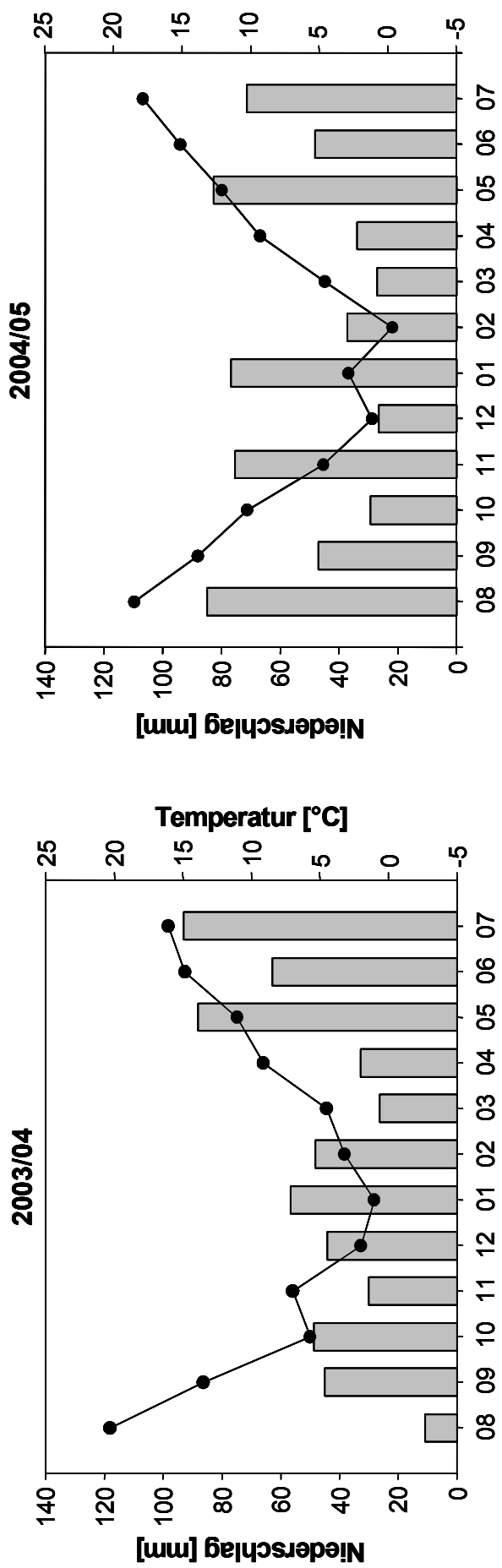

In Abb. 2.3 sind die relative Luftfeuchte sowie die Temperatur während der Inokulationsphasen der vier Versuchsjahre dargestellt. Im ersten Versuchsjahr 2001/02 waren deutliche Unterschiede in der Pflanzenentwicklung zwischen den Aussaatterminen zu sehen. Die Parzellen des frühen Aussaattermins wurden am 22./23.04. zu BBCH 65-69 noch vor den Parzellen der zweiten Aussaat zu BBCH 61-65 
inokuliert. Am 22.04. war es morgens sehr taunass, tagsüber wurde es sehr warm und trocken, so dass die Zahnstocher sehr schnell austrockneten. Am 23.04. war es morgens kaum taunass und bedeckt und mit ca. $15^{\circ} \mathrm{C}$ etwas kühler. Zur Inokulation zu BBCH 61-65 des zweiten Aussaattermins am 25.04. war es durch den Regen am Vortag anfangs noch sehr nass, tagsüber trocknete der Bestand jedoch ab und auch in den darauf folgenden Tagen war es sehr trocken. Die Inokulation zu BBCH 65-69 des zweiten Aussaattermins wurde vom 06.-08.05. durchgeführt. Am ersten Tag war der Bestand vom vorhergehenden Regen noch stark durchnässt, trocknete jedoch relativ schnell bei Temperaturen um $15^{\circ} \mathrm{C}$ ab. Die Inokulationen zu BBCH 71 wurden vom 13. bis 15.05. durchgeführt. Am ersten Tag war der Bestand durch ein vorhergehendes Regenereignis sehr nass, durch Temperaturen um $15^{\circ} \mathrm{C}$ und Sonnenschein trocknete der Bestand jedoch rasch ab und auch am nächsten Tag war nur wenig Feuchtigkeit im Bestand. Am 15.05. war der Bestand morgens taunass, trocknete im Verlauf des Tages jedoch schnell ab. Auch in den darauf folgenden Wochen war die Luftfeuchtigkeit sehr gering, unterbrochen durch einzelne Regenereignisse.

Im Jahr 2003 war es zum ersten Inokulationstermin am 5. Mai sehr warm und trocken. Die Zahnstocher sind innerhalb weniger Minuten nach der Inokulation deutlich getrocknet, so dass einige Inokulationen möglicherweise nicht in Infektionen resultierten. Da es keine erkennbaren Entwicklungsunterschiede der Pflanzen zwischen dem frühen und dem normalem Aussaattermin gab, wurden die Inokulation zu BBCH 65-69 für die beiden Sorten und Aussaattermine nicht getrennt durchgeführt. Am 8.05. war der Bestand bei hohen Temperaturen sehr trocken, so dass die Zahnstocher auch hier schnell austrockneten. Abends und nachts regnete es, so dass an den beiden darauf folgenden Inokulationstagen die Bedingungen für eine Infektion bei geringeren Temperaturen optimal waren. Die Inokulation $\mathrm{zu}$ BBCH 71 wurde am 21.05. durchgeführt. Auch zu diesem Zeitpunkt waren die Infektionsbedingungen mit ausreichend Feuchte im Bestand und Temperaturen um $15-16^{\circ} \mathrm{C}$ optimal.

Das Jahr 2004 war allgemein feuchter als das Vorjahr und auch die Bedingungen zu den verschiedenen Inokulationsterminen waren besser. Zum ersten Inokulationstermin zu $\mathrm{BBCH}$ 61-65 am 29.04. war es mit ca. $17^{\circ} \mathrm{C}$ relativ warm und trocken. $\mathrm{Zu}$ den übrigen Terminen war der Bestand morgens taunass und die Temperaturen waren mit ca. 12 bis $15^{\circ} \mathrm{C}$ relativ kühl. Tagsüber fielen vereinzelt Schauer, so dass die Feuchtigkeitsbedingungen für eine Infektion gegeben waren. 
Im Versuchsjahr 2004/05 waren nur sehr geringe Unterschiede zwischen den Blüteterminen der verschiedenen Sorten $\mathrm{zu}$ beobachten, so dass alle Sorten zum gleichen Termin inokuliert werden konnten. Am 3. Mai war keine Taubildung festzustellen und der Pflanzenbestand war relativ trocken. Durch gemäßigte Temperaturen von ca. $15^{\circ} \mathrm{C}$ trockneten die Zahnstocher jedoch nicht sehr schnell aus. Am darauf folgenden Tag war der Bestand durch nächtliche Regenfälle sehr nass. Auch direkt nach der Inokulation traten Regenschauer auf. Die Sorte Prince wurde aufgrund einer sehr verlangsamten Pflanzenentwicklung erst rund eine Woche später am 9. Mai inokuliert. Zu diesem Termin war es durch anhaltenden Regen sehr nass und sehr kühl.

\subsection{Inokulationsmethoden}

\subsubsection{Sclerotinia-Inokulation}

\subsubsection{Produktion von Sclerotinia-Inokulum}

Holzzahnstocher wurden in $\mathrm{PDB}$ bei $120^{\circ} \mathrm{C}$ für $15 \mathrm{~min}$ autoklaviert. Nach dem Autoklavieren wurde überschüssige Flüssigkeit abgegossen und mit zwei S. sclerotiorum-Isolaten (Tab. 2.1) beimpft. Mehrere Agarplugs einer ca. eine Woche alten Pilzkultur von jedem Isolat wurden gleichmäßig verteilt mit der myzelbewachsenen Seite nach unten auf die Zahnstocher gelegt. Die Gläser wurden anschließend bei RT inkubiert.

Für die Gewächshausversuche wurden jeweils 55 Zahnstocher in Schnappdeckelgläschen mit $20 \mathrm{ml}$ PDB angesetzt und mit jeweils zwei Myzelplugs pro Isolat beimpft. Für die Feldversuche wurden ca. 800 Zahnstocher in Weckgläsern mit ca. $250 \mathrm{ml}$ PDB angesetzt. Nach dem Autoklavieren und dem Abgießen des überflüssigen Mediums wurden die Gläser mit jeweils fünf Myzelplugs pro Isolat beimpft. 

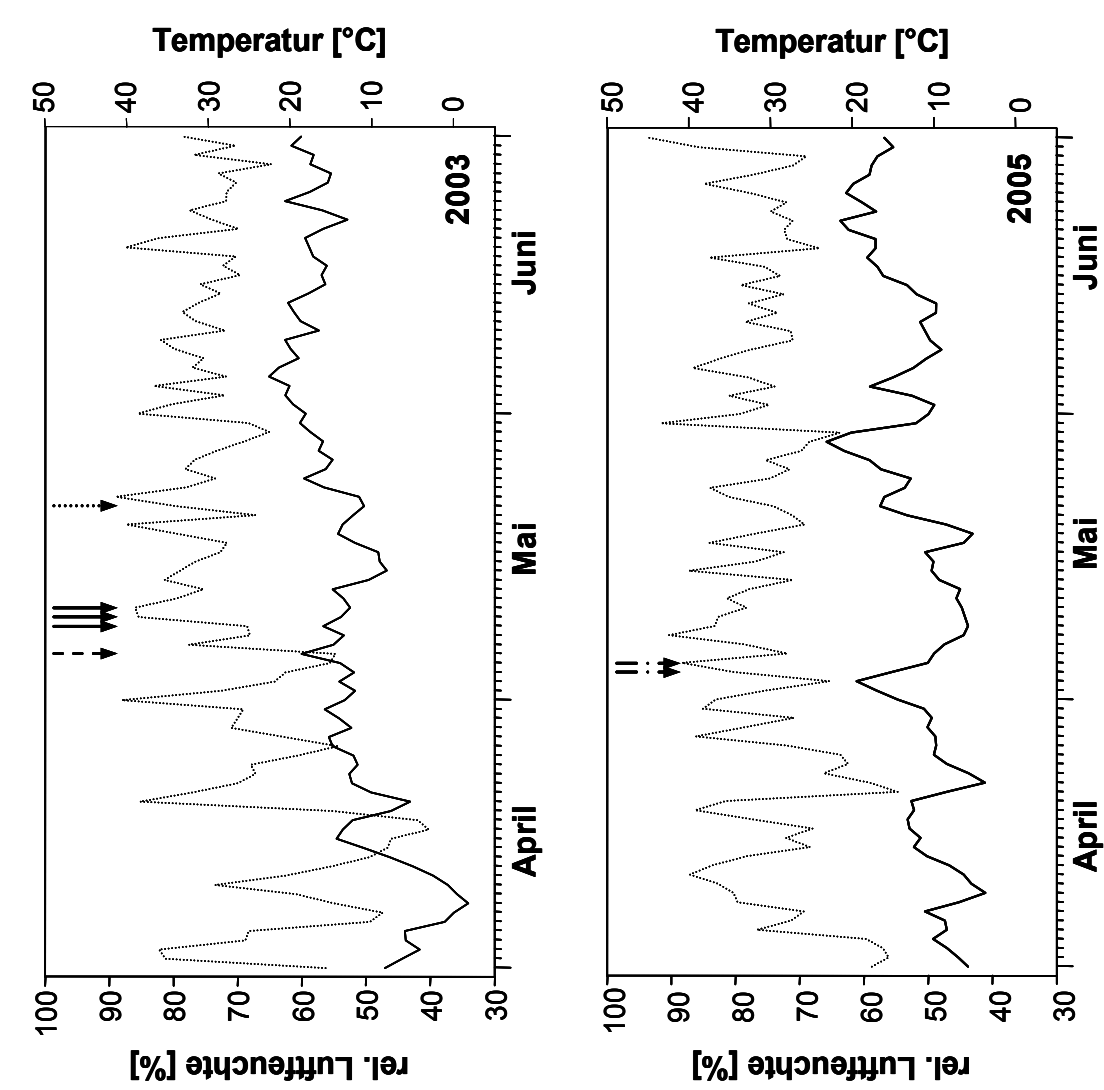

$\dot{2}$ so 气े : $\Xi 0$ 응. a $\sim \stackrel{\infty}{\Sigma}$ 离 를 믕 零 흥 क $\exists . \frac{2}{0}$ 声壳 늘 $\overline{\mathrm{F}}$ 这 寻 五 N

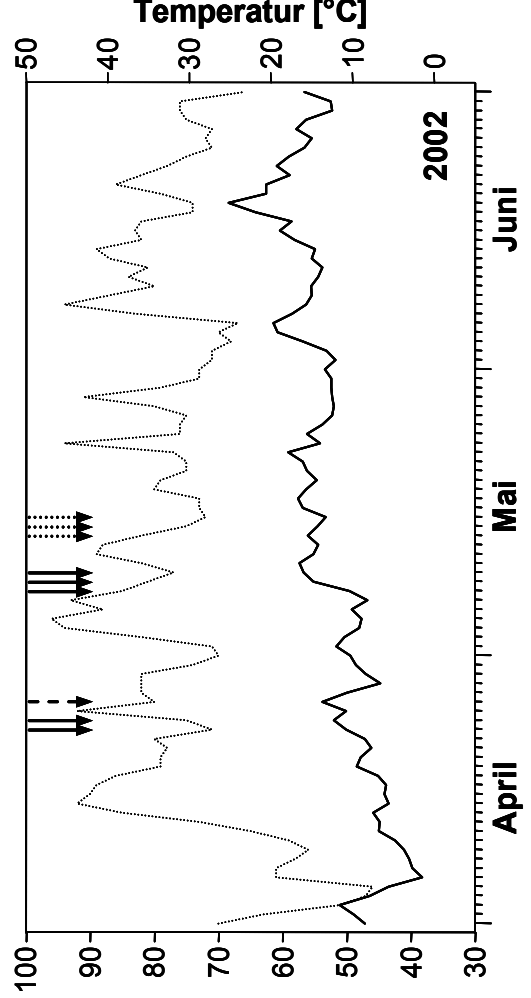

[\%] әิบขnวщกา "ן

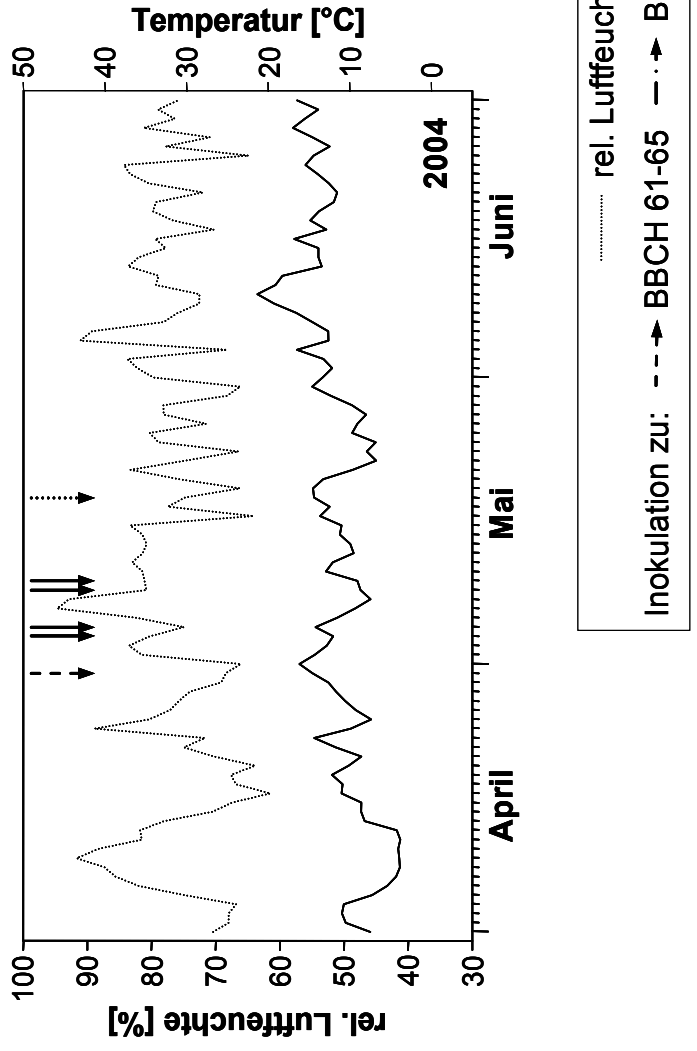

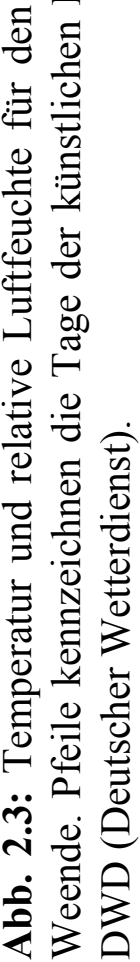




\subsubsection{Zahnstocher-Inokulation mit S. sclerotiorum}

Um eine möglichst natürliche Infektion zu simulieren, wurden die Infektionen in einer Blattachsel in mittlerer Pflanzenhöhe gesetzt. Der Zahnstocher wurde schräg in die Blattachsel gesteckt, ohne jedoch den Stängel auf der gegenüberliegenden Seite zu durchstechen. Pro Pflanze wurde eine Blattachsel inokuliert. Bei den späteren Inokulationsterminen wurde aufgrund von Stängelverhärtungen mit einem Dosenöffner ein Loch in der Blattachsel vorgestochen, in das dann der Zahnstocher gesteckt wurde.

\subsubsection{Gewächshausversuche zur Optimierung der Zahnstochermethode}

Rapspflanzen der Sorte Talent wurden in ein Gemisch aus Einheitserde, gedämpfter Komposterde und Sand (3:3:1) ausgesät und für eine Woche im Gewächshaus angezogen. Anschließend wurden die Pflanzen für 40 Tage in einem Klimaschrank bei $5^{\circ} \mathrm{C}$ vernalisiert. Nach der Vernalisation wurden die Pflanzen umgetopft (Bodengemisch siehe oben, Topfgröße 13x13 cm) und bei Lichtintervallen von 14 Stunden Licht und 10 Stunden Dunkelheit im Gewächshaus weiter angezogen. Da die Temperatur nicht genau reguliert werden konnte, traten Schwankungen von $16-30^{\circ} \mathrm{C}$ auf. In regelmäßigen Intervallen von ca. vier Wochen wurden die Pflanzen mit ca. $2 \mathrm{~g}$ Hakaphos-Dünger $(15 \% \mathrm{~N}, 11 \% \mathrm{P}, 15 \% \mathrm{~K}$ sowie Spurenelemente) gedüngt. Zur Vermeidung von Mehltaubefall wurden die Pflanzen zweimal mit dem Mittel Zenit M (750 g/l Fenpropidin) gespritzt.

Die Pflanzen wurden zur Vollblüte (BBCH 65) wie unter 2.6.1.2 beschrieben inokuliert. Um eine ausreichend hohe Luftfeuchte (>90\%) für eine erfolgreiche Infektion zu gewährleisten, wurden die inokulierten Pflanzen für eine Woche unter einen Folientunnel platziert. Die Wachstumsbedingungen waren entsprechend den oben genannten. Pro Variante wurden 30 Pflanzen inokuliert.

Zur Optimierung der Inokulationsmethode wurden die Anzuchtbedingungen (Nährmedium, Sklerotienbildung, Lagerung) des Inokulummaterials variiert (Tab. 2.9). Für die Varianten 9-12 wurden Blütenblätter von Rapspflanzen im Gewächshaus gesammelt, mit einem Ultrathurrax im Nährmedium zerkleinert, und vor dem Autoklavieren in das Medium gegeben. In den Varianten 13-15 wurde das Nährmedium nach dem Autoklavieren und vor dem Beimpfen der Zahnstocher nicht komplett abgegossen, sondern es verblieb soviel Nährmedium-Rest (Nm-Rest) im Gefäß, dass die Zahnstocher in das Medium eintauchten. 
Tab. 2.9: Varianten der Inokulumanzucht zur Optimierung der Inokulationsmethodik

\begin{tabular}{|c|c|c|c|}
\hline Variante & Nährmedium & $\begin{array}{l}\text { Sklerotien- } \\
\text { bildung }\end{array}$ & Lagerung \\
\hline 1 & 1x PDB & ja & frisches Inokulum \\
\hline 2 & $1 \mathrm{x}$ PDB & nein & frisches Inokulum \\
\hline 3 & 1x PDB & ja & 1 Woche, $4^{\circ} \mathrm{C}$ \\
\hline 4 & $1 \mathrm{x} \mathrm{PDB}$ & nein & 1 Woche, $4^{\circ} \mathrm{C}$ \\
\hline 5 & $2 \mathrm{x}$ PDB & ja & frisches Inokulum \\
\hline 6 & $2 \mathrm{x}$ PDB & nein & frisches Inokulum \\
\hline 7 & $2 \mathrm{x}$ PDB & ja & 1 Woche, $4^{\circ} \mathrm{C}$ \\
\hline 8 & $2 \mathrm{x}$ PDB & nein & 1 Woche, $4^{\circ} \mathrm{C}$ \\
\hline 9 & 1x PDB + 0,1\% Blütenblätter & ja & frisches Inokulum \\
\hline 10 & 1x PDB + 0,1\% Blütenblätter & nein & frisches Inokulum \\
\hline 11 & $1 \mathrm{x}$ PDB + 0,1\% Blütenblätter & ja & 1 Woche, $4^{\circ} \mathrm{C}$ \\
\hline 12 & 1x PDB + 0,1\% Blütenblätter & nein & 1 Woche, $4^{\circ} \mathrm{C}$ \\
\hline 13 & 1x PDB + Nm-Rest & nein & frisches Inokulum \\
\hline 14 & 2x PDB $+\mathrm{Nm}$-Rest & nein & frisches Inokulum \\
\hline 15 & $\begin{aligned} \text { 1x PDB } & +0,1 \% \text { Blütenblätter } \\
& + \text { Nm-Rest }\end{aligned}$ & nein & frisches Inokulum \\
\hline
\end{tabular}

Die Auswertung der Versuche erfolgte vier Wochen nach Inokulation. Es wurden die Befallshäufigkeit (\% befallene Pflanzen pro Variante), Boniturnote (Tab. 2.10) und Läsionslänge festgehalten.

\subsubsection{Sclerotinia-Inokulation mit der Zahnstochermethode im Feldversuch}

Für die Sclerotinia-Inokulation im Feld wurde das Inokulummaterial entsprechend der Variante 2 der Optimierungsversuche im Gewächshaus (Anzucht in 1xPDB, keine Sklerotienbildung, keine Lagerung der beimpften Zahnstocher) angezogen. Die Inkubationsdauer bis zum vollständigen Durchwachsen der Zahnstocher mit Myzel, jedoch ohne Sklerotienbildung, betrug ca. 1 Woche.

Je nach Witterung konnten 7 bis 10 Tage nach der Inokulation im Feld erste typische Sclerotinia-Symptome beobachtet werden. 
Tab. 2.10: Boniturschema für S. sclerotiorum an Winterraps

\begin{tabular}{|c|c|}
\hline Boniturnote & Infektionsstärke \\
\hline 1 & kein Befall \\
\hline 2 & $\begin{array}{l}\text { Einzelinfektionen, }<50 \% \text { stängelumgreifend, Schote partiell } \\
\text { infiziert }\end{array}$ \\
\hline 3 & $\begin{array}{l}\text { Einzelinfektionen, }<100 \% \text { stängelumgreifend } \\
\text { oder: einzelne Schoten }\end{array}$ \\
\hline 4 & Zwischenstufe \\
\hline 5 & $\begin{array}{l}\text { Symptom stängelumgreifend, auch in Längsrichtung deutlich } \\
\text { ausgedehnt, Stängelmark noch intakt } \\
\text { oder: Mehrfachinfektionen } \\
\text { (Schoten: mehr als } 3 \text { Schoten infiziert) }\end{array}$ \\
\hline 6 & Zwischenstufe \\
\hline 7 & $\begin{array}{l}\text { Erste Stängelschädigung erkennbar, Stängel auf Druck } \\
\text { brechend, Mark deutlich geschädigt, Sklerotienbildung }\end{array}$ \\
\hline 8 & Zwischenstufe \\
\hline 9 & $\begin{array}{l}\text { Stängel faserig und brüchig, Pflanze nicht mehr standfest, } \\
\text { erkennbare Notreife, reichliche Sklerotienbildung }\end{array}$ \\
\hline
\end{tabular}

\subsubsection{Verticillium-Inokulation im Feld}

Zur Inokulation der Pflanzen mit $V$. longisporum im Feld wurde eine Bodenverseuchung mit unterschiedlichen Mengen von natürlich infiziertem Rapsstroh durchgeführt (Tab. 2.11). Das infizierte Stroh wurde nach der Rapsernte 2002 auf einem Versuchsfeld in Biestow des Pflanzenschutzamtes Mecklenburg-Vorpommern, Rostock, gesammelt. Die Rapsstängel wurden mit einer Retsch-Mühle zerkleinert (Partikelgröße $8 \mathrm{~mm}$ ) und direkt vor der Aussaat in den Parzellen gleichmäßig verteilt. Das verteilte Rapsstroh wurde anschließend mit einer Kreiselegge in die obere Bodenschicht $(5 \mathrm{~cm})$ eingearbeitet.

Tab. 2.11: Ausgebrachte Menge an Inokulum in den unterschiedlichen Varianten zur Erarbeitung der Befalls-Verlust-Relationen von $V$. longisporum an Winterraps.

\begin{tabular}{cc}
\hline Variante & $\begin{array}{c}\text { Inokulummenge } \\
\text { /Parzelle }\end{array}$ \\
\hline 1 & $0 \mathrm{~g}$ \\
2 & $300 \mathrm{~g}$ \\
3 & $600 \mathrm{~g}$ \\
4 & $900 \mathrm{~g}$ \\
5 & $1200 \mathrm{~g}$ \\
\hline
\end{tabular}




\subsection{Befallsermittlung}

\subsubsection{Sclerotinia-Bonitur im Feld}

Die visuelle Bonitur des Sclerotinia-Befalls erfolgte zu BBCH 81-83 im Feld. Neben der Befallshäufigkeit in der gesamten Parzelle wurde auch die Befallsschwere nach dem in Tab. 2.10 angegebenen Schema bonitiert. Hierzu wurde die durchschnittliche Befallsstärke der infizierten Pflanzen einer Parzelle zu Grunde gelegt.

\subsubsection{Verticillium-Bonitur im Labor}

Der Verticillium-Befall wurde an 100 Stoppeln pro Parzelle im Labor bonitiert, die nach der Ernte zufällig über eine Parzelle verteilt gezogen wurden. Mit Hilfe eines Binokulars wurde die Befallshäufigkeit und Befallsschwere bonitiert. Es wurde bonitiert nach Vorhandensein von Mikrosklerotien an der Oberfläche/unter der Epidermis des Haupttriebes, im Stängelinneren und in der Wurzel. Die Befallsschwere wurde in drei Klassen eingeteilt (Tab. 2.12).

Tab. 2.12: Boniturschema für $V$. longisporum an Rapsstoppeln nach der Ernte.

\begin{tabular}{cl}
\hline Boniturnote & Infektionsstärke \\
\hline 0 & kein Besatz mit Mikrosklerotien \\
1 & mittlerer, nur vereinzelter Besatz mit \\
2 & Mikrosklerotien \\
starker Besatz mit Mikrosklerotien \\
\hline
\end{tabular}

\subsubsection{Berechnung des Befallsindex für $V$. longisporum}

Auf Grundlage der bonitierten Befallshäufigkeiten und Befallsstärken wurde ein Befallsindex nach folgender Formel berechnet:

$$
\mathrm{d}_{\mathrm{I}}=(0 * \mathrm{a}+1 * \mathrm{~b}+2 * \mathrm{c}) / \mathrm{n}
$$

wobei $\mathrm{a}=$ Anzahl Pflanzen mit der Boniturnote $0, \mathrm{~b}=$ Anzahl Pflanzen mit der Boniturnote 1, $\mathrm{c}=$ Anzahl Pflanzen mit der Boniturnote 2 und $\mathrm{n}=$ Gesamtanzahl Pflanzen ist. 


\subsubsection{Erfassung weiterer Schaderreger im Feld}

In den Feldversuchen zur Schadwirkung von S. sclerotiorum wurde das Auftreten von P. lingam als Befallshäufigkeit in den Parzellen parallel zur Sclerotinia-Bonitur bonitiert. In den Feldversuchen zur Schadwirkung von $V$. longisporum wurde bei der Stoppelbonitur im Labor gleichzeitig die Befallshäufigkeit mit S. sclerotiorum sowie die Befallsstärke von $P$. lingam erfasst. Die Phoma-Bonitur erfolgte nach einem neunstufigen Boniturschema von KRÜGER (1982) (Tab. 2.13).

Tab. 2.13: Boniturschema für $P$. lingam nach KRÜGER (1982)

\begin{tabular}{cll}
\hline Boniturnote & Symptom am Wurzelhals & Symptom am Stängel \\
\hline 1 & kein Befall & kein Befall \\
2 & kleine Flecken an der & kleine Flecken an der \\
& Oberfläche & $\begin{array}{l}\text { Oberfläche } \\
\text { größere Flecken an der }\end{array}$ \\
3 & kleine Flecken mit geringer & Oberfläche mit geringer \\
& Verkorkung und/oder & Verkorkung \\
4 & Verbräunungen im Wurzelhals & Zwischenstufe \\
5 & Zwischenstufe & tiefere Befallsstellen am \\
& Verkorkung & Stängel \\
7 & Zwischenstufe & Zwischenstufe \\
7 & über 50\% des Wurzelhalses tief & tiefe Befallsstellen mit \\
& verkorkt & Pyknidien \\
9 & Zwischenstufe & Zwischenstufe \\
& Pflanze abgestorben, starke & Pflanze abgestorben, tiefe \\
\hline
\end{tabular}

\subsection{Quantifizierung des bodenbürtigen Inokulums von Verticillium spp.}

Anhand von Bodenproben wurde die Verseuchung mit Verticillium spp. in den unterschiedlich stark inokulierten Parzellen mit Hilfe der von STEINBACH et al. (2002) beschriebenen Methode untersucht. Die Bodenproben wurden im Versuchsjahr 2002/03 zu Vegetationsende am 29.10.2002 und im Versuchsjahr 2003/04 zu Vegetationsbeginn am 01.04.2004 gezogen.

An fünf gleichmäßig über die Parzelle verteilten Stellen wurden ca. 100 g Boden aus der oberen Bodenschicht $(5-10 \mathrm{~cm})$ entnommen und eine Mischprobe pro Parzelle hergestellt. Die Proben wurden für einige Tage im Gewächshaus luftgetrocknet und 
anschließend auf $2 \mathrm{~mm}$ gesiebt. Je Bodenprobe wurden drei Wiederholungen à $25 \mathrm{~g}$

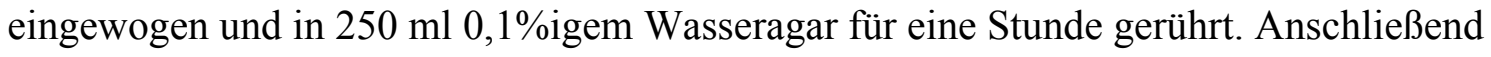
wurde jeweils ein Aliquot von $500 \mu l$ homogener Bodensuspension auf zehn Petrischalen mit Verticillium-Selektivmedium gleichmäßig mit einem Drigalsky-Spatel verteilt. Bis zum Antrocknen der Agaroberfläche blieben die Petrischalen geöffnet unter der Impfkabine stehen. Die Inkubation der Petrischalen erfolgte fünf Wochen bei 18$20^{\circ} \mathrm{C}$ im Dunkeln.

Zur Auswertung der Platten wurde die Agaroberfläche unter fließendem Wasser vorsichtig mit einem Gummispatel gereinigt. Mit Hilfe eines Kolonie-Zählgerätes wurden die Verticillium-Kolonien auf der Unterseite der Petrischale gezählt. Eine Differenzierung zwischen verschiedenen Verticillium spp. war hierbei anhand der Koloniecharakteristika nicht möglich.

Die Berechnung des Bodeninokulums pro Gramm Boden wurde nach folgender Formel vorgenommen:

$\mathrm{cfu} / \mathrm{g}$ Boden $=($ Anzahl Kolonien $* 1 \mathrm{~g}) / 0,05 \mathrm{~g}$

\subsection{Erhebung der Ertragsparameter}

Zur Erfassung der Ertragsparameter wurden die Versuchsparzellen (Gesamtparzellen) mit einem Parzellenmähdrescher beerntet. Nach der Ermittlung des Kornertrages jeder Parzelle wurde eine Ernteprobe von ca. $500 \mathrm{~g}$ entnommen, anhand derer die Kornfeuchte, der Schmutzanteil, das TKG (Tausendkorngewicht) und der Ölgehalt bestimmt wurden. Unter Berücksichtigung der ermittelten Ergebnisse wurde der Ertrag auf eine einheitliche Kornfeuchte von 9\% und 0\% Schmutzanteil bezogen und auf Hektarerträge (dt/ha) hochgerechnet.

Zur Bestimmung der Kornfeuchte wurden ca. $50 \mathrm{~g}$ der Ernteprobe direkt nach der Ernte eingewogen, für $24 \mathrm{~h}$ bei $103^{\circ} \mathrm{C}$ getrocknet und nach Abkühlung auf $80^{\circ} \mathrm{C}$ zurückgewogen.

Zur weiteren Untersuchung wurden die Ernteproben mit einem Trieur gereinigt und durch Zurückwiegen der gereinigten Proben der Schmutzanteil bestimmt. 
Zur Bestimmung des TKG wurden mit Hilfe eines elektronischen Zählgerätes rund 1000 luftgetrocknete Rapskörner abgezählt und gewogen. Das Gewicht wurde anschließend auf genau eintausend Körner berechnet.

Anhand einer Probe von 3 g luftgetrockneter Rapssamen wurde der Ölgehalt mittels Nah-Infrarot-Reflektions-Spektroskopie (NIRS) festgestellt.

\subsection{Nachweis von $V$. longisporum in Pflanzenmaterial mittels ELISA}

Zur Untersuchung der Befallsdynamik von $V$. longisporum im Verlauf der Vegetationsperiode wurden mit Hilfe des von CERNUSKO (1995) entwickelten ELISATests Pflanzenproben auf Befall mit $V$. longisporum untersucht.

\subsubsection{Probenahme und -aufbereitung}

Im Verlauf der Vegetation wurden regelmäßig Pflanzenproben aus den Beprobungsparzellen gezogen (Tab.2.14). Pro Parzelle und Beprobungstermin wurden jeweils fünf Pflanzen entnommen. Die Pflanzenwurzeln wurden mit Leitungswasser gewaschen, um anhaftende Erde zu entfernen.

Nach den Probenahmen wurden die Pflanzen bei $30^{\circ} \mathrm{C}$ getrocknet bzw. vorerst bei minus $20^{\circ} \mathrm{C}$ eingefroren und anschließend bei $30^{\circ} \mathrm{C}$ getrocknet. Die getrockneten Pflanzenproben wurden anschließend gemahlen und über Nacht bei $4^{\circ} \mathrm{C}$ auf einem Schüttler mit Extraktionspuffer extrahiert $(1: 20 \mathrm{w} / \mathrm{v})$. Nach der Extraktion wurden $1000 \mu 1$ der Extrakte in Reaktionsgefäße überführt und bei $13.000 \mathrm{rpm}$ zentrifugiert. Der Überstand wurde direkt im ELISA eingesetzt.

Tab. 2.14: Probenahmetermine in den Verticillium-Versuchen in den Vegetationsperioden 2002/03 und 2003/04.

\begin{tabular}{ccc}
\hline $\begin{array}{c}\text { BBCH- } \\
\text { Stadium }\end{array}$ & $\mathbf{2 0 0 2 / 0 3}$ & $\mathbf{2 0 0 3 / 0 4}$ \\
\hline 18 & 29.10 .02 & 28.10 .03 \\
50 & 25.03 .03 & 02.04 .04 \\
60 & 22.04 .03 & 28.04 .04 \\
70 & 22.05 .03 & 03.06 .04 \\
83 & 23.06 .03 & 01.07 .04 \\
89 & 15.07 .03 & 30.07 .04 \\
\hline
\end{tabular}




\subsubsection{Durchführung des ELISA-Tests}

Die Durchführung des ELISA-Tests erfolgte in Mikrotiterplatten mit $350 \mu 1$ Kavitäten (Nunc, Wiesbaden).

Alle Proben wurden in zweifacher Wiederholung getestet.

1. Beschichtung der Mikrotiterplatten mit $100 \mu 1 /$ Trog Beschichtungspuffer + Serum-AK (1:1000) und Inkubation über Nacht bei $4^{\circ} \mathrm{C}$

2. $3 \times 3$ min mit Waschpuffer waschen

3. Blocken der freien Bindungsstellen mit $200 \mu 1 /$ Trog Beschichtungspuffer $+0,2 \%$ RSA für eine Stunde bei $37^{\circ} \mathrm{C}$ im Wasserbad.

4. wie 2.

5. Auftragen von Probe, Proteinstandard und Extraktionspuffer (je $100 \mu \mathrm{l}$ ) nach Befüllungsplan, Inkubation für vier Stunden bei $37^{\circ} \mathrm{C}$ im Wasserbad.

6. wie 2.

7. Detektion mit $100 \mu \mathrm{l}$ biotinylierter AK, 1:2000 verdünnt in PPK/Tween $+0,2 \%$ RSA, Inkubation über Nacht bei $4^{\circ} \mathrm{C}$

8. wie 2.

9. Zugabe von $100 \mu \mathrm{l}$ StrAp, 1:10.000 in PPK/Tween $+0,2 \%$ RSA. Inkubation der Platten für eine Stunde bei $37^{\circ} \mathrm{C}$ im Wasserbad

10. wie 2 .

11. Auftragen von $100 \mu \mathrm{l}$ Substratlösung (pNPP in Substratpuffer, $1 \mathrm{mg} / \mathrm{ml}$ Puffer) und anschließende Inkubation der Platten im Dunkeln bei Raumtemperatur.

Nach 1h, $2 \mathrm{~h}$ und $3 \mathrm{~h}$ erfolgte die Messung der Extinktion in einem Photometer (Spectra 2, SLT Laboratories, Crailsheim) bei einer Wellenlänge von $405 \mathrm{~nm}$ und einer Referenzwellenlänge von $592 \mathrm{~nm}$.

Aus den jeweils zwei Messwerten für eine Probe wurde der Mittelwert errechnet. Durch Subtraktion des OD-Wertes der Negativkontrolle der jeweiligen ELISA-Platte wurden die Messwerte bereinigt.

\subsection{Statistische Verrechnung der Daten}

Die statistische Verrechnung der Daten erfolgte mit dem Programm STATGRAPHICS ${ }^{\circledR}$ Plus Version 5.1, wobei der Vergleich der Mittelwerte der Varianten hinsichtlich 
signifikanter Unterschiede mit dem Tukey-Test durchgeführt wurde. Die Signifikanz der Regression wurde mit dem Durbin-Watson-Test berechnet.

Die Irrtumswahrscheinlichkeit wird wie folgt angegeben:

n.s.: nicht signifikant; $*$ : $\leq \leq 0,10 ; * * \mathrm{p} \leq 0,05 ; * * *$ : $\mathrm{p} \leq 0,01$.

Die Regressionsgeraden sind in der Form $y=a+b^{*} x$ dargestellt, wobei a der $y$ Achsenabschnitt und $\mathrm{b}$ die Steigung der Regressionsgeraden ist

\subsection{Validierung der Wirtschaftlichkeit von Fungizidmaßnahmen gegen S. sclerotiorum}

\subsubsection{Datensammlung}

Aus allen dokumentierten Feldversuchen zur Bekämpfung von Pilzkrankheiten in Winterraps der amtlichen Pflanzenschutzdienste der Länder wurden Daten zur Wirtschaftlichkeitsuntersuchung von Fungizidmaßnahmen gegen $S$. sclerotiorum gesammelt. Es wurden nur Versuche berücksichtigt, für die statistisch verrechnete Ertragsergebnisse, Angaben zur Befallshäufigkeit und Angaben zum Fungizideinsatz in den behandelten Varianten vorlagen und die eine Kontrollvariante enthielten. Der gesamte Datensatz umfasste 1036 verschiedene Behandlungen in 163 Feldversuchen aus dem Zeitraum 1991 bis 2003 (Tab. 2.15).

Tab. 2.15: Zusammensetzung des Datensatzes für die Wirtschaftlichkeitsberechnung von Fungizidmaßnahmen gegen S. sclerotiorum von 1991 bis 2003.

\begin{tabular}{lccc}
\hline \multicolumn{1}{c}{ Bundesland } & $\begin{array}{c}\text { Anzahl } \\
\text { Feldversuche }\end{array}$ & $\begin{array}{c}\text { Anzahl versch. } \\
\text { Behandlungen }\end{array}$ & Zeitraum \\
\hline Schleswig-Holstein & 61 & 464 & $1991-2003$ \\
Mecklenburg-Vorpommern & 32 & 128 & $1991-2003$ \\
Niedersachsen & 11 & 86 & $1991-2003$ \\
Brandenburg & 6 & 51 & $1998-2000$ \\
Sachsen & 28 & 177 & $1998-2003$ \\
Thüringen & 13 & 67 & $2000-2003$ \\
Rheinland-Pfalz & 6 & 30 & $1998-2001$ \\
Bayern & 6 & 33 & $2000-2002$ \\
\hline Gesamt & $\mathbf{1 6 3}$ & $\mathbf{1 0 3 6}$ & $\mathbf{1 9 9 1 - 2 0 0 3}$ \\
\hline
\end{tabular}




\subsubsection{Kostenfaktoren}

Für die Berechnung der Kosten einer Fungizidanwendung zur Vollblüte gegen S. sclerotiorum wurden die nachfolgend beschriebenen Kosten veranschlagt. Die Kosten für die Fungizide incl. Mehrwertsteuer (Anhang Tab. A2) wurden den Preislisten der Raiffeisen Genossenschaft Nord entnommen. Die Überfahrtskosten (Anhang Tab. A.3) umfassen Maschinenkosten und Kraftstoffkosten für Traktor und Spritzgerät sowie Arbeitszeitkosten. Die anzusetzenden Kosten wurden den KTBL-Taschenbüchern der entsprechenden Jahre entnommen. Die Durchfahrtsverluste wurden mit 2,6\% angesetzt. Die Grundlagen zur Berechnung der Durchfahrtsverluste sind im Anhang in Tab. A5 aufgeführt. Die Rapserzeugerpreise sind Durchschnittswerte über ein Jahr (Juli bis Juni) und basieren auf Daten der ZMP (Zentrale Markt- und Preisberichtstelle für Erzeugnisse der Land-, Forst- und Ernährungswirtschaft GmbH) (Anhang Tab. A.4).

\subsection{Entwicklung einer artspezifischen PCR zum in vitro-Nachweis von V. longisporum}

\subsubsection{Isolierung von Nukleinsäuren}

\subsubsection{Isolierung genomischer DNA aus filamentösen Pilzen}

Zur DNA-Extraktion wurde Pilzmyzel aus Schüttelkulturen verwendet. Nach dreiwöchiger Inkubation bei $18-20^{\circ} \mathrm{C}$ im Dunkeln wurde das Myzel mit Hilfe einer Wasserstrahlpumpe über einen Glasfaserfilter (Schleicher \& Schuell, Dassel) abgenutscht und dreimal mit sterilem Leitungswasser gespült. Anschließend wurde das Myzel lyophilisiert. Zur DNA-Extraktion wurden entsprechende Mengen an Probenmaterial eingewogen und unter Zugabe von flüssigem Stickstoff im Mörser mechanisch aufgeschlossen.

\subsection{DNA-Extraktion mit dem DNeasy Plant Mini/Maxi Kit}

Die DNA-Extraktion wurde mit Hilfe des „DNeasy Plant Mini Kit“ bzw. „DNeasy Plant Maxi Kit" der Firma Qiagen durchgeführt. Bei dieser Methode wird die DNA durch Zentrifugation und Bindung an Silica-Säulen von anderen Zellbestandteilen getrennt.

Durch Zugabe von Puffer AP1 und RNase A wurden die Proben für 10 min bei $65^{\circ} \mathrm{C}$ lysiert. Nach der Lyse wurden Proteine und Polysaccharide durch Zugabe von Puffer 
AP2 bei einem Inkubationsschritt für 10 min auf Eis gefällt. Anschließend wurden Zellbruchstücke durch Zentrifugation im „QIAshredder“ entfernt. Das gereinigte Lysat wurde mit 1,5 Vol. des Puffers AP3/E versetzt und auf die „DNeasy Spin Column“, eine Silica-Säule, aufgetragen. Durch Zentrifugation bindet die DNA an die Säule. Weitere Bestandteile wie Proteine und Polysaccharide wurden durch zwei Waschschritte mit dem Puffer AW entfernt. Durch Zugabe von Puffer AE wurde die DNA von der Säule eluiert und anschließend bei $-20^{\circ} \mathrm{C}$ gelagert. (Methode nachzulesen im Handbuch S. 2224. http://www1.qiagen.com/literature/handbooks/PDF/GenomicDNAStabilizationAnd Purification/FromAnimalAndPlantIssues/DNY_MinMax/1026510HB_DNY_012004W W_LR.pdf Die Zusammensetzung der unterschiedlichen Puffer ist vom Hersteller nicht angegeben)

\subsection{DNA-Extraktionsmethode nach MöLLER et al. (1992)}

Neben der DNA-Extraktion mit dem DNeasy Plant Mini/Maxi Kit wurde ebenfalls die Methode von MöLLER et al. (1992) durchgeführt.

Es wurden $150 \mathrm{mg}$ des gemahlenen Pilzmyzels in 3,5 ml TES-Puffer resuspendiert. Nach Zugabe von 22,5 $\mu$ l Proteinase $\mathrm{K}$ wurden die Proben für $1 \mathrm{~h}$ bei $55^{\circ} \mathrm{C}$ im Wasserbad inkubiert. Während der Inkubation wurde der Ansatz gelegentlich vorsichtig geschwenkt. Anschließend wurden dem Ansatz $980 \mu 1$ einer $5 \mathrm{M} \mathrm{NaCl-Lösung} \mathrm{und} \mathrm{zur}$ Komplexierung von Proteinen und sauren Polysacchariden $455 \mu \mathrm{l}$ einer 10\%igen CTAB-Lösung hinzu gegeben. Die Inkubation erfolgte für $10 \mathrm{~min}$ bei $65^{\circ} \mathrm{C} \mathrm{im}$ Wasserbad. Zur anschließenden Entfernung der Komplexe wurde der Ansatz mit 4,9 ml eines Chloroform/Isoamylalkohol-Gemisches (24:1) versetzt und $30 \mathrm{~min}$ bei $0^{\circ} \mathrm{C}$ inkubiert. Nach 20minütiger Zentrifugation bei $4500 \mathrm{x} g$ und $4{ }^{\circ} \mathrm{C}$ wurde der wässrige Überstand in ein neues Reaktionsgefäß überführt und mit 1,6 $\mathrm{ml}(1 / 3 \mathrm{Vol}$.) einer $5 \mathrm{M}$ $\mathrm{NH}_{4}$-Acetat-Lösung versetzt. Um verbliebene Verunreinigungen zu präzipitieren wurde dieser Ansatz nach einstündiger Inkubation bei $0^{\circ} \mathrm{C}$ erneut zentrifugiert $(20 \mathrm{~min}, 4500 \mathrm{x}$ $\left.g, 4^{\circ} \mathrm{C}\right)$ und der wässrige Überstand in neue Reaktionsgefäße überführt. Durch Zugabe von $20 \mu 1 \mathrm{RNase} A(10 \mathrm{mg} / \mathrm{ml})$ wurde die RNA degradiert (Inkubation $1 \mathrm{~h}, 37^{\circ} \mathrm{C}$ ).

In einer anschließenden Phenol-Chloroform-Extraktion wurde das RNase A-Protein entfernt. Die wässrige Phase wurde einer folgenden Ammoniumacetat-IsopropanolFällung unterzogen und das getrocknete Pellet schließlich in $300 \mu$ TE-Puffer resuspendiert. 


\subsection{DNA-Extraktion für die Verwendung der DNA im Southern-Blot}

Für die Extraktion großer Mengen DNA für die Verwendung im Southern-Blot wurde die Methode in Anlehnung an MurRay \& THOMPSOn (1980) und Lis \& SchleIF (1975) angewendet.

Es wurden $200 \mathrm{mg}$ des in flüssigen Stickstoff zermahlenen lyophilisierten Pilzmyzels mit $10 \mathrm{ml}$ TES-Puffer und $4 \mathrm{mg}$ Proteinase $\mathrm{K}$ versetzt und für $45 \mathrm{~min}$ bei $45^{\circ} \mathrm{C}$ inkubiert. Während der Inkubationszeit wurde der Ansatz alle $10 \mathrm{~min}$ vorsichtig geschwenkt. Anschließend wurden dem Ansatz zur Komplexierung von Proteinen und sauren Polysacchariden 3,9 ml einer $5 \mathrm{M} \mathrm{NaCl-Lösung} \mathrm{sowie} \mathrm{1,4} \mathrm{ml}$ einer 10\%igen CTAB-Lösung hinzugegeben und gründlich gemischt. Nach einer 10minütigen Inkubation bei $65^{\circ} \mathrm{C}$ wurde der Ansatz auf Eis gestellt und mit $10 \mathrm{ml}$ eines Chloroform/ Isoamylalkohol-Gemisches (24:1) versetzt. Der Ansatz wurde gründlich gemischt und für $30 \mathrm{~min}$ auf Eis inkubiert. Durch eine anschließende Zentrifugation $\left(4500 \mathrm{rpm}, 5^{\circ} \mathrm{C}\right.$, 20 min) wurde die Phasentrennung herbeigeführt. Der wässrige Überstand wurde in ein neues Reaktionsgefäß überführt und mit $10 \mathrm{ml}$ Isopropanol vermischt. Nach 30minütiger Inkubation bei RT wurde die DNA bei $4500 \mathrm{rpm}$ für 10 min sedimentiert. Der Überstand wurde dekantiert und das Pellet zweimal mit 70\%igem Ethanol gewaschen. Nachdem das Pellet vollständig getrocknet ist, wurde es in $300 \mu 1 \mathrm{TE}-$ Puffer resuspendiert.

\subsubsection{Isolierung von Plasmiden aus $E$. coli}

Durch die Transformation in E. coli können Plasmide in vivo amplifiziert werden. Für die analytische Plasmidpräparation wurde die Methode nach BIRNBOIM (1983) in einem kleinen Maßstab angewendet.

In $40 \mathrm{ml}$ sterilen Reagenzgläsern wurden $3 \mathrm{ml}$ Terrific-Broth-Medium mit einer Bakterienstammkultur beimpft und über Nacht auf dem Roll-Inkubator bei $37^{\circ} \mathrm{C}$ inkubiert. Aliquots von $1 \mathrm{ml}$ wurden in Reaktionsgefäße überführt und die Bakterienzellen für $5 \mathrm{~min}$ bei $8000 \mathrm{rpm}$ sedimentiert. Der Überstand wurde verworfen und die Zellen mit $200 \mu$ l eiskalter GLC-Lösung versetzt. Der Ansatz wurde gut gemischt und für 20 min bei RT inkubiert. Anschließend wurden zur Alkalisierung $300 \mu 1 \mathrm{LYZ}$ hinzu pipettiert und der Ansatz vorsichtig geschwenkt. Nach 10 min Inkubation bei RT wurden $250 \mu \mathrm{l}$ HS-Puffer zur Neutralisierung hinzu gegeben, der Ansatz gut gemischt und für $30 \mathrm{~min}$ auf Eis inkubiert. Durch eine anschließende Zentrifugation für $10 \mathrm{~min}$ 
bei $5^{\circ} \mathrm{C}$ und $13.000 \mathrm{rpm}$ wurden die Zelltrümmer sedimentiert. Der Überstand wurde in ein neues Reaktionsgefäß überführt und zur Fällung der DNA mit 0,6 Vol. Isopropanol versetzt. Nach einer Inkubation für $10 \mathrm{~min}$ bei RT wurde die DNA für $10 \mathrm{~min}$ bei $13.000 \mathrm{rpm}$ sedimentiert. Der Überstand wurde verworfen und das Pellet zweimal mit $70 \%$ igem Ethanol gewaschen. Nachdem das Pellet für $10 \mathrm{~min}$ bei $30^{\circ} \mathrm{C}$ in der SpeedVac-Zentrifuge getrocknet wurde, wurde die DNA in $50 \mu 1$ TE-Puffer resuspendiert.

\subsubsection{Isolierung von DNA-Fragmenten aus Agarosegelen}

Die Isolierung von DNA-Fragmenten aus Agarosegelen wurde nach der von VoGELSTEIN \& GILLESPIE (1979) beschriebenen Methode durchgeführt.

Die DNA wurde im TBE-Agarosegel elektrophoretisch aufgetrennt. Der für die Färbung vorgesehene Teil des Gels wurde im Ethidiumbromid-Wasserbad gefärbt (siehe Kap. 2.12.13.1) und die Position der gesuchten Bande unter UV-Licht auf einem Transilluminator mit einem Skalpell gekennzeichnet. Nach Abschalten des UV-Lichts wurden die nicht gefärbten Teile des Gels angelegt und das gewünschte Fragment aus dem Gel herausgeschnitten. Der Agaroseblock wurde gewogen und nach Zugabe von 3 Vol. Binding Puffer für ca. $10 \mathrm{~min}$ bei $50^{\circ} \mathrm{C}$ im Wasserbad aufgeschmolzen. Anschließend wurden $6 \mu 1$ Prep-A-Gene-Matrix (6 $\mu 1 / \mu$ g DNA) hinzugefügt und unter regelmäßigem Mischen für 5-10 min bei RT inkubiert. Durch Zentrifugation für $30 \mathrm{sec}$ bei $13.000 \mathrm{rpm}$ wurde die Prep-A-Gene-Matrix sedimentiert, der Überstand wurde verworfen. Durch Zugabe von Binding-Puffer $(500 \mu$ l bei $6 \mu l)$ wurde das Pellet resuspendiert. Nach einer erneuten Zentrifugation (30 sec, $13.000 \mathrm{rpm}$ ) folgten zwei Waschschritte mit 25x Matrixvolumen Wasch-Puffer und wiederum jeweils $30 \mathrm{sec}$ Zentrifugation bei $13.000 \mathrm{rpm}$. Das Pellet wurde anschließend in $20 \mu \mathrm{l}$ TE-Puffer resuspendiert und für $5 \mathrm{~min}$ bei $50^{\circ} \mathrm{C}$ im Wasserbad inkubiert. Durch einen abschließenden Zentrifugationsschritt für $30 \mathrm{sec}$ bei $13.000 \mathrm{rpm}$ wurden Feststoffe sedimentiert und der Überstand wurde in ein neues Reaktionsgefäß überführt.

\subsubsection{Isolierung von DNA-Fragmenten aus Polyacrylamidgelen}

Für die Isolierung von DNA-Fragmenten aus Polyacrylamidgelen wurden die gesamten Gele mit Ethidiumbromid angefärbt (siehe Kap. 2.12.13.2) und die gewünschten Banden unter UV-Licht mit einem Skalpell aus dem Gel herauspräpariert. Das Gelstück 
wurde in ein Reaktionsgefäß überführt und zerkleinert, um eine bessere Elution der DNA aus dem Gel zu gewährleisten. Das zerkleinerte Gelmaterial wurde mit $10 \mu 1$ DNA-Elutionspuffer pro $\mathrm{mm}^{3} \mathrm{Gel}$ versetzt. Die Proben wurden bei $-20^{\circ} \mathrm{C}$ inkubiert, bis das Gelmaterial durchgefroren war, anschließend bei $50^{\circ} \mathrm{C}$ im Wasserbad zügig wieder aufgetaut und für $5 \mathrm{~min}$ bei $90^{\circ} \mathrm{C}$ inkubiert. Durch den Einfrier-/Auftauschritt wird die Matrix zerbrochen und dadurch die Elutionszeit verringert. Die Elution der DNA erfolgte bei $37^{\circ} \mathrm{C}$ und $200 \mathrm{rpm}$ über Nacht. Der Ansatz wurde schließlich für $2 \mathrm{~min}$ bei RT und 1000 x $g$ zentrifugiert, um die Gelfragmente zu sedimentieren. Der Überstand wurde in ein neues Reaktionsgefäß überführt. Das Gel wurde nochmals mit der Hälfte des ursprünglichen Volumens DNA-Elutionspuffer versetzt und $30 \mathrm{~min}$ bei $37^{\circ} \mathrm{C}$ und 200 rpm geschüttelt. Die Überstände wurden vereinigt und dreimal mit einem gleichen Volumen Phenol und je einmal mit einem gleichen Volumen Chloroform/ Isoamylalkohol (24:1) und Diethylether extrahiert. Zur Phasentrennung wurden die Proben jeweils 2 min bei 15000 rpm und RT zentrifugiert. Zur Präzipitation der DNA wurden der wässrigen Phase der Etherextraktion 2,5 Vol. 70\%iger Ethanol zugegeben und für $20 \mathrm{~min}$ auf Eis inkubiert. Bei anschließender Zentrifugation $\left(15 \mathrm{~min}, 4^{\circ} \mathrm{C}, 5500\right.$ rpm) wurde die DNA pelletiert. Das Pellet wurde mit 70\%igem Ethanol gespült, getrocknet und in $50 \mu 1$ TE-Puffer resuspendiert.

\subsubsection{Quantifizierung der extrahierten DNA}

Die Quantifizierung der extrahierten DNA erfolgte durch visuelle Schätzung. Sowohl von den DNA-Proben als auch von dem Größenstandard wurden definierte Volumina auf ein Agarosegel aufgetragen. Nach erfolgter Elektrophorese wurden die Gele in Ethidiumbromid angefärbt (siehe Kap. 2.12.13) und die Banden unter UV-Licht sichtbar gemacht. Das Ethidiumbromid interkaliert zwischen den Basen der DNA, absorbiert Licht im ultravioletten Bereich und emittiert Licht bei einer Wellenlänge von $590 \mathrm{~nm}$. Die Lichtintensität ist dabei proportional zur vorhandenen DNA-Menge. Durch einen Vergleich der Helligkeit der Banden der DNA-Proben im Vergleich zum Größenstandard konnte so die DNA-Menge in den Proben ausreichend genau abgeschätzt werden. 


\subsubsection{Aufreinigung von Nukleinsäuren}

\subsubsection{Phenol-Chloroform-Extraktion}

Mit Hilfe der Phenol-Chloroform-Extraktion können Verunreinigungen mit Proteinen oder Polysaccharidresten aus DNA-haltigen wässrigen Proben entfernt werden. Hierzu werden die Proben mit 1 Vol. eines Phenol/Chloroform/Isoamylalkohol-Gemisches (25:24:1) durch wiederholtes Invertieren gemischt. Während der anschließenden Zentrifugation für $10 \mathrm{~min}, 12000 \mathrm{x} \mathrm{g}$ und $4^{\circ} \mathrm{C}$ trennt sich die wässrige, DNA-haltige Phase von der organischen Phase. Durch das Phenol werden Protein- und Polysaccharidreste denaturiert. Diese Bestandteile befinden sich in der unteren Phenolphase oder bilden eine weißliche Interphase. Die obere wässrige Phase wird in ein neues Reaktionsgefäß überführt und zum Entfernen von Phenolresten mit einem Chloroform/Isoamylalkohol-Gemisch (24:1) versetzt. Durch wiederholtes Invertieren wird dieser Ansatz gründlich gemischt und anschließend für 10 min bei $12000 \mathrm{x} g$ und $4^{\circ} \mathrm{C}$ zentrifugiert. Der DNA-haltige Überstand wird in ein neues Reaktionsgefäß überführt und einer Ammoniumacetat-Isopropanol-Fällung unterzogen.

\subsubsection{Ethidiumbromid-Phenolextraktion}

Eine weitere Methode zur Entfernung von Proteinen aus DNA-Lösungen ist die Ethidiumbromid-Phenolextraktion. Diese Aufreinigungsmethode wurde insbesondere für die Aufreinigung von Proben für die DNA-Sequenzierung eingesetzt.

Die DNA-Lösungen $(200 \mu \mathrm{l})$ werden mit $150 \mu \mathrm{l}$ einer 7,5 M Ammoniumacetat-Lösung und anschließend mit $15 \mu$ l Ethidiumbromid (1\%) gemischt. Nach 10 min Inkubation bei RT wurde der Ansatz mit $150 \mu$ Tris-äquilibriertem Phenol versetzt und 5 min geschüttelt. Nach Zentrifugation (10 min, $\mathrm{rpm}_{\max }$ ) wurde die wässrige Phase in ein neues Reaktionsgefäß überführt. Ethidiumbromid und restliches Phenol wurde durch eine zweimalige Extraktion mit Chloroform/Isoamylalkohol (24:1) entfernt. Durch die Zugabe von 2,5 Vol. Ethanol (10 min Inkubation bei RT) und anschließender Zentrifugation (10 min, $\mathrm{rpm}_{\max }$ ) wurde die DNA gefällt. Das Pellet wurde zweimal mit $70 \%$ igem Ethanol gespült, anschließend luftgetrocknet und in $150 \mu 1$ TE-Puffer resuspendiert. 


\subsubsection{Fällung von Nukleinsäuren}

\subsubsection{Ammoniumacetat-Isopropanol-Fällung}

Für die Ammoniumacetat-Isopropanol-Fällung wird zunächst eine AmmoniumacetatKonzentration von 2,5 M eingestellt sowie 0,8 Vol. eiskaltes Isopropanol hinzu gegeben und für 30 min bei RT inkubiert. Der Ansatz wird anschließend für 5 min bei $5500 \mathrm{x} g$ und $4{ }^{\circ} \mathrm{C}$ zentrifugiert und der Überstand dekantiert. Das Pellet wird zweimal mit 70\%igem Ethanol gewaschen, getrocknet und im gewünschten Volumen TE-Puffer aufgenommen.

\subsubsection{Ammoniumacetat-Ethanol-Fällung}

Zur Fällung und Konzentrierung genomischer DNA wurde eine AmmoniumacetatEthanol-Fällung durchgeführt. Die DNA wurde mit 1 Vol. einer $5 \mathrm{M} \mathrm{NH}_{4} \mathrm{Ac}$-Lösung gemischt und anschließend mit 2,5 Vol. 96\%igem Ethanol versetzt. Der Ansatz wurde gemischt, für 10 min bei RT inkubiert und anschließend zentrifugiert (30 min, $4^{\circ} \mathrm{C}$, 5500 rpm). Das Pellet wurde mit 70\%igem Ethanol gespült, getrocknet und schließlich im gewünschten Volumen TE-Puffer aufgenommen.

\subsubsection{Enzymatische Modifikation der DNA}

\subsubsection{Spaltung der DNA durch Restriktionsendonukleasen}

Für die Hybridisierung und Klonierung wurde die DNA mit Restriktionsendonukleasen gespalten. Die Restriktionsansätze wurden mit den von den Herstellern mitgelieferten Puffern und Pufferzusätzen durchgeführt. Die jeweiligen Bedingungen sind in den entsprechenden Kapiteln angegeben.

\subsubsection{Dephosphorylierung linearisierter Plasmide}

Für die Klonierung wurde der Plasmid-Vektor pBluescript $\mathrm{SK}^{-}$mit der Restriktionsendonuklease SmaI linearisiert. Dazu wurden $5 \mu$ g Plasmid-DNA mit $40 \mathrm{U}$ $S m a \mathrm{I}$ in einem Endvolumen von $20 \mu \mathrm{l}$ verdaut. Die Inkubation erfolgte für $2 \mathrm{~h}$ bei $30^{\circ} \mathrm{C}$. Zur Inaktivierung der Restriktionsendonuklease SmaI wurde der Ansatz für 10 min bei $65^{\circ} \mathrm{C}$ inkubiert. 
Mit Hilfe der alkalischen Phosphatase aus Rinderdarm („,calf intestine alkaline phosphatase“, CIAP) wurden die Phosphatgruppen vom 5'-Ende abgetrennt, um eine Rezirkularisierung des linearisierten Plasmid-Vektors während der Ligationsreaktion zu verhindern.

Die Dephosphorylierung wurde direkt im Restriktionsansatz durchgeführt. Fünf $\mu \mathrm{g}$ linearisierter Plasmid-Vektor (Größe 3000 bp, entspricht insgesamt 6,6 pmol zu dephosphorylierender Enden) wurden mit 1 U CIAP dephosphoryliert. Der Ansatz wurde für $30 \mathrm{~min}$ bei $37^{\circ} \mathrm{C}$ inkubiert.

\subsubsection{Phosphorylierung von Fragmenten zur Klonierung}

Für die Ligation der aus dem Gel extrahierten DNA-Fragmente der PCR-fingerprintings in den Vektor pBluescript $\mathrm{SK}^{-}$wurden mit Hilfe der T4-Polynukleotid-Kinase endständige Phosphatgruppen des ATP auf das 5`-Hydroxylende der zu ligierenden DNA-Fragmente übertragen.

In der hier vorliegenden Arbeit wurde $1 \mu \mathrm{g}$ DNA mit $10 \mathrm{U}$ T4-Polynukleotid-Kinase und $2 \mathrm{mM}$ ATP in einem Endvolumen von $20 \mu \mathrm{l}$ phosphoryliert. Die Inkubation wurde für $3 \mathrm{~h}$ bei $37^{\circ} \mathrm{C}$ durchgeführt.

Durch anschließende Inkubation von 10 min bei $70^{\circ} \mathrm{C}$ wurde das Enzym inaktiviert.

\subsubsection{Generierung von DNA-Fragmenten mit glatten Enden}

Die Restriktionsspaltung des Plasmid-Vektors mit der Restriktionsendonuklease SmaI produziert so genannte „blunt ends“, d. h., es sind keine endständigen Basenüberhänge vorhanden. Die aus den PCR-fingerprintings hervorgehenden DNA-Fragmente haben jedoch aufgrund der Verwendung von Taq-Polymerase so genannte ,sticky ends“, d. h., am 3'-Ende der amplifizierten DNA-Fragmente ist ein überstehendes Adenosinmolekül vorhanden. Für die Ligation der DNA-Fragmente mit dem mit SmaI linearisierten Plasmid-Vektor pBluescript $\mathrm{SK}^{-}$muss der Basenüberhang entfernt werden. Hierfür wurde die „blunt end“-produzierende $P f u$-Polymerase eingesetzt.

In einem Endvolumen von $25 \mu 1$ wurden $20 \mu 1$ der vorher phosphorylierten Probe mit $1 \mathrm{U} P f u$-Polymerase für $30 \mathrm{~min}$ bei $72^{\circ} \mathrm{C}$ inkubiert. 
Für die anschließende Ligationsreaktion wurde der Probenansatz einer Phenol/Chloroform-Extraktion mit anschließender Ammoniumacetat-Ethanol-Fällung unterzogen.

\subsubsection{Ligationsreaktion}

Für die Ligation der DNA-Fragmente in den Plasmid-Vektor wurde die T4 DNA-Ligase verwendet. Dieses Enzym katalysiert die Bildung einer Phosphodiesterbindung zwischen einer 5 '-Phosphatgruppe und einer 3'-Hydroxygruppe unter Verwendung von ATP. Durch die Fähigkeit der Reparatur von Doppelstrangbrüchen eignet sich die T4 DNA-Ligase sehr gut für „,blunt end“-Ligationen.

Die Ligation erfolgte mit äquimolaren Mengen an Plasmid-Vektor und DNA-Fragment, wobei $10 \mathrm{ng}$ des Plasmid-Vektors pBluescript $\mathrm{SK}^{-}$eingesetzt wurden. Die Ligation erfolgte über Nacht bei RT in Gegenwart von 0,5 mM ATP, $10 \mathrm{mM} \mathrm{MgCl} 2,7,5 \%$ (w/v) $\mathrm{PEG}_{6000}$ und $5 \mathrm{U}$ T4 DNA-Ligase in einem Endvolumen von $50 \mu 1$.

\subsubsection{Markierung von DNA-Sonden durch PCR}

Die im Rahmen dieser Arbeit zu markierende DNA lag in den Vektoren pBluescript SK ${ }^{-}$ vor. Vor der Markierung der DNA-Sonde mit Digoxigenin-markiertem Desoxyuraciltriphosphat (dUTP) wurde der Vektor mit der Restriktionsendonuklease PvuII gespalten, um die Spezifität der Amplifikation zu erhöhen. Durch die Spaltung des Vektors mit diesem Enzym wurden die „multiple cloning site“ mit dem klonierten Insert sowie flankierende Regionen des Vektors ausgeschnitten. Die Restriktionsspaltung fand unter folgenden Bedingungen statt: 0,5 $\mu \mathrm{l}$ DNA, $5 \mathrm{U} P v u \mathrm{II}$, in einem Endvolumen von $20 \mu \mathrm{l}, 37^{\circ} \mathrm{C}, 1 \mathrm{~h}$.

Die Markierung der DNA-Sonde basiert auf dem Prinzip der PCR. Ausgehend von Primern, die die „multiple cloning site“ flankieren, wird bei der Strangsynthese anstelle des dTTPs zu 30\% DIG-markiertes dUTP eingebaut.

Die Markierungs-PCR fand unter folgenden Bedingungen statt: 2-10 ng DNA-Matrize, 0,2 mM dNTPs wobei dTTP zu 30\% durch DIG-dUTP substituiert wurde, 1 pmol Primer (M13-20, M13 reverse), $2 \mathrm{mM} \mathrm{MgCl}$, 1x Puffer (vom Hersteller mitgeliefert), 3 U Taq-Polymerase in einem Endvolumen von $25 \mu 1$ (Thermocycler PCR Sprint, Firma 
Hybaid). Als Kontrolle wurden parallel Ansätze mit nicht markierten dNTPs amplifiziert.

Das PCR-Programm für die Markierung der DNA-Sonde wies folgende Kontur auf:
$94^{\circ} \mathrm{C}, 2 \mathrm{~min}$
$55^{\circ} \mathrm{C}, 1 \mathrm{~min}$;
$72^{\circ} \mathrm{C}, 3 \mathrm{~min}$ (1 Zyklus)
$94^{\circ} \mathrm{C}, 1 \mathrm{~min}$;
$55^{\circ} \mathrm{C}, 1 \mathrm{~min}$;
$72^{\circ} \mathrm{C}, 3 \mathrm{~min}$ (4 Zyklen)
$92^{\circ} \mathrm{C}, 1 \mathrm{~min}$;
$55^{\circ} \mathrm{C}, 1 \mathrm{~min}$;
$72^{\circ} \mathrm{C}, 3 \mathrm{~min} \quad(25 \mathrm{Zyklen})$

Für die Kontrolle der Effizienz der Markierung der Sonden-DNA mit DIG-dUTP sowie der Amplifikation wurde eine gelelektrophoretische Analyse durchgeführt.

Für die gelelektrophoretische Analyse wurden $3 \mu 1$ des Markierungsansatzes auf ein 1,5\%iges Agarosegel aufgetragen. Parallel wurde nicht markierte Sonden-DNA als Kontrolle aufgetragen. Durch die Inkorporation des DIG-dUTP war der erwartete Banden-shift der markierten Sonde im Vergleich zur nicht markierten Sonde deutlich zu erkennen.

\subsubsection{Transformation chemokompetenter $E$. coli-Stämme}

Für die Vermehrung in vitro erzeugter rekombinanter Plasmide wurden diese in chemokompetente E. coli (HANAHAN, 1983; INOUE et al., 1990) transformiert.

Für die Transformation wurden die bei $-70^{\circ} \mathrm{C}$ gelagerten kompetenten Zellen langsam auf Eis aufgetaut. Die Zellsuspension wurde mit $10 \mu 1$ des Ligationsansatzes versetzt und für 30 min auf Eis inkubiert. Die Transformation wurde durch eine anschließende Hitzebehandlung bei $42^{\circ} \mathrm{C}$ für $40 \mathrm{sec}$ im Wasserbad durchgeführt. Nach der Hitzebehandlung wurde der gesamte Ansatz in $800 \mu 1$ auf $37^{\circ} \mathrm{C}$ vorgewärmtes SOCMedium überführt und für $1 \mathrm{~h}$ bei $37^{\circ} \mathrm{C}$ inkubiert. Anschließend wurde der Ansatz in $200 \mu 1$ Portionen auf MacConkey-Agar mit Antibiotikazusatz (100 ppm Ampicillin) ausplattiert und über Nacht bei $37^{\circ} \mathrm{C}$ inkubiert.

\subsubsection{Nachweis der Integration klonierter DNA-Fragmente}

\subsubsection{Selektion rekombinanter Plasmide}

Die Selektion rekombinanter Plasmide erfolgte auf der Grundlage der $\alpha$ Komplementation des verwendeten E. coli-Stammes. Durch einen Defekt im lacZ-Gen, 
welches die $\alpha$-Untereinheit der $\beta$-Galactosidase codiert, ist das Bakterium nicht in der Lage, Laktose abzubauen. Durch Transformation mit dem Plasmid pBluescript SK welches eine intakte Kopie des lacZ-Gens trägt, kann das Bakterium komplementiert werden. Innerhalb des lacZ-Gens ist die „multiple-cloning site“ lokalisiert, so dass bei erfolgreicher Rekombination dieses Gen inaktiviert wird.

Die Selektion rekombinanter Plasmide wurde durch Ausplattieren von je $200 \mu \mathrm{l}$ der Transformationsansätze auf den laktosehaltigen und mit Antibiotika versetzten MacConkey-Agar durchgeführt. Die Agarplatten wurden anschließend über Nacht bei $37^{\circ} \mathrm{C}$ inkubiert. Laktose verwertende Bakterien senken den $\mathrm{pH}-$ Wert, was $\mathrm{zu}$ einem Farbumschlag führt. Diese Kolonien, die lediglich den rezirkularisierten Vektor und damit ein intaktes lacZ-Gen enthalten, verfärben sich pink/rot. Bakterienkolonien, die Laktose nicht verwerten können, da sie das rekombinante Plasmid tragen, verursachen keinen Farbumschlag des Mediums und die Kolonien bleiben weiß. Die weißen Kolonien wurden auf LB-Medium überimpft und für weitere Analysen eingesetzt.

\subsubsection{2 „,colony-PCR“}

Mit Hilfe der „colony-PCR“ wurde überprüft, welche E. coli-Klone das Plasmid mit dem Insert enthalten. Es wurden hierfür Bakterienklone als DNA-Matrize in einer PCR eingesetzt. Mit einer sterilen Pipettenspitze wurde eine kleine Menge einer Kolonie in jeweils $50 \mu$ steriles $\mathrm{H}_{2} \mathrm{O}_{\text {bidest }}$ überimpft und zur Lyse der Zellen für 5 min bei $95^{\circ} \mathrm{C}$ inkubiert. Zu große Mengen an DNA-Matrize können zu einer Inhibierung der PCRReaktion führen.

Als Primer wurde ein Gemisch der Oligonukleotide UNI und REV eingesetzt, die an den flankierenden Seiten der „multiple-cloning site“ binden. Nur bei erfolgreicher Insertion des DNA-Fragments konnte somit ein Amplifikat erzielt werden.

Die Amplifikation der klonierten DNA-Fragmente wurde in einem $20 \mu \mathrm{l}$ Ansatz durchgeführt. Das verwendete Pipettierschema ist in Tab. 2.16 angegeben.

Tab. 2.16: Pipettierschema der „,colony-PCR“

\begin{tabular}{|c|c|c|c|c|c|c|}
\hline $\begin{array}{c}\mathbf{1 0 x} \\
\text { Puffer }\end{array}$ & $\begin{array}{c}\mathbf{2 , 5} \mathbf{m M} \\
\mathbf{d N T P s}\end{array}$ & $\begin{array}{c}\mathbf{1 0} \boldsymbol{\mu M} \\
\text { Primer }\end{array}$ & $\begin{array}{c}\mathbf{2 5} \mathbf{~ m M} \\
\mathbf{M g C l}_{\mathbf{2}}\end{array}$ & $\begin{array}{c}\text { Taq-Pol. } \\
\mathbf{1} \mathbf{U} / \boldsymbol{\mu l}\end{array}$ & $\begin{array}{c}\text { DNA- } \\
\text { Matrize }\end{array}$ & H $_{\mathbf{2}} \mathbf{O}_{\text {bidest }}$ \\
\hline $2 \mu \mathrm{l}$ & $2 \mu \mathrm{l}$ & $2 \mu \mathrm{l}$ & $1,6 \mu \mathrm{l}$ & $2 \mu \mathrm{l}$ & $1 \mu \mathrm{l}$ & $9,4 \mu \mathrm{l}$ \\
\hline
\end{tabular}




\subsubsection{Restriktionsspaltung mit PvuII}

Nach der Plasmidpräparation (siehe Kap. 2.12.1.2) wurde eine Kontrollspaltung mit der Restriktionsendonuklease $P v u I I$ durchgeführt. Auf beiden Seiten der „multiple-cloning site“ des Plasmids pBluescript $\mathrm{SK}^{-}$ist eine $P v u \mathrm{II}-\mathrm{Sch}$ ittstelle vorhanden, so dass nach einer elektrophoretischen Auftrennung der Spaltungsansätze bei rekombinanten Plasmiden zwei Banden zu sehen sein müssen.

In der Restriktionsspaltung wurden $0,5 \mu l$ der Plasmidpräparation mit $5 \mathrm{U} P v u \mathrm{II}$ in einem Gesamtvolumen von $20 \mu \mathrm{l}$ verdaut. Die Inkubation erfolgte für $1 \mathrm{~h}$ bei $37^{\circ} \mathrm{C}$.

\subsubsection{DNA-Transfer mittels Vakuum-Blot}

Für die Hybridisierungsanalysen wurde DNA auf einer Trägermembran immobilisiert. In der hier vorliegenden Arbeit wurde eine positiv geladene Nylonmembran (Hybond$\mathrm{N}+$, Amersham Bioscience, UK) verwendet. Der DNA-Transfer erfolgte mit Hilfe der VacuGene XL Apparatur (Pharmacia, Freiburg) durch alkalischen Transfer aus einem Agarosegel.

Für die Hybridisierungsanalysen wurden $5 \mu \mathrm{g}$ DNA der Isolate Vl 40 bzw. Vd 3 mit $30 \mathrm{U}$ der Restriktionsendonuklease HindIII in einem Gesamtvolumen von $100 \mu \mathrm{l}$ verdaut. Die Inkubation erfolgte für $4 \mathrm{~h}$ bei $37^{\circ} \mathrm{C}$. Die verdaute DNA wurde anschließend einer Ammoniumacetat-Isopropanol-Fällung unterzogen und über Nacht in $20 \mu \mathrm{T}$ TE-Puffer resuspendiert. Anschließend wurden $5 \mu \mathrm{g}$ der verdauten DNA auf ein 1\%iges 0,5xTBE-Agarosegel aufgetragen und bei einer Spannung von 2,5 V pro cm Elektrodenabstand für $4 \mathrm{~h}$ elektrophoretisch aufgetrennt.

Die DNA im Gel wurde zunächst für 10 min mit 0,25 N HCl partiell depuriniert, um Strangbrüche zu induzieren. Durch die anschließende 10minütige Inkubation des Gels in $0,5 \mathrm{~N} \mathrm{NaOH}, 1,5 \mathrm{M} \mathrm{NaCl}$ wurde die DNA denaturiert, um eine spätere Hybridisierung mit der ebenfalls denaturierten Sonde zu gewährleisten.

Die Nylonmembran wurde auf eine poröse Transferplatte unter die Transfermaske gelegt und eingespannt. Das Gel wurde auf die Transfermaske gelegt, wobei die Gelränder die Transfermaske rund 0,5 cm überlappten, und mit Denaturierungslösung überstaut. Für 90 min wurde ein Unterdruck von 40 mbar angelegt. Die Nylonmembran wurde anschließend zur Neutralisierung und um anhaftende Agarose abzuwaschen für 5 min mit 2x SSC bei RT gespült und luftgetrocknet. Die Fixierung der DNA auf der Membran erfolgt für $30 \mathrm{~min}$ bei $120^{\circ} \mathrm{C}$. 


\subsubsection{DNA-DNA-Hybridisierung und Stringenzwaschung}

Um unspezifische Bindungen von Sonden-DNA an die Nylonmembran zu reduzieren, wurde die Membran zunächst in der Prähybridisierungslösung (DIG Easy Hyb) inkubiert. Die Membran wurde in eine Hybridisierungsröhre überführt und $10 \mathrm{ml}$ auf $68^{\circ} \mathrm{C}$ vorgewärmte Prähybridisierungslösung hinzugefügt. Die Inkubation erfolgte in einem Hybridisierungsofen (Hybaid Mini Hybridization Oven, MWG Biotech, Ebersdorf) für mindestens $30 \mathrm{~min}$ bei $68^{\circ} \mathrm{C}$. Nach Ablauf der Inkubationszeit wurde die Prähybridisierungslösung abgegossen und durch $5 \mathrm{ml}$ auf Hybridisierungstemperatur $\left(68^{\circ} \mathrm{C}\right)$ vorgewärmte Hybridisierungslösung (DIG Easy Hyb) ersetzt. Die Hybridisierungslösung enthielt die markierte DNA-Sonde in einer Konzentration von 25 ng/ml. Die DNA-Sonde wurde zuvor für $5 \mathrm{~min}$ bei $95^{\circ} \mathrm{C}$ in $50 \mu 1$ Hybridisierungslösung denaturiert, so dass sie an die einzelsträngig vorliegenden homologen Sequenzen auf der Membran binden konnte. Die Hybridisierung wurde über Nacht bei $68^{\circ} \mathrm{C}$ durchgeführt.

Zur Entfernung unspezifisch gebundener DNA-Sonde von der Nylonmembran wurden nach der Hybridisierung Stringenzwaschungen durchgeführt. Zunächst wurde die Membran zweimal für 15 min in $2 x \mathrm{SSC}+0,1 \% \mathrm{SDS}$ bei $75^{\circ} \mathrm{C}$ gewaschen, gefolgt von zwei Waschschritten für $15 \min$ bei $75^{\circ} \mathrm{C}$ in $0,1 \mathrm{SSC}+0,1 \% \mathrm{SDS}$.

\subsubsection{Detektion markierter DNA-Sonden}

Die Detektion der spezifisch gebundenen DNA-Sonden wurde mit Hilfe von Digoxigenin-spezifischen Antikörpern, die mit einer alkalischen Phosphatase gekoppelt sind, durchgeführt. Der Nachweis erfolgte über Chemolumineszenz mit dem Substrat CDP-Star. Durch die an die Antikörper gekoppelte alkalische Phosphatase wird das Substrat umgesetzt, wobei Lichtenergie entsteht. Über die Schwärzung die die abgegebene Lichtenergie auf einem Röntgenfilm hervorruft, wurden die Lichtsignale nachgewiesen.

Zur Detektion der spezifisch gebundenen DNA-Sonden wurde die Membran für 2 min bei RT in $50 \mathrm{ml}$ Waschpuffer geschwenkt. Unspezifische Bindungsstellen wurden durch eine 30minütige Inkubation in $50 \mathrm{ml}$ Blocking-Puffer abgesättigt. Anschließend erfolgte die Antikörperbindung in einer 1:10.000 in Blocking-Puffer verdünnten Antikörperlösung für $30 \mathrm{~min}$ bei RT. Die Membran wurde anschließend zweimal für $15 \mathrm{~min}$ bei RT in Waschpuffer gewaschen. Durch eine 3minütige Inkubation bei RT in 
Äquilibrierungspuffer wurde der pH-Wert auf 9,5 eingestellt. Anschließend wurde die Membran auf eine Polypropylenfolie gelegt und $500 \mu 1$ einer 1:100 in Äquilibrierungspuffer verdünnten CDP-Star-Lösung aufgetropft. Durch das Auflegen einer Deckfolie wurde die CDP-Star-Lösung gleichmäßig verteilt. Nach 5 min Inkubation bei RT wurde überflüssige Flüssigkeit ausgestrichen und die Membran in die Folie eingeschweißt. Nach 10 min bei $37^{\circ} \mathrm{C}$ wurde die eingeschweißte Membran in eine Expositionskassette überführt und ein Röntgenfilm (Fuji Medical X-Ray Film 100 NF, Tokyo, Japan) aufgelegt. Zunächst wurde eine Expositionszeit von 5 min gewählt. Je nach Signalstärke wurde die Expositionszeit verlängert. Die Entwicklung des Röntgenfilms erfolgte für jeweils 2 min Inkubation in Entwickler (Kodak LX24, Paris, Frankreich), Wasser, Fixierer (Kodak AL 4, Paris, Frankreich) und wiederum Wasser.

\subsubsection{Amplifikation der DNA mittels PCR-fingerprinting}

Zur Differenzierung unterschiedlicher Verticillium spp. wurden verschiedene PCRfingerprintings sowie RAPD-Analysen durchgeführt. Bei einem Fingerprinting werden sich mehrfach wiederholende Sequenzabschnitte amplifiziert, die keine sequenzabhängigen Informationen tragen. Innerhalb einer Art können große Unterschiede in diesen Sequenzpolymorphismen auftreten.

Die für die Fingerprinting-Analysen eingesetzten Primer sind in Tabelle 2.17 aufgelistet.

Tab. 2.17: Verwendete Primer für die Fingerprinting-Analysen von Verticillium spp.

\begin{tabular}{|l|l|l|}
\hline Bezeichnung & Sequenz (5'zu 3') & Referenz \\
\hline RAPD OPA-13 & CAG CAC CCA C & KARAPAPA et al. (1997) \\
\hline RAPD A-06 & GCC AGC TGT ACG & KoIKE et al. (1996) \\
\hline ERIC & $\begin{array}{l}\text { 1.R: ATG TAA GCT CCT GGG CAT TAC C } \\
\text { 2.F: AAG TAA GTG ACT GGG GTG AGC G }\end{array}$ & $\begin{array}{l}\text { WEINGART \& VÖLKSCH } \\
(1997)\end{array}$ \\
\hline VNTR & GGT GGC GGC TCT & HEATH et al. (1993) \\
\hline BOX & CTA CGG CAA GGC GAC GCT GAC G & VERSALOVIC et al. (1994) \\
\hline
\end{tabular}

Die Amplifikation der DNA-Fragmente erfolgte in einem $50 \mu 1$ Ansatz. Das verwendete Pipettierschema ist in Tab. 2.18 aufgeführt. Da $V$. longisporum spezifische Banden später sequenziert werden sollten, wurde der normalen Taq-Polymerase eine $P f u$ - 
Polymerase mit einer ,,proofreading“-Aktivität zugemischt, um die Fehlerrate bei der Strangverlängerung und dadurch Sequenzfehler zu verhindern.

Tab. 2.18: Pipettierschema der PCR-fingerprinting -Ansätze

\begin{tabular}{|c|c|c|c|c|c|c|c|}
\hline \multirow{2}{*}{$\begin{array}{c}10 x \\
\text { Puffer }\end{array}$} & \multirow{2}{*}{$\begin{array}{l}2,5 \mathrm{mM} \\
\text { dNTP's }\end{array}$} & \multirow{2}{*}{$\begin{array}{l}10 \mu \mathrm{M} \\
\text { Primer }\end{array}$} & \multirow{2}{*}{$\begin{array}{l}25 \mathrm{mM} \\
\mathrm{MgCl}_{2}\end{array}$} & \multicolumn{2}{|c|}{ Polymerasen } & \multirow{2}{*}{$\begin{array}{c}\text { DNA } \\
10 \mathrm{ng} / \mu \mathrm{l}\end{array}$} & \multirow{2}{*}{$\begin{array}{c}\text { Bidest } \\
\mathrm{H}_{2} \mathrm{O} \text { steril }\end{array}$} \\
\hline & & & & $\begin{array}{c}\text { Taq-Pol. } \\
5 \mathrm{U} / \mu \mathrm{l}\end{array}$ & $\begin{array}{c}P f u \text {-Pol. } \\
2,5 \text { U/ } \mu \mathrm{l}\end{array}$ & & \\
\hline $5 \mu 1$ & $5 \mu 1$ & $5 \mu 1$ & $4 \mu 1$ & $1,25 \mu 1$ & $0,1 \mu 1$ & $1 \mu 1$ & $28,74 \mu 1$ \\
\hline
\end{tabular}

Die für die unterschiedlichen Primer eingesetzten Temperaturen und Zyklen sind in Tabelle 2.19 aufgeführt.

Tab. 2.19: PCR-Konturen für die unterschiedlichen Fingerprinting-Primer

\begin{tabular}{|c|c|c|c|c|}
\hline Primer & Denaturierung & Annealing & Extension & Zyklen \\
\hline RAPD OPA-13 & $94^{\circ} \mathrm{C}, 3 \mathrm{~min}$ & $34^{\circ} \mathrm{C}, 1 \mathrm{~min}$ & $75^{\circ} \mathrm{C}, 2 \mathrm{~min}$ & $1 \mathrm{x}$ \\
& $94^{\circ} \mathrm{C} 1 \mathrm{~min}$ & $34^{\circ} \mathrm{C}, 1 \mathrm{~min}$ & $75^{\circ} \mathrm{C}, 2 \mathrm{~min}$ & $44 \mathrm{x}$ \\
& $94^{\circ} \mathrm{C}, 1 \mathrm{~min}$ & $34^{\circ} \mathrm{C}, 1 \mathrm{~min}$ & $75^{\circ} \mathrm{C}, 7 \mathrm{~min}$ & $1 \mathrm{x}$ \\
\hline RAPD A-06 & $94^{\circ} \mathrm{C}, 3 \mathrm{~min}$ & $40^{\circ} \mathrm{C}, 1 \mathrm{~min}$ & $75^{\circ} \mathrm{C}, 2 \mathrm{~min}$ & $1 \mathrm{x}$ \\
& $94^{\circ} \mathrm{C} 1 \mathrm{~min}$ & $40^{\circ} \mathrm{C}, 1 \mathrm{~min}$ & $75^{\circ} \mathrm{C}, 2 \mathrm{~min}$ & $44 \mathrm{x}$ \\
& $94^{\circ} \mathrm{C}, 1 \mathrm{~min}$ & $40^{\circ} \mathrm{C}, 1 \mathrm{~min}$ & $75^{\circ} \mathrm{C}, 7 \mathrm{~min}$ & $1 \mathrm{x}$ \\
\hline ERIC & $94^{\circ} \mathrm{C}, 3 \mathrm{~min}$ & $52^{\circ} \mathrm{C}, 1 \mathrm{~min}$ & $75^{\circ} \mathrm{C}, 3 \mathrm{~min}$ & $1 \mathrm{x}$ \\
& $94^{\circ} \mathrm{C}, 1 \mathrm{~min}$ & $52^{\circ} \mathrm{C}, 1 \mathrm{~min}$ & $75^{\circ} \mathrm{C}, 3 \mathrm{~min}$ & $35 \mathrm{x}$ \\
\hline VNTR & $94^{\circ} \mathrm{C}, 3 \mathrm{~min}$ & $57^{\circ} \mathrm{C}, 1 \mathrm{~min}$ & $75^{\circ} \mathrm{C}, 3 \mathrm{~min}$ & $1 \mathrm{x}$ \\
& $94^{\circ} \mathrm{C}, 1 \mathrm{~min}$ & $57^{\circ} \mathrm{C}, 1 \mathrm{~min}$ & $75^{\circ} \mathrm{C}, 3 \mathrm{~min}$ & $29 \mathrm{x}$ \\
\hline BOX & $94^{\circ} \mathrm{C}, 3 \mathrm{~min}$ & $52^{\circ} \mathrm{C}, 1 \mathrm{~min}$ & $75^{\circ} \mathrm{C}, 3 \mathrm{~min}$ & $1 \mathrm{x}$ \\
& $94^{\circ} \mathrm{C}, 1 \mathrm{~min}$ & $52^{\circ} \mathrm{C}, 1 \mathrm{~min}$ & $75^{\circ} \mathrm{C}, 3 \mathrm{~min}$ & $29 \mathrm{x}$ \\
\hline
\end{tabular}

\subsubsection{DNA-Sequenzierung}

Für die Sequenzierung der aus dem Gel extrahierten und klonierten Fragmente wurden die in dem Vektor pBluescript $\mathrm{SK}^{-}$vorliegenden DNA-Proben wie in Kapitel 2.12.1.2 beschrieben aus E. coli isoliert. Zur Entfernung von Verunreinigungen aus der DNAProbe, v. a. mit der DNA assoziierte Proteine, die die Qualität der Sequenzierung beeinflussen, wurden die DNA-Proben einer Ethidiumbromid-Phenolextraktion unterzogen (siehe Kap. 2.12.3.2). Von jeder DNA-Probe wurde $1 \mu \mathrm{g}$ DNA in einer 
SpeedVac-Zentrifuge eingetrocknet. Die Sequenzierung wurde von der Firma MWG Biotech (Ebersberg, Deutschland) durchgeführt. Als Primer wurden M13 uni (-21) bzw. M13 rev (-29) eingesetzt.

Sequenz der eingesetzten Primer:

M13 uni (-21): 5'-TGT AAA ACG ACG GCC AGT-3'

M13 rev (-29): 5'-GGA AAC AGC TAT GAC CAT G-3'

\subsubsection{In vitro-Nachweis von $V$. longisporum mittels PCR}

Von den aus den Hybridisierungsanalysen als spezifisch für $V$. longisporum hervorgegangenen DNA-Sonden, wurden PCR-Primer abgeleitet. In nachfolgenden Untersuchungen wurden die Spezifität sowie die optimalen Bedingungen für den in vitro-Nachweis von $V$. longisporum überprüft.

\subsubsection{Primer Design}

Basierend auf den Sequenzen der V. longisporum spezifischen DNA-Fragmente wurden die Primer abgeleitet. Das Primer-Design wurde mit Hilfe des Programms OligoPerfect $^{\mathrm{TM}}$ Designer, welches die Firma invitrogen auf ihrer Internetseite zur Verfügung stellt, durchgeführt. Als Parameter für das Primer Design wurden folgende Bedingungen festgelegt: Primer Größe: 19-22 bp, GC-Gehalt: 45-80\%, Produktgröße: 100-300 bp, Annealing-Temperatur: 57-63 ${ }^{\circ} \mathrm{C}$. Die Synthese der Primer wurde von der Firma invitrogen (Karlsruhe) durchgeführt.

Die Sequenzen der in der Optimierung eingesetzten Primer sind im Folgenden angegeben:

pV1O2/3-6 F: 5' GAT ACC GAC CAG GCC TTA CA 3'

pV1O2/3-6 R: 5' GAG CAA CTC AAG CAT CAC CA 3'

pVlE5-23 F: 5' ACT TTT CGG GGA AAT GTG C 3'

pVlE5-23 R: 5' TAA GTT GGC AGC ATC ACC TG 3' 


\subsubsection{Amplifikationsbedingungen}

Die Amplifikation des spezifischen DNA-Fragments wurde in einem Endvolumen von $25 \mu 1$ durchgeführt. Die Rahmenbedingungen für die Amplifikation waren 0,2 mM dNTPs, 1 pmol Primer, 1 U Taq-Polymerase und $1,5 \mathrm{mM} \mathrm{MgCl}_{2}$. Da sich diese Bedingungen als geeignet für die spezifische Amplifikation erwiesen haben, wurde auf weitere Optimierungen verzichtet.

Die Kontur des PCR-Laufes entsprach folgendem Schema:

$\begin{array}{llll}94^{\circ} \mathrm{C}, 3 \mathrm{~min} & 66,5^{\circ} \mathrm{C}, 1 \mathrm{~min} & 72^{\circ} \mathrm{C}, 1 \mathrm{~min} & \text { (1 Zyklus) } \\ 94^{\circ} \mathrm{C}, 1 \mathrm{~min} & 66,5^{\circ} \mathrm{C}, 1 \mathrm{~min} & 72^{\circ} \mathrm{C}, 1 \mathrm{~min} & \text { (29 Zyklen) } \\ & & 72^{\circ} \mathrm{C}, 5 \mathrm{~min} & \text { (1 Zyklus) }\end{array}$

\subsubsection{Geldokumentation}

\subsubsection{Dokumentation der Agarosegele}

Die Gele wurden zunächst in einem Ethidiumbromid-Wasserbad $(2 \mu \mathrm{g} / \mathrm{ml})$ für ca. 10 min bei RT angefärbt. Um überschüssiges Ethidiumbromid von den Gelen abzuwaschen und eine bessere Kontrastierung zu erreichen, wurden diese anschließend für fünf bis zehn Minuten in einem Wasserbad bei RT entfärbt. Unter UV-Licht erfolgte die Dokumentation über eine Videokamera mit Filter und der Geldokumentationssoftware Multi-Analyst (Gel Doc System Biorad, München).

\subsubsection{Dokumentation der Polyacrylamidgele}

Die Polyacrylamidgele wurden entsprechend den Agarosegelen für nur eine Minute im Ethidiumbromid-Wasserbad $(2 \mu \mathrm{g} / \mathrm{ml})$ angefärbt und anschließend für eine Minute im Wasserbad gespült. Die Dokumentation der Polyacrylamidgele erfolgte ebenfalls unter UV-Licht über eine Videokamera mit Filter und der Geldokumentationssoftware MultiAnalyst (Gel Doc System Biorad, München). 


\section{Ergebnisse}

\subsection{Einfluss unterschiedlicher Methoden der Inokulumproduktion auf die}

\section{Sclerotinia- Befallshäufigkeit im Gewächshaus}

Zur Optimierung der Inokulationsmethode für S. sclerotiorum wurden nach dem ersten Feldversuchsjahr Gewächshausversuche durchgeführt. In diesen Versuchen wurde die Anzuchtmethode für das Inokulummaterial durch verschiedene Anzuchtmedien und unterschiedlich lange Inkubationszeiten der Zahnstocher variiert (siehe Kap. 2.6.1.3). Vier Wochen nach der Inokulation wurden die Befallsparameter Boniturnote, Läsionslänge und Befallshäufigkeit erfasst.

Die Ergebnisse der Gewächshausversuche sind in Tab. 3.1 aufgeführt. Nur in wenigen Fällen sind die Unterschiede zwischen den Varianten statistisch abzusichern $(p \leq 0,05)$.

Tab. 3.1: Einfluss der Inokulumerzeugung von S. sclerotiorum auf Boniturnote, Läsionslänge und Befallshäufigkeit an Raps (Sorte Talent). Mittelwerte von je 30 Pflanzen. Unterschiedliche Buchstaben kennzeichnen signifikante Unterschiede, TukeyTest, $\mathrm{p} \leq 0,05$.

\begin{tabular}{|c|c|c|c|}
\hline Variante & $\begin{array}{c}\text { Boniturnote } \\
\pm \text { SD }\end{array}$ & $\begin{array}{c}\text { Läsionslänge } \\
\pm \text { SD [cm] }\end{array}$ & $\begin{array}{c}\text { Befallshäufigkeit } \\
{[\%]}\end{array}$ \\
\hline 1 & $3,63 \pm 2,5 \mathrm{ab}$ & $4,68 \pm 2,6 \mathrm{ab}$ & $90 \mathrm{~b}$ \\
\hline 2 & $4,57 \pm 3,1 \mathrm{ab}$ & $5,27 \pm 3,5 \mathrm{~b}$ & $87 \mathrm{~b}$ \\
\hline 3 & $3,63 \pm 3,2 \mathrm{ab}$ & $3,85 \pm 3,8 \mathrm{ab}$ & $67 \mathrm{ab}$ \\
\hline 4 & $4,77 \pm 3,3 \mathrm{ab}$ & $4,98 \pm 3,9 \mathrm{ab}$ & $80 \mathrm{ab}$ \\
\hline 5 & $3,03 \pm 2,7 \mathrm{ab}$ & $3,65 \pm 3,3 \mathrm{ab}$ & $73 \mathrm{ab}$ \\
\hline 6 & $4,37 \pm 3,1 \mathrm{ab}$ & $4,55 \pm 3,7 \mathrm{ab}$ & $80 \mathrm{ab}$ \\
\hline 7 & $4,60 \pm 3,3 \mathrm{ab}$ & $4,82 \pm 3,9 \mathrm{ab}$ & $73 \mathrm{ab}$ \\
\hline 8 & $3,17 \pm 2,9 \mathrm{ab}$ & $3,68 \pm 3,6 \mathrm{ab}$ & $63 \mathrm{~b}$ \\
\hline 9 & $2,73 \pm 2,2 \mathrm{ab}$ & $3,66 \pm 2,6 \mathrm{ab}$ & $87 \mathrm{~b}$ \\
\hline 10 & $4,03 \pm 3,0 \mathrm{ab}$ & $3,97 \pm 3,1 \mathrm{ab}$ & $83 \mathrm{~b}$ \\
\hline 11 & $4,97 \pm 3,0 \mathrm{~b}$ & $5,28 \pm 3,4 \mathrm{~b}$ & $87 \mathrm{~b}$ \\
\hline 12 & $4,17 \pm 3,3 \mathrm{ab}$ & $4,97 \pm 3,8 \mathrm{ab}$ & $80 \mathrm{ab}$ \\
\hline 13 & $4,73 \pm 3,4 \mathrm{ab}$ & $5,65 \pm 3,8 \mathrm{~b}$ & $87 \mathrm{~b}$ \\
\hline 14 & $4,67 \pm 3,6 \mathrm{ab}$ & $5,38 \pm 4,0 \mathrm{~b}$ & $77 \mathrm{ab}$ \\
\hline 15 & $2,17 \pm 2,3 \mathrm{a}$ & $1,91 \pm 2,7 \mathrm{a}$ & $50 \mathrm{a}$ \\
\hline
\end{tabular}

${ }^{\text {a }}$ Boniturnote 1-9: $1=$ kein Befall, $9=$ sehr starker Befall (siehe Kap. 2.6.1.4) 
In der Variante 15 (1 x PDB + Nährmediumrest + 0,1\% Blütenblätter, keine Sklerotienproduktion, ohne Lagerung) wurden die geringsten Befallsparameter bonitiert, in den Varianten 11 und 13 (1 x PDB + 0,1\% Blütenblätter, Sklerotienbildung, 1 Woche Lagerung bzw. 1 x PDB + Nährmediumrest, keine Sklerotienbildung, frisches Inokulum) wurden die höchsten Werte erfasst.

Die Boniturnote unterscheidet sich lediglich in zwei Varianten signifikant voneinander. Variante 11 hat mit 4,97 die höchste Boniturnote, Variante 15 mit 2,17 die geringste Note. Alle weiteren Boniturnoten schwanken zwischen 2,73 $(=>50 \%$ und $<100 \%$ stängelumgreifende Läsionen) und 4,77 (stängelumgreifendes Symptom, Ausbreitung in Längsrichtung). In den Varianten 1-4 (autoklaviert in 1 x PDB) ist die Boniturnote sowohl im frischen als auch im einer Woche bei $4^{\circ} \mathrm{C}$ gelagertem Material höher in den Varianten ohne Sklerotienbildung. In den Varianten 5 bis 8 (autoklaviert in 2 x PDB) und 9 bis 12 (autoklaviert in 1 x PDB $+0,1 \%$ Blütenblätter) ist im frischen Material ohne Sklerotienbildung und im einer Woche bei $4{ }^{\circ} \mathrm{C}$ gelagerten Material in der Variante mit Sklerotienbildung die Boniturnote höher.

Da die Boniturnote auf der Symptomausbreitung an der Pflanze basiert, spiegelt die Läsionslänge die Ergebnisse der Boniturnoten exakt wider.

Auch in der Anzahl befallener Pflanzen pro Variante (= Befallshäufigkeit) sind nur wenige signifikante Unterschiede zwischen den verschiedenen Varianten zu finden. Wie auch bei der Auswertung der Boniturnoten und Läsionslängen weist Variante 15 mit nur $50 \%$ erzielter Befallshäufigkeit den geringsten Wert auf und unterscheidet sich signifikant von den Varianten 1, 2, 9, 11 und 13. Für alle drei unterschiedlichen Anzuchtmedien (1 x PDB, 2 x PDB und 1 x PDB $+0,1 \%$ Blütenblätter) wurden im Mittel höhere Befallshäufigkeiten durch den Einsatz frischen Inokulummaterials erzielt als durch die Verwendung von bereits einer Woche bei $4^{\circ} \mathrm{C}$ gelagerten Materials. Höhere Befallshäufigkeiten in Varianten mit Sklerotienproduktion ließen sich statistisch nicht absichern. Der Vergleich der verschiedenen Anzuchtmedien zeigt in den in $2 \mathrm{x}$ PDB autoklavierten Varianten 5 bis 8 geringere Befallshäufigkeiten als in den Varianten 1 bis 4 ( 1 x PDB) und 9 bis 12 ( 1 x PDB + 0,1\% Blütenblätter). Durch die Zugabe von $0,1 \%$ Blütenblätter zu 1 x PDB wurden in den bei $4{ }^{\circ} \mathrm{C}$ gelagerten Varianten höhere Befallshäufigkeiten erreicht, in den Varianten, in denen frisches Inokulummaterial verwendet wurde, sind die Befallshäufigkeiten ohne die Zugabe von Blütenblättern zum Anzuchtmedium etwas höher. 
Für die weitere Produktion von Sclerotinia-Inokulum wurde die Anzucht in 1 x PDB und Verwendung von frischem Inokulummaterial ohne Sklerotienproduktion (Variante 2) angewendet. Die Entscheidung für diese Variante basiert auf den in diesem Anzuchtmedium mit frischem Inokulum erzielten höchsten Befallshäufigkeiten und die höhere erzielte Boniturnote und Läsionslänge mit Inokulummaterial ohne Sklerotienproduktion. Die Anzucht in 1 x PDB mit Zugabe von Blütenblättern wurde aufgrund zu geringer Praktikabilität nicht durchgeführt.

\subsection{Auftreten von Krankheiten und Schädlingen im Feld}

\subsubsection{Einfluss von Jahr, Sorte, Inokulationstermin und Bestandesdichte auf die Sclerotinia-Befallshäufigkeit}

In den Feldversuchen zur Untersuchung des Einflusses von Inokulationszeitpunkt und agronomischer Parameter auf die Schadwirkung von $S$. sclerotiorum wurde zu insgesamt drei unterschiedlichen Entwicklungsterminen der Pflanzen (BBCH 61-65, $\mathrm{BBCH}$ 67-69 und $\mathrm{BBCH}$ 71) künstlich inokuliert. Die erzielten Befallshäufigkeiten wurden im Entwicklungsstadium 81-83 visuell erfasst.

Während in den beiden ersten Versuchsjahren 2001/02 und 2002/03 kein natürlicher Sclerotinia-Befall auf den Versuchsfeldern zu beobachten war, trat im Versuchsjahr 2003/04 natürlicher Sclerotinia-Befall auf. Die auf natürlichen Infektionen basierenden Befallshäufigkeiten im Mittel über alle Kontrollparzellen sowie den nicht inokulierten Parzellen des Versuches zum Kompensationspotential betrugen in der Hybridsorte Maja 6,9\% und in der Liniensorte Prince 5,7\%. Der Unterschied zwischen den beiden Sorten ist statistisch nicht abzusichern ( $\mathrm{p} \leq 0,05, \mathrm{t}$-Test). Auch zwischen den Aussaatterminen und den Bestandesdichten ließen sich keine signifikanten Unterschiede im Auftreten der natürlichen Infektionen nachweisen. Im Versuch zum Kompensationspotential war im Mittel über beide Sorten eine Befallshäufigkeit von 6,5\% zu verzeichnen. Zwischen den Sorten und dem Prozentsatz reduzierter Pflanzen pro Parzelle konnten keine signifikanten Unterschiede gefunden werden (Tukey-Test, $\mathrm{p} \leq 0,05$ ).

Die nach künstlicher Inokulation zu verschiedenen Terminen erzielten S. sclerotiorumBefallshäufigkeiten in den einzelnen Jahren und Sorten sind in Tab. 3.2 dargestellt. Datengrundlage für diese Auswertung bilden die Parzellen mit einer ZielBefallshäufigkeit von 10-50\% aus den Versuchsjahren 2001/02 bis 2003/04. Im ersten 
Versuchsjahr war die erzielte Befallshäufigkeit aller Inokulationstermine und beider Sortentypen nur sehr gering und zeigte keine statistisch abzusichernden Unterschiede zwischen den Varianten. Im zweiten und dritten Versuchsjahr waren die erzielten Befallshäufigkeiten deutlich höher, wobei sich diese Unterschiede zwischen den einzelnen Versuchsjahren nur bei der Liniensorte statistisch absichern ließen.

Vergleicht man die Sortentypen innerhalb der Jahre miteinander, wurden in den Jahren 2001/02 und 2002/03 höhere Befallshäufigkeiten in der Liniensorte Prince erzielt, als in der Hybridsorte Talent. Durch den Wechsel der Hybridsorte von Talent zu Maja im Jahr 2003/04 hat sich dieses Verhältnis umgekehrt.

Tab. 3.2: Erzielte Befallshäufigkeiten in einer Hybrid- und einer Liniensorte nach künstlicher Inokulation mit $S$. sclerotiorum (10-50\%) zu unterschiedlichen Entwicklungsstadien in den Jahren 2001/02 bis 2003/04 an den Standorten „Dragoneranger", „Große Lage“ und „Große Breite“ in Göttingen-Weende. Unterschiedliche Buchstaben kennzeichnen signifikante Unterschiede, $p \leq 0,05$ (TukeyTest).

\begin{tabular}{|c|c|c|c|c|}
\hline $\begin{array}{c}\text { Inokulations- } \\
\text { termin } \\
{[\text { [BBCH] }}\end{array}$ & Sortentyp* & \multicolumn{4}{|c|}{ Erzielte Befallshäufigkeit [\%] $\mathbf{2}$ SD } \\
\hline \multirow{2}{*}{$61-65$} & $\mathrm{H}$ & $2,6 \pm 1,3 \mathrm{a}$ & $7,7 \pm 5,0 \mathrm{abcd}$ & $18,1 \pm 7,1 \mathrm{ef}$ \\
\cline { 2 - 5 } & $\mathrm{L}$ & $4,8 \pm 2,9 \mathrm{abc}$ & $16,9 \pm 13,8 \mathrm{def}$ & $13,1 \pm 7,4 \mathrm{cde}$ \\
\hline \multirow{2}{*}{$67-69$} & $\mathrm{H}$ & $6,2 \pm 3,5 \mathrm{abc}$ & $9,2 \pm 7,5 \mathrm{abcd}$ & $17,5 \pm 9,2 \mathrm{e}$ \\
\cline { 2 - 5 } & $\mathrm{L}$ & $9,2 \pm 7,9 \mathrm{abcd}$ & $20,0 \pm 11,5 \mathrm{ef}$ & $22,7 \pm 11,4 \mathrm{f}$ \\
\hline \multirow{2}{*}{71} & $\mathrm{H}$ & $3,1 \pm 2,4 \mathrm{ab}$ & $12,6 \pm 7,0 \mathrm{bcde}$ & $25,4 \pm 14,0 \mathrm{f}$ \\
\cline { 2 - 5 } & $\mathrm{L}$ & $3,4 \pm 2,3 \mathrm{abc}$ & $21,8 \pm 13,1 \mathrm{ef}$ & $21,6 \pm 13,4 \mathrm{ef}$ \\
\hline
\end{tabular}

* : H = Hybridsorte (Talent in 2001/02 und 2002/03, Maja in 2003/04), L = Liniensorte (Prince in 2001/02-2003/04)

Für beide Sortentypen ist in den beiden letzten Versuchsjahren 2002/03 und 2003/04 eine tendenziell höhere Befallshäufigkeit mit fortschreitender Pflanzenentwicklung zu verzeichnen. Signifikante Unterschiede bei einer Irrtumswahrscheinlichkeit von $\mathrm{p} \leq$ 0,05 sind bei der Hybridsorte lediglich im Jahr 2003/04 zwischen dem zweiten und dritten Inokulationstermin und bei der Liniensorte im Jahr 2003/04 zwischen dem ersten und zweiten Inokulationstermin vorhanden. Im Jahr 2001/02 steigt die erzielte 
Befallshöhe vom ersten zum zweiten Inokulationstermin, zum dritten Inokulationstermin sinkt sie dann wieder auf dasselbe Level wie zum ersten Termin ab.

Im Versuchsjahr 2004/05 wurden in vier Hybrid- und drei Liniensorten 10-70\% der Pflanzen pro Parzelle zu BBCH 65-67 künstlich infiziert. Die Sorte Prince wurde 10 Tage nach der Aussaat per Hand nachgesät und zeigte eine deutlich verlangsamte Entwicklung auf. Die künstliche Inokulation führte zu keinen Infektionen, so dass diese Sorte im Folgenden nicht berücksichtig wird.

Lediglich die Sorten Viking und Elektra wiesen einen signifikanten $(\mathrm{p} \leq 0,05)$ Unterschied in der mittleren Befallshäufigkeit auf (Abb. 3.1). Zwischen Hybrid- und Liniensorten sind keine signifikanten Unterschiede zu beobachten. Ein signifikanter Zusammenhang zwischen den in der Bundessortenliste vergebenen Boniturnoten für die Sclerotinia-Anfälligkeit und der im Feld beobachteten Befallshäufigkeit nach künstlicher Inokulation war nicht vorhanden.

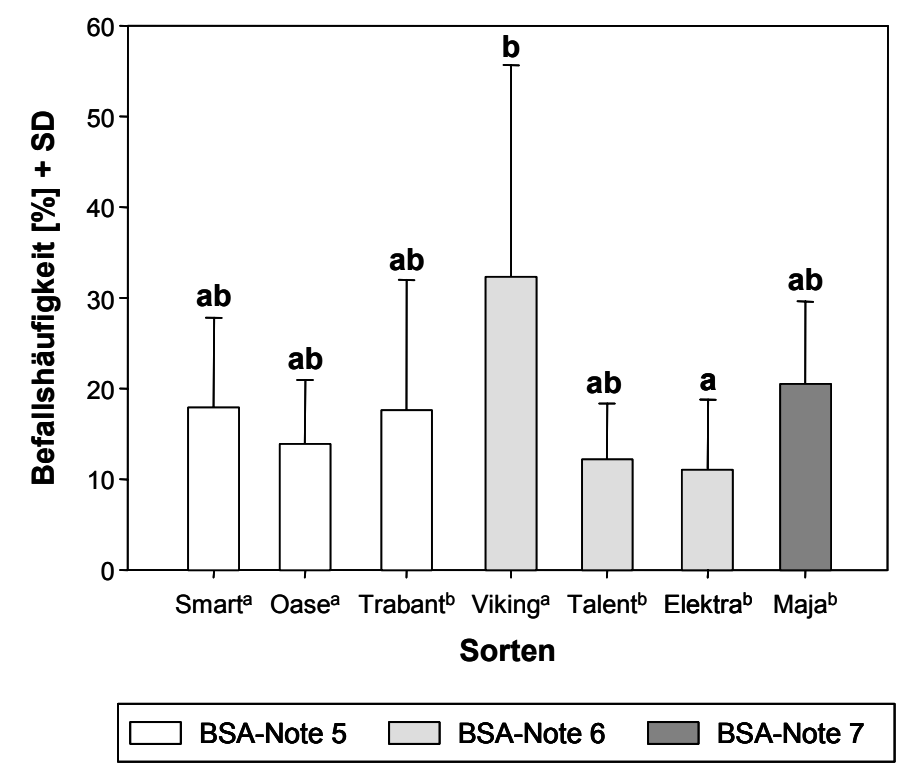

Abb. 3.1: Mittlere Befallshäufigkeiten in verschiedenen Rapssorten nach künstlicher Inokulation mit S. sclerotiorum (10-70\%) zu BBCH 65-67 im Jahr 2004/05 am Standort „Dragoneranger“ in Göttingen-Weende. Unterschiedliche Buchstaben kennzeichnen signifikante Unterschiede, $\mathrm{p} \leq 0,05$ (Tukey-Test). ${ }^{\mathrm{a}}=$ Liniensorte, $^{\mathrm{b}}=$ Hybridsorte

Weitere untersuchte Versuchsfaktoren waren der Aussaattermin und die Bestandesdichte. Beide Sortentypen (Hybride und Liniensorte) wurden zu einem für die Region Göttingen frühen und normalen Termin in zwei Aussaatstärken gesät (siehe 
Kap. 2.4.2.3) und zu BBCH 67-69 inokuliert. Im Mittel über die drei Versuchsjahre 2001/02-2003/04 sind keine signifikanten $(\mathrm{p} \leq 0,05)$ Unterschiede in der erzielten mittleren Befallshäufigkeit zwischen den Aussaatterminen und Bestandesdichten in den beiden Sortentypen aufgetreten (Abb. 3.2). Wechselwirkungen zwischen Versuchsjahr und Aussaattermin bzw. Bestandesdichte sind nicht aufgetreten.

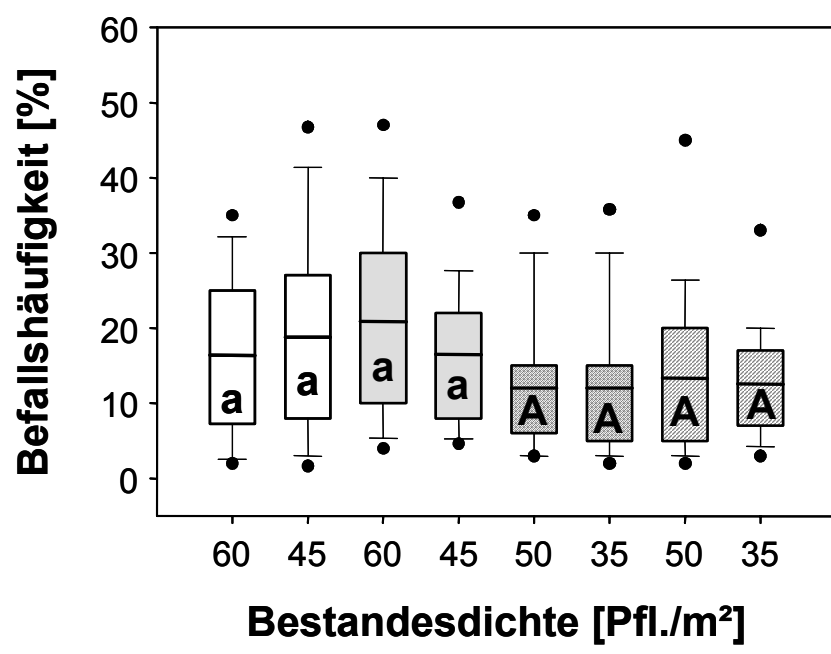

\section{Erklärung Box-and-Whisker-Plot}

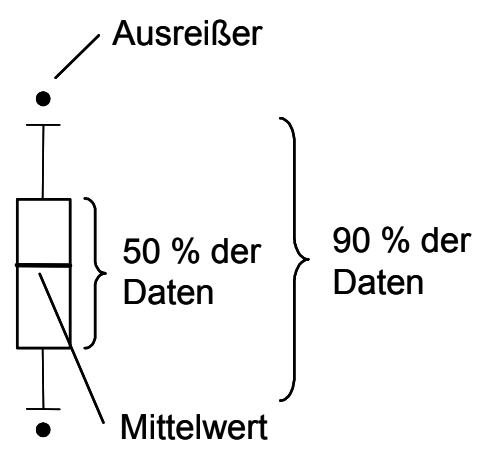

$\square \begin{aligned} & \text { Liniensorte, } \\
& \text { frühe Aussaat }\end{aligned} \square \begin{aligned} & \text { Liniensorte, } \\
& \text { späte Aussaat }\end{aligned} \square \begin{aligned} & \text { Hybridsorte, } \\
& \text { frühe Aussaat }\end{aligned} \square$\begin{tabular}{l}
$\begin{array}{l}\text { Hybridsorte, } \\
\text { späte Aussaat }\end{array}$ \\
\hline
\end{tabular}

Abb. 3.2: Sclerotinia-Befallshäufigkeit nach künstlicher Inokulation zu BBCH 67-69 in Abhängigkeit von Aussaattermin und Bestandesdichte in Hybrid- und Liniensorte, gemittelt über die Versuchsjahre 2001/02 bis 2003/04 an den Standorten „Dragoneranger", „Große Lage“ und „Große Breite“ in Göttingen-Weende. Hybridsorte: Talent (2001/02 und 2002/03), Maja (2003/04); Liniensorte: Prince (2001/02-2003/04). Unterschiedliche Buchstaben kennzeichnen signifikante Unterschiede innerhalb der Sortentypen, $p \leq 0,05$ (Tukey-Test).

\subsubsection{Auftreten weiterer Krankheiten und Schädlinge}

In den Versuchen zur Untersuchung der Schadwirkung von S. sclerotiorum war in allen Versuchsjahren ein deutlicher Befall mit P. lingam zu beobachten. In allen Versuchsjahren wurde eine Herbstbehandlung mit Caramba durchgeführt, um neben der wachstumsregulatorischen Wirkung Herbstinfektionen mit $P$. lingam zu verhindern. Im Versuchsjahr 2003/04 war im Frühjahr starker Blattbefall mit P. lingam zu verzeichnen, so dass eine zweimalige Fungizidapplikation mit Folicur durchgeführt wurde. Trotz der Fungizidapplikationen konnte in allen Versuchsjahren zu BBCH 81-83 Stängelbefall mit P. lingam bonitiert werden. In den Versuchsjahren 2001/02 und 2003/04 war eine 
sehr hohe Befallshäufigkeit von $P$. lingam $\mathrm{zu}$ beobachten, während in den Versuchsjahren 2002/03 und 2004/05 nur geringe Befallshäufigkeiten festgestellt werden konnten (Tab. 3.3). Multiple Regressionsanalysen wiesen jedoch keinen signifikanten Einfluss von P. lingam auf den Ertrag auf.

Tab. 3.3: Mittlere Befallshäufigkeit von Stängelbefall mit $P$. lingam in den Versuchsjahren 2001/02 bis 2004/05 in Linien- und Hybridsorte an den Standorten „Dragoneranger“, „Große Breite“ und „Große Lage“ in Göttingen-Weende. Sorten: Liniensorte 2001/02-2003/04: Prince; Hybridsorte: 2001/02-2002/03: Talent, 2003/04: Maja.

\begin{tabular}{ccccc}
\hline \multirow{2}{*}{ Sorte } & \multicolumn{4}{c}{ Mittlere $\boldsymbol{P}$. lingam-Befallshäufigkeit [\%] } \\
& $\mathbf{2 0 0 1 / 0 2}$ & $\mathbf{2 0 0 2 / 0 3}$ & $\mathbf{2 0 0 3 / 0 4}$ & $\mathbf{2 0 0 4 / 0 5 *}$ \\
\hline Linie & 78,7 & 11,3 & 59,0 & 13,2 \\
Hybride & 62,6 & 5,7 & 70,5 & \\
\hline
\end{tabular}

*= im Versuchsjahr 2004/05 wurde die $P$. lingam-Befallshäufigkeit über alle Sorten gemittelt, da keine signifikanten Unterschiede bei $\mathrm{p} \leq 0,01$ auftraten.

Weitere Krankheiten (Botrytis cinerea, Alternaria brassicae) und Schädlinge (Ceutorhynchus napi, Ceutorhynchus assimilis, Dasineura brassicae, Meligethes aeneus) traten in den Sclerotinia-Versuchen nur vereinzelt mit einer Befallshäufigkeit unter $5 \%$ auf.

In den Verticillium-Versuchen konnten ebenfalls in beiden Versuchsjahren 2002/03 und 2003/04 hohe Befallshäufigkeiten mit $P$. lingam bonitiert werden. Des Weiteren trat im Versuchsjahr 2003/04 natürlicher Befall mit S. sclerotiorum mit Befallshäufigkeiten von 4 bis $21 \%$ auf. Eine multiple Regressionsanalyse wies jedoch keinen signifikanten Einfluss von $S$. sclerotiorum oder P. lingam auf die Befalls-Verlust-Relation auf.

\subsection{Befalls-Verlust-Relationen von $S$. sclerotiorum an Winterraps}

\subsubsection{Einfluss des Inokulationstermins auf die Schadwirkung von $S$. sclerotiorum}

Die natürlichen Infektionen mit $S$. sclerotiorum finden zum Zeitpunkt der Blüte statt. Immer wieder wird jedoch auch von Spätinfektionen während der Schotenbildung berichtet. Um Unterschiede in der Ertragswirkung durch Infektionen zu verschiedenen Entwicklungsstadien der Pflanzen festzustellen, wurden in einem Feldversuch Pflanzen 
$\mathrm{zu}$ verschiedenen Terminen (BBCH 61-65 und $\mathrm{BBCH} 71$ ) inokuliert und die Wirkung auf die Ertragsparameter untersucht.

Der Einfluss der Inokulation zu unterschiedlichen Terminen auf den Ertrag gemittelt über alle drei Versuchsjahre ist in Abb. 3.3 dargestellt. $\mathrm{Zu}$ beiden Inokulationsterminen und in beiden Sortentypen wurde durch die künstliche Inokulation eine signifikante Ertragsminderung verursacht. Sowohl bei der Hybridsorte als auch bei der Liniensorte war die Ertragswirkung einer Inokulation zu BBCH 61-65 stärker als nach Inokulation $\mathrm{zu} \mathrm{BBCH}$ 71. In der Hybridsorte ist ein Ertragsrückgang um 0,35\% pro 1\% Befallshäufigkeit nach einer Infektion zu BBCH 61-65 zu verzeichnen gewesen, im Vergleich zu 0,31\% Ertragsrückgang pro 1\% Befallshäufigkeit nach Inokulation zu $\mathrm{BBCH}$ 71. Bei der Liniensorte ergaben sich Ertragsrückgänge von 0,40\% (BBCH 6165) bzw. 0,26\% (BBCH 71) pro 1\% Befallshäufigkeit. Ein statistischer Vergleich der Regressionslinien zeigt jedoch, dass sich die stärkere Ertragsminderung durch die frühere Inokulation weder über alle Jahre gesehen noch in den einzelnen Versuchsjahren signifikant von der späteren Inokulation unterscheidet.

Auch ein Vergleich der beiden Sortentypen miteinander zeigt keine abzusichernden Unterschiede.
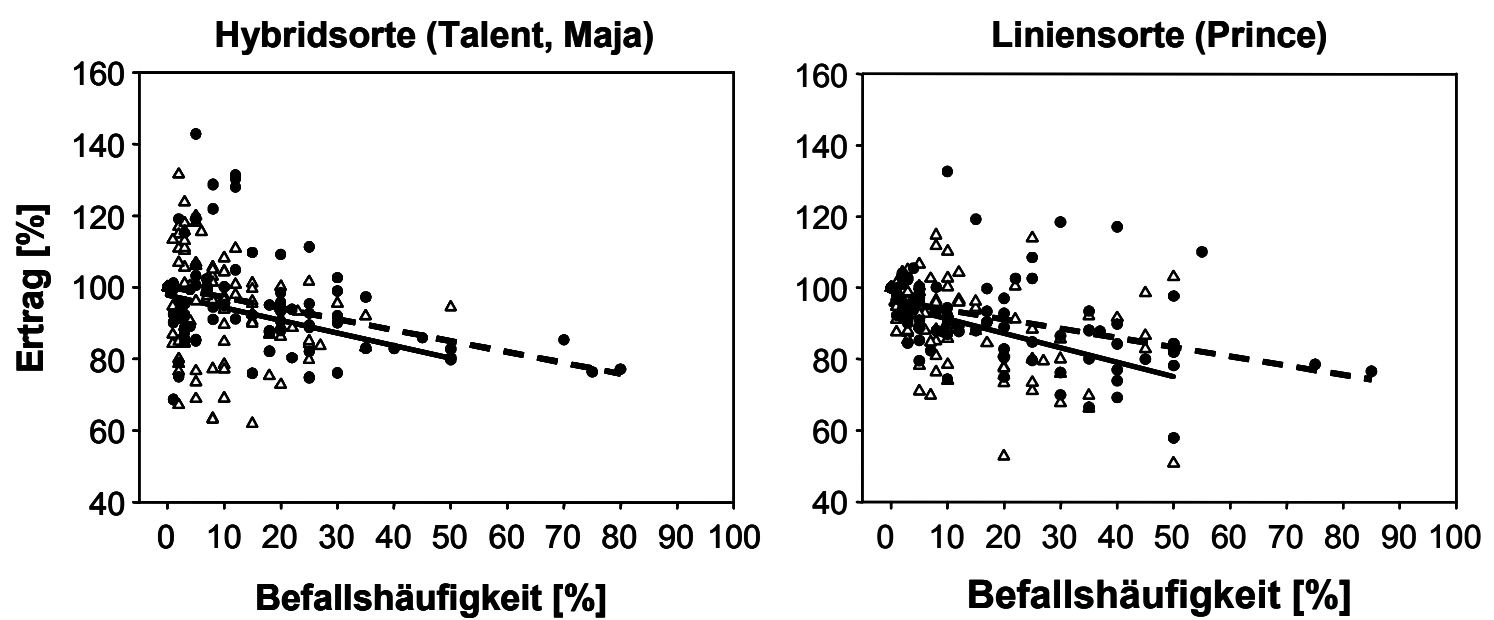

$$
\begin{array}{ll}
\Delta-\text { BBCH 61-65 } & \bullet-- \text { BBCH 71 } \\
y=97,84-0,35 x & y=100,29-0,31 x \\
r^{2}=0,05^{* *} & r^{2}=0,14^{* * *}
\end{array}
$$$$
\begin{array}{ll}
\Delta-\text { BBCH 61-65 } & \bullet-- \text { BBCH } 71 \\
y=95,32-0,40 x & y=96,34-0,26 x \\
r^{2}=0,18^{\star * \star} & r^{2}=0,17^{* * *}
\end{array}
$$

Abb. 3.3: Einfluss des Inokulationstermins auf den Ertrag von Hybrid- und Liniensorte. Daten aus Feldversuchen an den Standorten „Dragoneranger“, „Große Lage“ und „Große Breite“, Göttingen-Weende in den Versuchsjahren 2001/02 bis 2003/04. Die Signifikanz der Regression wurde mit dem Durbin-Watson-Test überprüft. 
Die statistische Auswertung der einzelnen Versuchsjahre hat gezeigt, dass sich die Ertragsminderung durch $S$. sclerotiorum in der Hybridsorte in den einzelnen Jahren nicht signifikant voneinander unterscheidet. Bei der Liniensorte ist ein signifikanter Unterschied des dritten Versuchsjahres zu den beiden vorhergehenden Versuchsjahren mit einer Irrtumswahrscheinlichkeit von $\mathrm{p} \leq 0,10 \mathrm{zu}$ finden. Im Versuchsjahr 2003/04 war der durch $S$. sclerotiorum hervorgerufene Ertragsrückgang geringer als in den Jahren 2001/02 und 2002/03 (Anhang, Tab. A6).
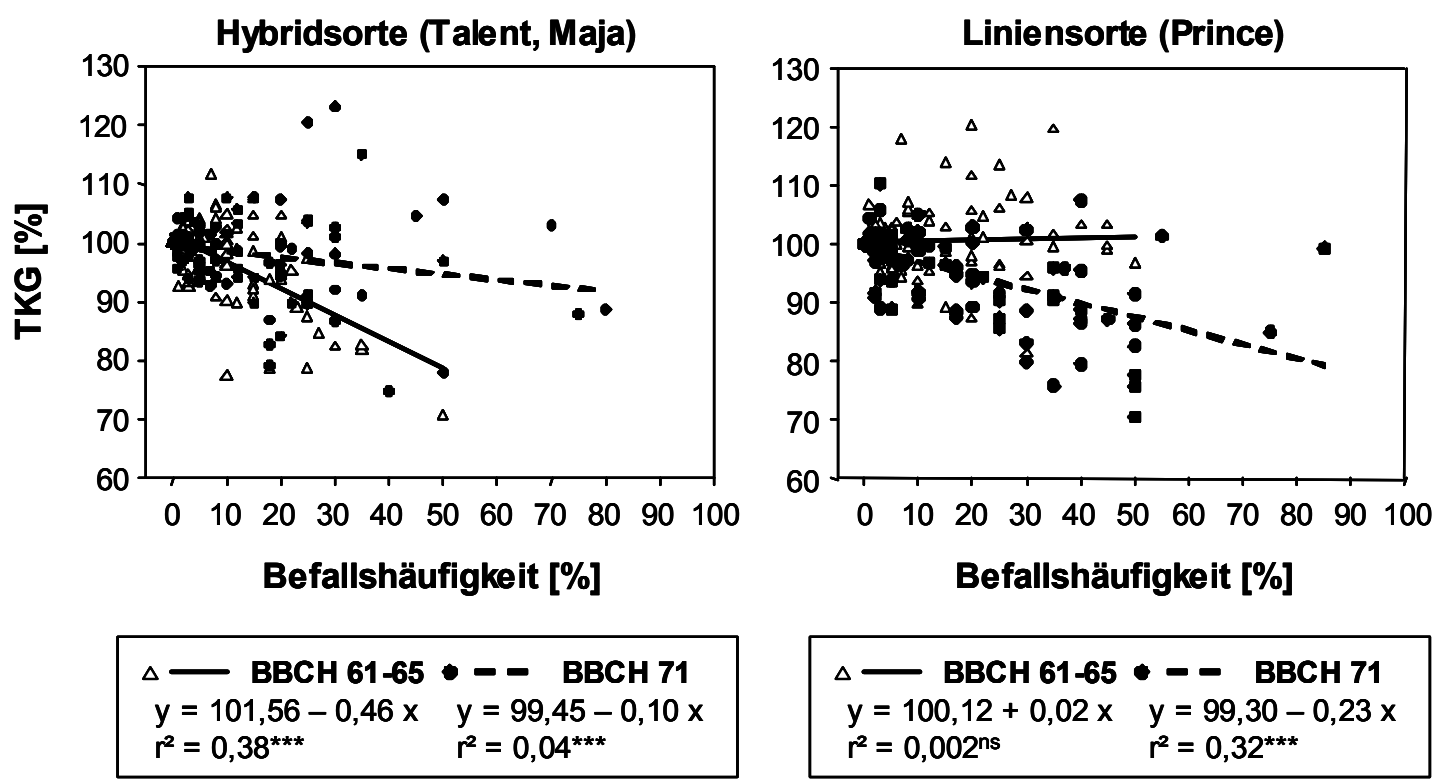

Abb. 3.4: Einfluss des Inokulationstermins auf das TKG von Hybrid- und Liniensorte. Daten aus Feldversuchen an den Standorten „Dragoneranger“, „Große Lage“ und "Große Breite“, Göttingen-Weende in den Versuchsjahren 2001/02 bis 2003/04. Die Signifikanz der Regression wurde mit dem Durbin-Watson-Test überprüft.

Neben dem Ertrag wurde auch die Wirkung des Befalls mit S. sclerotiorum auf TKG und Ölgehalt untersucht. Anders als in der Wirkung auf den Ertrag ist in der Hybridsorte im Mittel über die drei Versuchsjahre ein stärkerer Rückgang des TKG durch eine späte Inokulation zu BBCH 71 als durch eine Inokulation zu BBCH 61-65 zu finden (Abb. 3.4). Für die Liniensorte ist dieses Verhältnis genau entgegen gesetzt. Bei diesem Sortentyp ist, wie auch beim Ertrag, im Mittel über die drei Versuchsjahre ein stärkerer Rückgang im TKG durch eine frühe Inokulation zu verzeichnen. Eine Inokulation zu BBCH 71 führt zu keiner signifikanten Änderung des TKG. Zu beiden Inokulationsterminen unterscheiden sich die Sortentypen signifikant voneinander (frühe 
Inokulation $\mathrm{p} \leq 0,01$, späte Inokulation $\mathrm{p} \leq 0,05)$. Innerhalb der Sortentypen sind ebenfalls signifikante Unterschiede zwischen den Inokulationsterminen bei $\mathrm{p} \leq 0,01 \mathrm{zu}$ sichern.

Der Vergleich der einzelnen Versuchsjahre miteinander zeigt bei der Hybridsorte nur für den frühen Inokulationstermin signifikante Unterschiede ( $\leq \leq 0,10$ bzw. $p \leq 0,01)$ zwischen dem dritten Versuchsjahr 2003/04 und den beiden vorhergehenden Versuchsjahren 2001/02 und 2002/03. Während in den ersten beiden Versuchsjahren ein leichter positiver Effekt von $S$. sclerotiorum auf das TKG zu verzeichnen war, zeigt das TKG im dritten Versuchsjahr eine negative Korrelation zum S. sclerotiorum-Befall. Dieser sehr deutliche Effekt in der Reaktion des TKG auf den Pilzbefall weist darauf hin, dass der Wechsel der Hybridsorte von Talent zu Maja die Ursache hierfür ist. In allen drei Versuchsjahren unterschieden sich die Inokulationstermine signifikant voneinander ( $p \leq 0,05$ bzw. $p \leq 0,01$ in 2001/02). In den Versuchsjahren 2001/02 und 2002/03 hat eine Inokulation zu BBCH 71 einen stärker mindernden Effekt auf das TKG als eine Inokulation zu BBCH 61-65, während im Versuchsjahr 2003/04 dieses Verhältnis entgegen gesetzt ist (Anhang, Tab. A7).

Bei der Liniensorte unterscheiden sich die drei Jahre in der Reaktion des TKG auf eine Inokulation zu BBCH 61-65 nicht signifikant voneinander. Im Versuchsjahr 2003/04 ist bei der Inokulation zu BBCH 71 ein signifikant $(\mathrm{p} \leq 0,01)$ stärkerer mindernder Effekt auf das TKG zu verzeichnen, als in den beiden vorhergehenden Versuchsjahren. In allen drei Versuchsjahren ist durch eine Inokulation zu BBCH 61-65 ein leichter, jedoch nicht signifikanter $(\mathrm{p} \leq 0,10)$ Anstieg des TKG mit zunehmender $S$. sclerotiorumBefallshäufigkeit zu verzeichnen. Durch eine Inokulation zu BBCH 71 hingegen ist eine Minderung des TKG mit steigender Befallshäufigkeit zu beobachten. Im Versuchsjahr 2002/03 ist der Unterschied zwischen den Inokulationsterminen jedoch nicht statistisch abzusichern $(\mathrm{p} \leq 0,10)$ (Anhang, Tab. A7). Unterschiede zwischen den Sorten sind im ersten Versuchsjahr bei beiden Inokulationsterminen nicht $\mathrm{zu}$ finden. Im zweiten Versuchsjahr unterschieden sich die Sorten zum frühen Inokulationstermin signifikant voneinander $(\mathrm{p} \leq 0,05)$. Bei der Hybridsorte Talent war hier ein stärkerer positiver Effekt auf das TKG zu verzeichnen als bei der Liniensorte Prince. Im dritten Versuchsjahr unterschieden sich die Sorten zu beiden Inokulationsterminen signifikant voneinander ( $\mathrm{p} \leq 0,05$ bzw. $\mathrm{p} \leq 0,01)$. Während bei der Hybridsorte Maja zum frühen Inokulationstermin eine Minderung des TKG zu verzeichnen war, konnte bei der Liniensorte Prince eine Steigerung des TKG beobachtet werden. Inokulationen zu 
BBCH 71 führten bei beiden Sorten zu einem Rückgang des TKG, wobei hier die Liniensorte einen stärkeren Effekt aufwies (Anhang, Tab. A7).

Der Einfluss einer Sclerotinia-Inokulation zu unterschiedlichen Terminen auf die Qualitätseigenschaft Ölgehalt (Abb. 3.5) ist geringer als die Wirkung auf das TKG und den Ertrag. Auch in diesem Qualitätsparameter ist die Wirkung in den beiden Sortentypen zu beiden Inokulationsterminen signifikant abweichend voneinander. Bei der Hybridsorte ist durch eine Inokulation $\mathrm{zu}$ BBCH $71 \mathrm{im}$ Mittel über die drei Versuchsjahre kein signifikanter Rückgang im Ölgehalt nachweisbar. Eine Inokulation zu BBCH 61-65 hingegen führt zu einer Minderung des Ölgehaltes von 2,5\% pro 10\% Befallshäufigkeit. In der Liniensorte wurden zu beiden Inokulationsterminen nur sehr geringe Minderungen des Ölgehaltes (gemittelt über die drei Versuchsjahre) von 4\% bzw. $9 \%$ bei $10 \%$ Befallshäufigkeit verursacht, die sich nicht signifikant voneinander unterscheiden.
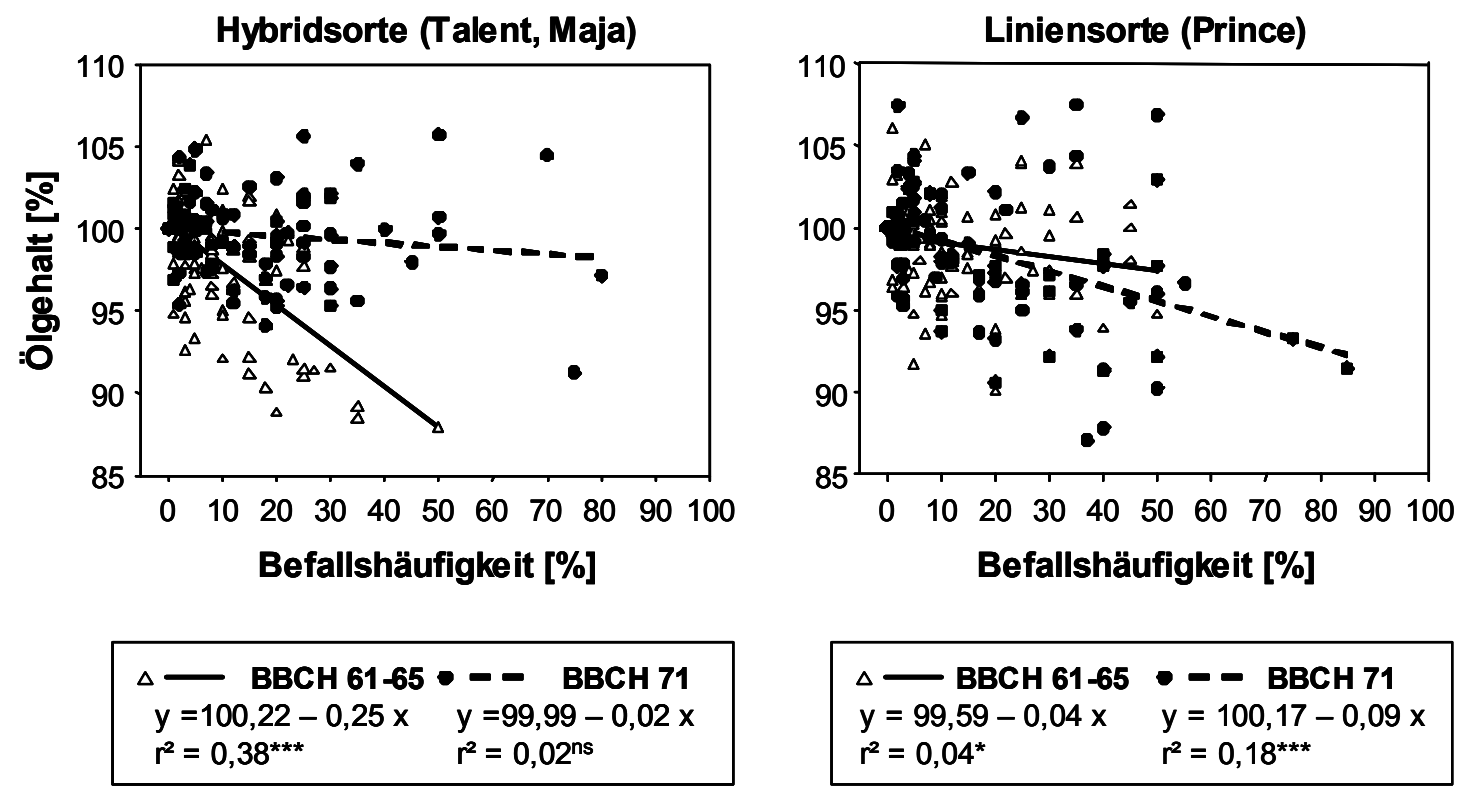

$$
\begin{array}{ll}
\Delta-\text { BBCH 61-65 } & --- \text { BBCH } 71 \\
y=99,59-0,04 x & y=100,17-0,09 x \\
r^{2}=0,04^{*} & r^{2}=0,18^{* * *}
\end{array}
$$

Abb. 3.5: Einfluss des Inokulationstermins auf den relativen Ölgehalt von Hybrid- und Liniensorte. Daten aus Feldversuchen an den Standorten „Dragoneranger“, „Große Lage“ und „Große Breite“, Göttingen-Weende in den Versuchsjahren 2001/02 bis 2003/04. Die Signifikanz der Regression wurde mit dem Durbin-Watson-Test überprüft.

Statistisch abzusichernde Unterschiede in der Reaktion von S. sclerotiorum-Befall auf den Ölgehalt zwischen den drei Versuchsjahren ist bei der frühen Inokulation der Hybridsorte zwischen den Jahren 2001/02 und 2002/03 sowie 2002/03 (p $\leq 0,10$ ) und 
2003/04 (p $\leq$ 0,01) zu beobachten. Während in den Jahren 2001/02 und 2003/04 ein Rückgang des Ölgehaltes mit zunehmendem S. sclerotiorum-Befall beobachtet werden konnte, war im Versuchsjahr 2002/03 ein leichter Anstieg des Ölgehaltes zu verzeichnen. Zwischen den Inokulationsterminen sind bei der Hybridsorte in allen drei Versuchsjahren signifikante Unterschiede zu finden. Im ersten sowie im dritten Versuchsjahr hat eine Inokulation zu BBCH 61-65 einen stärkeren negativen Effekt auf den Ölgehalt, während im zweiten Versuchsjahr die späte Inokulation zu BBCH 71 einen negativen Effekt aufzeigte wohingegen die frühe Inokulation eine positive Reaktion auf den Ölgehalt aufwies (Anhang, Tab. A8).

Bei der Liniensorte ist die Reaktion des Ölgehaltes auf einen Befall mit S. sclerotiorum im Versuchsjahr 2001/02 zu beiden Inokulationsterminen gleich und nur sehr gering. In den beiden folgenden Versuchsjahren führt eine Inokulation $\mathrm{zu}$ BBCH $71 \mathrm{zu}$ einem stärkeren Rückgang des Ölgehaltes, wobei nur im Jahr 2002/03 der Unterschied statistisch abzusichern ist $(\mathrm{p} \leq 0,10)$ (Anhang, Tab. A8).

Sortenunterschiede in der Relation zwischen S. sclerotiorum-Befall und Ölgehalt sind lediglich bei dem frühen Inokulationstermin im Versuchsjahr 2003/04 zu finden ( $\mathrm{p} \leq$ 0,05). Die Hybride zeigt hier einen stärkeren Rückgang des Ölgehaltes als die Liniensorte.

\subsubsection{Einfluss von Aussaattermin und Bestandesdichte auf die Schadwirkung von}

\section{S. sclerotiorum}

In einem weiteren Feldversuch wurde der Einfluss verschiedener anbautechnischer Maßnahmen auf die Schadwirkung von S. sclerotiorum untersucht. Als variierende Faktoren wurden zwei Aussaattermine sowie zwei Bestandesdichten gewählt. Die Frühsaat wurde im Zeitraum vom 10. bis 15. August und die Normalsaat im Zeitraum vom 20. bis 25. August durchgeführt. Für jeden Sortentyp wurden außerdem zwei Bestandesdichten gewählt. Für die Hybridsorte lagen diese bei 50 und 35 Pflanzen $/ \mathrm{m}^{2}$, für die Liniensorte bei 60 und 45 Pflanzen $/ \mathrm{m}^{2}$.

Um Aussagen über den Einfluss des Aussaattermins und der Bestandesdichte auf den Ertrag an sich zu machen, wurden die Erträge aus den Kontrollparzellen ausgewertet (Abb. 3.6).

Die Hybridsorte zeigt wie erwartet bei beiden Aussaatterminen und Bestandesdichten ein etwas höheres Ertragsniveau als die Liniensorte. Innerhalb der Sortentypen Hybride 
und Linie sind keine signifikanten Unterschiede zwischen einer frühen und einer normalen Aussaat sowie zwischen den beiden Bestandesdichten zu erkennen. Der Ertrag in Parzellen mit einer höheren Bestandesdichte ist jedoch bei beiden Sortentypen und beiden Aussaatterminen etwas höher als in Parzellen mit geringerer Bestandesdichte. Ein vorgezogener Aussaattermin, bereits in der ersten Augusthälfte, führt ebenfalls bei beiden Sortentypen zu einem tendenziell höheren Ertrag, der sich jedoch statistisch nicht absichern lässt.

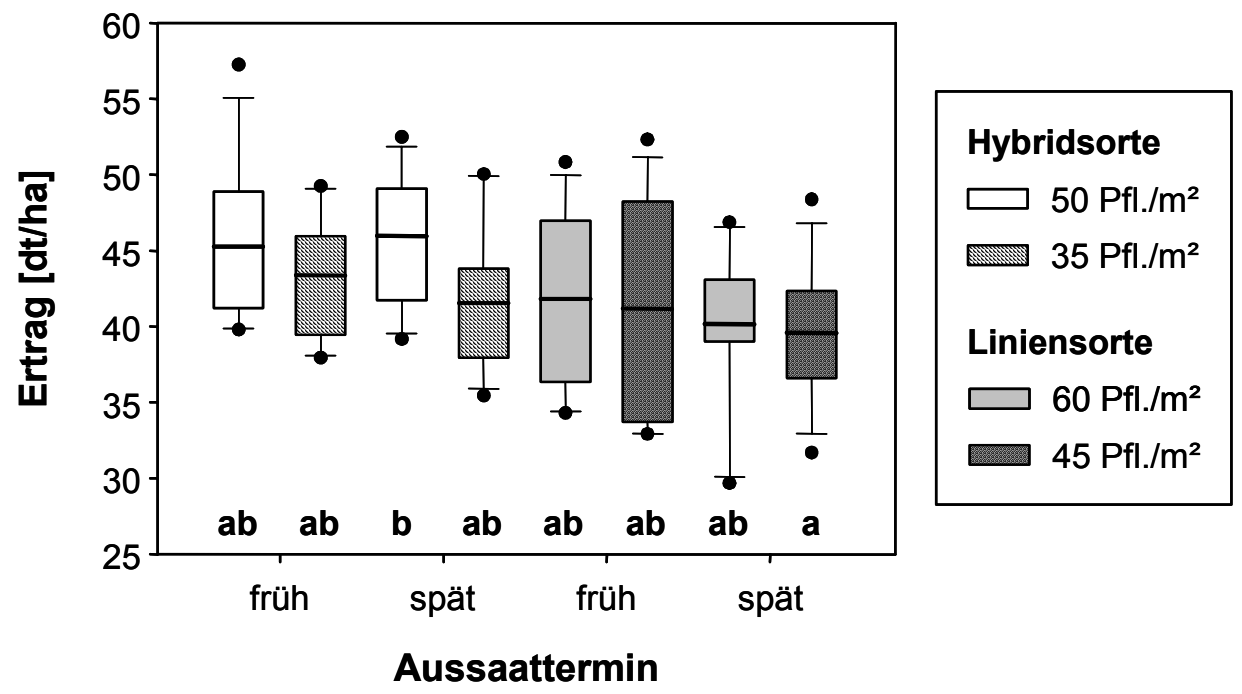

Abb. 3.6: Erträge der Kontrollparzellen der verschiedenen Aussaatvarianten der Hybrid- und Liniensorte. Mittel über jeweils vier Wiederholungen in den Jahren 2001/02 bis 2003/04, Standorte „Dragoneranger“, „Große Lage“ und „Große Breite“, Göttingen-Weende. Unterschiedliche Buchstaben kennzeichnen signifikante Unterschiede, $\mathrm{p} \leq 0,05$ (Tukey-Test).

Auch der Vergleich der verschiedenen Varianten in den einzelnen Versuchsjahren zeigt in allen drei Versuchsjahren keine signifikanten Unterschiede zwischen den verschiedenen Aussaatterminen und Bestandesdichten innerhalb einer Sorte und zwischen den beiden Sorten (Anhang, Tab. A9). Ausnahme hiervon ist im Versuchsjahr 2001/02 die Hybride der normalen Aussaat mit der hohen Bestandesdichte, die sich von allen vier Varianten der Liniensorte signifikant unterscheidet.

Die Ertragsparameter TKG und Ölgehalt zeigen wie der Ertrag keine abzusichernden Unterschiede zwischen einer Früh- und einer Normalsaat und einer hohen und geringen Bestandesdichte (Abb. 3.7). Das TKG ist in allen Varianten in der Hybridsorte höher als 
in der Liniensorte. Dahingegen hat die Liniensorte in allen Varianten einen höheren Ölgehalt als die Hybride.

Auch die Betrachtung der einzelnen Versuchsjahre zeigen keine abzusichernden Unterschiede in TKG und Ölgehalt zwischen den verschiedenen Varianten innerhalb einer Sorte (siehe Anhang Tab. A9). Zwischen den Sorten innerhalb eines Versuchsjahres sind im Versuchsjahr 2001/02 abzusichernde Unterschiede lediglich zwischen zwei Varianten sowohl im TKG als auch im Ölgehalt zu beobachten. Im Versuchsjahr 2002/03 hingegen unterschieden sich alle Varianten der Hybridsorte von denen der Liniensorte im TKG. Im dritten Versuchsjahr sind keine signifikanten Unterschiede zwischen den Sorten in TKG und Ölgehalt aufgetreten.
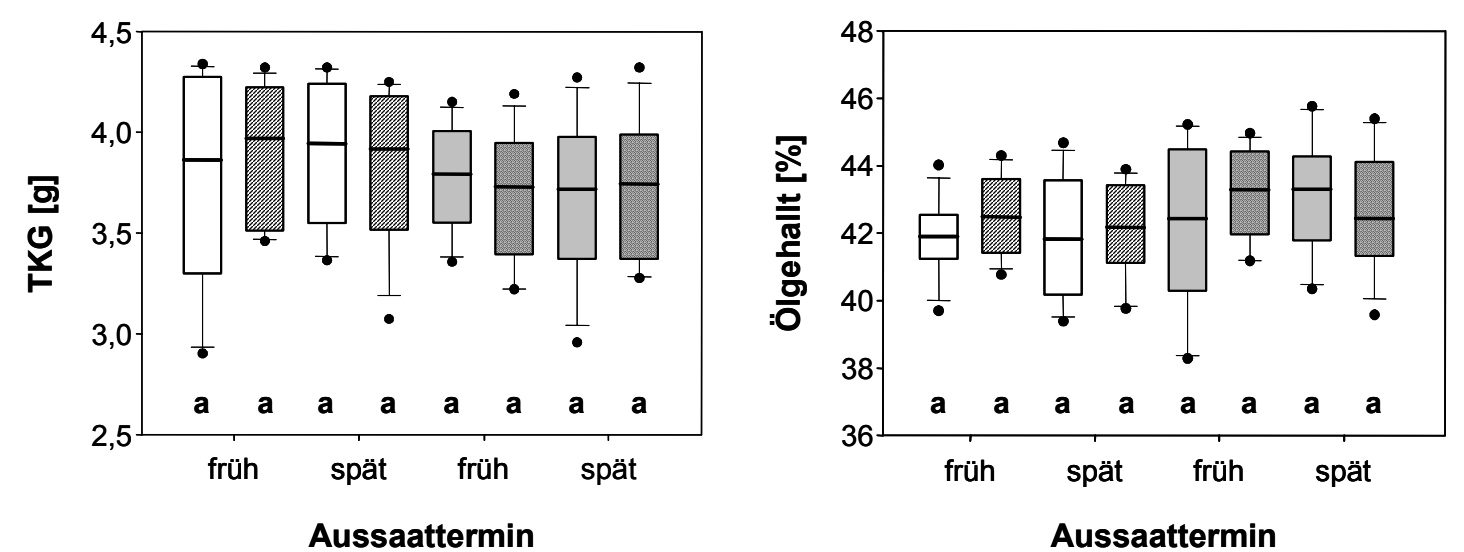

$$
\begin{array}{|l}
\hline \text { Hybridsorte } \square 50 \mathrm{Pfl} . / \mathrm{m}^{2} \square 35 \mathrm{Pfl} . / \mathrm{m}^{2} \\
\text { Liniensorte } \square 60 \mathrm{Pfl} . \mathrm{m}^{2} \square 45 \mathrm{Pfl} . / \mathrm{m}^{2}
\end{array}
$$

Abb. 3.7: TKG und Ölgehalt der Kontrollparzellen der verschiedenen Aussaatvarianten der Hybrid- und Liniensorte. Mittel über jeweils vier Wiederholungen in den Jahren 2001/02 bis 2003/04, Standorte „Dragoneranger“", „Große Lage“ und „Große Breite“, Göttingen-Weende. Unterschiedliche Buchstaben kennzeichnen signifikante Unterschiede, $\mathrm{p} \leq 0,05$ (Tukey-Test).

Die Untersuchung der Schadwirkung von $S$. sclerotiorum auf den Ertrag in Abhängigkeit von Aussaattermin und Bestandesdichte erbrachten die in Abb. 3.8 gemittelt über die drei Versuchsjahre dargestellten Ergebnisse. Bei der Hybridsorte unterscheiden sich die Regressionen zwischen Befallshäufigkeit und Ertrag sowohl zwischen den Bestandesdichten innerhalb eines Aussaattermins als auch zwischen den Aussaatterminen innerhalb einer Bestandesdichte. Allerdings lassen sich hierbei keine 
Gesetzmäßigkeiten über die Abhängigkeit der Schadwirkung von den Parametern Aussaattermin und Bestandesdichte ableiten. Während bei einer Frühsaat eine signifikant $(\mathrm{p} \leq 0,05)$ stärkere Ertragsminderung bei der hohen Bestandesdichte zu finden ist, ist der Ertragsrückgang bei der Normalsaat in Parzellen mit einer geringeren Bestandesdichte signifikant $(\mathrm{p} \leq 0,01)$ höher als bei der hohen Bestandesdichte. Der Vergleich der Aussaattermine zeigt bei einer geringen Bestandesdichte einen signifikant ( $\mathrm{p} \leq 0,05)$ stärkeren ertragsmindernden Effekt der Normalsaat mit 9,4\% Ertragsverlust pro $10 \%$ Befallshäufigkeit im Vergleich zu der Frühsaat mit 2,3\%. Bei einer hohen Bestandesdichte ist jedoch die Ertragsminderung in der Frühsaat mit 7\% Ertragsverlust pro $10 \%$ Befallshäufigkeit signifikant $(\mathrm{p} \leq 0,01)$ stärker ausgeprägt als in der Normalsaat mit 3,1\% Ertragsverlust. Aus diesen Ergebnissen kann man auf Wechselwirkungen zwischen dem Aussaattermin und der Bestandesdichte schließen.

Im Gegensatz zu den Ergebnissen der Hybridsorte konnten bei der Liniensorte im Mittel über die drei Versuchsjahre keine signifikanten Unterschiede in der Ertragswirkung von S. sclerotiorum zwischen den Aussaatterminen und den Bestandesdichten gefunden werden (Abb. 3.8). In der Frühsaat ist die Ertragswirkung tendenziell stärker als bei der Normalsaat. Der tendenziell stärker ertragsmindernde Effekt in der hohen gegenüber der geringen Bestandesdichte lässt sich ebenfalls nicht statistisch absichern.

Zwischen den drei Versuchsjahren 2001/02 bis 2003/04 sind sowohl bei der Hybridsorte als auch bei der Liniensorte keine signifikanten Unterschiede in der Schadwirkung auf den Ertrag in Abhängigkeit von Aussaattermin und Bestandesdichte aufgetreten. Mit Ausnahme der Normalsaaten der Hybriden in den Versuchsjahren 2002/03 und 2003/04 sowie in der Liniensorte 2002/03 war bei einer höheren Bestandesdichte ein stärkerer ertragsmindernder Effekt einer Sclerotinia-Infektion zu verzeichnen (Anhang, Tab. A10).

Die Wirkung eines zunehmenden Sclerotinia-Befalls auf das TKG ist in Abb. 3.9 dargestellt. Entgegengesetzt zu den Ergebnissen der Ertragsauswertung, ist für die Hybridsorte im Vergleich der Bestandesdichten innerhalb der Aussaattermine bei dem TKG eine stärkere negative Wirkung des Sclerotinia-Befalls in der geringeren Bestandesdichte bei der Frühsaat und bei der hohen Bestandesdichte in der Normalsaat zu verzeichnen. Die Unterschiede zwischen den Bestandesdichten innerhalb der Aussaattermine lassen sich statistisch jedoch nicht absichern. Zwischen den Aussaatterminen lässt sich bei der hohen Bestandesdichte ein signifikant $(p \leq 0,01)$ stärkerer Rückgang des TKG in der Normalsaat zu finden als in der Frühsaat. Die 
Varianten der geringen Bestandesdichte unterscheiden sich zwischen den Aussaatterminen nicht signifikant voneinander.

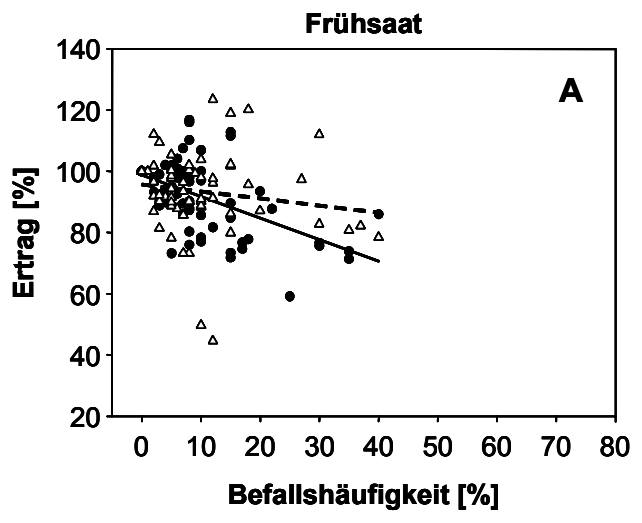

- $50 \mathrm{Pfl} . / \mathrm{m}^{2}, \mathrm{y}=98,73-0,70 \mathrm{x} ; \mathrm{r}^{2}=0,27^{* * *}$ $\triangle 35 \mathrm{Pfl} . / \mathrm{m}^{2}, y=95,70-0,23 x ; r^{2}=0,03^{\text {ns }}$

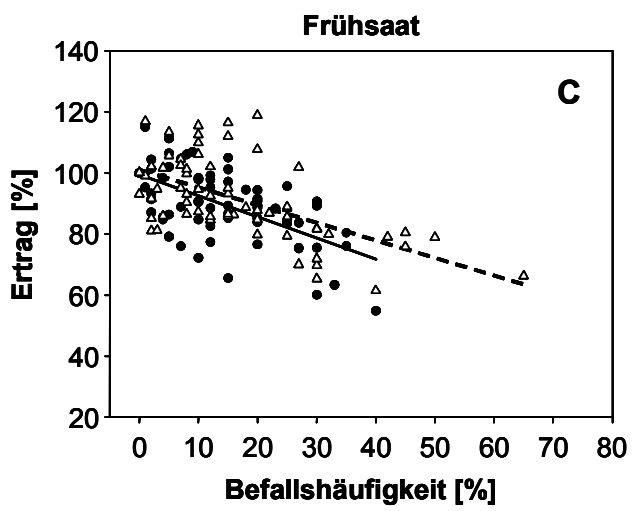

느 $60 \mathrm{Pfl} . / \mathrm{m}^{2}, \mathrm{y}=99,38-0,69 \mathrm{x} ; \mathrm{r}^{2}=0,39^{* * *}$ $\_$_ $45 \mathrm{Pfl} . / \mathrm{m}^{2}, \mathrm{y}=100,97-0,58 \mathrm{x} ; \mathrm{r}^{2}=0,38^{* *}$

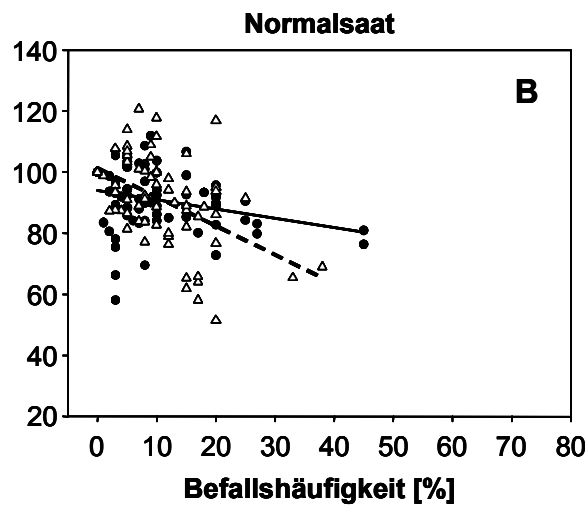

- $50 \mathrm{Pfl} . / \mathrm{m}^{2}, \mathrm{y}=94,13-0,31 \mathrm{x} ; \mathrm{r}^{2}=0,08^{* *}$ $\triangle 35 \mathrm{Pfl} . / \mathrm{m}^{2}, y=101,23-0,94 \mathrm{x} ; \mathrm{r}^{2}=0,25^{\star \star}$

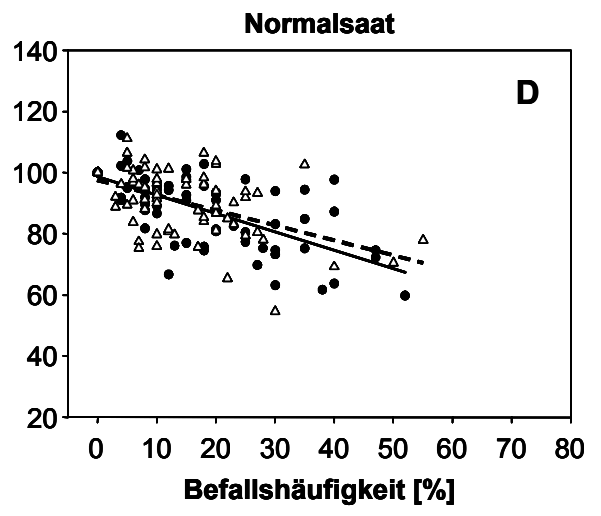

느 $60 \mathrm{Pfl} . / \mathrm{m}^{2}, \mathrm{y}=98,66-0,60 \mathrm{x} ; \mathrm{r}^{2}=0,45^{* * *}$ $\_\_45 \mathrm{Pfl} . / \mathrm{m}^{2}, \mathrm{y}=97,55-0,49 \mathrm{x} ; \mathrm{r}^{2}=0,26^{* * *}$

Abb. 3.8: Ertragswirkung von $S$. sclerotiorum in Abhängigkeit von Aussaattermin, Bestandesdichte und Sortentyp. A und B: Hybride, C und D: Liniensorte. Mittel über die Versuchsjahre 2001/02 bis 2003/04 an den Standorten „Dragoneranger“, „Große Lage“ und „Große Breite“, Göttingen-Weende. Die Signifikanz der Regression wurde mit dem Durbin-Watson-Test überprüft.

Auch bei der Liniensorte sind keine Gesetzmäßigkeiten für die Wirkung eines Sclerotinia-Befalls in Abhängigkeit der Parameter Aussaattermin und Bestandesdichte zu finden. Nur in der Variante der geringen Bestandesdichte des normalen Saattermins konnte ein signifikanter Zusammenhang zwischen Befallshäufigkeit und TKG gefunden 
werden. Pro 10\% Befallshäufigkeit ist eine Abnahme des TKG um 1,6\% zu verzeichnen.

Ein Vergleich der beiden Sortentypen zeigt in den Varianten der Frühsaat keine statistisch abzusichernden Unterschiede in der Wirkung eines Sclerotinia-Befalls auf das TKG, sowohl in der hohen als auch in der geringen Bestandesdichte. In den Varianten der Frühsaat ist lediglich in der hohen Bestandesdichte ein signifikant ( $\mathrm{p} \leq$ 0,01) stärkerer negativer Einfluss eines Sclerotinia-Befalls auf das TKG bei der Hybridsorte als bei der Liniensorte $\mathrm{zu}$ finden. In den Varianten der geringen Bestandesdichte sind keine Unterschiede zwischen den Sorten abzusichern.

Der Ölgehalt wurde durch einen Befall der Pflanzen mit S. sclerotiorum im Mittel über die drei Versuchsjahre allgemein nur sehr gering beeinflusst (Abb. 3.10). Für die Hybridsorte war in den Frühsaatvarianten lediglich bei einer geringen Bestandesdichte ein leichter Rückgang im Ölgehalt zu verzeichnen, bei einer hohen Bestandesdichte war ein leichter, jedoch nicht signifikanter Anstieg des Ölgehalts mit steigender Befallshäufigkeit zu beobachten. In den Varianten der Normalsaat stieg der Ölgehalt sowohl in Varianten der geringen als auch in Varianten der hohen Bestandesdichte mit zunehmender Befallshäufigkeit nahezu identisch signifikant an. Die Unterschiede zwischen den Aussaatterminen innerhalb der Bestandesdichten und zwischen den Bestandesdichten innerhalb der Aussaattermine ließen sich jedoch statistisch nicht absichern.

Für die Liniensorte ließ sich lediglich in der geringen Bestandesdichte der Frühsaat eine signifikante negative Regression von Sclerotinia-Befallshäufigkeit zu Ölgehalt feststellen. Diese Regression zeigt einen signifikanten Unterschied $(\mathrm{p} \leq 0,05) \mathrm{zu}$ der hohen Bestandesdichte der Frühsaat. In den Normalsaatvarianten unterschieden sich die Bestandesdichtevarianten nicht signifikant voneinander, ebenso wie die Aussaattermine innerhalb der Bestandesdichten.

Eine nach Versuchsjahren getrennte Auswertung der Schadwirkung von S. sclerotiorum auf TKG und Ölgehalt in Abhängigkeit der Faktoren Sorte, Aussaattermin und Bestandesdichte wies in allen drei Versuchsjahren keine signifikanten Unterschiede ( $\mathrm{p} \leq$ 0,10) zwischen den Sortentypen auf. Auch zwischen den einzelnen Varianten innerhalb einer Sorte konnten keine signifikanten Unterschiede der einzelnen Versuchsjahre in der Wirkung auf das TKG verzeichnet werden (Anhang, Tab. A11). Die Auswertungen des Einflusses auf den Ölgehalt ergaben lediglich bei der Liniensorte Prince einen 
signifikanten Unterschied $(\mathrm{p} \leq 0,05)$ zwischen den Versuchsjahren in der Variante normaler Aussaattermin, niedrige Bestandesdichte. Während in den Versuchsjahren 2002/03 und 2003/04 ein negativer Effekt auf den Ölgehalt beobachtet werden konnte, führte zunehmender Sclerotinia-Befall im Versuchsjahr 2001/02 zu einer Erhöhung des Ölgehaltes (Anhang, Tab. A.12).

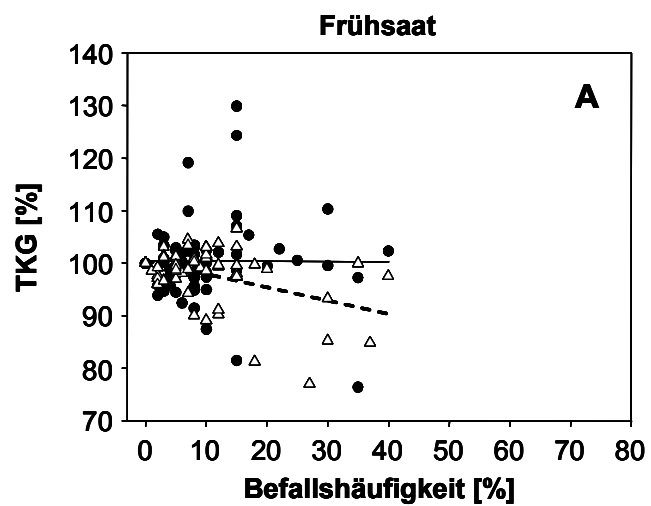

- $50 \mathrm{Pfl} . / \mathrm{m}^{2}, \mathrm{y}=100,45-0,01 \mathrm{x} ; \mathrm{r}^{2}=0,00^{\text {ns }}$ $\triangle 35 \mathrm{Pfl} . / \mathrm{m}^{2}, y=100,44-0,25 x ; r^{2}=0,19^{* * *}$

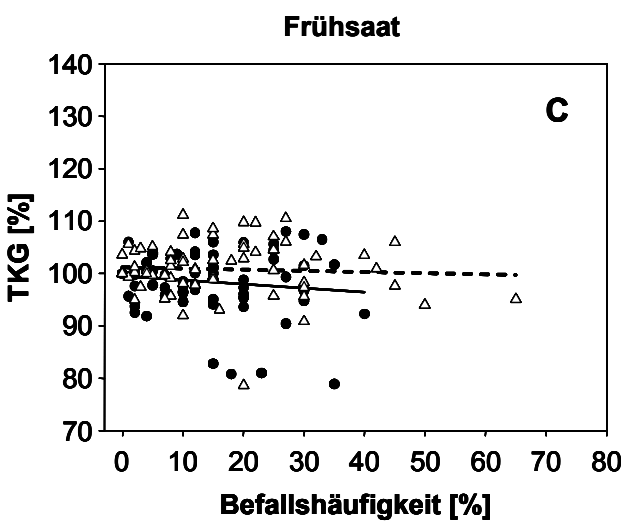

- $60 \mathrm{Pfl} . / \mathrm{m}^{2}, \mathrm{y}=99,57-0,08 \mathrm{x} ; \mathrm{r}^{2}=0,02^{\mathrm{ns}}$ $\therefore \quad \triangle 45 \mathrm{Pfl} . / \mathrm{m}^{2}, y=101,17-0,02 x ; r^{2}=0,00^{\text {ns }}$

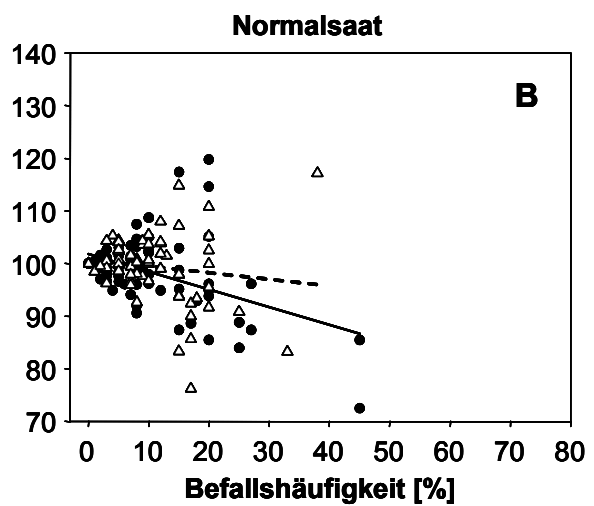

- $50 \mathrm{Pfl} . / \mathrm{m}^{2}, \mathrm{y}=101,82-0,34 \mathrm{x} ; \mathrm{r}^{2}=0,20^{* *}$ $\therefore 35 \mathrm{Pfl} . / \mathrm{m}^{2}, y=100,73-0,13 x ; r^{2}=0,02^{\text {ns }}$

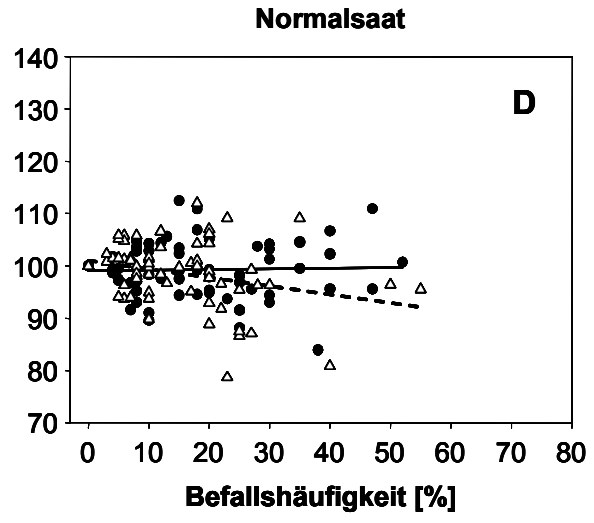

- $60 \mathrm{Pfl} / \mathrm{m}^{2}, y=99,05+0,01 x ; r^{2}=0,00^{\text {ns }}$ $\therefore$ _ $45 \mathrm{Pfl} / \mathrm{m}^{2}, y=101,00-0,16 x ; r^{2}=0,09^{* * *}$

Abb. 3.9: Wirkung von $S$. sclerotiorum auf das $T K G$ in Abhängigkeit von Aussaattermin, Bestandesdichte und Sortentyp. A und B: Hybride, C und D: Liniensorte. Mittel über die Versuchsjahre 2001/02 bis 2003/04 an den Standorten „Dragoneranger“, „Große Lage“ und „Große Breite“, Göttingen-Weende. Die Signifikanz der Regression wurde mit dem Durbin-Watson-Test überprüft. 

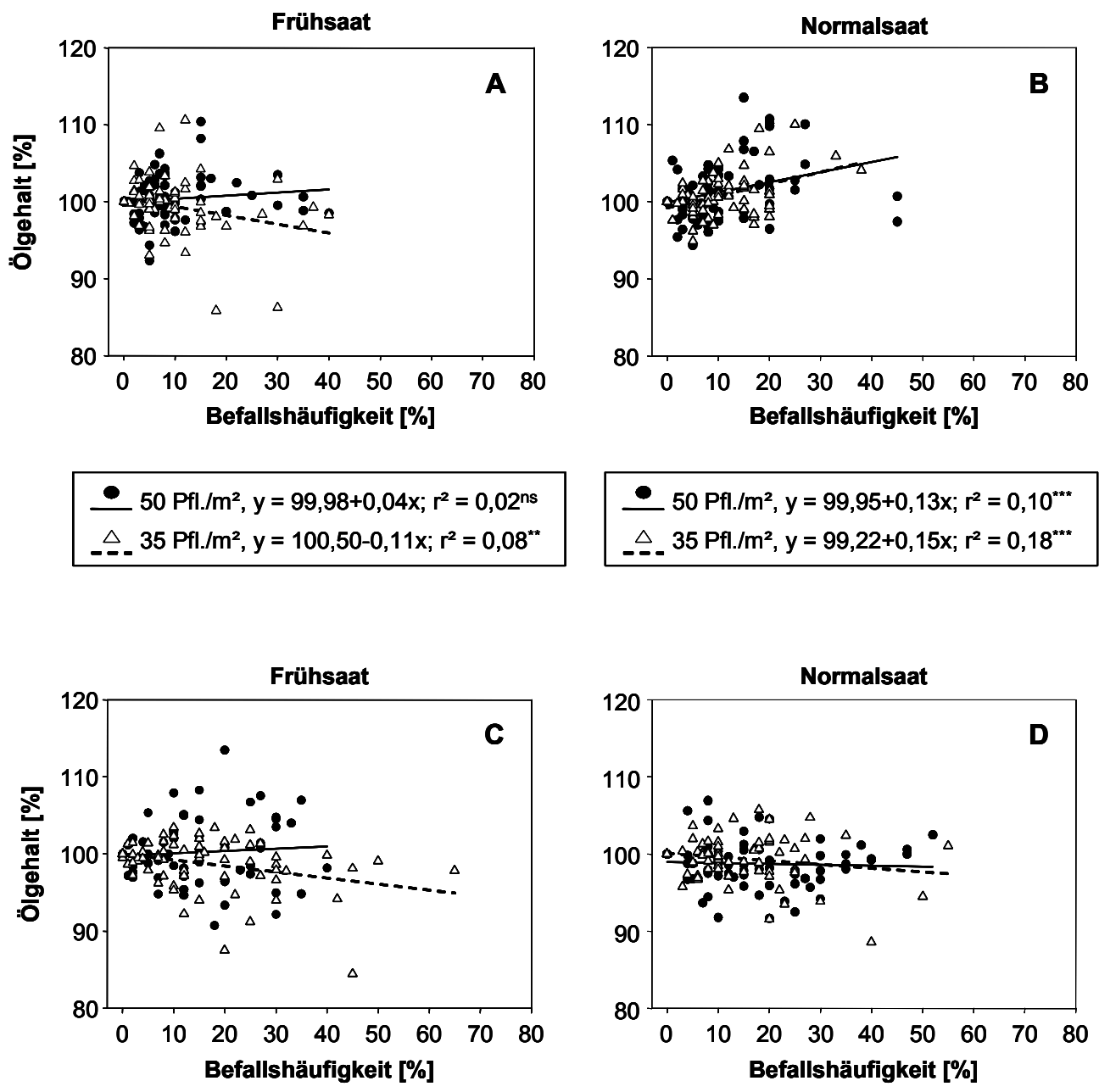

는 $60 \mathrm{Pfl} / \mathrm{m}^{2}, y=99,78+0,03 x ; r^{2}=0,01^{\mathrm{ns}}$ $\triangle 45 \mathrm{Pfl} / \mathrm{m}^{2}, y=100,02-0,08 x ; r^{2}=0,11^{* *}$

는 $60 \mathrm{Pfl} . / \mathrm{m}^{2}, y=99,94-0,01 x ; \mathrm{r}^{2}=0,00^{\text {ns }}$ $\therefore 45 \mathrm{Pfl} . / \mathrm{m}^{2}, y=100,01-0,05 x ; r^{2}=0,03^{n s}$

Abb. 3.10: Wirkung von S. sclerotiorum auf den relativen Ölgehalt in Abhängigkeit von Aussaattermin, Bestandesdichte und Sortentyp. A und B: Hybride, C und D: Liniensorte. Mittel über die Versuchsjahre 2001/02 bis 2003/04 an den Standorten „Dragoneranger“, „Große Lage“ und „Große Breite“, Göttingen-Weende. Die Signifikanz der Regression wurde mit dem Durbin-Watson-Test überprüft.

\subsubsection{Einfluss der Sorte auf die Schadwirkung von S. sclerotiorum}

Zur Untersuchung sortenspezifischer Reaktionen in Ertrag und TKG auf Befall mit S. sclerotiorum wurden im Versuchsjahr 2004/05 in vier Hybridsorten (Trabant, Talent, Elektra, Maja) und drei Liniensorten (Smart, Oase, Viking) Befallshäufigkeiten von 070\% mit der Zahnstocherinokulation eingestellt. Die Erträge der Kontrollparzellen sind in Abb. 3.11 dargestellt. Mit 58,22 dt/ha erzielte die Liniensorte Viking den höchsten Ertrag, die Liniensorte Oase mit 41,32 dt/ha den geringsten. Eine statistische 
Auswertung der Daten war nicht möglich, da die Kontrollparzellen nur in einfacher Wiederholung vorlagen.

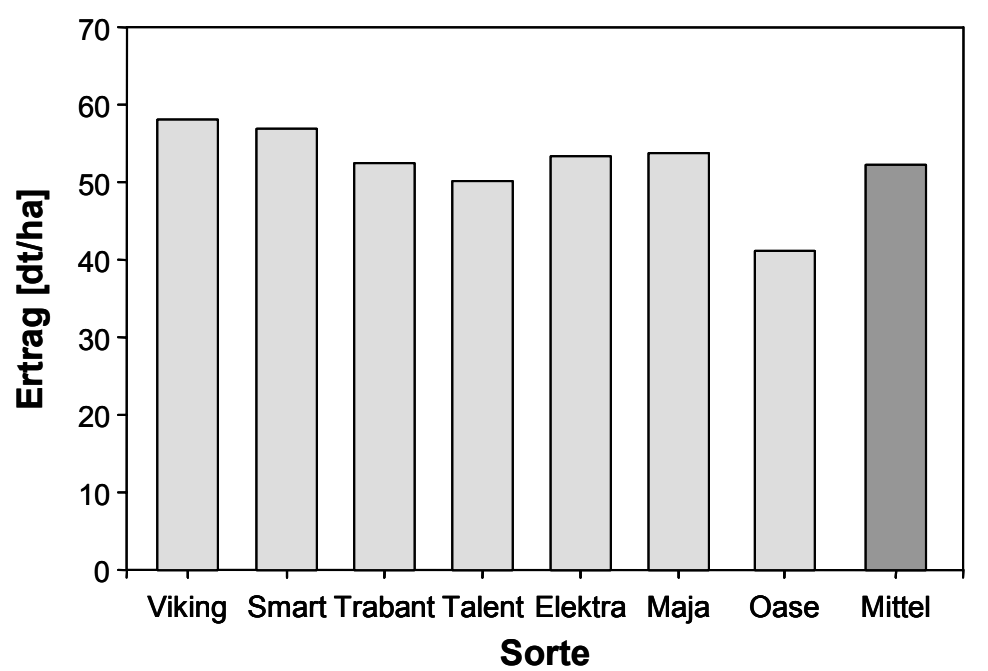

Abb. 3.11: Ertrag der nicht inokulierten Kontrollparzellen in den verschiedenen Rapssorten im Versuchsjahr 2004/05 am Standort „Dragoneranger“ in GöttingenWeende.

Die Regressionskoeffizienten und Bestimmtheitsmaße für die Beziehung zwischen Ertrag bzw. TKG und Befallshäufigkeit in Abhängigkeit von der Rapssorte sind in Tab. 3.4 aufgeführt. Zwischen den verschiedenen Sorten waren keine signifikanten Unterschiede $(\mathrm{p} \leq 0,10)$ in der Ertragsreaktion auf einen Sclerotinia-Befall zu finden. Die Liniensorte Oase wies mit 5,8\% Ertragsrückgang pro $10 \%$ Befallshäufigkeit den geringsten Ertragsrückgang auf, während die Hybridsorte Talent mit 13,1\% Ertragsrückgang pro $10 \%$ Befallshäufigkeit die stärkste Ertragsreaktion aufwies. Die Regression dieser Sorten sowie die der Sorte Elektra zwischen Befallshäufigkeit und Ertrag konnte statistisch jedoch nicht abgesichert werden.

Auch in der Reaktion des TKG auf eine Sclerotinia-Infektion konnten keine signifikanten Unterschiede zwischen den Sorten festgestellt werden. Lediglich bei der Sorte Maja konnte ein signifikanter Einfluss einer Sclerotinia-Infektion auf das TKG beobachtet werden (Tab. 3.4).

Ebenso wie bei dem Parameter Befallshäufigkeit konnte kein Zusammenhang zwischen dem Ertragseffekt und der vom Bundessortenamt in der beschreibenden Sortenliste vergebenen Boniturnote für die Anfälligkeit gegen S. sclerotiorum festgestellt werden. 
Tab. 3.4: Regressionskoeffizient und Bestimmtheitsmaß der Beziehung Ertrag bzw. TKG und Befallshäufigkeit in Abhängigkeit der Rapssorte im Versuchsjahr 2004/05 am Standort „Dragoneranger“ in Göttingen-Weende. Die Signifikanz der Regression wurde mit dem Durbin-Watson-Test überprüft.

\begin{tabular}{|c|cc|cc|}
\hline \multirow{2}{*}{ Sorte } & \multicolumn{2}{|c|}{ Ertrag } & \multicolumn{2}{c|}{ TKG } \\
& b & $\mathbf{r}^{2}$ & b & $\mathbf{r}^{2}$ \\
\hline Viking $^{1}$ & $-0,61 \mathrm{a}$ & $0,73^{* * *}$ & $0,01 \mathrm{a}$ & $0,00^{\mathrm{ns}}$ \\
Smart $^{1}$ & $-1,08 \mathrm{a}$ & $0,44^{*}$ & $-0,12 \mathrm{a}$ & $0,05^{\mathrm{ns}}$ \\
Trabant $^{2}$ & $-0,93 \mathrm{a}$ & $0,74^{* * *}$ & $0,12 \mathrm{a}$ & $0,23^{\mathrm{ns}}$ \\
Talent $^{2}$ & $-1,31 \mathrm{a}$ & $0,21^{\mathrm{ns}}$ & $0,26 \mathrm{a}$ & $0,15^{\mathrm{ns}}$ \\
Elektra $^{2}$ & $-1,04 \mathrm{a}$ & $0,34^{\mathrm{ns}}$ & $0,44 \mathrm{a}$ & $0,31^{\mathrm{ns}}$ \\
Maja $^{2}$ & $-0,78 \mathrm{a}$ & $0,39^{*}$ & $-0,28 \mathrm{a}$ & $0,64^{* *}$ \\
Oase $^{1}$ & $-0,58 \mathrm{a}$ & $0,09^{\mathrm{ns}}$ & $0,15 \mathrm{a}$ & $0,05^{\mathrm{ns}}$ \\
\hline
\end{tabular}

${ }^{1}=$ Liniensorte $^{2}=$ Hybridsorte $\mathrm{b}=$ Regressionskoeffizient, $\mathrm{r}^{2}=$ Bestimmtheitsmaß

\subsection{Ertragswirkung der mechanischen Pflanzenreduktion}

Raps ist als Pflanze bekannt, die Pflanzenverluste im Bestand durch Ausbildung neuer Nebentriebe und vermehrten Ansatz von Ertragskomponenten kompensieren kann. Um Erkenntnisse über das Kompensationspotential neuerer Rapssorten nach späten Pflanzenverlusten, wie sie z. B. durch eine Sclerotinia-Infektion entstehen können, zu erlangen, wurden in einem Feldversuch zu Beginn der Schotenbildung (BBCH 71) Reduzierungen der Bestandesdichte bis 70\% durchgeführt.

In Abb. 3.12 ist die Regression zwischen Pflanzenreduktion und Ertrag bzw. TKG für die beiden Sortentypen Hybride und Linie dargestellt. Mit steigender Pflanzenreduktion ist bei beiden Sortentypen eine deutliche Ertragsminderung zu erkennen. Der Unterschied in der Ertragsminderung zwischen der Hybridsorte mit 0,67\% Ertragsverlust pro 1\% Pflanzenreduktion und der Liniensorte mit $0,60 \%$ ist nur sehr gering und statistisch nicht abzusichern. Im Gegensatz zu dem Ertragsrückgang mit steigender Pflanzenreduktion ist bei beiden Sortentypen ein signifikanter Anstieg des TKG zu verzeichnen. Der Unterschied zwischen den Sortentypen ist auch hier nicht signifikant unterschiedlich voneinander, wobei die TKG-Steigerung pro $1 \%$ 
Pflanzenreduktion der Liniensorte mit $0,19 \%$ geringfügig höher ist als die der Hybridsorte mit $0,13 \%$.

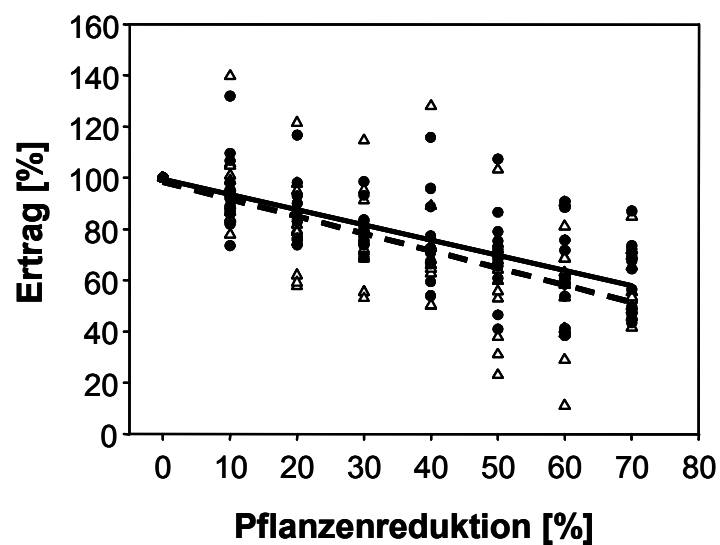

\begin{tabular}{|ll|}
\hline$\Delta-$ Hybridsorte & $\bullet-$ Liniensorte \\
$y=98,38-0,67 x$ & $y=99,56-0,60 x$ \\
$r^{2}=0,44^{* * *}$ & $r^{2}=0,51^{\star * *}$ \\
\hline
\end{tabular}

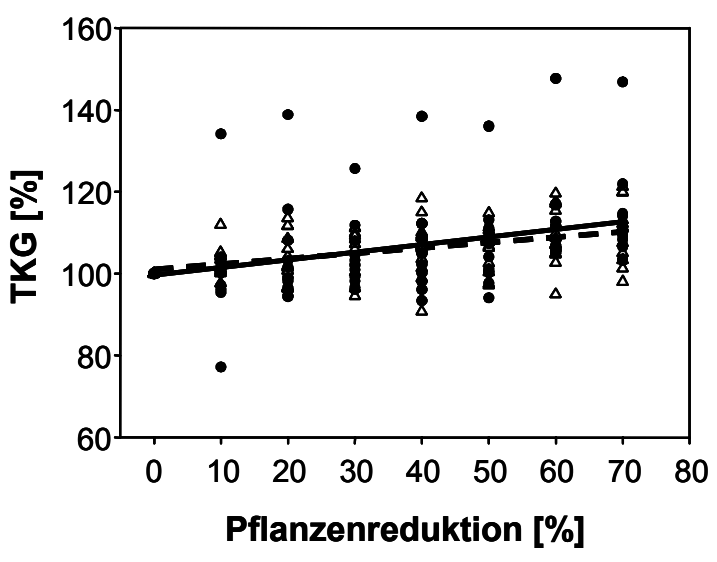

$$
\begin{array}{ll}
\begin{array}{ll}
\Delta-\text { Hybridsorte } & \bullet-\text { Liniensorte } \\
y=101,01+0,13 x & y=99,56+0,19 x \\
r^{2}=0,22^{\star \star \star} & r^{2}=0,15^{\star \star \star}
\end{array}
\end{array}
$$

Abb. 3.12: Regression zwischen Pflanzenreduktion und Ertrag bzw. TKG in den Versuchsjahren 2001/02 bis 2003/04, Standorte „Dragoneranger“, „Große Lage“ und „Große Breite“, Göttingen-Weende. Die Signifikanz der Regression wurde mit dem Durbin-Watson-Test überprüft.

Eine nach Versuchsjahren getrennte Betrachtung der Regressionen zwischen Pflanzenreduktion und Ertrag bzw. TKG wies für beide Sortentypen keine signifikanten Unterschiede zwischen den einzelnen Versuchsjahren auf $(\mathrm{p} \leq 0,10)$. Auch zwischen den Sortentypen konnten in keinem Versuchsjahr signifikante Unterschiede gefunden werden $(p \leq 0,10)$. Die Ergebnisse der Regressionsanalysen der einzelnen Versuchsjahre sind im Anhang in Tab. A13 aufgeführt.

Abbildung 3.13 stellt den tatsächlich eingetretenen Ertragsverlust der beiden Sortentypen im Mittel über die drei Versuchsjahre im Vergleich zu dem erwarteten Ertragsverlust (bei 10\% Pflanzenreduktion werden 10\% Ertragsverlust erwartet usw.) dar. Bei beiden Sortentypen liegt der tatsächlich eingetretene Ertragsverlust unterhalb des erwarteten. Die beiden Sortentypen unterscheiden sich dabei nicht signifikant voneinander (t-test, $\mathrm{p} \leq 0,05)$. Die Liniensorte weist jedoch etwas geringere Ertragsverluste als die Hybridsorte auf.

Die Kompensation ist die Differenz zwischen erwartetem und eingetretenem Ertragsverlust. In den Feldversuchen konnte mit steigender Pflanzenreduktion eine stetig steigende Kompensation beobachtet werden (Abb. 3.14). Bei 70\% Pflanzen- 
reduktion wurde bei beiden Sortentypen eine Kompensation von ca. 30\% erzielt. Tendenziell zeigt die Liniensorte ein etwas höheres Kompensationsvermögen als die Hybridsorte, jedoch lassen sich diese Unterschiede statistisch nicht absichern (TukeyTest, $\mathrm{p} \leq 0,05)$.

Eine nach Versuchsjahren getrennte Auswertung der Ergebnisse zeigte für das Versuchsjahr 2001/02 die höchsten Werte für die Kompensation auf, im Versuchsjahr 2002/03 die geringsten (Anhang, Abb. A1). Signifikante Unterschiede zwischen den Versuchsjahren sowie zwischen den Sorten ließen sich jedoch nicht absichern.

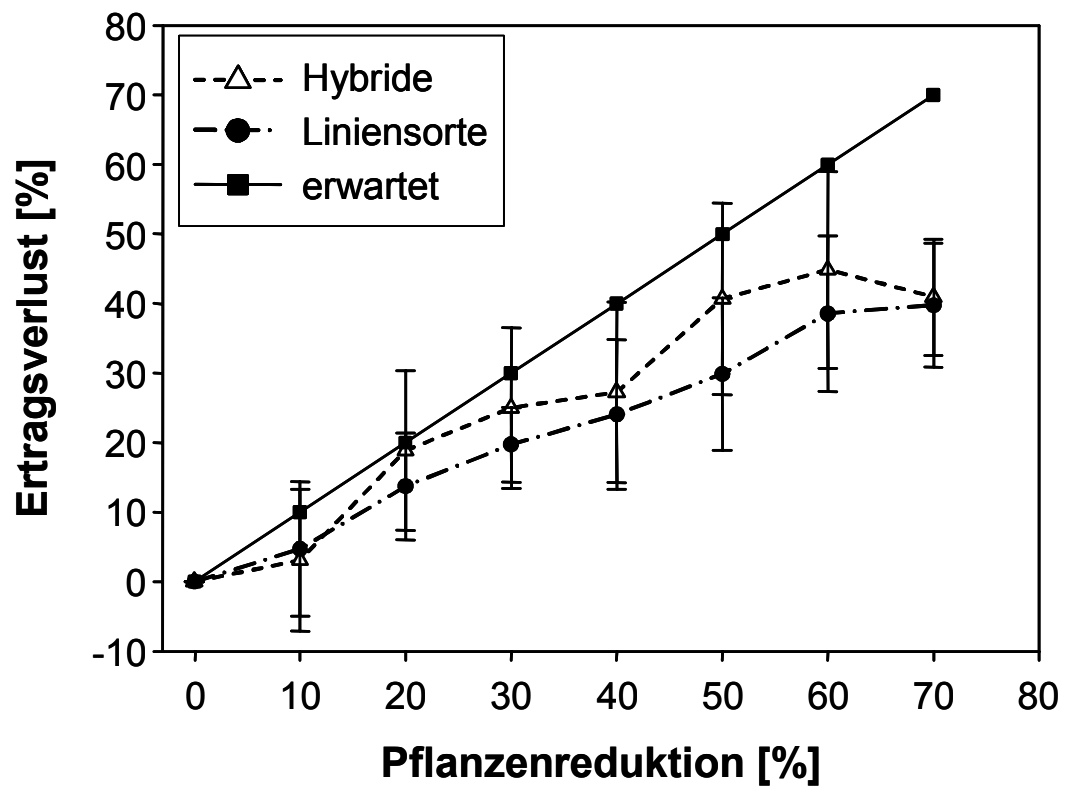

Abb. 3.13: Ertragsverlust von Hybrid- und Liniensorte in Abhängigkeit von der Pflanzenreduktion im Vergleich zum erwarteten Ertragsverlust. Daten aus den Versuchsjahren 2001/02 bis 2003/04, Standorte „Dragoneranger“, „Große Lage“ und „Große Breite“, Göttingen-Weende. 


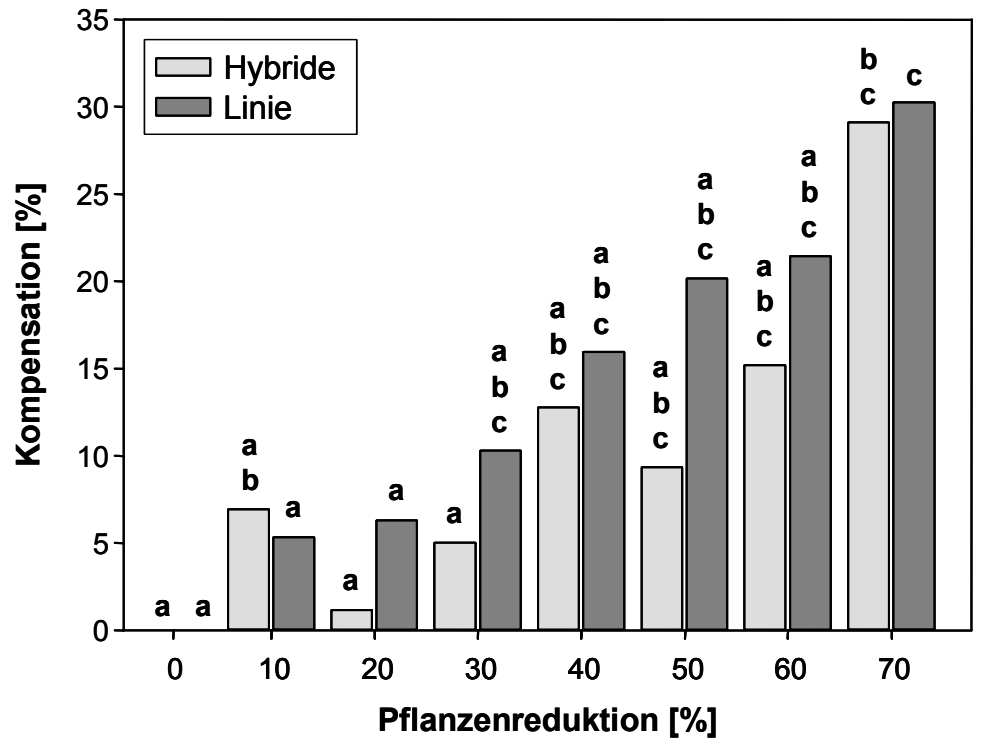

Abb. 3.14: Kompensation in Relation zur Pflanzenreduktion bei Hybrid- und Liniensorte. Mittel über die Versuchsjahre 2001/02 bis 2003/04, Standorte „Dragoneranger“, „Große Lage“ und „Große Breite“, Göttingen-Weende. Unterschiedliche Buchstaben kennzeichnen signifikante Unterschiede, $p \leq 0,05$ (Tukey-Test).

Im Versuchsjahr 2003/04 wurde die Kompensation in Relation zum Termin der Bestandesdichteregulierung untersucht. $\mathrm{Zu}$ vier Terminen, $\mathrm{BBCH} 50,55,60$ und 65 wurden 50\% der Pflanzen pro Parzelle entfernt.
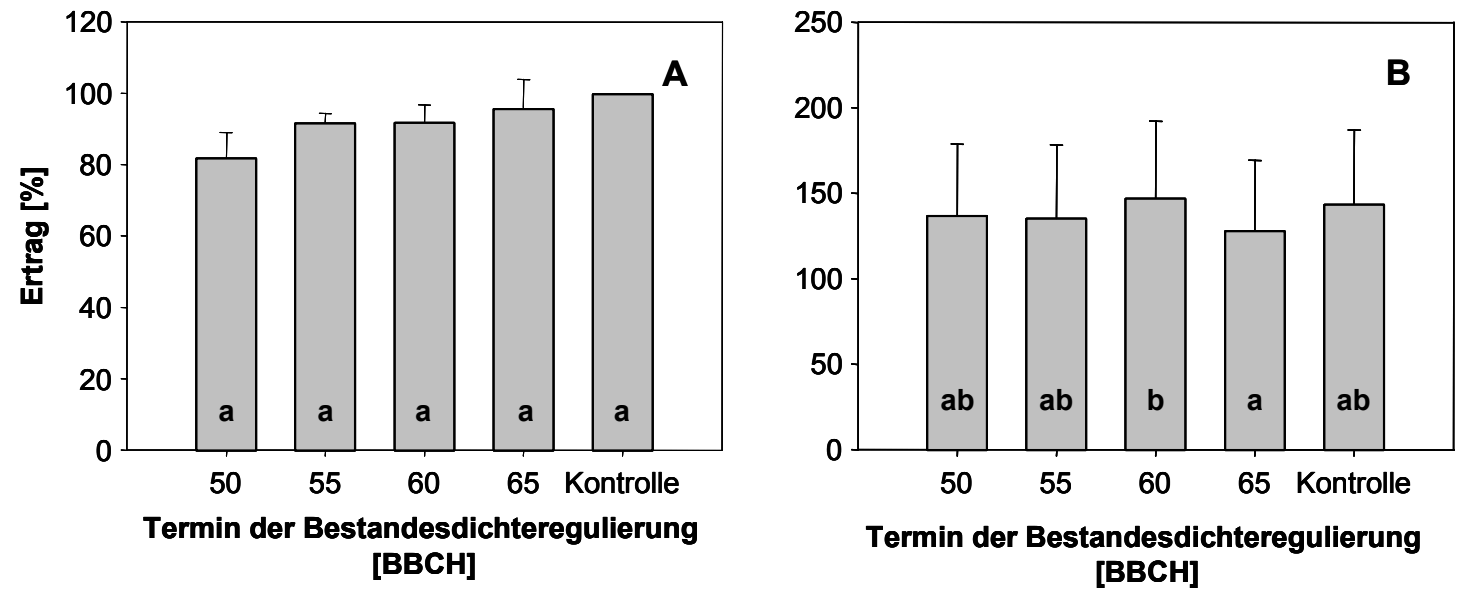

Abb. 3.15: Ertrag in Relation zur nicht behandelten Kontrolle nach Bestandesdichteregulierung (50\%) zu verschiedenen Terminen in der Hybridsorte Maja (A) und der Liniensorte Prince (B). Versuchsstandort „Große Breite“, GöttingenWeende, Versuchsjahr 2003/04, Mittel über vier Wiederholungen. Unterschiedliche Buchstaben kennzeichnen signifikante Unterschiede, $\mathrm{p} \leq 0,05$ (Tukey-Test). 
In der Hybridsorte Maja ist ein tendenziell steigender Ertrag bei Bestandesdichteregulierung zu fortschreitender Pflanzenentwicklung zu erkennen (Abb. 3.15A), jedoch sind die Ertragsunterschiede zur nicht regulierten Kontrollparzelle sowie zwischen den unterschiedlichen Terminen nicht statistisch abzusichern $(\mathrm{p} \leq 0,05)$. In der Liniensorte Prince sind ebenfalls keine signifikanten Ertragsunterschiede der behandelten Varianten zur nicht behandelten Kontrolle $\mathrm{zu}$ finden (Abb. 3.15B). Eine Bestandesdichteregulierung zu BBCH 65 führte jedoch zu einem signifikant geringeren Relativertrag als eine Bestandesdichteregulierung zu BBCH 60.

Das TKG weist sowohl bei der Hybrid- als auch bei der Liniensorte keine signifikanten Unterschiede $(\mathrm{p} \leq 0,05)$ zwischen den behandelten Varianten und der nicht behandelten Kontrolle sowie zwischen den unterschiedlichen Varianten auf (Abb. 3.16).
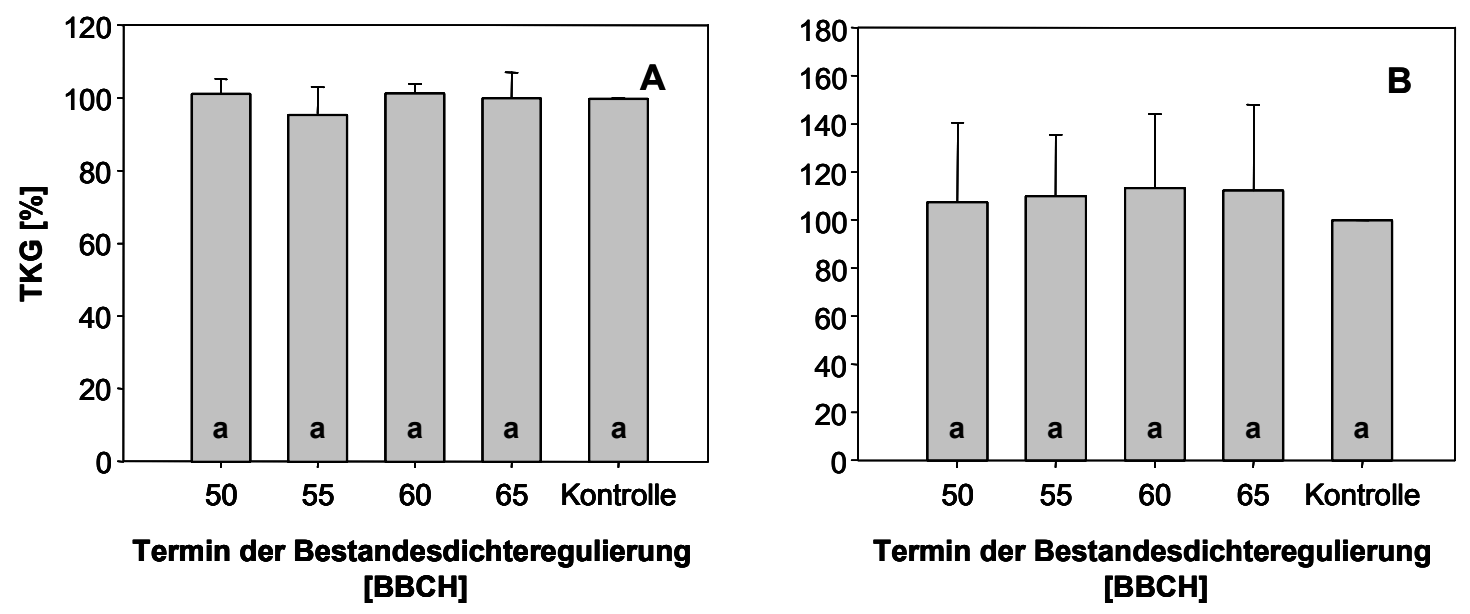

Abb. 3.16: $T K G$ in Relation zur nicht behandelten Kontrolle nach Bestandesdichteregulierung (50\%) zu verschiedenen Terminen in der Hybridsorte Maja (A) und der Liniensorte Prince (B). Versuchsstandort „Große Breite“, Göttingen-Weende, Versuchsjahr 2003/04, Mittel über vier Wiederholungen. Unterschiedliche Buchstaben kennzeichnen signifikante Unterschiede, $\mathrm{p} \leq 0,05$ (Tukey-Test).

Im Vergleich zu der im vorhergehenden Versuch beschriebenen Kompensation nach einer Bestandesdichteregulierung um 50\% zu BBCH 71 von ca. 20\% in der Liniensorte und ca. $10 \%$ in der Hybridsorte (Abb. 3.14), konnte bei früher durchgeführten Bestandesdichteregulierungen eine deutlich höhere Kompensation erzielt werden. In der Hybridsorte Maja ist entsprechend einer ansteigenden Tendenz des Ertrages ebenfalls eine tendenziell steigende Kompensation mit fortschreitender Pflanzenentwicklung von 
$64 \%$ bis $92 \% \mathrm{zu}$ verzeichnen (Abb. 3.17A). Zwischen den Varianten sind jedoch keine signifikanten Unterschiede vorhanden $(\mathrm{p} \leq 0,05)$. Auch bei der Liniensorte Prince ist der Verlauf der Kompensation mit fortschreitender Pflanzenentwicklung ebenfalls entsprechend dem Verlauf des Ertrages. Lediglich zwischen dem 3. und 4. Termin ist ein signifikanter Unterschied in der Kompensation $\mathrm{zu}$ verzeichnen. Mit einer Kompensation von 115\% nach einer Bestandesdichteregulierung zu BBCH 60 unterscheidet sich dieser Termin signifikant $(\mathrm{p} \leq 0,05)$ von dem folgenden Termin $\mathrm{zu}$ BBCH 65 mit nur 68\% Kompensation (Abb. 3.17B).
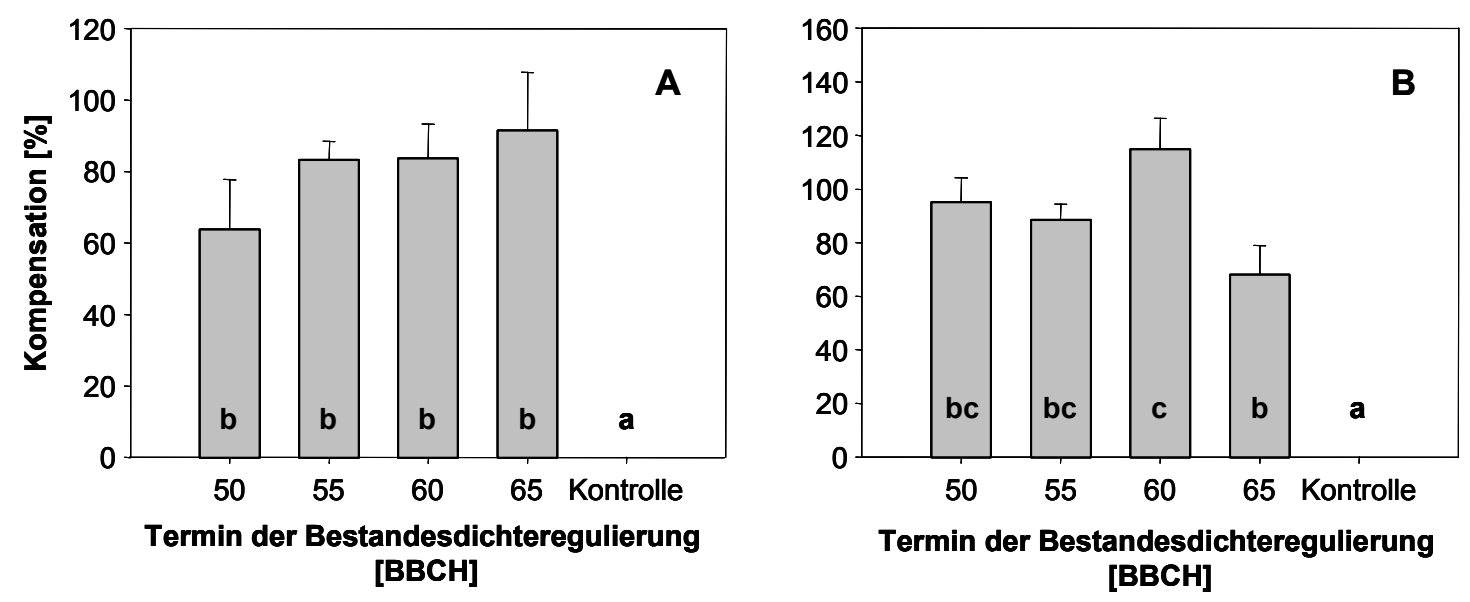

Abb. 3.17: Kompensation bezüglich Ertrag in Relation zur nicht behandelten Kontrolle nach Bestandesdichteregulierung (50\%) zu verschiedenen Terminen in der Hybridsorte Maja (A) und der Liniensorte Prince (B). Versuchsstandort „Große Breite“, GöttingenWeende, Versuchsjahr 2003/04, Mittel über vier Wiederholungen. Unterschiedliche Buchstaben kennzeichnen signifikante Unterschiede, $\mathrm{p} \leq 0,05$ (Tukey-Test).

3.5 Wirtschaftlichkeit von Fungizidmaßnahmen gegen $S$. sclerotiorum in den Jahren 1991 - 2003

\subsubsection{Ertragswirkung von Fungizidapplikationen im Winterraps in den Jahren} 1991 bis 2003

Zur Ermittlung der Ertragswirkung von Fungizidapplikationen zu verschiedenen Entwicklungsstadien der Pflanzen und von verschiedenen Kombinationen von Fungizidapplikationen wurde der Ertrag der jeweiligen Variante in Vergleich zur unbehandelten Kontrollvariante gesetzt. 
Die Ergebnisse dieser Auswertung sind in Tab. 3.5 aufgeführt. Die Mehrfachbehandlungen resultierten in höheren Ertragsdifferenzen als die Einfachbehandlungen, wobei die Variante Frühjahr + Blütenapplikation mit 11,71\% die höchste Ertragsdifferenz erzielte. Unter den Einfachbehandlungen schnitt die Frühjahrsapplikation mit 6,80\% Mehrertrag (=2,80 dt/ha) am besten ab, gefolgt von der Blütenbehandlung mit 5,70\% Mehrertrag (= 2,41 dt/ha). Die Herbst-Einfachbehandlung und die Herbst + Frühjahrsbehandlung erzielten in ihrer Gruppe die geringsten Ertragsdifferenzen.

Tab. 3.5: Ertragswirkung von Fungizidapplikationen im Winterraps getrennt nach Applikationsterminen von 1991 bis 2003. (Ertragsdifferenz $=$ Vergleich zur unbehandelten Kontrolle). Basierend auf Daten aus den offiziellen Feldversuchen der Pflanzenschutzdienste der Länder.

\begin{tabular}{|c|c|c|c|c|}
\hline Behandlung & $\begin{array}{c}\text { Anzahl } \\
\text { Versuche }\end{array}$ & [dt/ha] & $\begin{array}{c}\text { ragsdiffere } \\
\text { von...bis } \\
\text { [dt/ha] } \\
\end{array}$ & {$[\%]$} \\
\hline $\begin{array}{l}\text { Einfachbehandlungen } \\
\text { Herbst }\end{array}$ & 28 & 1,98 & $-0,5 \ldots 4,4$ & 5,22 \\
\hline Frühjahr bis Blüte & 112 & 2,80 & $-1 \ldots 8,4$ & 6,80 \\
\hline Blüte & 592 & 2,41 & $-7,8 \ldots 12,3$ & 5,70 \\
\hline $\begin{array}{l}\text { Mehrfachbehandlungen } \\
\text { Herbst + Frühjahr }\end{array}$ & 22 & 3,91 & $-1,6 \ldots 6,3$ & 9,16 \\
\hline Frühjahr + Blüte & 88 & 3,95 & $-3,2 \ldots 13,2$ & 11,71 \\
\hline Herbst + Frühjahr + Blüte & 13 & 4,58 & $-1,1 \ldots 16,4$ & 11,43 \\
\hline Gesamt & 855 & 3,27 & & 8,34 \\
\hline
\end{tabular}

Die größte Schwankung in der erzielten Ertragsdifferenz ist mit $20,1 \mathrm{dt} / \mathrm{ha}$ bei der Blütenbehandlung $\mathrm{zu}$ finden. Mit einer Schwankung von 4,9 dt/ha weist die Herbstbehandlung den geringsten Wert auf (Tab. 3.5).

In Abb. 3.18 ist die durch eine Fungizidbehandlung zur Vollblüte erreichte Ertragsdifferenz zur unbehandelten Kontrolle und die Befallshäufigkeit in den unbehandelten Kontrollparzellen als Mittel über die einzelnen Jahre dargestellt. Die Befallshäufigkeit zeigt jahresbedingte starke Schwankungen von unter $10 \%$ bis über $70 \%$ SclerotiniaBefallshäufigkeit. Im Jahr 1994 war die durchschnittliche Befallshäufigkeit mit 6,3\% am geringsten, gefolgt von 1999 mit 7,2\% und 1993 mit 7,5\%. In den Jahren 1995 und 1996 war mit durchschnittlich 75,1\% bzw. 65,2\% ein überdurchschnittlich hoher Befall 
zu verzeichnen. Die erzielte Ertragsdifferenz schwankte von ca. $1 \mathrm{dt} / \mathrm{ha}$ bis ca. $4 \mathrm{dt} / \mathrm{ha}$. Mit steigender Befallshäufigkeit ist tendenziell eine erhöhte Ertragsdifferenz zu erkennen. In den Jahren mit den höchsten Befallshäufigkeiten wurden mit 3,57 dt/ha in 1995 und 3,89 dt/ha in 1996 ebenfalls die höchsten Ertragsdifferenzen erzielt. Die geringste Ertragsdifferenz wurde im Jahr 1994 mit der geringsten Befallshäufigkeit erzielt. Der Mehrertrag durch eine Vollblütenbehandlung betrug in diesem Jahr lediglich 0,96 dt/ha. Der Korrelation zwischen Befallshäufigkeit und Ertragsdifferenz lässt sich jedoch statistisch nicht absichern.

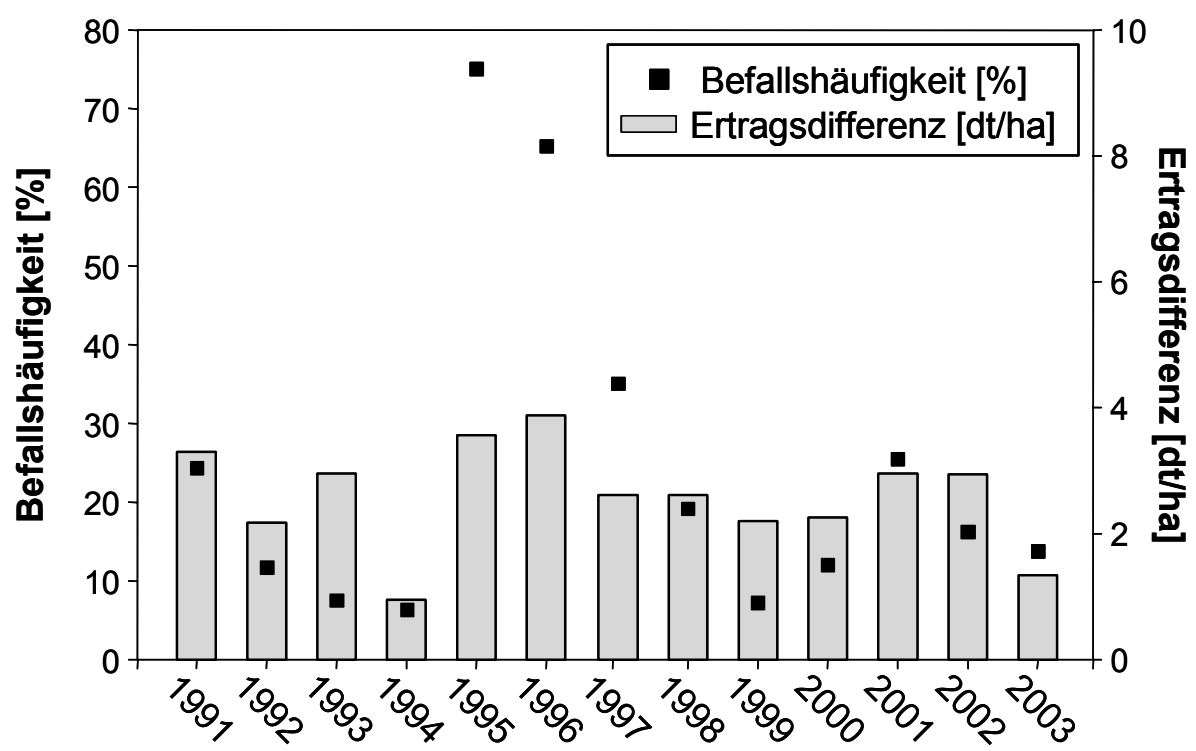

Abb. 3.18: Mittlere Befallshäufigkeit und Ertragswirkung einer Fungizidbehandlung zur Vollblüte im Winterraps in den Jahren 1991 bis 2003 im Vergleich zur unbehandelten Kontrolle. Daten aus den offiziellen Feldversuchen der Pflanzenschutzdienste der Länder.

\subsubsection{Wirkungsgrad von Fungiziden gegen $S$. sclerotiorum}

Durch eine Gegenüberstellung der Befallshäufigkeiten in den unbehandelten Kontrollparzellen und der behandelten Varianten kann der Wirkungsgrad gegen ein bestimmtes Pathogen errechnet werden. Aus dem vorliegenden Datensatz der Jahre 1991-2003 konnten insgesamt 715 einzelne Varianten für eine Auswertung des Wirkungsgrades der $\mathrm{zu}$ verschiedenen Zeitpunkten eingesetzten Fungizide gegen S. sclerotiorum herangezogen werden. 
Tab. 3.6: Wirkungsgrad von Fungizidapplikationen in Winterraps zu verschiedenen Terminen gegen S. sclerotiorum im Zeitraum 1991-2003. Basierend auf Daten aus den offiziellen Feldversuchen der Pflanzenschutzdienste der Länder.

\begin{tabular}{|c|c|c|c|c|}
\hline \multirow{2}{*}{ Applikationstermin } & \multirow{2}{*}{$\begin{array}{c}\text { Anzahl } \\
\text { Varianten }\end{array}$} & \multicolumn{2}{|c|}{ Sclerotinia-Befall [\%] } & \multirow{2}{*}{$\begin{array}{l}\text { Wirkungs- } \\
\text { grad }[\%]\end{array}$} \\
\hline & & unbehandelt & behandelt & \\
\hline Einfachbehandlungen & & & & \\
\hline Herbst & 31 & 7,78 & 5,48 & 29,56 \\
\hline Frühjahr bis Blüte & 144 & 12,06 & 12,29 & $-1,91$ \\
\hline Blüte & 422 & 20,1 & 7,7 & 61,69 \\
\hline Mehrfachbehandlungen & & & & \\
\hline Herbst + Frühjahr & 22 & 8,28 & 5,94 & 28,26 \\
\hline Frühjahr + Blüte & 84 & 20,00 & 6,73 & 66,35 \\
\hline Herbst + Frühjahr + Blüte & 12 & 17,32 & 3,13 & 81,98 \\
\hline
\end{tabular}

Durch Fungizidbehandlungen, die eine Applikation während der Blüte enthielten, wurden erwartungsgemäß die höchsten Wirkungsgrade erzielt (Tab. 3.6), was auf einem Zusammentreffen der Infektion und der Fungizidapplikation beruht. Durch einen einmaligen Fungizideinsatz zur Blüte reduzierte sich der S. sclerotiorum-Befall von $20,1 \%$ in der Kontrolle auf 7,7\% in der behandelten Variante. Dies entspricht einem Wirkungsgrad von $61,69 \%$. Eine kombinierte Frühjahrs-Blüten-Behandlung erreichte einen Wirkungsgrad von 66,35\%, eine dreifache Behandlung im Herbst, Frühjahr und zur Blüte erzielte mit $81,98 \%$ den höchsten Wirkungsgrad gegen S. sclerotiorum. Die erhöhten Wirkungsgrade der kombinierten Blütenbehandlungen im Vergleich zur einfachen Blütenbehandlung sowie die positiven Wirkungsgrade einer Herbst- und einer kombinierten Herbst-Frühjahrs-Behandlung sind möglicherweise dem Einfluss auf die physiologischen Eigenschaften der Pflanzen $\mathrm{zu}$ Gute $\mathrm{zu}$ schreiben. Eine einfache Herbstbehandlung wies mit rund 30\% einen nur geringen Wirkungsgrad auf. Die im Frühjahr behandelten Versuche wiesen keinen Unterschied in der S. sclerotiorumBefallshäufigkeit in den behandelten Parzellen zu den nicht behandelten Kontrollparzellen auf.

\subsubsection{Beurteilung der Wirtschaftlichkeit}

Zur Beurteilung der Wirtschaftlichkeit von Fungizidapplikationen wurden die angefallenen Kosten der Wirkung der Behandlung (= Mehrertrag) gegenüber gestellt. 
Die Kosten setzen sich zusammen aus den Fungizidkosten, Überfahrtkosten (umfassen Kosten für Maschinen, Kraftstoffkosten sowie Arbeitszeitkosten), und bei Blütenbehandlungen den Durchfahrtsverlusten, der entsprechenden Jahre. Die Gesamtkosten für Fungizidbehandlungen zu unterschiedlichen Applikationsterminen wurden jeweils als Mittelwerte über die Jahre 1991 bis 2003 über die in den Versuchen angewendeten Fungizide berechnet (Tab. 3.7). Für die Berechnung des kostendeckenden Mehrertrages wurde der durchschnittliche Rapspreis des entsprechenden Jahres zugrunde gelegt.

Tab. 3.7: Gesamtkosten und kostendeckender Mehrertrag für Fungizidapplikationen in Winterraps zu unterschiedlichen Applikationsterminen in den Jahren 1991 bis 2003. Basierend auf Daten aus den offiziellen Feldversuchen der Pflanzenschutzdienste der Länder.

\begin{tabular}{|l|c|c|}
\hline \multicolumn{1}{|c|}{ Applikationstermin } & $\begin{array}{c}\text { Gesamtkosten } \\
{[€]}\end{array}$ & $\begin{array}{c}\text { Kostendeckender } \\
\text { Mehrertrag [dt/ha] }\end{array}$ \\
\hline Herbst & 27,49 & 1,30 \\
\hline Frühjahr & 47,98 & 2,27 \\
\hline Blüte* & 71,04 & 3,32 \\
\hline Herbst + Frühjahr & 74,91 & 3,53 \\
\hline Blüte + Frühjahr* & 116,59 & 5,45 \\
\hline Herbst + Frühjahr +Blüte* & 154,24 & 7,22 \\
\hline
\end{tabular}

* Durchfahrtsverluste wurden mit 2,6\% angerechnet

Die in Tab. 3.8 angegebenen Ertragsverluste durch eine Durchfahrt sind Mittelwerte über alle Blütenbehandlungen aus den jeweiligen Jahren. Grundlage der Berechnung ist der Ertrag der unbehandelten Kontrollparzellen aus dem Datensatz der offiziellen Feldversuche der Pflanzenschutzdienste der Länder.

Im Mittel über die analysierten Versuchsjahre traten Ertragsverluste von 1,17 dt/ha durch eine Durchfahrt zum Zeitpunkt der Blüte auf. Im Jahr 1991 waren die Ertragsverluste mit 0,95 dt/ha am geringsten. Die höchsten Durchfahrtsverluste traten im Jahr 1993 mit 1,29 dt/ha auf (Tab. 3.8). 
Tab. 3.8: Ertragsverluste durch eine Durchfahrt zum Zeitpunkt der Blüte in den Jahren 1991 bis 2003 basierend auf Daten aus den offiziellen Feldversuchen der Pflanzenschutzdienste der Länder. Unterschiedliche Buchstaben kennzeichnen signifikante Unterschiede, $\mathrm{p} \leq 0,05$ (Tukey-Test).

\begin{tabular}{|c|c|}
\hline Jahr & $\begin{array}{c}\text { Durchfahrtsverlust } \\
\mathbf{( 2 , 6 \% )}[\mathbf{d t} / \mathbf{h a}]\end{array}$ \\
\hline 1991 & $0,95 \mathrm{a}$ \\
\hline 1992 & $1,08 \mathrm{ab}$ \\
\hline 1993 & $1,29 \mathrm{ce}$ \\
\hline 1994 & $1,3 \mathrm{cde}$ \\
\hline 1995 & $1,03 \mathrm{a}$ \\
\hline 1996 & $1,1 \mathrm{abcd}$ \\
\hline 1997 & $1,16 \mathrm{abcd}$ \\
\hline 1998 & $1,23 \mathrm{bcd}$ \\
\hline 1999 & $1,38 \mathrm{e}$ \\
\hline 2000 & $1,18 \mathrm{abcd}$ \\
\hline 2001 & $1,25 \mathrm{bcde}$ \\
\hline 2002 & $1,11 \mathrm{abd}$ \\
\hline 2003 & $1,24 \mathrm{bcd}$ \\
\hline Mittelwert & $\mathbf{1 , 1 7}$ \\
\hline
\end{tabular}

Der Anteil kostendeckender und damit wirtschaftlicher Fungizidbehandlungen in Abhängigkeit vom Applikationstermin ist in Tab. 3.9 aufgeführt. Eine alleinige Blütenbehandlung erwies sich lediglich in $32,7 \%$ der ausgewerteten Versuche als wirtschaftlich. Einfachbehandlungen im Herbst oder Frühjahr hingegen erreichten in $57,1 \%$ bzw. in 53,6\% der Versuche die Wirtschaftlichkeit. Bei den Mehrfachbehandlungen erwies sich eine kombinierte Herbst-Frühjahrs-Behandlung mit $72,7 \%$ als die beste Behandlungsmöglichkeit. Eine kombinierte Frühjahrs-Blüten-Behandlung wies mit 42,7\% eine immer noch höhere Wirtschaftlichkeit als eine alleinige Blütenbehandlung auf. Eine dreifache Fungizidapplikation im Herbst, Frühjahr und zur Blüte war nur in $25 \%$ der ausgewerteten Versuche wirtschaftlich. Die Kosten einer solch intensiven Fungizidstrategie konnten nur in wenigen Fällen durch den erzielten Mehrertrag gedeckt werden. 
Tab. 3.9: Anteil wirtschaftlicher Fungizidbehandlungen in Winterraps getrennt nach unterschiedlichen Applikationsterminen von 1991 bis 2003. Basierend auf Daten aus den offiziellen Feldversuchen der Pflanzenschutzdienste der Länder.

\begin{tabular}{|l|c|c|}
\hline \multicolumn{1}{|c|}{ Applikationstermin } & $\begin{array}{c}\text { Anzahl } \\
\text { Versuche }\end{array}$ & $\begin{array}{c}\text { Wirtschaftliche } \\
\text { Behandlungen } \\
{[\%]}\end{array}$ \\
\hline $\begin{array}{l}\text { Einfachbehandlungen } \\
\text { Herbst }\end{array}$ & 16 & 57,14 \\
\hline Frühjahr bis Blüte & 110 & 53,64 \\
\hline Blüte* & 556 & 32,73 \\
\hline $\begin{array}{l}\text { Mehrfachbehandlungen } \\
\text { Herbst + Frühjahr }\end{array}$ & 22 & 72,73 \\
\hline Frühjahr + Blüte* & 82 & 42,7 \\
\hline Herbst + Frühjahr + Blüte* & 12 & 25 \\
\hline
\end{tabular}

* Durchfahrtsverluste wurden mit 2,6\% angerechnet

Die nach einzelnen Jahren getrennte Betrachtung der Wirtschaftlichkeit in Relation zur durchschnittlichen Befallshöhe des jeweiligen Jahres weist einen signifikanten Zusammenhang auf. Befallshäufigkeit und Anteil wirtschaftlicher Behandlungen weisen eine positive Korrelation auf (Abb. 3.19). Die Ergebnisse der einzelnen Versuchsjahre sind im Anhang in Tab. A14 aufgeführt. Im Jahr 1994 mit der geringsten Befallshäufigkeit von 6,33\% wurde in keinem Versuch der kostendeckende Mehrertrag durch eine Blütenbehandlung erreicht. Der höchste Anteil wirtschaftlicher Behandlungen von 63,83\% wurde im Jahr 1995 mit der höchsten Befallshäufigkeit von $75,06 \%$ erreicht.

Bei einer nach Bundesländern getrennten Betrachtung der Versuchsdaten aus den Jahren 1991-2003 sind große Unterschiede in der Sclerotinia-Befallshäufigkeit sowie im Anteil wirtschaftlicher Behandlungen zu erkennen (Tab. 3.10). Entsprechend der Anbauintensität von Winterraps in den Bundesländern sind in Schleswig-Holstein mit 24,78\% und in Mecklenburg-Vorpommern mit 23,61\% die höchsten Befallshäufigkeiten im Mittel über die untersuchten Versuchsjahre aufzuweisen. Der Anteil wirtschaftlicher Fungizidbehandlungen war jedoch in den Bundesländern Niedersachsen mit 57,14\% und Sachsen mit 50,00\% deutlich höher als in Schleswig-Holstein und Mecklenburg-Vorpommern mit 36,62\% bzw. 35,29\%. Zwischen der SclerotiniaBefallshäufigkeit und dem Anteil wirtschaftlicher Fungizidapplikationen sind keine signifikanten Zusammenhänge zu beobachten. 


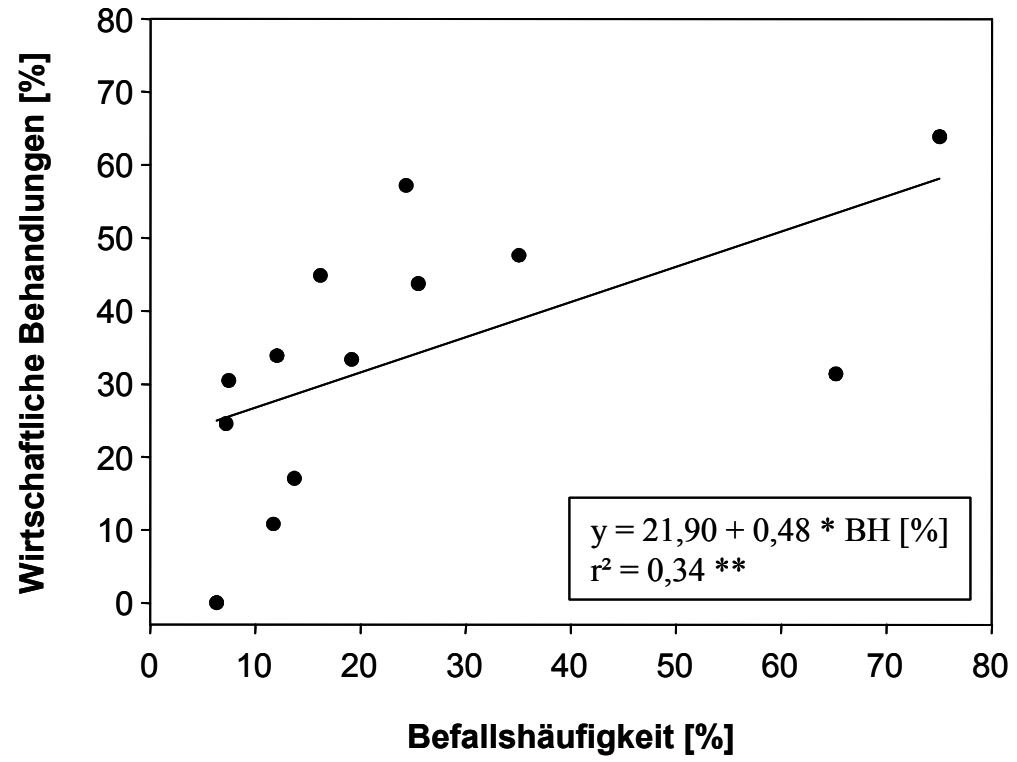

Abb. 3.19: Regression zwischen Sclerotinia-Befallshäufigkeit und Anteil wirtschaftlicher Fungizidbehandlungen zur Blüte in Winterraps in den Jahren 1991-2003. Basierend aus Daten aus den offiziellen Feldversuchen der Pflanzenschutzdienste der Länder. Die Signifikanz der Regression wurde mit dem Durbin-Watson-Test überprüft.

Tab. 3.10: Anteil wirtschaftlicher Fungizidbehandlungen zur Vollblüte in Winterraps zur Sclerotinia-Bekämpfung in den einzelnen Bundesländern. Basierend auf Daten aus den offiziellen Feldversuchen der Pflanzenschutzdienste der Länder.

\begin{tabular}{|c|c|c|c|c|}
\hline Bundesland & Zeitraum & $\begin{array}{c}\text { Anzahl } \\
\text { Versuche }\end{array}$ & $\begin{array}{c}\text { Befalls- } \\
\text { häufigkeit } \\
{[\%]}\end{array}$ & $\begin{array}{c}\text { Wirtschaftliche } \\
\text { Behandlungen* } \\
{[\%]}\end{array}$ \\
\hline Rheinland-Pfalz & $1998-2001$ & 6 & 2,70 & 16,67 \\
\hline Niedersachsen & $1991-2001$ & 7 & 10,29 & 57,14 \\
\hline Schleswig-Holstein & $1991-2003$ & 392 & 24,78 & 36,62 \\
\hline Sachsen & $1998-2003$ & 53 & 14,53 & 50,00 \\
\hline Thüringen & $2000-2003$ & 35 & 16,34 & 28,57 \\
\hline Brandenburg & $1998-2000$ & 40 & 8,43 & 10,71 \\
\hline Bayern & $2000-2002$ & 20 & 20,00 & 0,00 \\
\hline Mecklenburg-Vorpommern & $1991-2003$ & 42 & 23,61 & 35,29 \\
\hline
\end{tabular}

* Durchfahrtsverluste wurden mit 2,6\% angerechnet 


\subsection{Entwicklung ökonomischer Schadensschwellen für $S$. sclerotiorum in Winterraps}

Basierend auf den Ergebnissen der dreijährigen Feldversuche zum Einfluss des Befallszeitpunktes und der Wirtschaftlichkeitsuntersuchung der Jahre 1991 bis 2003 wurden ökonomische Schadensschwellen für S. sclerotiorum in Winterraps entwickelt (Tab. 3.11). Die Berechnung der zu tolerierenden Befallshäufigkeit wird nach der Formel

$$
\mathrm{y}=[(100-\mathrm{kM}[\%])-\mathrm{a}] / \mathrm{b}
$$

durchgeführt, wobei kM [\%] den kostendeckenden Mehrertrag, a den y-Achsenabschnitt (= Ertragsniveau ohne Befall) und $\mathrm{b}$ die Steigung der Regressionsgeraden (= Ertragsverlust pro 1\% Befallshäufigkeit) darstellt.

Der kostendeckende Mehrertrag (und damit die Gesamtkosten), die Ertragserwartung, die Rapssorte sowie der Infektionszeitpunkt beeinflussen die Höhe des zu tolerierenden Sclerotinia-Befalls. Mit steigender Ertragserwartung sinkt der zu tolerierende Befall, da der prozentuale kostendeckende Mehrertrag bei gleich bleibenden Kosten sinkt (Tab. 3.11).

Die statistische Auswertung der Regression zwischen Befallshäufigkeit und Ertrag zeigte sowohl zwischen den beiden Sortentypen als auch zwischen den beiden Infektionsterminen (BBCH 61-65 und $\mathrm{BBCH}$ 71) keine signifikanten Unterschiede (siehe Kap. 3.3.1). In der Schadensschwelle sind die Unterschiede zwischen den Sortentypen und den Infektionsterminen jedoch sehr hoch. Da die Liniensorte eine stärkere Ertragsreaktion auf einen Sclerotinia-Befall als die Hybridsorte zeigt, ist die Schadensschwelle für die Liniensorte mit ca. 10\% geringerem zu tolerierenden Befall deutlich geringer als die der Hybridsorte. Sowohl bei einem frühen als auch bei dem späten Inokulationstermin ist die wirtschaftliche Schadensschwelle der Hybridsorte um den Faktor 1,5-2,2 höher als die der Liniensorte. Mit steigender Ertragserwartung werden die Unterschiede zwischen den Sorten größer (Tab. 3.11).

Obwohl die Anfälligkeit zu BBCH 71 höher ist als zu BBCH 61-65 (siehe Tab. 3.2) ist die Ertragsreaktion geringer (siehe Abb. 3.3). Die geringere Ertragsreaktion auf eine spätere Infektion schlägt sich in der Schadensschwelle sehr deutlich nieder. Bei beiden Sortentypen liegt die Schadensschwelle der Spätinfektion zu BBCH 71 im Vergleich zu einer Infektion zu BBCH 61-65 um ca. 10\% höher. Innerhalb der Sorten sind bei der Hybridsorte um den Faktor 1,5-1,8 und bei der Liniensorte um den Faktor 1,8-2,4 
erhöhte wirtschaftliche Schadensschwellen nach Inokulationen zu BBCH 71 zu verzeichnen. Für eine Ertragserwartung von 30 bis $50 \mathrm{dt} / \mathrm{ha}$ schwankt die zu tolerierende Sclerotinia-Befallshäufigkeit bei einer frühen Infektion für die Liniensorte zwischen 16 bis 5\%, während bei einer späten Infektion die Schwankungsbreite zwischen 29 und 12\% liegt. Für die Hybridsorte liegt die Schadensschwelle bei einer Infektion zu BBCH 61-65 zwischen 25 und 13\% und bei einer Infektion zu BBCH 71 zwischen 37 und 23\% (Tab. 3.11).

Tab. 3.11: Ökonomische Schadensschwellen in Winterraps für Hybrid- und Liniensorte in Abhängigkeit von Ertragserwartung, kostendeckendem Mehrertrag und Infektionszeitpunkt, basierend auf Feldversuchen in den Jahren 2001/02-2003/04 in Göttingen-Weende, Standorte „Dragoneranger“, „Große Lage“ und „Große Breite“.

\begin{tabular}{|c|cc|cc|cc|}
\hline $\begin{array}{c}\text { Ertrags- } \\
\text { erwartung }\end{array}$ & \multicolumn{2}{|c|}{$\begin{array}{c}\text { Kostendeckender } \\
\text { Mehrertrag }\end{array}$} & \multicolumn{3}{|c|}{$\begin{array}{c}\text { Ökonomische Schadensschwelle [\% Befall] } \\
\text { Hybridsorte }\end{array}$} & \multicolumn{2}{c|}{ Liniensorte } \\
[dt/ha] & [dt/ha] & [\%] & BBCH 61-65 & BBCH 71 & BBCH 61-65 & BBCH 71 \\
\hline 30 & 3,32 & 11,07 & 25,25 & 37,24 & 15,81 & 28,63 \\
35 & 3,32 & 9,49 & 20,76 & 32,06 & 11,89 & 22,53 \\
40 & 3,32 & 8,30 & 17,40 & 28,17 & 8,96 & 17,96 \\
45 & 3,32 & 7,38 & 14,79 & 25,14 & 6,67 & 14,40 \\
50 & 3,32 & 6,64 & 12,69 & 22,72 & 4,84 & 11,56 \\
\hline
\end{tabular}

Die für die Praxis relevante Schadensschwelle ist die des frühen Infektionstermins zu BBCH 61-65, da aus technischen Gründen eine Behandlung zum Zeitpunkt der Schotenbildung in der Praxis nicht mehr möglich ist. Von Spätinfektionen zum Zeitpunkt der Schotenbildung wird in der Praxis nur vereinzelt berichtet. Wie die Ergebnisse der hier vorliegenden Arbeit zeigen, ist die Ertragswirkung der Spätinfektionen deutlich geringer als Infektionen zum Zeitpunkt der Blüte.

\subsection{Eingliederung der Schadensschwellen in das Prognosemodell SkleroPro}

Durch Eingliederung in das neue Prognosemodell SkleroPro (КоCH \& VON TIEDEMANN, 2005a, b) finden die erarbeiteten wirtschaftlichen Schadensschwellen eine praktische Anwendung. Die wirtschaftliche Schadensschwelle wurde nicht als feststehende Größe in das Modell integriert, sondern als Bestandteil einer Formel zur Berechnung eines Grenzwertes infektionsgünstiger Stunden, die für eine wirtschaftliche Fungizid- 
applikation erreicht werden muss. Für die Integration in das Modell SkleroPro wurde die wirtschaftliche Schadensschwelle der Hybridsorte des frühen Inokulationstermins gewählt.

Die Schwelle infektionsgünstiger Stunden wird nach folgenden Formeln berechnet:

Regression infg. Stunden-Befallshäufigkeit: BH [\%] $=4,76+0,21$ infg. Std.

Regression Befallshäufigkeit-Ertrag: Ertrag [\%] = 97,837 - 0,352659 * BH [\%]

Ertragserwartung E [dt/ha] = Eingabe durch Anwender

Mittelkosten $\mathrm{M}[€ / \mathrm{ha}]=$ Eingabe durch Anwender

Überfahrtkosten $U[€ /$ ha $]=$ Eingabe durch Anwender

Rapspreis $\mathrm{P}[€ / \mathrm{dt}]=$ Eingabe durch Anwender

Durchfahrtsverluste D $[€ /$ ha $]=E * 0,026 * \mathrm{P}$

Gesamtkosten $\mathrm{K}=\mathrm{M}+\mathrm{U}+\mathrm{D}$

kostendeckender Mehrertrag (kM) CCSY $[\mathrm{dt} / \mathrm{ha}]=\mathrm{K} / \mathrm{P}$

kostendeckender Mehrertrag $(\mathrm{kM}) \mathrm{CCSY}[\%]=\left[(\mathrm{K} / \mathrm{P})^{*} 100\right] / \mathrm{E}$

wirtschaftliche Schadensschwelle S [\%] = [(100-kM) - 97,837]/-0,352659

Schwellenwert infektionsgünstiger Stunden $\operatorname{Inh}_{\mathrm{i}}=(\mathrm{S}-4,76) / 0,21=$

$$
\operatorname{Inh}_{i}=\frac{\frac{2.2-C C S Y \cdot \frac{100}{E}}{-0.35}-4.76}{0.21}
$$

Die Angaben zu Ertragserwartung, Mittelkosten, Überfahrtkosten sowie der Rapspreis werden vom Anwender des Modells selbst eingegeben. Auf Basis dieser Angaben wird der kostendeckende Mehrertrag berechnet, so dass anwenderspezifische Schwellenwerte berechnet werden können.

\subsection{Befalls-Verlust-Relationen von $\boldsymbol{V}$. longisporum an Winterraps}

\subsubsection{Bodenbürtiges Inokulum von Verticillium spp. in Abhängigkeit von der ausgebrachten Inokulummenge}

Zur Untersuchung der Schadwirkung von $V$. longisporum wurden verschiedene Befallsstufen mit Hilfe einer künstlichen Inokulation eingestellt. Die Inokulation 
erfolgte über eine Bodenverseuchung mit unterschiedlichen Mengen natürlich befallenen Rapsstrohs. Zur Bestimmung des tatsächlich im Boden vorhandenen Inokulums an $V$. longisporum wurden im Versuchsjahr 2002/03 zu Vegetationsende im Oktober bzw. im Versuchsjahr 2003/04 zu Vegetationsbeginn Anfang April Bodenproben aus den unterschiedlich stark inokulierten Parzellen gezogen und auf ein Selektivmedium ausplattiert. Die Ergebnisse des Versuchsjahres 2003/04 wurden aus der Arbeit von KEUNECKE (2005) übernommen. In Abb. 3.20 sind die Ergebnisse dieser Untersuchung dargestellt.

Zwischen den beiden Versuchsjahren sind sehr große Unterschiede in der Menge des bodenbürtigen Verticillium-Inokulums zu erkennen. Im Versuchsjahr 2002/03 sind ca. 10 bis 12,5fach höhere cfu-Gehalte pro Gramm Boden nachgewiesen worden als im Versuchsjahr 2003/04.

In beiden Versuchsjahren wurde in den nicht inokulierten Kontrollparzellen die höchste Menge an bodenbürtigem Verticillium-Inokulum nachgewiesen. Zwischen den unterschiedlich stark inokulierten Parzellen schwanken die Mengen an VerticilliumInokulum nur schwach. Die unterschiedlichen Mengen an ausgebrachtem Inokulum spiegeln sich nicht in den nachgewiesenen Mengen an bodenbürtigem VerticilliumInokulum wider. Einen signifikanten Unterschied zwischen den verschiedenen Varianten gibt es lediglich im Versuchsjahr 2002/03 zwischen der Kontrollvariante und der mit $300 \mathrm{~g}$ Stroh am geringsten inokulierten Variante (Abb. 3.20).
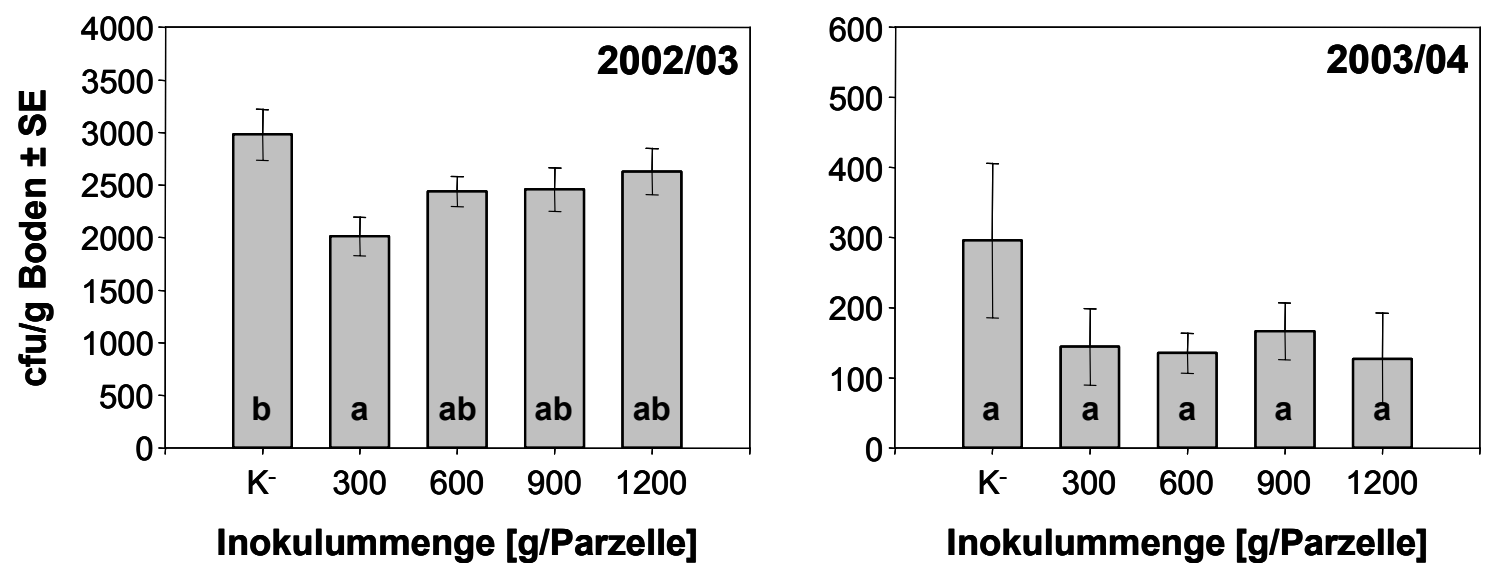

Abb. 3.20: Bodenbürtiges Verticillium-Inokulum auf den Versuchsflächen in den Jahren 2002/03 und 2003/04 nach künstlicher Bodenverseuchung mit unterschiedlichen Mengen Inokulum an den Standorten „Große Breite“ und „Große Lage“ in GöttingenWeende. Mittel über vier Wiederholungen pro Variante. Unterschiedliche Buchstaben kennzeichnen signifikante Unterschiede, $\mathrm{p} \leq 0,05$ (Tukey-Test). 


\subsubsection{Befallsparameter in Abhängigkeit von der ausgebrachten Inokulummenge}

Die Befallsparameter Befallsstärke und Befallshäufigkeit wurden durch eine Bonitur von 100 Stoppeln pro Parzelle nach der Ernte erfasst. Der Befallsindex ist ein Wert, der die Anzahl an Pflanzen mit den unterschiedlichen Boniturnoten darstellt.

Im Versuchsjahr 2002/03 waren die erzielten Befallshäufigkeiten in den inokulierten Parzellen mit im Mittel über vier Wiederholungen bis zu 54,15\% deutlich höher als im darauf folgenden Versuchsjahr mit nur bis zu 33,75\% Befallshäufigkeit (Tab. 3.12). Die höchste erzielte Befallshäufigkeit in einer Einzelparzelle im Versuchsjahr 2002/03 lag bei 70\%, während die höchste Befallshäufigkeit im folgenden Versuchsjahr 2003/04 lediglich bei rund $44 \%$ lag. Die mittlere Befallshäufigkeit in den nicht inokulierten Kontrollparzellen lag in beiden Jahren bei rund 10\% (Tab. 3.12). Die deutlich geringeren Befallshäufigkeiten in 2003/04 im Gegensatz zu 2002/03 spiegeln die Ergebnisse der Auswertung des bodenbürtigen Verticillium-Inokulums (siehe Kap. 3.8.1) wider.

Tab. 3.12: Befallshäufigkeit und Befallsindex nach künstlicher Inokulation von Winterraps in Relation zur ausgebrachten Inokulummenge in den Versuchsjahren 2002/03 (Sorte Prince) und 2003/04 (Sorte Wotan) an den Standorten „Große Breite“ und „Große Lage“ in Göttingen-Weende. Bonitur von 100 Stoppeln pro Parzelle, Mittel über vier Wiederholungen. Unterschiedliche Buchstaben kennzeichnen signifikante Unterschiede, $\mathrm{p} \leq 0,05$ (Tukey-Test).

\begin{tabular}{c|ccc|ccc}
\hline $\begin{array}{c}\text { Inokulum- } \\
\text { menge } \\
\text { [g/Parzelle] }\end{array}$ & \multicolumn{3}{|c|}{ Befallshäufigkeit \pm SE } & \multicolumn{3}{c}{ Befallsindex \pm SE } \\
\hline \multirow{2}{*}{ Kontrolle } & Mittelwert & $\mathbf{2 0 0 2 / 0 3}$ & $\mathbf{2 0 0 3 / 0 4}$ & Mittelwert & $\mathbf{2 0 0 2 / 0 3}$ & $\mathbf{2 0 0 3 / 0 4}$ \\
& 10,65 & 12,04 & 9,25 & 0,26 & 0,40 & 0,12 \\
& $\pm 2,0 \mathrm{a}$ & $\pm 3,9 \mathrm{a}$ & $\pm 1,3 \mathrm{a}$ & $\pm 0,07 \mathrm{a}$ & $\pm 0,10 \mathrm{a}$ & $\pm 0,02 \mathrm{a}$ \\
300 & 27,89 & 43,53 & 12,25 & 0,31 & 0,53 & 0,10 \\
& $\pm 6,8 \mathrm{ab}$ & $\pm 7,3 \mathrm{~b}$ & $\pm 1,4 \mathrm{ab}$ & $\pm 0,10 \mathrm{a}$ & $\pm 0,11 \mathrm{a}$ & $\pm 0,02 \mathrm{a}$ \\
600 & 30,17 & 38,10 & 22,25 & 0,25 & 0,40 & 0,11 \\
& $\pm 3,9 \mathrm{ab}$ & $\pm 3,1 \mathrm{~b}$ & $\pm 4,5 \mathrm{abc}$ & $\pm 0,06 \mathrm{a}$ & $\pm 0,02 \mathrm{a}$ & $\pm 0,04 \mathrm{a}$ \\
\multirow{3}{*}{900} & 40,95 & 54,15 & 27,75 & 0,16 & 0,20 & 0,12 \\
& $\pm 6,1 \mathrm{~b}$ & $\pm 4,8 \mathrm{~b}$ & $\pm 5,8 \mathrm{bc}$ & $\pm 0,05 \mathrm{a}$ & $\pm 0,11 \mathrm{a}$ & $\pm 0,02 \mathrm{a}$ \\
& 41,31 & 48,87 & 33,75 & 0,28 & 0,43 & 0,13 \\
& $\pm 4,9 \mathrm{~b}$ & $\pm 7,2 \mathrm{~b}$ & $\pm 4,7 \mathrm{c}$ & $\pm 0,06 \mathrm{a}$ & $\pm 0,04 \mathrm{a}$ & $\pm 0,05 \mathrm{a}$ \\
\hline
\end{tabular}

Im ersten Versuchsjahr 2002/03 zeichnete sich keine klare Steigerung der Befallshäufigkeit mit steigender Menge an ausgebrachtem Inokulum ab. Vielmehr bildeten sich drei Klassen, wobei die nicht inokulierte Kontrollparzelle die geringste 
Befallshäufigkeit aufwies und die erste Klasse bildete. Variante 2 und 3 mit 300 bzw. $600 \mathrm{~g}$ Inokulummenge bildeten eine Klasse mit ca. 40\% Befallshäufigkeit und Variante 4 und 5, mit 900 bzw. $1200 \mathrm{~g}$ Inokulummenge bildeten die dritte Klasse mit einer mittleren Befallshäufigkeit von ca. 50\%. Signifikante Unterschiede $(\mathrm{p} \leq 0,05)$ zwischen den Befallshäufigkeiten ließen sich lediglich zwischen der nicht inokulierten und den inokulierten Varianten absichern ( $\mathrm{p} \leq$ 0,05). Im folgenden Versuchsjahr 2003/04 zeigte sich eine zunehmende Befallshäufigkeit mit steigender Inokulummenge mit zum Teil signifikant unterschiedlichen mittleren Befallshäufigkeiten in den verschiedenen Varianten (Tab. 3.12).

Der Befallsindex zeigt vergleichbar mit der Befallshäufigkeit deutlich höhere Werte im ersten als im zweiten Versuchsjahr (Tab. 3.12). Im Versuchsjahr 2002/03 schwankten die Werte zwischen 0,20 und 0,53, während sie im Versuchsjahr 2003/04 nur noch Werte von 0,05 bis 0,13 annahmen. In beiden Versuchsjahren konnten keine signifikanten Unterschiede zwischen den Varianten beobachtet werden $(\mathrm{p} \leq 0,05)$.

Bei der Verticillium-Bonitur im Labor wurden der äußere Befall des Haupttriebes, der Befall im Stängelmark sowie der Befall der Wurzel getrennt voneinander erfasst (Tab. 3.13). Die Befallshäufigkeit der Gesamtpflanze gibt an, wie viele Pflanzen pro Parzelle in wenigstens einem der bonitierten Pflanzenteile einen Befall aufwiesen.

Tab. 3.13: Verticillium-Befallshäufigkeit an Winterraps in Abhängigkeit von der ausgebrachten Inokulummenge, unterteilt nach Befall am Haupttrieb, im Stängelmark und in der Wurzel befallener Pflanzen. Daten aus den Versuchsjahren 2002/03 und 2003/04 am Standort Göttingen-Weende. Mittelwerte über vier Wiederholungen. Unterschiedliche Buchstaben kennzeichnen signifikante Unterschiede, $\mathrm{p} \leq 0,05$ (TukeyTest).

\begin{tabular}{|c|c|c|c|c|c|c|c|c|}
\hline \multirow{3}{*}{$\begin{array}{c}\text { Inokulum- } \\
\text { menge } \\
\text { [g/Parzelle] }\end{array}$} & \multirow{2}{*}{\multicolumn{2}{|c|}{$\begin{array}{c}\text { Befalls- } \\
\text { häufigkeit [\%] }\end{array}$}} & \multicolumn{6}{|c|}{$\begin{array}{c}\text { Anteil befallener Pflanzenteile [\%] } \\
\text { in befallenen Pflanzen }\end{array}$} \\
\hline & & & \multicolumn{2}{|c|}{ Haupttrieb } & \multicolumn{2}{|c|}{ Stängelmark } & \multicolumn{2}{|c|}{ Wurzel } \\
\hline & $02 / 03$ & 03/04 & $02 / 03$ & $03 / 04$ & $02 / 03$ & 03/04 & $02 / 03$ & 03/04 \\
\hline Kontrolle & 12,0 & 9,3 & 51,72 & 71,67 & 41,93 & 68,06 & 63,13 & 66,11 \\
\hline 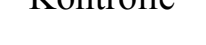 & $\mathrm{a}$ & $\mathrm{a}$ & $\mathrm{a}$ & $\mathrm{a}$ & $\mathrm{a}$ & $\mathrm{a}$ & $\mathrm{a}$ & $\mathrm{a}$ \\
\hline 300 & $\begin{array}{c}43,5 \\
b\end{array}$ & $\begin{array}{c}12,3 \\
\mathrm{ab}\end{array}$ & $\begin{array}{c}54,75 \\
\mathrm{a}\end{array}$ & $\begin{array}{c}89,01 \\
\text { b }\end{array}$ & $\begin{array}{c}44,59 \\
\mathrm{a}\end{array}$ & $\begin{array}{l}95,00 \\
\text { a }\end{array}$ & $\begin{array}{c}70,86 \\
\mathrm{a}\end{array}$ & $\begin{array}{c}79,13 \\
\mathrm{a}\end{array}$ \\
\hline 600 & $\begin{array}{c}38,1 \\
\mathrm{~b}\end{array}$ & $\begin{array}{c}22,3 \\
a b c\end{array}$ & $\begin{array}{c}53,02 \\
\mathrm{a}\end{array}$ & $\begin{array}{c}84,88 \\
\mathrm{ab}\end{array}$ & $\begin{array}{c}57,09 \\
\mathrm{a}\end{array}$ & $\begin{array}{l}85,91 \\
\mathrm{a}\end{array}$ & $\begin{array}{l}67,81 \\
\mathrm{a}\end{array}$ & $\begin{array}{c}68,25 \\
\mathrm{a}\end{array}$ \\
\hline 900 & $\begin{array}{c}54,2 \\
\mathrm{~b}\end{array}$ & $\begin{array}{c}27,8 \\
b c\end{array}$ & $\begin{array}{c}58,87 \\
\mathrm{a}\end{array}$ & $\begin{array}{c}82,49 \\
\mathrm{ab}\end{array}$ & $\begin{array}{c}60,29 \\
\mathrm{a}\end{array}$ & $\begin{array}{l}89,42 \\
\text { a }\end{array}$ & $\begin{array}{c}62,65 \\
\mathrm{a}\end{array}$ & $\begin{array}{c}78,01 \\
\mathrm{a}\end{array}$ \\
\hline 1200 & $\begin{array}{c}48,9 \\
\mathrm{~b}\end{array}$ & $\begin{array}{c}33,8 \\
\mathrm{c}\end{array}$ & $\begin{array}{c}64,31 \\
\mathrm{a}\end{array}$ & $\begin{array}{l}82,75 \\
\mathrm{ab}\end{array}$ & $\begin{array}{c}66,14 \\
\mathrm{a}\end{array}$ & $\begin{array}{l}86,73 \\
\mathrm{a}\end{array}$ & $\begin{array}{c}66,66 \\
\mathrm{a}\end{array}$ & $\begin{array}{c}78,41 \\
\mathrm{a}\end{array}$ \\
\hline
\end{tabular}


Im Versuchsjahr 2002/03 war der Anteil befallener Wurzeln in allen Varianten höher als der Anteil befallener Haupttriebe oder befallenen Stängelmarks. Mit ansteigender Inokulummenge zeigte sich jedoch für keinen Pflanzenteil eine signifikante Steigerung des Anteils befallener Pflanzenteile ( $\mathrm{p} \leq 0,05)$. Während der Anteil befallener Wurzeln auf einem relativ gleich bleibenden Niveau blieb, war für den Anteil befallener Haupttriebe und befallenen Stängelmarks eine ansteigende Tendenz ab der dritten bzw. zweiten Inokulationsstufe zu erkennen. Im folgenden Versuchsjahr 2003/04 war im Gegensatz zum Jahr 2002/03 der Anteil befallener Wurzeln geringer als der Anteil befallener Haupttriebe und befallenen Stängelmarks. Der Anteil befallener Pflanzenteile stieg von der Kontrolle zur ersten Inokulationsstufe relativ stark an, jedoch ließ sich lediglich für den Haupttrieb die Zunahme statistisch absichern $(p \leq 0,05)$ (Tab. 3.13).

Tab. 3.14: Befallsstärke von $V$. longisporum an Winterraps. Anteil Pflanzen in den unterschiedlichen Boniturklassen in Relation zur ausgebrachten Inokulummenge in den Versuchsjahren 2002/03 und 2003/04 am Standort Göttingen-Weende. Mittelwert über vier Wiederholungen. Unterschiedliche Buchstaben kennzeichnen signifikante Unterschiede innerhalb eines Versuchsjahres, $p \leq 0,05$ (Tukey-Test).

\begin{tabular}{|c|c|c|c|c|c|c|}
\hline \multirow{3}{*}{$\begin{array}{c}\text { Inokulum- } \\
\text { menge } \\
\text { [g/Parzelle] }\end{array}$} & \multicolumn{6}{|c|}{ Anteil Pflanzen [\%] } \\
\hline & \multicolumn{3}{|c|}{ 2002/03 } & \multicolumn{3}{|c|}{$2003 / 04$} \\
\hline & BN 0 & BN 1 & BN 2 & BN 0 & BN 1 & BN 2 \\
\hline Kontrolle & $94,95 \mathrm{f}$ & $4,29 a$ & $0,76 \mathrm{a}$ & $96,50 \mathrm{e}$ & $2,50 \mathrm{ab}$ & $1,00 \mathrm{a}$ \\
\hline 300 & $72,47 \mathrm{e}$ & $24,34 \mathrm{bcd}$ & $3,19 \mathrm{a}$ & $94,25 \mathrm{de}$ & $2,75 \mathrm{ab}$ & $3,00 \mathrm{ab}$ \\
\hline 600 & $72,60 \mathrm{e}$ & $19,84 \mathrm{abcd}$ & $7,55 \mathrm{ab}$ & $91,50 \mathrm{cde}$ & $4,25 \mathrm{ab}$ & $4,25 \mathrm{ab}$ \\
\hline 900 & $63,09 \mathrm{e}$ & $30,29 \mathrm{~d}$ & $6,61 \mathrm{ab}$ & $88,50 \mathrm{c}$ & $7,00 \mathrm{~b}$ & $4,50 \mathrm{ab}$ \\
\hline 1200 & $63,02 \mathrm{e}$ & $27,22 \mathrm{~cd}$ & $9,76 a b c$ & $89,75 \mathrm{~cd}$ & $5,00 \mathrm{ab}$ & $5,25 \mathrm{ab}$ \\
\hline
\end{tabular}

Boniturklassen: BN $0=$ kein Befall, BN $1=$ geringer Besatz mit Mikrosklerotien, BN $2=$ starker Besatz mit Mikrosklerotien.

Die Verteilung der Pflanzen auf die verschiedenen Boniturklassen in Abhängigkeit von der ausgebrachten Inokulummenge ist in Tabelle 3.14 aufgeführt. Der größte Anteil der Pflanzen wies keinen Besatz mit Mikrosklerotien auf. Der Anteil an stark befallenen Pflanzen (BN 2) war in beiden Versuchsjahren nur sehr gering. In beiden Versuchsjahren konnte mit zunehmender Menge an ausgebrachtem Inokulum, entsprechend der ansteigenden Befallshäufigkeit, ein ansteigender Anteil an Pflanzen mit geringem und starkem Besatz mit Mikrosklerotien beobachtet werden. Die Zunahme an Pflanzen mit 
geringem Besatz mit Mikrosklerotien war dabei stärker als die Zunahme an Pflanzen mit starkem Besatz mit Mikrosklerotien (Tab. 3.14).

\subsubsection{Einfluss von $V$. longisporum auf Ertrag und Qualität des Erntegutes}

Um die Schadwirkung von $V$. longisporum zu erfassen, wurde der Ertrag jeder einzelnen Parzelle erfasst und relativ zur nicht inokulierten Kontrolle dargestellt (Abb. 3.21). In beiden Versuchsjahren konnte keine statistisch abzusichernde Ertragsminderung im Mittel über die vier Wiederholungen einer Variante erzielt werden ( $\mathrm{p} \leq$ 0,05). Auch die Auswertung der Einzelparzellen ergab keine signifikante Regression zwischen Befallshäufigkeit und Ertrag bzw. zwischen Befallsindex und Ertrag (Anhang, Abb. A2).

Während im Versuchsjahr 2002/03 ein tendenziell geringerer Ertrag bei höherer Befallshäufigkeit zu verzeichnen war, war im Versuchsjahr 2003/04 der Ertrag in der nicht inokulierten Kontrolle geringer als in den inokulierten Varianten.
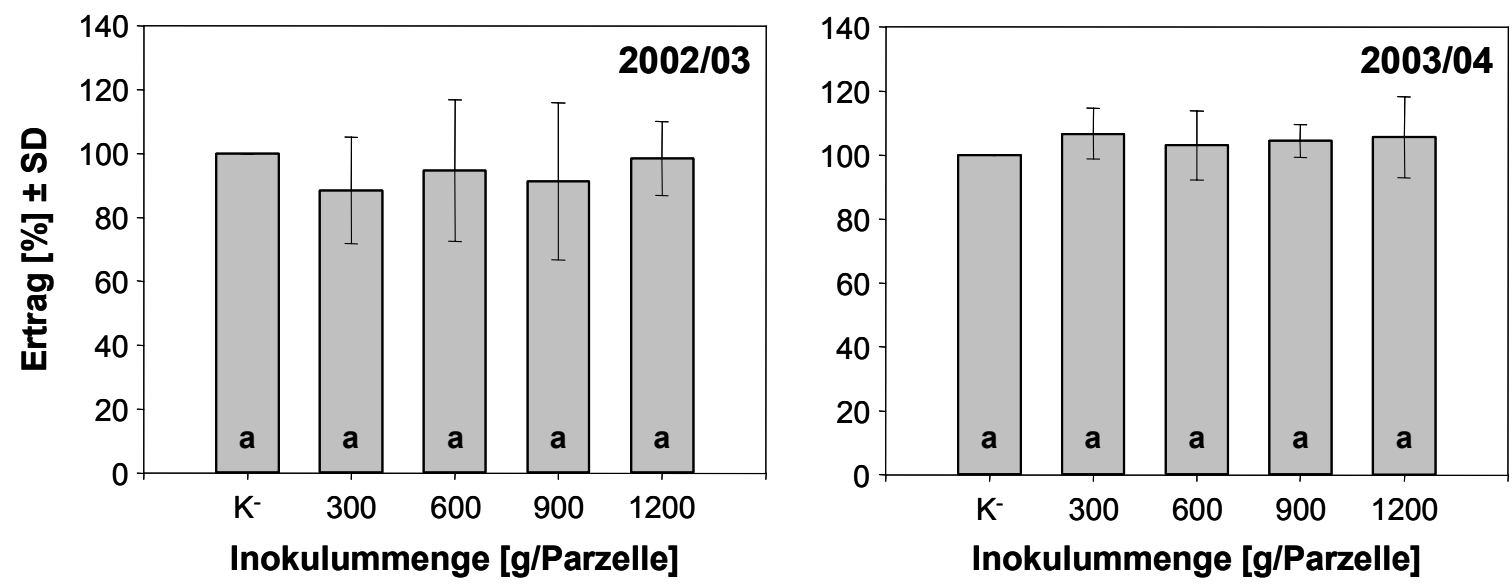

Abb. 3.21: Ertrag der unterschiedlichen Varianten im Vergleich zur Kontrolle in den Jahren 2002/03 und 2003/04 am Standort „Große Breite“ und „Große Lage“, GöttingenWeende. Mittel über vier Wiederholungen. Ertragsniveau in Kontrollen: 2002/03: 40,26 $\mathrm{dt} / \mathrm{ha}$; 2003/04: 40,57 dt/ha. Unterschiedliche Buchstaben kennzeichnen signifikante Unterschiede, $\mathrm{p} \leq 0,05$ (Tukey-Test). 

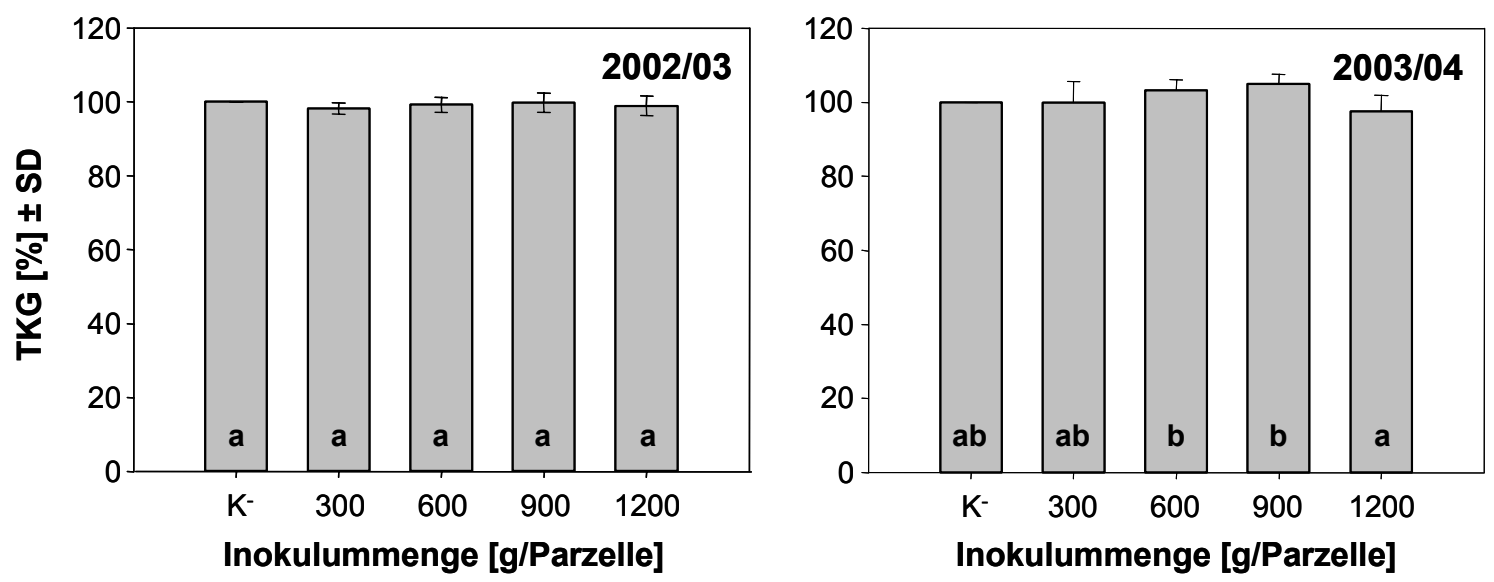

Abb. 3.22: TKG der unterschiedlichen Varianten im Vergleich zur Kontrolle in den Jahren 2002/03 und 2003/04 an den Standorten „Große Breite“ und „Große Lage“, Göttingen-Weende. Mittel über vier Wiederholungen. Unterschiedliche Buchstaben kennzeichnen signifikante Unterschiede, $\mathrm{p} \leq 0,05$ (Tukey-Test). TKG in Kontrollparzellen: 2002/03: 3,76 g, 2003/04: 4,47 g.

Neben dem Ertrag wurden die Qualitätsparameter TKG und Ölgehalt des Erntegutes untersucht. In beiden Versuchsjahren konnte keine signifikante Reduktion des TKG im Vergleich zur nicht inokulierten Kontrolle beobachtet werden ( $\leq \leq 0,05)$ (Abb. 3.22). Im Versuchsjahr 2003/04 wies die mit 1200 g Inokulummaterial am stärksten inokulierte Variante ein signifikant geringeres TKG als die mit $600 \mathrm{~g}$ und $900 \mathrm{~g}$ inokulierten Varianten auf.
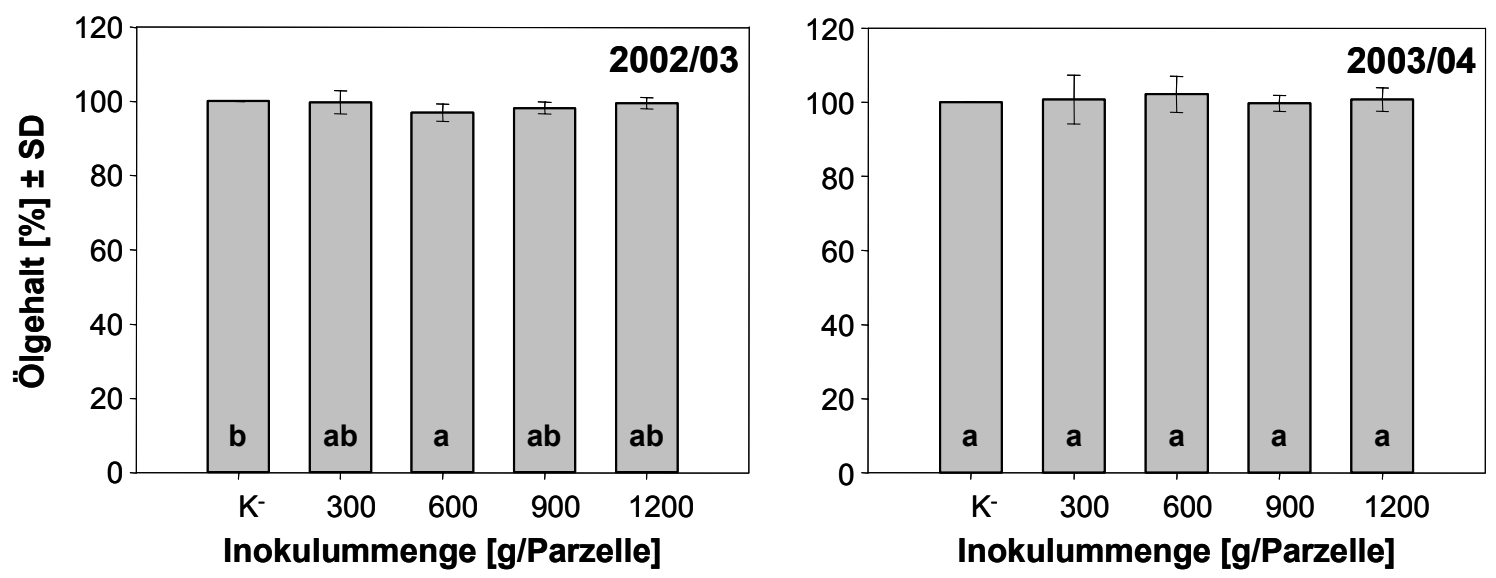

Abb. 3.23: Relativer Ölgehalt der unterschiedlichen Varianten im Vergleich zur Kontrolle in den Jahren 2002/03 und 2003/04 an den Standorten „Große Breite“ und „Große Lage“, Göttingen-Weende. Mittel über vier Wiederholungen. Unterschiedliche Buchstaben kennzeichnen signifikante Unterschiede, $\mathrm{p} \leq 0,05$ (Tukey-Test). Ölgehalt in Kontrollparzellen: 2002/03: 42,49\%. 2003/04: 44,58\%. 
Auch die Untersuchung des Ölgehaltes des Erntegutes zeigte keinen mindernden Einfluss einer Verticillium-Infektion auf den Ölgehalt auf. Lediglich im Versuchsjahr 2002/03 wies die Variante 3 (600 g Inokulummaterial) einen signifikant ( $\leq \leq 0,05)$ geringeren Ölgehalt als die nicht inokulierte Kontrollparzelle auf (Abb. 3.23).

Auch die Regressionen zwischen TKG bzw. Ölgehalt der Einzelparzellen und Befallshäufigkeit bzw. Befallsindex wiesen keinen signifikanten Zusammenhang auf (Anhang, Abb. A3 und A4).

\subsection{Befallsverlauf von $V$. longisporum in Winterraps im Feld}

Zur Untersuchung der Ausbreitungsdynamik und des Befallsverlaufes von V. longisporum in der Pflanze wurden regelmäßig im Verlauf der Vegetation Pflanzenproben aus den unterschiedlich stark inokulierten Parzellen entnommen. Nach Aufbereitung der Pflanzenproben (siehe Kapitel 2.10.1) wurden die Pflanzen getrennt nach Wurzel und Stängel mit dem ELISA auf Befall mit $V$. longisporum untersucht.

In Abb. 3.24 ist die Ausbreitungsdynamik von $V$. longisporum als Mittel über die Versuchsjahre 2002/03 und 2003/04 dargestellt. Vor Winter konnte weder im Wurzelmaterial noch im Stängelmaterial $V$. longisporum mit dem ELISA nachgewiesen werden. $\mathrm{Zu}$ Vegetationsbeginn im Frühjahr konnten sehr geringe Pilzkonzentrationen in Wurzelmaterial aus allen drei untersuchten Parzellen detektiert werden. Zu BBCH 70 ist der Pilz vereinzelt im Stängelmaterial nachweisbar. Mit Beginn der Abreife (BBCH 83) ist sowohl im Stängel- als auch im Wurzelmaterial eine deutliche Besiedelung durch $V$. longisporum zu detektieren. Die Unterschiede in der Pilzkonzentration zwischen Stängel- und Wurzelmaterial sind nur sehr gering. In Pflanzenmaterial aus den Kontrollparzellen und der am geringsten inokulierten Parzelle ist weniger Pilzmaterial in der Wurzel als im Stängel nachzuweisen, während in Pflanzenproben aus der am höchsten inokulierten Parzelle im Wurzelmaterial geringfügig mehr Pilzmaterial nachzuweisen ist. Zum letzten Probenahmetermin direkt vor der Ernte (BBCH 89) ist ein deutlicher Anstieg der Pilzkonzentration in Stängeln sowie in Wurzeln in Proben aus den inokulierten Parzellen zu verzeichnen. Die nachgewiesenen Pilzkonzentrationen in Pflanzen aus der nicht inokulierten Kontrollparzelle sind vom Probenahmetermin zu Beginn der Abreife (BBCH 83) bis zum Termin zur Ernte (BBCH 89) nicht weiter angestiegen. $\mathrm{Zu}$ dem letzten Probenahmetermin ist eine deutliche Abstufung der 
unterschiedlich stark inokulierten Parzellen zu erkennen. In Pflanzenproben aus der am höchsten inokulierten Parzelle konnten deutlich höhere Pilzkonzentrationen detektiert werden als in Pflanzen der geringsten Inokulationsstufe und aus der Kontrollparzelle.

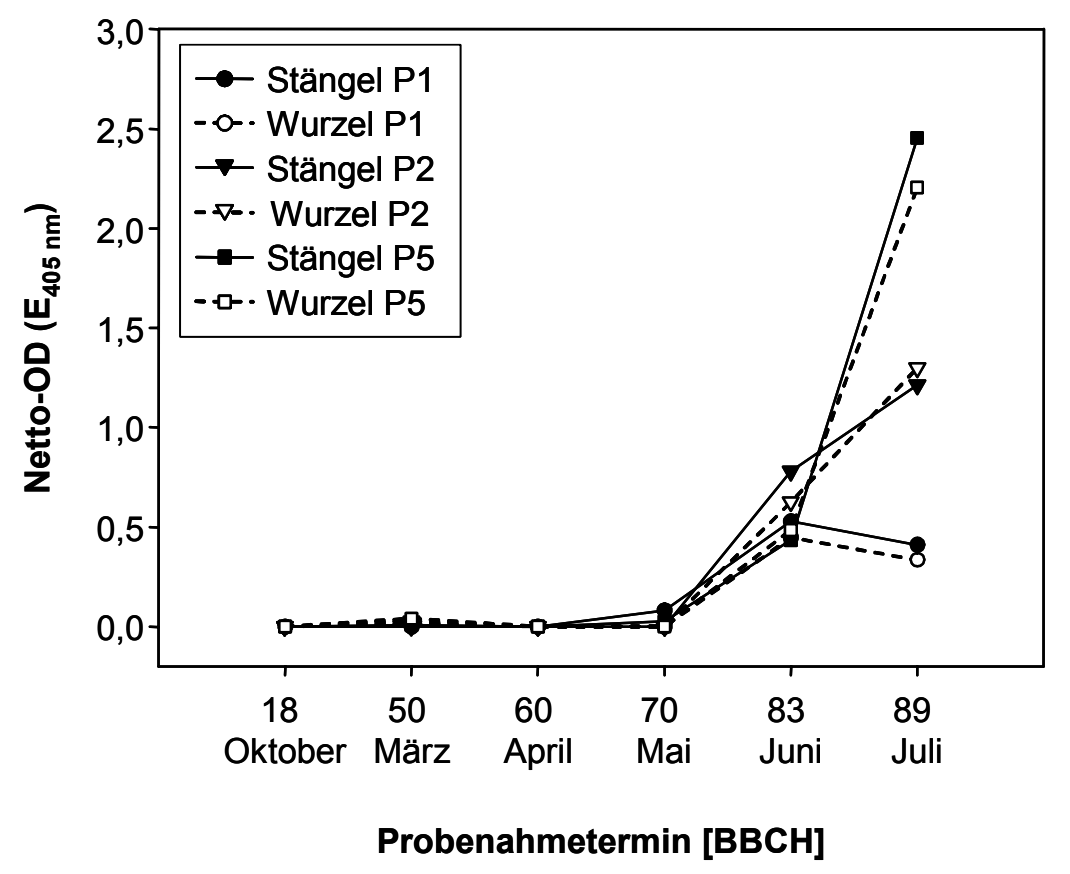

Abb. 3.24: Nachweis von $V$. longisporum in Stängel- und Wurzelmaterial von Winterraps (Sorte Prince und Wotan) im Verlauf der Vegetation mit Hilfe des ELISA. Mittel über je 5 Pflanzen aus den Jahren 2002/03 und 2003/04. Varianten: P1 = Kontrolle, P2 = $300 \mathrm{~g}$ Inokulum, P5 = $1200 \mathrm{~g}$ Inokulum/Parzelle.

Vergleicht man die beiden Versuchsjahre miteinander, so sind neben den unterschiedlichen Befallshäufigkeiten auch Unterschiede in der Ausbreitungsdynamik des Pilzes in der Pflanze im Verlauf der Vegetationsperiode zu erkennen (Abb. 3.25). In beiden Versuchsjahren konnte erst zu Vegetationsbeginn im März ein Befall der Pflanzen mit $V$. longisporum mit dem ELISA nachgewiesen werden. Während im ersten Versuchsjahr zu BBCH 50 lediglich in Pflanzen aus der hoch inokulierten Parzelle ein $V$. longisporum-Befall festgestellt werden konnte, wiesen im zweiten Versuchsjahr Pflanzen aus allen drei untersuchten Parzellen V. longisporum-Befall auf. Die weitere Befallsentwicklung scheint im Versuchsjahr 2003/04 im Vergleich zu dem vorhergehenden Jahr jedoch etwas verlangsamt. Während im Mai zu BBCH 70 im Versuchsjahr 2002/03 sowohl im Stängel- als auch im Wurzelmaterial ein Befall mit V. longisporum mittels ELISA detektiert werden konnte, ist im Versuchsjahr 2003/04 erst zum nachfolgenden Termin (BBCH 83) ein deutlicher Befall nachzuweisen. Zum 
letzten Probenahmetermin vor der Ernte $(\mathrm{BBCH} 89)$ ist in beiden Versuchsjahren ein Anstieg in der Pilzkonzentration im Wurzel- und Stängelmaterial zu sehen. Eine Ausnahme hiervon stellt das Versuchsjahr 2002/03 mit der nicht inokulierten Kontrollvariante dar. In dieser Variante sinkt die $V$. longisporum-Konzentration in Wurzel- und Stängelmaterial im Zeitraum von BBCH $83 \mathrm{zu}$ BBCH 89 auf ein geringeres Niveau ab. Die Ursache hierfür kann jedoch in der Auswahl der untersuchten Pflanzen liegen. Die beiden inokulierten Varianten $(2=300 \mathrm{~g}$ Inokulum und $5=1200 \mathrm{~g}$ Inokulum) weisen deutlich höhere Pilzkonzentrationen als Pflanzen aus der Kontrollvariante auf.
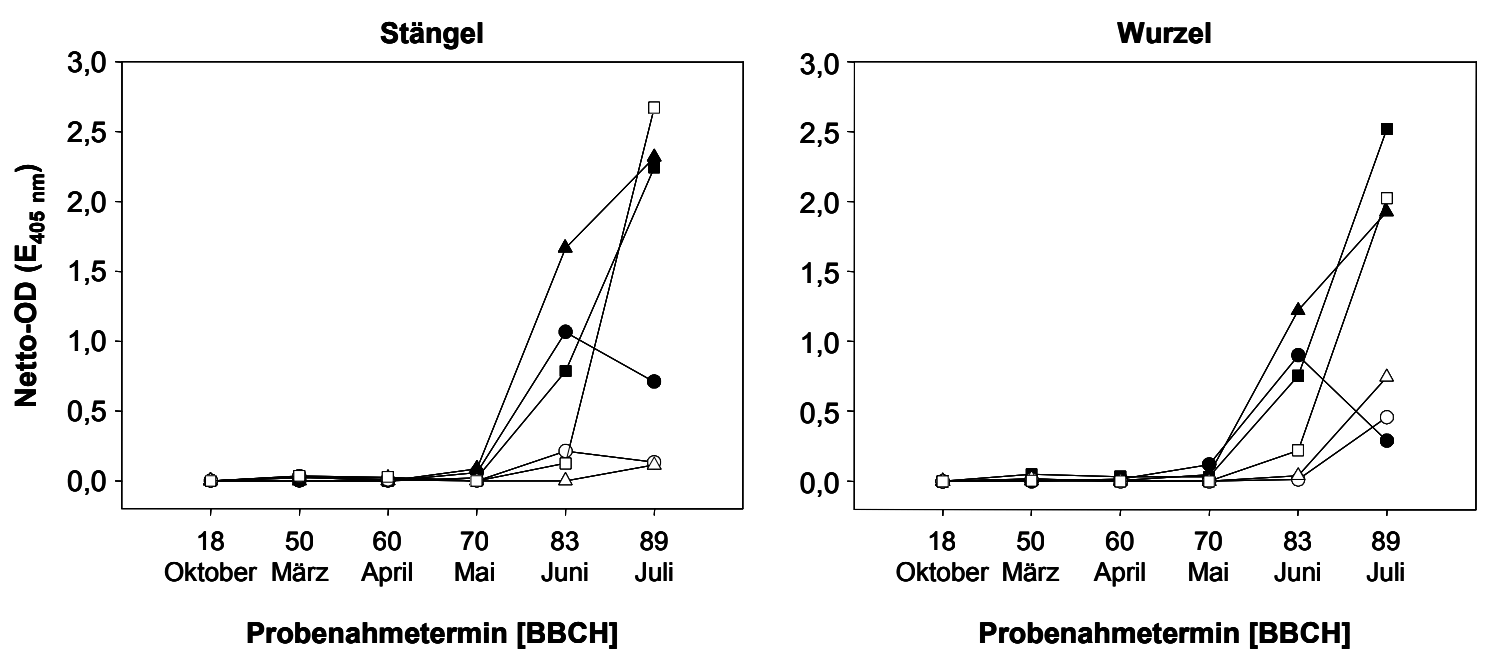

$$
\begin{array}{lll}
\multimap \text { P1 } 2003 & - \text { P2 } 2003 & \longrightarrow \text { P5 } 2003 \\
\multimap \text { P1 } 2004 & - \text { P2 } 2004 & \square \text { P5 } 2004
\end{array}
$$

Abb. 3.25: Entwicklung des Verticillium-Befalls in Stängel und Wurzel von Winterraps im Verlauf der Vegetation nach Detektion mit dem ELISA in den Versuchsjahren 2002/03 (Sorte Prince) und 2003/04 (Sorte Wotan) an den Standorten „Große Breite“ und „Große Lage“ in Göttingen-Weende. (P1: Kontrollparzelle, P2: 300 g Inokulum, P5: $1200 \mathrm{~g}$ Inokulum/Parzelle).

Während im Stängelmaterial in beiden Varianten etwa dieselbe $V$. longisporumKonzentration nachgewiesen wurde, ist im Wurzelmaterial eine deutlich höhere Pilzkonzentration in Pflanzen aus der hoch inokulierten Variante $5 \mathrm{zu}$ finden. Die Unterschiede zwischen der $V$. longisporum-Konzentration in Wurzel- und Stängelmaterial liegen im Versuchsjahr 2002/03 im Mittel über die drei Varianten bei 0,36. Im Versuchsjahr 2003/04 liegt die Pilzkonzentration in der hoch inokulierten Variante 5 auf demselben Niveau wie im vorhergehenden Versuchsjahr. In der Kontrollvariante und 
der gering inokulierten Variante 2 sind nur sehr geringe $V$. longisporumKonzentrationen im Stängelmaterial nachzuweisen. Im Wurzelmaterial ist der Unterschied zwischen diesen beiden Varianten ebenfalls sehr gering, die Pilzkonzentration liegt jedoch auf einem höheren Niveau als im Stängelmaterial. Insgesamt liegt der Unterschied in der Pilzkonzentration zwischen Wurzel- und Stängelmaterial im Mittel über die drei untersuchten Varianten bei 0,54 und ist damit höher als im vorhergehenden Versuchsjahr.

Betrachtet man den Zusammenhang zwischen bonitierter Befallshäufigkeit in Wurzelbzw. Stängelmaterial und den Ergebnissen des ELISA-Tests (Abb. 3.26) lässt sich eine positive Korrelation zwischen diesen beiden Parametern erkennen. Mit steigender Befallshäufigkeit ist eine steigende, im ELISA gemessene Netto-OD zu verzeichnen. Für das Stängelmaterial ist mit 0,07 ein stärkerer Anstieg der Netto-OD mit steigender Befallshäufigkeit zu verzeichnen als für Wurzelmaterial mit 0,04, jedoch ist dieser Unterschied statistisch nicht abzusichern.

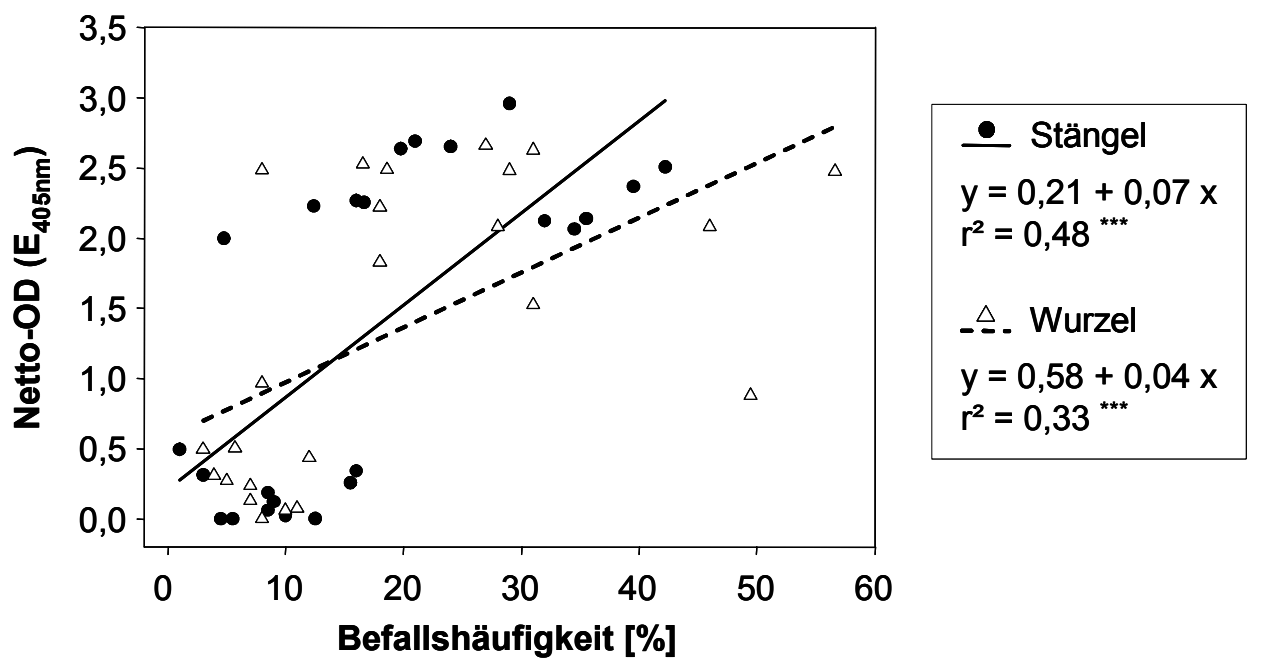

\begin{abstract}
Abb. 3.26: Regression zwischen bonitierter Befallshäufigkeit und Netto-OD, gemessen mit dem ELISA, in Wurzel- und Stängelmaterial von Winterraps. Daten aus nicht inokulierten Kontrollparzellen und Parzellen inokuliert mit 300 g bzw. 1200 g Inokulum/Parzelle in den Versuchsjahren 2002/03 und 2003/04 an den Standorten „Große Breite“ und „Große Lage“ in Göttingen-Weende. Die Signifikanz der Regression wurde mit dem Durbin-Watson-Test überprüft.
\end{abstract}

Zwischen Relativertrag und im ELISA gemessener Netto-OD ist eine negative Korrelation zu beobachten (Abb. 3.27). Die Ertragsminderung bei steigender Netto-OD 
in Wurzel- oder Stängelmaterial ist jedoch nur sehr gering und lässt sich statistisch nicht absichern.

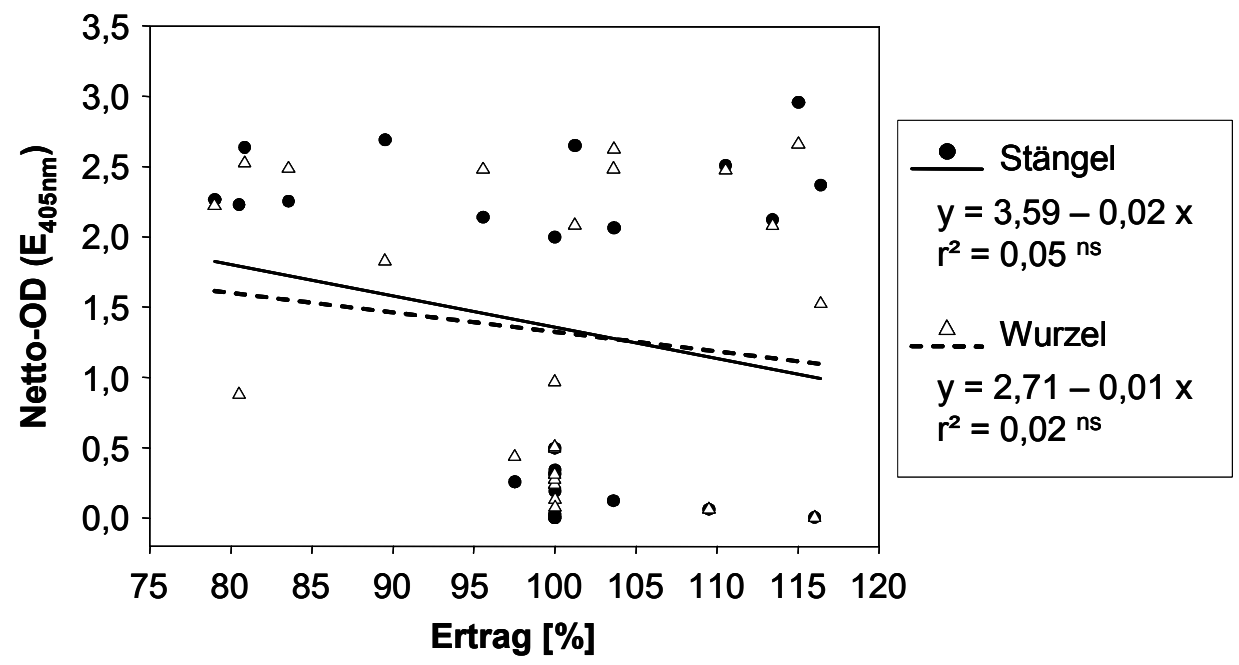

\begin{abstract}
Abb. 3.27: Regression zwischen Relativertrag und Netto-OD, gemessen mit dem ELISA, in Wurzel- und Stängelmaterial von Winterraps. Daten aus nicht inokulierten Kontrollparzellen und Parzellen inokuliert mit 300 g bzw. 1200 g Inokulum/Parzelle in den Versuchsjahren 2002/03 und 2003/04 an den Standorten „Große Breite“ und „Große Lage“ in Göttingen-Weende. Die Signifikanz der Regression wurde mit dem Durbin-Watson-Test überprüft.
\end{abstract}

\title{
3.10 In vitro-Nachweis von $V$. longisporum mittels artspezifischer PCR
}

\subsubsection{Herstellung von DNA-Sonden}

Für die Herstellung artspezifischer DNA-Sonden für $V$. longisporum, wurde GesamtDNA von $V$. longisporum und $V$. dahliae in RAPD-Analysen und in verschiedenen PCR-fingerprintings (VNTR, ERIC, BOX) eingesetzt. Nach elektrophoretischer Auftrennung der amplifizierten Fragmente wurden Banden aus dem Gel extrahiert, die spezifisch nur bei $V$. longisporum auftraten.

Insgesamt konnten 23 distinkte Banden präpariert werden. Basierend auf einer PCR mit VNTR-Primern konnten fünf Fragmente extrahiert werden, aus der PCR mit dem RAPD-Primer OPA-13 gingen sechs, aus der PCR mit dem RAPD-Primer A-06 vier, aus der PCR mit den BOX-Primern fünf und aus der PCR mit den ERIC-Primern drei Fragmente hervor. Aufgrund einer zu geringen DNA-Konzentration der extrahierten DNA-Fragmente wurden die DNA-Proben einer Reamplifikation mit den 
entsprechenden Primern unterzogen. Insgesamt neun Proben wiesen nach der Reamplifikation nur eine einzelne Bande auf und wurden im Weiteren für die Klonierung und anschließende Sequenzierung weitergeführt (VNTR: 2, RAPD OPA-13: 1, RAPD A-06: 1, BOX: 3, ERIC: 2 Fragmente).

\subsubsection{Spezifität der DNA-Sonden}

Die Spezifität der Sonden für $V$. longisporum wurde mit Hilfe einer SouthernHybridisierung überprüft. Verdaute Gesamt-DNA von V. longisporum V1 40 und V. dahliae Vd 3 wurden geblottet und mit den DIG-dUTP-markierten Sonden hybridisiert.

Von den insgesamt neun untersuchten Sonden gingen lediglich zwei für $V$. longisporum artspezifische Sonden hervor (Tab. 3.15). Die artspezifischen Sonden waren pV1O2/3-6, welche aus den PCR-fingerprintings mit dem RAPD-Primer Paar OPA-13 hervorging, sowie die Sonde pVlE5-23, welche aus der PCR-fingerprinting mit den ERIC Primern hervorging.

Tab. 3.15: Sondeneigenschaften und Hybridisierungsmuster mit der HindIII gespaltenen Gesamt-DNA von $V$. longisporum und $V$. dahliae.

\begin{tabular}{|c|c|c|c|c|}
\hline \multirow{2}{*}{ Primergrundlage } & \multirow{2}{*}{ Sonde } & \multirow{2}{*}{$\begin{array}{c}\text { Länge }^{a} \\
\text { [bp] }\end{array}$} & \multicolumn{2}{|c|}{ Hybridisierung mit } \\
\hline & & & VI 40 & Vd 3 \\
\hline RAPD OPA-13 & $\mathrm{pV} 1 \mathrm{O} 2 / 3-6$ & 665 & + & - \\
\hline RAPD A-06 & pV1A2-13 & 446 & + & + \\
\hline \multirow{2}{*}{ ERIC } & pVlE3/4-22 & k.E. & + & + \\
\hline & pVlE5-23 & 179 & + & - \\
\hline \multirow{2}{*}{ VNTR } & pVlV1-1 & 523 & + & + \\
\hline & $\mathrm{pVIV3/4-2}$ & k.E. & + & + \\
\hline \multirow{3}{*}{$\mathrm{BOX}$} & $\mathrm{pVlB} 1 / 2-17$ & k.E. & + & + \\
\hline & $\mathrm{pVlB} 3 / 4-18$ & 167 & + & + \\
\hline & $\mathrm{pVlB5} / 6-19$ & 349 & + & + \\
\hline
\end{tabular}

$+=$ Hybridisierung mit der DNA-Sonde; - = keine Hybridisierung mit der DNA-Sonde; $\mathrm{a}=$ Anzahl Nukleotide basierend auf Sequenzierungsergebnissen; k.E. $=$ kein Ergebnis 
Die für $V$. longisporum artspezifischen DNA-Sonden wurden sequenziert, um basierend auf der Sequenz Oligonukleotide für die Entwicklung einer diagnostischen PCR abzuleiten. Die Oligonukleotide wurden anschließend als Primer in der Entwicklung einer PCR zum artspezifischen Nachweis für $V$. longisporum eingesetzt. Die Sequenzen der spezifischen DNA-Sonden sind nachfolgend in 5'-3'-Richtung dargestellt. Die Bindungsstellen der auf Basis der angegebenen Sequenzen entwickelten Primer sind grau hinterlegt.

$\begin{array}{cl}\mathbf{p V I O 2 / 3 - 6} & \\ 1 & \text { CAGCACCCACGAAAAAGAAGACAAAGTGTCAGTTCTCTCCATGAGCGAAC } \\ 51 & \text { CTTTGTGATAGATACTAACATCGCCGCAGCCCCGCCCAAGTCCAGAAAA } \\ 101 & \text { AAATGATACCACACGAAGGATCGAGTTAGGCACTTTGTACAATACTG } \\ 151 & \text { TCCAACAATCTTTTACCCAACTGTTCTCCCAGAGTCCCCAGAACTTTGCT } \\ 201 & \text { TCTGTCATGTTTACAGCGTTCGTGCTTATGCCAGTGGGTGTCGTCATG } \\ 251 & \text { GTACGACCCCGGTCAGGGGTCGTGGATGCGCACCGCGATACCGACCAGG } \\ 301 & \text { CCTTACACATTGAACCGGTGTTACTGGCATGGACCTCTGCTGAATCCTTG } \\ 351 & \text { CAACCGAGCTTAGTAGATCTGTTAGAGTCACTGTTGACTCTGGGACGCCA } \\ 401 & \text { GCTGAGATGGTGATGCTTGAGTGCTCATATGAACATATCAGACAGGGTG } \\ 451 & \text { TGTGCCTTTTGCAGTTGATCAGAATGTGAAGGCTGATACTTCATCCTTGC } \\ 501 & \text { TACGACCCAGTGTCTCTCGCTAGGTGGACGTCAAAAATACTCCCGCCCT } \\ 551 & \text { TTCTGACCTGTGGTGGATGCTGGCCTGGTGGTGCGTCCGATGTCATCAC } \\ 601 & \text { GGTTGTAGACGTTGATCGTTGATTGTTGCCTGTTGCTAGGGGCTCAGTGT } \\ 651 & \text { CTGGTGTGGGTGCTG }\end{array}$

pVIE5-23

1 ATtTTAACAAAATATTAACGCTTACAATTTAGGTGGCACTTTTCGGGGAA

51 ATGTGCGCGGAACCCCTATTTGTTTATTTTTCTAAATACATTCAAATATG

101 TATCCGCTCATGAGACAATAACCCTGATAAATGCTTCAGGTGATGCTGCC

151 AACTTACTGATTTAGTGTATGATGGTGTT

\subsubsection{Artspezifischer in vitro-Nachweis von $V$. longisporum}

\subsubsection{Eigenschaften der artspezifischen Primer}

Für die Entwicklung artspezifischer Primer wurden die Sequenzen der DNA-Sonden pV1O2/3-6 und pVlE5-23 verwendet. Das Primer-Design wurde mit dem Programm OligoPerfect ${ }^{\mathrm{TM}}$ Designer erstellt. Die von den Sequenzen der DNA-Sonden abgeleiteten Primer sowie deren Eigenschaften sind in Tab. 3.16 aufgeführt. 
Tab. 3.16: Nukleotidsequenzen und Eigenschaften der von den DNA-Sonden abgeleiteten Primer.

\begin{tabular}{|c|c|c|c|c|c|}
\hline Bezeichnung & $\begin{array}{c}\text { Nukleotidsequenz } \\
\text { 5' zu 3' } \\
\end{array}$ & $\begin{array}{c}\text { GC-Gehalt } \\
{[\%]}\end{array}$ & $\begin{array}{l}\mathbf{T m} \\
{\left[{ }^{\circ} \mathbf{C}\right]}\end{array}$ & $\begin{array}{c}\text { Länge } \\
\text { [bp] }\end{array}$ & $\begin{array}{l}\text { Amplifikat- } \\
\text { größe [bp] }\end{array}$ \\
\hline pVlE5-23 F & $\begin{array}{l}\text { ACT TTT CGG GGA } \\
\text { AAT GTG C }\end{array}$ & 47,37 & 65 & 19 & \multirow{2}{*}{119} \\
\hline pVlE5-23 R & $\begin{array}{l}\text { TAA GTT GGC AGC } \\
\text { ATC ACC TG }\end{array}$ & 50,00 & 68 & 20 & \\
\hline $\mathrm{pVlO} 2 / 3-6 \mathrm{~F}$ & $\begin{array}{l}\text { GAT ACC GAC } \\
\text { CAG GCC TTA CA }\end{array}$ & 55,00 & 70 & 20 & \multirow{2}{*}{140} \\
\hline $\mathrm{pVlO} 2 / 3-6 \mathrm{R}$ & $\begin{array}{l}\text { GAG CAA CTC } \\
\text { AAG CAT CAC CA }\end{array}$ & 50,00 & 68 & 20 & \\
\hline
\end{tabular}

\subsubsection{Optimierung der PCR-Reaktion}

Die Spezifität der PCR-Reaktion und der eingesetzten Primer ist stark abhängig von den Rahmenbedingungen der Reaktion. Wichtige Einflussfaktoren auf die Spezifität sind Magnesiumkonzentration, DNA-Polymerasekonzentration sowie die AnnealingTemperatur. Für die Primerpaare pV1E5-23 und pV1O2/3-6 wurden diese Bedingungen auf einem Gradientencycler (Biometra $\mathrm{T}$ gradient) optimiert. Die hier dargestellten PCR-Analysen wurden mit einer Magnesiumkonzentration von 1,5 mM und einer DNA-Polymerasekonzentration von $1 \mathrm{U}$ pro Reaktionsansatz durchgeführt. Da unter diesen Bedingungen ein erfolgreicher artspezifischer in vitro-Nachweis von $V$. longisporum möglich ist, wurden keine weiteren Untersuchungen zur Optimierung der Magnesium- und DNA-Polymerasekonzentration durchgeführt.

Die Schmelztemperaturen für die eingesetzten Primer sind in Tab. 3.16 angegeben. Die Schmelztemperatur ist die Temperatur, bei der die betrachteten DNA-Moleküle zu 50\% denaturiert sind und somit einzelsträngig vorliegen. Im Allgemeinen wird eine Annealing-Temperatur gewählt, die $5^{\circ} \mathrm{C}$ unter der Schmelztemperatur der Primer liegt. Es ist jedoch notwendig, die optimale Annealing-Temperatur empirisch zu überprüfen. Für die Primerpaare pVlE5-23 und pV1O2/3-6 wurden Annealing-Temperaturen von $49^{\circ} \mathrm{C}$ bis $66^{\circ} \mathrm{C}$ geprüft. Bei dem Primerpaar pVlE5-23 erfolgte bei keiner Temperaturstufe eine Amplifikation des spezifischen Fragments. Auf weitere Untersuchungen mit diesem Primerpaar wurde aufgrund der vermutlich fehlenden Sequenzhomologie zwischen Primer und genomischer DNA verzichtet. 
Für das Primerpaar pV1O2/3-6 konnte bei allen untersuchten Temperaturstufen eine Amplifikation des spezifischen Fragments beobachtet werden (Abb. 3.28).

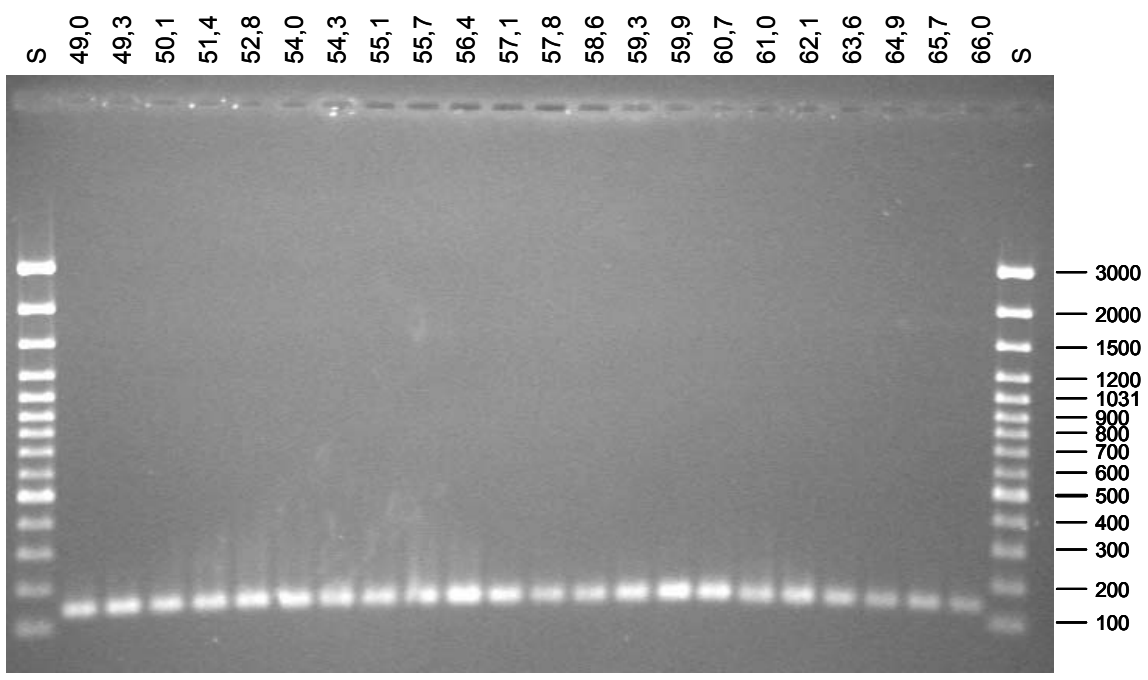

Abb. 3.28: PCR-Amplifikation spezifischer DNA-Fragmente aus $V$. longisporum V1 40 bei verschiedenen Annealing-Temperaturen unter Verwendung des Primerpaares pV1O2/3-6. S: Größenstandard 100 bp ladder Plus

\subsubsection{Ergebnisse der Spezifitätsuntersuchungen des Primerpaares pVIO2/3-6}

Weitergehende Untersuchungen haben gezeigt, dass erst bei einer AnnealingTemperatur von $66,4^{\circ} \mathrm{C}$ eine artspezifische Amplifikation des DNA-Fragments bei ausreichender Ausbeute stattfindet (Abb. 3.29). Bei Annealing-Temperaturen von $62,0^{\circ} \mathrm{C}$ und $64,0^{\circ} \mathrm{C}$ konnte in allen drei $V$. longisporum-Isolaten sowie in den V. dahliae-Isolaten Vd 3 und Vd 16 ein Amplifikat von 140 bp erzielt werden. Bei einer Annealing-Temperatur von $64,0^{\circ} \mathrm{C}$ trat bei dem Isolat Vd 3 neben dem 140 bpFragment eine weitere Bande von ca. 70 bp auf. Das $V$. dahliae-Isolat Vd 57 wies kein Amplifikat auf. Bei Annealing-Temperaturen von $66,4^{\circ} \mathrm{C}$ und $67,6^{\circ} \mathrm{C}$ wurde nur in den drei $V$. longisporum-Isolaten das spezifische Fragment von 140 bp amplifiziert. 

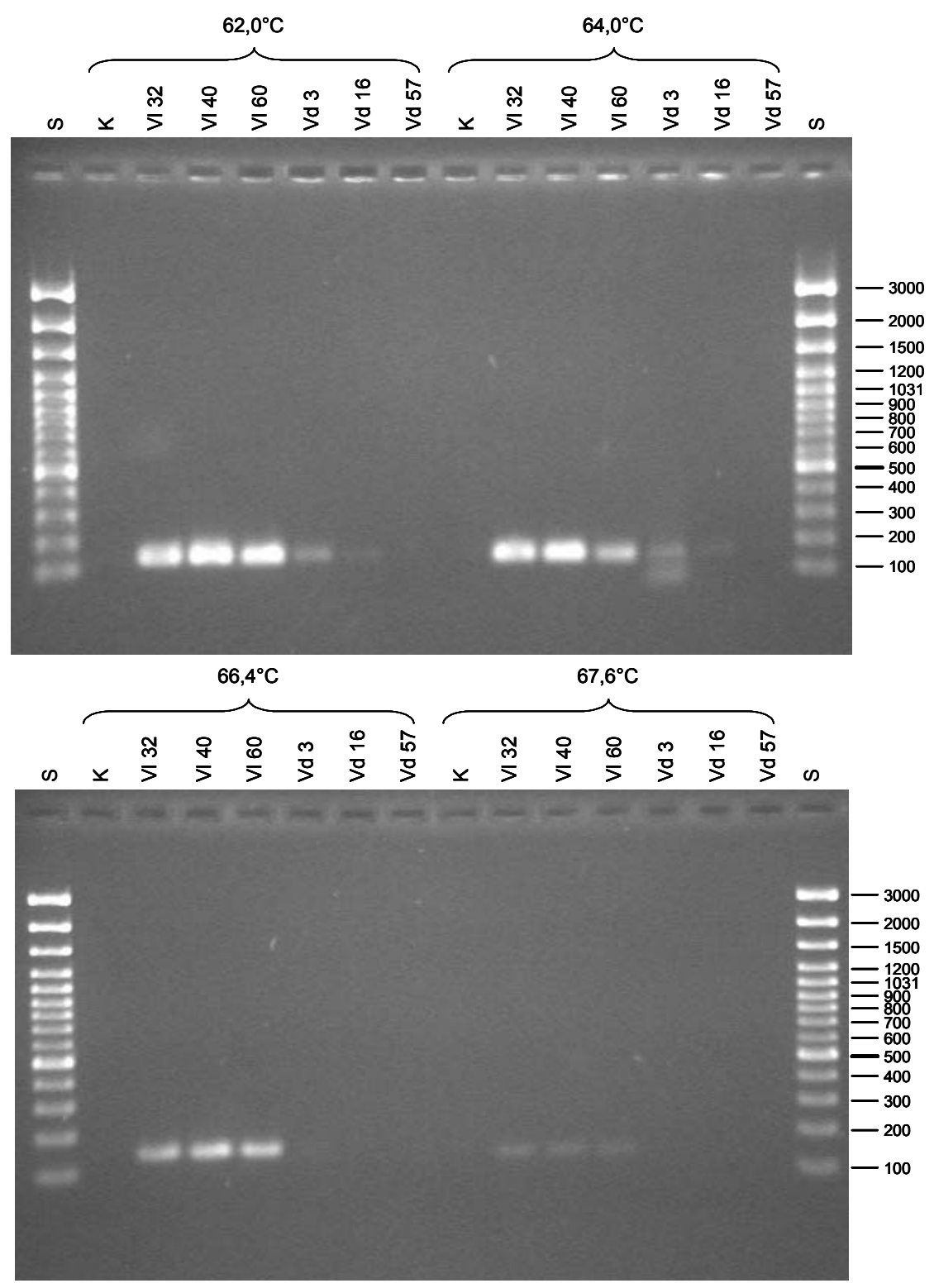

Abb. 3.29: Spezifitätstest des Primerpaares pVlO2/3-6 mit Gesamt-DNA aus verschiedenen $V$. longisporum und $V$. dahliae-Isolaten bei unterschiedlichen Annealing-Temperaturen. S: Größenstandard 100 bp ladder Plus, K: Negativkontrolle

Die Überprüfung der Spezifität des Primer-Paares pV1O2/3-6 wurde mit einer Vielzahl verschiedener $V$. longisporum und $V$. dahliae-Isolate durchgeführt. Weiterhin wurde auf Kreuzreaktionen mit anderen Arten und Gattungen getestet. 


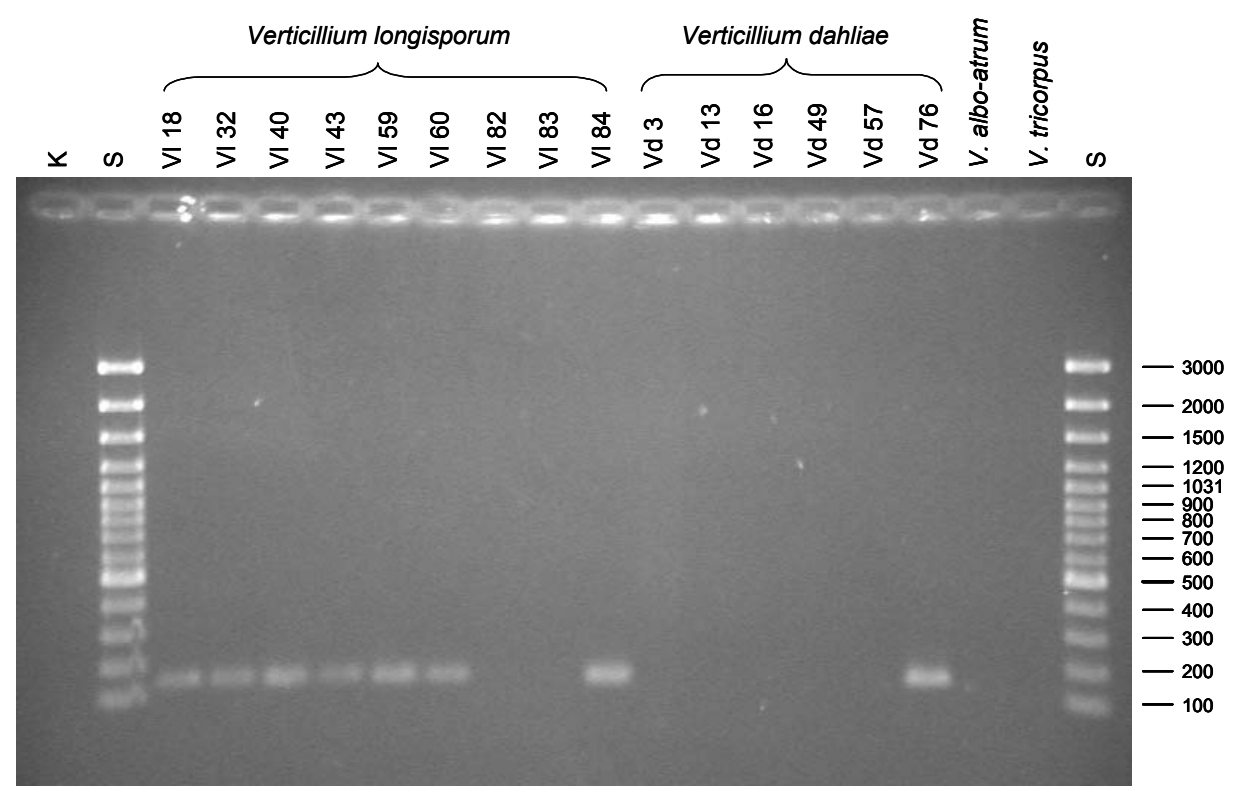

Abb. 3.30: Spezifitätstest des Primerpaares pVlO2/3-6 mit Gesamt-DNA aus verschiedenen Verticillium-Arten bei einer Annealing-Temperatur von $66,5^{\circ} \mathrm{C}$. S: Größenstandard 100 bp ladder Plus, K: Negativkontrolle

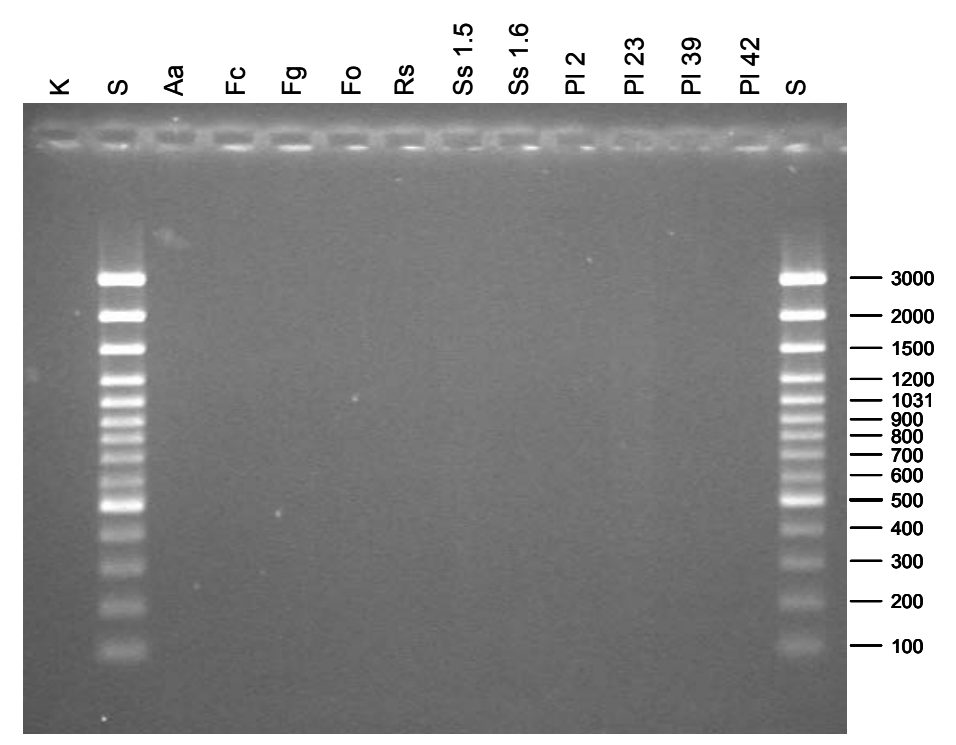

Abb. 3.31: Spezifitätstest des Primerpaares pVlO2/3-6 mit Gesamt-DNA aus verschiedenen Fusarien-Arten ( $F$. culmorum, $F$. graminearum, $F$. oxysporum) sowie verschiedenen $S$. sclerotiorum und $P$. lingam-Isolaten, $R$. solani und A. alternata bei einer Annealing-Temperatur von $66,5^{\circ} \mathrm{C}$. S: Größenstandard 100 bp ladder Plus, K: Negativkontrolle

Innerhalb der $V$. longisporum-Isolate konnte mit Ausnahme der Isolate V1 82 und V1 83 bei allen getesteten Isolaten das spezifische DNA-Fragment mit einer Größe von 140 bp amplifiziert werden (Abb. 3.30). Die Isolate V1 82 und V1 83 wiesen in vorhergehenden 
Untersuchungen bereits Unterschiede zu allen anderen $V$. longisporum-Isolaten auf und es wurde vermutet, dass diese beiden Isolate $V$. dahliae zuzuordnen sind. Innerhalb der V. dahliae-Isolate wies nur das Isolat Vd 76 das spezifische DNA-Fragment auf. Dieses Isolat zeigte bereits in früheren Fingerprinting-Analysen sowie als Myzelkultur charakteristische Merkmale der Art $V$. longisporum auf. Für $V$. albo-atrum und $V$. tricorpus sowie allen weiteren getesteten Gattungen wurde kein Amplifikat erzielt (Abb. 3.31).

\subsubsection{Nachweisgrenze für den in vitro-Nachweis von $V$. longisporum}

Die Sensitivität der artspezifischen PCR wurde anhand einer Verdünnungsreihe genomischer DNA unter den optimierten Bedingungen untersucht.

Die Nachweisgrenze war bei einer DNA-Menge von 61 pg erreicht (Abb. 3.32). Die Berechnung der Anzahl nachgewiesener Genome basiert auf der angegebenen Genomgröße von $V$. longisporum von $57 \times 10^{6}$ bp (COLLINS et al., 2003) und der Annahme, dass das amplifizierte DNA-Fragment eine „single copy sequence“ darstellt. Basierend auf diesen Annahmen und den Faustzahlen für die Berechnung des Gewichtes eines Basenpaares ergibt sich eine Nachweisgrenze bei 10.000 Genomen.

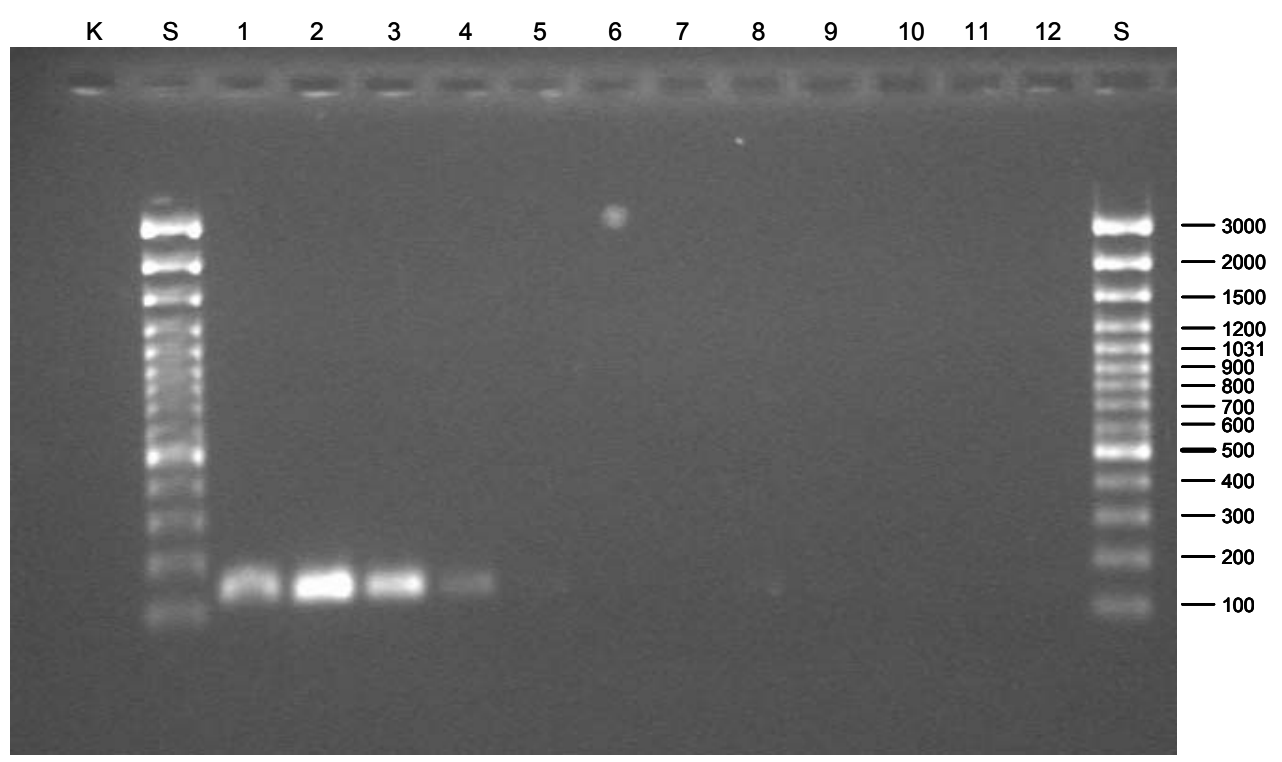

Abb. 3.32: Nachweisgrenze für den in vitro-Nachweis von $V$. longisporum (Isolat V1 40) mit dem Primerpaar pVlO2/3-6. S: Größenstandard 100 bp ladder Plus; K: Negativkontrolle; 1: $10 \mathrm{ng}$; 2: $5 \mathrm{ng}$; 3: $1 \mathrm{ng}$; 4: 0,1 ng; 5: $61 \mathrm{pg}$; 6: $31 \mathrm{pg}$; 7: $12 \mathrm{pg}$; 8: 6,1 pg; 9: 4,6 pg; 10: 3,1 pg; 11: 1,5 pg; 12: 0,6 pg. 


\section{Diskussion}

\subsection{Schadwirkung pilzlicher Pathogene an Winterraps}

Basierend auf einer Zunahme der Anbaufläche und einer steigenden Anbauintensität von Winterraps wird das Auftreten insbesondere von Fruchtfolgekrankheiten gefördert. Im Rapsanbau sind $S$. sclerotiorum und $V$. longisporum aufgrund von lang überdauernden Sklerotien bzw. Mikrosklerotien typische Fruchtfolgekrankheiten. In der hier vorliegenden Arbeit wurde das Schadpotential dieser Pathogene in Abhängigkeit von verschiedenen Parametern untersucht. Für S. sclerotiorum wurden aus den Ergebnissen dieser Untersuchungen wirtschaftliche Schadensschwellen entwickelt, welche in dem neuen Prognosemodell SkleroPro eine praktische Anwendung finden. Für das Pathogen $V$. longisporum wurde neben dem Schadpotential die Befallsdynamik näher untersucht. Eine weitere Fragestellung war die Entwicklung einer artspezifischen PCR-Nachweismethode zur Abgrenzung der an Raps pathogenen Verticillium-Art $V$. longisporum von weiteren an Raps nicht pathogenen Verticillium-Arten.

Informationen über die Schadwirkung sowie über die Befalls-Verlust-Relationen von Pathogenen sind für eine wirtschaftlich und ökologisch sinnvolle Bekämpfung von großem Nutzen (JAMES, 1974; MAdDEN ET AL., 1981; MADDEN, 1983; WALKER, 1983; CAMPBell \& MAdDEN, 1990; Freier et al., 1994). Bei der Untersuchung der Schadwirkung einer Krankheit ist die Erstellung eines Datensatzes mit unterschiedlichen Befallshäufigkeiten ein wichtiger Faktor (SHANE \& TENG, 1987). Zur Einstellung unterschiedlicher Befallshäufigkeiten können verschiedene Methoden angewendet werden. Neben gezielten Fungizidapplikationen oder künstlicher Inokulation stellen der Anbau unterschiedlich anfälliger Sorten oder die künstliche Simulation von Schäden weitere Möglichkeiten zur differenzierten Einstellung von Befallshäufigkeiten dar (WALKER, 1983). Durch mehrjährige Wiederholung der Feldversuche können jahresbedingte unterschiedliche Umweltbedingungen mit erfasst werden, die einen möglichen Einfluss auf die Ergebnisse ausüben.

Die Feldversuche zur Untersuchung der Schadwirkung von S. sclerotiorum und $V$. longisporum wurden in allen Versuchsjahren auf weitgehend befallsfreien Standorten durchgeführt. Mit Hilfe einer künstlichen Inokulation wurden unterschiedliche Befallshäufigkeiten eingestellt. Als Referenz für den Ertragsverlust befallener Parzellen im Vergleich zu nicht befallenen Parzellen ist eine Gesundparzelle unbedingt erforderlich 
(JAMES, 1974). In vielen Untersuchungen zum Einfluss von Pilzkrankheiten auf den Ertrag werden natürlich befallene Flächen als Standort ausgewählt, um eine Befallssicherheit zu gewährleisten. Unterschiedliche Befallshäufigkeiten werden auf solchen Standorten durch den Einsatz verschiedener Aufwandmengen an Fungiziden eingestellt (WALKER, 1983). Zahlreiche Fungizide haben jedoch neben der eigentlichen fungiziden Wirkung pflanzenphysiologische Wirkungen, die das Wachstum und die Entwicklung der Pflanzen und somit das Ertragsniveau beeinflussen können oder bekämpfen weitere Nichtziel-Pathogene, so dass der Ertragseffekt nicht einer einzelnen Krankheit zugeordnet werden kann (JAMES, 1974; WALKER, 1983; SAH \& MACKENZIE, 1987). Genaue Ertragserfassungen und -vergleiche zwischen befallenen und befallsfreien Parzellen sind unter diesem Gesichtspunkt nicht möglich. Ein weiterer Vorteil der künstlichen Inokulation ist die Möglichkeit, durch Inokulation der entsprechenden Anzahl an Pflanzen pro Parzelle exakte Befallshäufigkeiten einzustellen. Man darf jedoch nicht außer Acht lassen, dass die Inokulationsmethode selbst einen Einfluss auf die Schadwirkung haben kann, was von WALKER (1983) besonders für entomologische Fragestellungen diskutiert wird.

Zur Beschreibung von Befalls-Verlust-Relationen stehen verschiedene Modelle zur Verfügung (JAMES, 1974; WALKER, 1983; CAMPBELl \& MADDEN, 1990; MADDEN \& NuTTER, 1995). In den Critical-Point-Modellen wird häufig eine lineare Regression angewendet, wobei der Befall die unabhängige und der Ertragsverlust die abhängige Variable darstellt. Zu nur einem Termin während der Vegetation wird der Befall erfasst und mit dem Ertragsverlust in Beziehung gesetzt. Diese Art von Modell wurde z. B. für Reisbrand (Magnaporthe grisea), Mais-Blattdürre (Bipolaris maydis) oder Schwarzrost an Weizen (Puccinia graminis) gewählt (CAMPBELL \& MADDEN, 1990). Der Unterschied der Mulitple-Point-Modelle ist eine wiederholte Erfassung des Befallsgeschehens während der Vegetation. Hierdurch wird es ermöglicht, variierende Schadwirkungen, z. B. aufgrund unterschiedlicher Infektionstermine, zu berücksichtigen (KIM \& MCKENZIE, 1987). Die Formel zur Berechnung des Ertragsverlustes ergibt sich aus der Aufsummierung des anteiligen Regressionskoeffizienten, multipliziert mit dem Befall des jeweiligen Boniturtermins (z. B. Phytophthora infestans an Kartoffeln). Die Area-under-the-disease-progress-curveModelle (AUDPC) sind zwischen den Critical- und Multiple-Point-Modellen anzusiedeln. Diese Art von Modell beschreibt den Verlauf einer Epidemie. Ein Nachteil 
dieses Modells ist jedoch, dass nicht zwischen einem frühen, lang andauerndem und einem spätem schweren Befall unterschieden werden kann (JAMES, 1974). In der hier vorliegenden Arbeit wurden sowohl für S. sclerotiorum als auch für $V$. longisporum Critical-Point-Modelle zur Beschreibung der Befalls-Verlust-Relation eingesetzt. Bei beiden Pathogenen handelt es sich um monozyklische Erreger, bei denen innerhalb einer Vegetationsperiode keine epidemische Ausbreitung auftritt. Eine Befallsbonitur zu einem Termin kann daher den Ertragsverlust hinreichend genau erklären.

Die Beziehung zwischen Befall und Ertragsverlust kann verschiedene Formen annehmen, und beeinflusst entscheidend die Schadwirkung und die Bekämpfungsentscheidung (MADDEN, 1983; WALKER, 1983). Eine lineare Relation weist eine proportionale Beziehung zwischen Ertragsverlust und Befall auf; bei einer sigmoiden Relation, welche in den meisten Pathosystemen vorherrschend ist, ist der Ertragsverlust nicht proportional dem Befall. Bis zu einer bestimmten Schwelle wird nur ein geringer Ertragsverlust verursacht, der bei Überschreiten der Schwelle einen nahezu proportionalen Verlauf annimmt. Bei sehr hohem Befall flacht die Verlaufskurve wieder ab. Ein sehr starker Ertragsverlust bei nur sehr geringem Befall ist hauptsächlich bei Auftreten von Vektoren von Krankheiten zu finden, wie z. B. der Virusübertragung durch Blattläuse. Bei polyzyklischen Erregern ist anstelle eines additiven ein mulitplikativer Effekt zu beobachten. Der Ertragsausfall wird in solchen Systemen auf den logarithmischen Befall bezogen. Neben negativen Effekten des Befalls kann auch eine positive Korrelation zwischen Befallsauftreten und Ertrag vorhanden sein. Diese Form der Beziehung wird meist bei geringem Befall beobachtet und kann aufgrund von Kompensationsmechanismen oder hormonellen Veränderungen in der Pflanze hervorgerufen werden (WALKER, 1983). Ein Vergleich verschiedener Regressionsmodelle zur Beschreibung der Befalls-Verlust-Relationen von S. sclerotiorum und $V$. longisporum wies die lineare Regression als genauestes Modell zur Beschreibung der Beziehung aus.

\subsubsection{Befalls-Verlust-Relationen für $S$. sclerotiorum an Winterraps}

Zur Erarbeitung der Schadwirkung und Befalls-Verlust-Relationen für S. sclerotiorum in Abhängigkeit verschiedener Faktoren an Winterraps, wurden mit Hilfe der Zahnstochermethode unterschiedliche Befallshäufigkeiten eingestellt. 
Unter natürlichen Bedingungen sind Sclerotinia-Infektionen durch Ascosporen maßgeblich abhängig von Witterungsparametern. Myzelinfektionen, die bei der Infektion von Sonnenblumen eine wichtige Rolle spielen (ADAMS \& TATE, 1976; HuAng \& Dueck, 1980; HuAng \& Hoes, 1980; HuAnG, 1985), sind in Raps nur von sehr untergeordneter Bedeutung (HUANG \& DUECK, 1980). Die optimalen Bedingungen für Infektionen mit S. sclerotiorum sind bei Temperaturen zwischen 16 und $25^{\circ} \mathrm{C}$ und einer relativen Luftfeuchte von mindestens 80\% gegeben (WEISS et al., 1980; HERAN et al., 1999; Young et al., 2004; Koch \& Von Tiedemann, 2005a, b). Die Minimumtemperatur für eine Infektion liegt nach Ergebnissen aus aktuellen Untersuchungen bei $7^{\circ} \mathrm{C}$ (KoCH \& VON TIEDEMANN, 2005a, b). Über die Notwendigkeit von Blattnässe sind in der Literatur unterschiedliche Meinungen vertreten (ABAWI \& GROGAN, 1975; WEISS et al., 1980; HERAN et al., 1999). In Untersuchungen von ABAWI \& Grogan (1975), Jamaux et al. (1995) und Atallah \& Johnson (2004) konnte gezeigt werden, dass Blütenblätter eine wichtige Infektionsgrundlage für S. sclerotiorum darstellen.

Durch die künstliche Inokulation wird die starke Abhängigkeit der Infektionen von Witterungsparametern und dem Vorhandensein von Blütenblättern umgangen. Allerdings wird auch die erste mögliche Hürde, das Durchdringen des Pflanzenstängels übergangen, so dass mögliche Abwehrreaktionen der Pflanze durch z. B. verdickte Pflanzenzellwände nicht wirksam werden können. Da in der vorliegenden Arbeit jedoch die Ertragswirkung und nicht die Anfälligkeit von Winterraps untersucht werden sollte, konnte dieser Aspekt vernachlässigt werden.

In den Feldversuchen wurden Befalls-Verlust-Relationen in Abhängigkeit von verschiedenen Faktoren untersucht. Neben dem Einfluss des Zeitpunktes der Infektion wurden der Einfluss der agronomischen Parameter Aussaattermin, Bestandesdichte und Sortenwahl untersucht. Die Untersuchung dieser Faktoren sollte Aufschluss über die Möglichkeiten einer aktiven Beeinflussung der Schadwirkung durch den Anbauer geben.

Die aus künstlichen Inokulationen $\mathrm{zu}$ insgesamt drei unterschiedlichen Terminen (BBCH 61-65, 67-69 und 71) resultierenden Befallshäufigkeiten wiesen teilweise Unterschiede zwischen Sorten, Inokulationstermin und Versuchsjahren auf, die sich jedoch nur in wenigen Fällen statistisch absichern ließen. Im ersten Versuchsjahr wurden nur sehr geringe Befallshäufigkeiten erreicht. Durch Optimierung der 
Anzuchtbedingungen in Gewächshausversuchen konnten in den nachfolgenden Versuchsjahren höhere Befallshäufigkeiten erzielt werden. Mit steigendem Pflanzenalter war eine leicht steigende Tendenz in der erzielten Befallshäufigkeit zu erkennen. Versuche von ABAWI \& GROGAN (1975) an Bohnen wiesen ähnliche Ergebnisse auf. Zwischen Pflanzenalter und Befallshäufigkeit war eine enge positive Korrelation zu finden. Höhere Befallshäufigkeiten in älteren Pflanzen wurden allerdings einer größeren Anzahl an Verletzungen zugeschrieben. Wie auch die Untersuchungen von HUDYNCIA et al. (2000) zeigten, stellen Verletzungen der Pflanzen einen wichtigen Faktor für die Entwicklung von Infektionen dar.

Der Zeitpunkt der Infektion während der Vegetationsphase kann einen erheblichen Einfluss auf den Ertrag haben (MADDEN \& NUTTER, 1995). Wie die Feldversuche zur Ertragsminderung in Abhängigkeit des Infektionszeitpunktes zeigten, war sowohl in der Hybrid- als auch in der Liniensorte ein stärkerer Ertragsrückgang nach Infektionen zum Zeitpunkt der Vollblüte als nach Infektionen zum Anfang der Schotenbildung zu beobachten. Statistisch ließen sich diese Unterschiede jedoch nicht absichern. Dennoch lässt die geringere Ertragswirkung von späteren Infektionen in allen drei Versuchsjahren darauf schließen, dass Rapspflanzen mit zunehmendem Pflanzenalter ertraglich weniger sensibel auf eine Sclerotinia-Infektion reagieren. Besonders wichtig ist dieses Ergebnis im Hinblick auf die Bedeutung von Spätinfektionen mit S. sclerotiorum nach der Blüte. In der Literatur wird mehrfach von einer geringeren Ertragswirkung später Infektionen berichtet (NUTTER et al., 1993; SHIVPURI et al., 1999). In den Untersuchungen von DANIELSON et al. (2004) an Sojabohnen konnte eine geringere Schadwirkung von späteren Inokulationen mit S. sclerotiorum beobachtet werden, die sich statistisch jedoch nicht absichern ließ. Auch an Tomaten konnten geringere Ertragsverluste durch S. sclerotiorum mit zunehmendem Pflanzenalter zum Zeitpunkt der Infektion festgestellt werden (LOBO et al., 2000). Untersuchungen zur Anfälligkeit von Sojabohnen mit Hilfe künstlich inokulierter Stängelabschnitte ergaben widersprüchliche Ergebnisse. CHUN et al. (1987) konnten mit zunehmendem Pflanzenalter eine abnehmende Befallsstärke beobachten, wohingegen VUONG et al. (2004) an Stängelabschnitten älterer Pflanzen eine stärkere Symptomausprägung beobachteten.

Mögliche Ursache der geringeren Ertragswirkung später Infektionen kann in der temporären Ertragsstruktur der Rapspflanze zu finden sein. Die Ertragsstruktur eines 
Rapsbestandes setzt sich aus der Anzahl Pflanzen je Fläche, Anzahl Schoten je Pflanze, Anzahl Samen je Schote sowie dem mittleren Samengewicht zusammen (GEISLER, 1988). Den aufbauenden Prozessen der Ertragskomponenten stehen Reduktionsprozesse gegenüber. Sehr frühzeitig werden die einzelnen Ertragskomponenten in der Pflanze determiniert. Noch während der Blüte werden der Schotenansatz und die Samenanlagen festgelegt (GEISLER, 1988). Bei einer Inokulation zu BBCH 61-65 (Anfang Blüte bis Vollblüte) wird daher sehr stark in die Anlage der Ertragsfaktoren der Pflanze eingegriffen. Bei einer Inokulation zu Beginn der Schotenbildung (BBCH 71) sind die meisten Ertragskomponenten bereits festgelegt und lediglich die Ausbildung der Samen, und zum geringen Maße der Schoten, wird beeinflusst.

Neben dem Gesamtertrag wurden auch die Qualitätsparameter TKG und Ölgehalt untersucht. In diesen beiden Parametern konnte man deutliche Unterschiede zwischen den Sorten in der Reaktion auf $S$. sclerotiorum-Befall erkennen. Während die Hybridsorte im Mittel über die drei Versuchsjahre nach der frühen Inokulation mit einer stärkeren Reduktion des TKG im Vergleich zur späten Inokulation reagiert, wurde bei der Liniensorte lediglich durch die späte Inokulation zu BBCH 71 eine signifikante Minderung des TKG beobachtet. Betrachtet man die drei Versuchsjahre jedoch getrennt voneinander, so ist in den beiden ersten Versuchsjahren auch bei der Hybridsorte (Talent) eine stärkere Minderung des TKG nach einer späten Infektion im Vergleich zur frühen Inokulation zu beobachten. Nur im dritten Versuchsjahr ist dieses Verhältnis in der Hybridsorte Maja umgekehrt. Dies weist auf mögliche Wechselwirkungen zwischen Sorte und TKG-Reaktion auf einen Sclerotinia-Befall hin.

In Untersuchungen von KRÜGER und STOLTENBERG (1983) zum Einfluss von S. sclerotiorum auf Ertragsparameter in Raps konnte bei einer Befallshäufigkeit von $50 \%$ ein Rückgang des TKG um 23\% beobachtet werden. Dieses Ergebnis deckt sich mit der in der hier vorliegenden Arbeit beobachteten Reduktion des TKG nach einer Infektion zu BBCH 61-65 in der Hybridsorte im Mittel über die drei Versuchsjahre. Auch die Untersuchungen von POPE et al. (1989) an Einzelpflanzen wiesen einen signifikanten Einfluss von $S$. sclerotiorum auf das TKG befallener Pflanzen auf.

Der Ölgehalt weist nur eine sehr geringe Beeinflussung durch einen Befall mit S. sclerotiorum auf. Im Mittel über die drei Versuchsjahre ist bei der Hybridsorte lediglich nach einer Inokulation $\mathrm{zu} \mathrm{BBCH}$ 61-65 eine sehr geringe, signifikante Reduktion des Ölgehalts zu erkennen. Betrachtet man die drei Versuchsjahre getrennt 
voneinander, ist vergleichbar der Reaktion des TKG ein Sorteneffekt erkennbar. Lediglich im dritten Versuchsjahr, nachdem die Sorte Talent durch die Sorte Maja ersetzt wurde, konnte ein deutlich negativer Effekt einer Sclerotinia-Infektion auf den Ölgehalt verzeichnet werden. In der Liniensorte konnte sowohl nach einer frühen als auch nach der späteren Inokulation eine signifikante Minderung des Ölgehaltes beobachtet werden. In Großbritannien durchgeführte Untersuchungen zum Einfluss von Krankheiten auf Qualitätseigenschaften von Raps haben gezeigt, dass S. sclerotiorum nur einen sehr geringen Einfluss auf den Ölgehalt hatte (MCCARTNEY et al., 1999), wie er auch in der vorliegenden Arbeit beobachtet wurde. Untersuchungen von POPE et al. (1989) ergaben vergleichbare Ergebnisse.

Eine weitere Fragestellung dieser Arbeit war der Einfluss des Aussaattermins auf die Schadwirkung von S. sclerotiorum. In der Literatur ist eine Reihe von Untersuchungen zum Einfluss des Aussaattermins auf die Ertragsbildung von Raps zu finden. Späte Aussaattermine resultieren im Allgemeinen in einem geringeren Ertrag (DEGENHARDT \& Kondra, 1981; Mendham et al., 1981a, b; SEIDEl et al., 1984; AndERSSON \& Bengtsson, 1989; Yousaf et al., 2002; Sidlauskas \& Bernotas, 2003). Dieser Effekt ist zurückzuführen auf eine schlechtere Pflanzenentwicklung vor Winter und kleinere Pflanzen zur Blüte im Vergleich zu früher gesäten Beständen (MENDHAM et al., 1981a). Im Gegensatz dazu führten in Untersuchungen von LEACH et al. (1994) später gesäte Bestände zu höheren Erträgen, als etwa drei Wochen früher gesäte Bestände. In den eigenen Feldversuchen in den Jahren 2001/02 bis 2003/04 konnte kein signifikanter Effekt des Aussaattermins auf den Ertrag in den nicht inokulierten Kontrollparzellen beobachtet werden. Der Unterschied zwischen den Aussaatterminen war mit 10 bis 15 Tagen jedoch geringer als in einigen, aus der Literatur bekannten Untersuchungen (Mendham et al., 1981a, b; TAYLOR \& SMiTh, 1992). In Arbeiten von YousAF et al. (2002) und DEGENHARDT \& KONDRA (1981) hingegen sind die zeitlichen Unterschiede zwischen den Aussaatterminen vergleichbar. Auch in den von SEIDEL et al. (1984) durchgeführten Versuchen betrug der Unterschied zwischen den Aussaatterminen lediglich rund eine Woche, wodurch jedoch ein Ertragsunterschied von 18\% erzielt wurde.

Neben dem Aussaattermin wurde in den dreijährigen Feldversuchen auch die Aussaatstärke, und dadurch bedingt die Bestandesdichte variiert. Aufgrund von Kompensationseffekten resultieren geringere Aussaatstärken/Bestandesdichten nicht 
unbedingt in geringeren Erträgen (DEgENHARDT \& KondRA, 1981; MENDHAM et al., 1981b; SCARISBRICK et al., 1982; TAYLOR \& SMITH, 1992; LEACH et al., 1999; ANGADI et al., 2003). Sowohl in Sommer- als auch in Winterraps wurde in differenzierten Betrachtungen der Ertragskomponenten mit steigender Aussaatstärke/Bestandesdichte eine geringere Anzahl an Schoten pro Pflanze (Clarke et al., 1978; MendHAm et al., 1981b; SCARISBRICK et al., 1982; TAYLOR \& SMITH, 1992; LEACH et al., 1999; ANGADI et al., 2003) sowie eine geringere Anzahl Seitentriebe pro Pflanze (CLARKE et al., 1978) beobachtet. Das TKG wies eine Zunahme mit steigender Aussaatstärke auf (CLARKE et al., 1978; LEACH et al., 1999). In den Göttinger Feldversuchen konnten in Übereinstimmung mit den Ergebnissen von SCARISBRICK et al. (1982) und ANGADI et al. (2003) jedoch keine signifikanten Unterschiede im TKG zwischen den Bestandesdichten beobachtet werden.

Der Zusammenhang zwischen Bestandesdichte und Ertrag wies in Versuchen von SidLAUSKAS \& BERNOTAS (2003) einen asymptotischen Verlauf auf. Ab einer Bestandesdichte von 120 Pflanzen $/ \mathrm{m}^{2}$ wurde ein geringerer Ertragszuwachs mit steigender Pflanzendichte beobachtet. Ergebnisse aus Großbritannien zeigten eine Ertragszunahme mit ansteigender Bestandesdichte bis 50-60 Pflanzen $/ \mathrm{m}^{2}$. Bei höheren Bestandesdichten blieben die Erträge auf einem konstanten Niveau. Ab einer Bestandesdichte von $150 \mathrm{Pflanzen} / \mathrm{m}^{2}$ konnte ein Ertragsrückgang verzeichnet werden (LEACH et al., 1999). In den eigenen in Göttingen durchgeführten Feldversuchen konnten in den Versuchsjahren 2001/02 bis 2003/04 keine signifikanten Ertragsunterschiede in Parzellen mit unterschiedlichen Bestandesdichten gefunden werden. Tendenziell wurde jedoch bei beiden Sortentypen ein geringerer Ertrag in Parzellen mit geringerer Bestandesdichte erzielt. Mit einem Unterschied von nur $15 \mathrm{Pfl} . / \mathrm{m}^{2}$ zwischen den Bestandesdichten lagen diese jedoch unter denen in der Literatur beschriebenen Versuchen. Bei der Hybridsorte wurden Bestandesdichten von 50 und $35 \mathrm{Pfl} . / \mathrm{m}^{2}$ und bei der Liniensorte von 60 und $45 \mathrm{Pfl} . / \mathrm{m}^{2}$ gewählt. Diese Bestandesdichten lagen in dem Bereich, in dem nach LEACH et al. (1999) ein deutlicher Ertragszuwachs mit steigender Pflanzendichte zu finden ist.

Durch die Beeinflussung des Mikroklimas im Pflanzenbestand spielt die Bestandesdichte und in gewissem Maße auch der Aussaattermin durch eine Beeinflussung der Pflanzenentwicklung eine wichtige Rolle bei der natürlichen Infektion mit S. sclerotiorum (PARTYKA \& MAI, 1962; TURKINGTON \& MORRALL, 1993; WAHMHOFF, 
2000; KURLE et al., 2001). In Feldversuchen mit Raps und Bohnen konnten in früher gesäten Beständen höhere Befallshäufigkeiten beobachtet werden (HAAS \& BOLWYN, 1972; HU et al., 1999). Als mögliche Ursache wird auf eine frühere Abreife der früh gesäten Bestände hingewiesen. Ein Vergleich der Sclerotinia-Befallshäufigkeiten in Herbst- und Frühjahrsaussaaten in drei Versuchsjahren wies widersprüchliche Ergebnisse auf (TURKINGTON et al., 2001). Interaktionen zwischen dem Entwicklungsstadium der Pflanzen und den klimatischen Bedingungen während des für Infektionen wichtigen Zeitraumes waren in diesen Untersuchungen ausschlaggebend für die erzielten Befallshäufigkeiten.

Durch eine höhere relative Luftfeuchte fördern dichtere und höhere Pflanzenbestände Sclerotinia-Infektionen (WAHMHOFF, 2000; KORA et al., 2005), da eine längere Blattbenetzung ermöglicht wird. Hohe Bestandesdichte fördern weiterhin die Dauer von Zeiträumen mit relativen Luftfeuchten $>90 \%$, die für Sclerotinia-Infektionen förderlich sind (WAHMHOFF, 2000). In Untersuchungen von NoRDIN et al. (1992) an Sommerraps konnten jedoch keine oder nur geringe Unterschiede in der Sclerotinia-Befallshäufigkeit in Abhängigkeit von der Bestandesdichte beobachtet werden, und auch an Sojabohnen trat kein signifikanter Effekt bzw. nur in einzelnen Jahren ein Effekt der Bestandesdichte auf die Sclerotinia-Befallshäufigkeit auf (GRAU \& RADKE, 1984; Buzzell et al., 1993). Die Bestandesdichte ist nach WAHMHOFF (2000) jedoch kein geeigneter Wert, um das Mikroklima eines Pflanzenbestandes zu beurteilen. Vielmehr spielt der Deckungsgrad eine entscheidende Rolle. Besonders in Beständen mit geringer Pflanzendichte können die Rapspflanzen durch vermehrte Ausbildung von Seitentrieben einen vergleichbaren Deckungsgrad erzielen (WAHMHOFF, 2000). Dies wird auch durch die Ergebnisse von HAAS \& BOLWYN (1972) unterstützt, die in Bohnen eine höhere Befallshäufigkeit in Beständen mit geringerer Anzahl an Pflanzen jedoch höherem Deckungsgrad beobachten konnten.

Im Feldversuch zum Einfluss von Aussaattermin und Bestandesdichte auf die Schadwirkung von S. sclerotiorum zeigten sowohl die Liniensorte als auch die Hybridsorte keine signifikanten Unterschiede in der Befallshäufigkeit zwischen einem frühen und einem normalen Aussaattermin sowie zwischen den beiden Bestandesdichten. Es muss hierbei allerdings berücksichtigt werden, dass durch die künstliche Inokulation der Einfluss der Witterung auf die Infektion umgangen wird. Bestandes- 
dichte und Aussaattermin können somit nur noch auf die Symptomausprägung und die Schadwirkung der Infektionen einen Einfluss nehmen.

Die Analyse der Befalls-Verlust-Relationen in Abhängigkeit von Aussaattermin und Bestandesdichte wies keine signifikanten Unterschiede zwischen einer Früh- und einer Normalsaat sowie zwischen den beiden Bestandesdichten bei der Liniensorte auf. Tendenziell war eine stärkere Schadwirkung bei dichteren Pflanzenbeständen und früherer Aussaat zu verzeichnen. Die Ergebnisse der Hybridsorte wiesen Wechselwirkungen zwischen Aussaattermin und Bestandesdichte auf. In früh gesäten Parzellen war die Schadwirkung in dichteren Pflanzenbeständen höher, während in später gesäten Parzellen in dünneren Pflanzenbeständen eine stärkere Schadwirkung zu verzeichnen war.

Ableitend aus diesen Ergebnissen kann darauf geschlossen werden, dass die Schadwirkung von S. sclerotiorum weder von Aussaattermin noch Bestandesdichte wesentlich beeinflusst wird. Die Befallshäufigkeit kann jedoch durch eine Beeinflussung des Mikroklimas durch Aussaattermin und Bestandesdichte beeinflusst werden. Nach KURLE et al. (2001) ist über pflanzenbauliche Faktoren, die das Mikroklima im Bestand beeinflussen, sogar eine bessere Möglichkeit der Bekämpfung gegeben, als über Methoden zur Reduktion des bodenbürtigen Inokulums in Form von Sklerotien.

Aufgrund der in den ersten drei Versuchsjahren aufgetretenen Unterschiede in der Anfälligkeit der Sorten gegenüber einer künstlichen Inokulation mit S. sclerotiorum, sowie der unterschiedlichen Schadwirkungen in den Sorten, die sich besonders stark in den wirtschaftlichen Schadensschwellen niederschlugen, wurde im Versuchsjahr 2004/05 ein Sortenversuch angelegt. In diesem Versuch wurden sieben verschiedene Sorten auf ihre Befalls-Verlust-Relationen untersucht. Die im deutschen Rapsanbau zugelassenen Sorten weisen nur eine sehr geringe Variabilität hinsichtlich der Anfälligkeit gegenüber S. sclerotiorum auf (ANONYM, 2004). Wenig anfällige Sorten sind zurzeit in Deutschland nicht verfügbar. In China hingegen sind bereits mehrere resistente/tolerante Sorten verfügbar (LI et al., 1999; WANG et al., 1999; ZHAO et al., 2004), die einen großen Anteil der Rapsanbaufläche einnehmen (LI et al., 1999).

Natürliche Resistenzmechanismen gegen Sclerotinia spp. basieren auf einer Resistenz des Pflanzengewebes gegen eine Beschädigung durch das Pathogen, auf dem 
Vorhandensein antifungalen Materials oder auf der Bildung von Phytoalexinen (LUMSDEN, 1979). In Erucastrum gallicum, ein Unkraut aus der Familie der Brassicaceen, konnten PEDRAS \& AHIAHONU (2004) die Bildung von Phytoalexinen als Reaktion auf eine Infektion mit S. sclerotiorum nachweisen.

In Brassica napus konnten unterschiedlich stark ausgeprägt Anfälligkeiten gegenüber S. sclerotiorum in Abhängigkeit des Abreifezeitpunktes (SEDUN et al., 1989) oder des Sortentyps (ZHAO et al., 2004) beobachtet und erarbeitet werden (LI et al., 1999; Mullins et al., 1999; SHI et al., 2003; LIU et al., 2005). Einen weiteren Ansatz stellt die Züchtung blütenblattloser Rapssorten dar, da Blütenblätter ein entscheidender Faktor für erfolgreiche Sclerotinia-Infektionen sind (JAMAUX et al., 1995). JIANG (2001) konnte in blütenblattlosen Mutanten geringere Befallshäufigkeiten beobachten, als in herkömmlichen Linien.

Die im Versuchsjahr 2004/05 im Feld untersuchten Sorten, sind in der Bundessortenliste (ANONYM, 2004) mit den Noten 5-7 (mittel bis stark anfällig) eingestuft. Entsprechend der geringen Variabilität der Anfälligkeit des untersuchten Sortenspektrums konnten lediglich die Unterschiede zwischen den Sorten Viking und Elektra in der Befallshäufigkeit nach künstlicher Inokulation statistisch abgesichert werden. Eine Einteilung in Anfälligkeitsgruppen entsprechend der in der Bundessortenliste vergebenen Noten (ANONYM, 2004) war nicht möglich. Im Rahmen einer anderen Arbeit wurde im Institut für Pflanzenpathologie und Pflanzenschutz in Göttingen eine Vielzahl verschiedener Rapssorten mittels unterschiedlicher Inokulationsmethoden mit S. sclerotiorum infiziert (REWERTS, 2003). Auch hier konnte aufgrund der Versuchsergebnisse die vom Bundessortenamt vorgenommene Eingruppierung der verschiedenen Sorten in Anfälligkeitsklassen nicht nachvollzogen werden. Durch die künstliche Inokulation wird der natürliche Infektionsprozess jedoch nicht genau widergespiegelt. Es besteht daher die Möglichkeit, dass die Anfälligkeiten unter natürlichen Bedingungen von denen der künstlichen Bedingungen abweichen. Zur Klärung dieser Frage sind Gewächshausversuche mit einer der natürlichen Infektion näher kommenden Inokulationsmethode geplant.

Der Hauptaspekt des Sortenversuches war die Erarbeitung sortenspezifischer BefallsVerlust-Relationen. Es zeigten sich starke Unterschiede in der Ertragswirkung von 0,58\% (Oase) bis 1,3\% (Talent) Ertragsverlust pro 1\% Befallshäufigkeit zwischen den Sorten. Die Regression zwischen Befallshäufigkeit und Ertrag war bei den Sorten 
Talent, Elektra und Oase jedoch nicht signifikant. Ein Vergleich der Schadwirkung der untersuchten Sorten wies keine signifikanten Unterschiede auf. Ausgehend von diesen einjährigen Ergebnissen können keine sortenabhängigen Schadensschwellen entwickelt werden. Mehrjährige Feldversuche wären notwendig, um Sortenunterschiede in der Schadwirkung sicher erarbeiten zu können.

Neben der künstlichen Inokulation mit beimpften Zahnstochern wurden in parallel angelegten Feldversuchen zur Untersuchung des Kompensationspotentials von Winterraps Pflanzenverluste simuliert, wie sie z.B. durch eine Sclerotinia-Infektion hervorgerufen werden können. Eine methodische Fragestellung, die sich aus dieser Vorgehensweise ableitet, ist, inwieweit der durch diese beiden Methoden hervorgerufene Ertragsverlust voneinander abweicht. Sowohl durch die Pflanzenreduktion als auch durch die künstliche Inokulation $\mathrm{zu}$ BBCH 71 konnten deutliche Ertragsverluste verursacht werden. Vergleicht man diese beiden Methoden miteinander, ist zu erkennen, dass durch Pflanzenreduktion ein deutlich stärkerer Ertragsverlust hervorgerufen wurde, als durch eine künstliche Inokulation. Bei der Hybridsorte liegt der Ertragsverlust durch Pflanzenreduktion bei 0,67\% pro 1\% Pflanzenreduktion, bei der Liniensorte bei 0,60\%. Im Gegensatz dazu wurde durch eine künstliche Inokulation in der Hybridsorte $0,31 \%$ Ertragsverlust pro $1 \%$ Befallshäufigkeit und in der Liniensorte $0,26 \%$ Ertragsverlust verursacht. Mit S. sclerotiorum infizierte Pflanzen zeigten deutlich die typischen Symptome: weißliche Verfärbung des Stängels, frühzeitige Abreife und Sklerotienbildung im befallenen Gewebe. Trotz starken Befalls konnten die Pflanzen jedoch Schoten und Körner ausbilden und somit zum Gesamtertrag der Parzelle beitragen. Bei der Bestandesdichteregulierung wurden die Pflanzen in ca. $40 \mathrm{~cm}$ Höhe über dem Boden abgeschnitten und die Pflanzenreste in der Parzelle belassen. Durch das komplette Durchtrennen der Pflanzenstängel konnten die Pflanzen keinen Ertrag bilden und verrotteten zu großen Teilen.

Die exakte Simulation von biotischen Schäden und deren Auswirkungen auf die Pflanze durch mechanische Methoden stellt sich als sehr schwierig dar (WALKER, 1983). Eine Entfernung von Pflanzen zur Simulierung eines Befallsgeschehens ist nur für Krankheiten sinnvoll, die einen kompletten Pflanzenverlust nach sich ziehen (JAMES, 1974). S. sclerotiorum hingegen schädigt die Pflanze, führt jedoch in vielen Fällen nicht 
zu einem kompletten Pflanzenverlust. Die mechanische Bestandesdichteregulierung ist somit keine geeignete Methode zur Untersuchung der Schadwirkung dieser Krankheit.

Den Hauptaspekt dieses Feldversuches stellte die Untersuchung des Kompensationsvermögens später Pflanzenverluste dar. Aufgrund der im Übermaß angelegten Ertragskomponenten, die im Verlauf der Vegetation zu großen Teilen wieder reduziert werden (GEISLER, 1988), können Rapspflanzen Reduktionen von Ertragskomponenten durch äußere Einflüsse wie z. B. Schädlingsbefall oder Hagelschlag sehr gut ausgleichen. Die Kompensation beruht auf einer größeren Verfügbarkeit von Nährstoffen, Wasser, Licht und Standraum aufgrund geringer Konkurrenz durch benachbarte befallene Pflanzen (MCGREGOR, 1980; KLEIN-GEBBINCK \& WoODS, 2002). In den künstlich inokulierten Feldversuchen konnten keine Kompensationseffekte festgestellt werden. Ausschlaggebend hierfür könnte die Tatsache sein, dass die Pflanzen nicht komplett abgestorben sind und trotz Infektionen weiter Nährstoffe, Wasser und Standraum beansprucht haben und somit keine ausreichenden Ressourcen für eine Kompensation durch gesunde Pflanzen zur Verfügung standen.

Untersuchungen von MCGREGOR (1987) zeigten, dass durch eine erhöhte Anzahl von Schoten, Samen pro Schote und TKG sowie einer stärkeren Bildung von Seitentrieben ein Großteil an Pflanzenverlusten während des frühen vegetativen Wachstums kompensiert werden kann. Untersuchungen zur Ertragswirkung von Blüten- und Schotenschädlingen im Raps wiesen ein gutes Regenerationsvermögen auch nach Schädigung zu fortgeschrittener Pflanzenentwicklung auf (WILLIAMS \& FREE, 1979; TAtChell, 1983; Vietinghoff \& DAEBeler, 1986; Brown et al., 1999). Im Rahmen von dreijährigen Feldversuchen wurde die Kompensationsfähigkeit aktueller Rapssorten nach Pflanzenverlusten zu Beginn der Schotenbildung untersucht. $\mathrm{Zu}$ diesem Zweck wurden bei $0-70 \%$ der Pflanzen pro Parzelle zu BBCH 71 die Stängel durchtrennt. Diese Maßnahme resultierte in einem signifikanten Ertragsverlust. Die Anzahl durchtrennter Stängel pro Parzelle wies eine positive Korrelation zum Ertragsverlust auf. Das TKG hingegen wies eine hoch signifikante Steigerung mit zunehmender Pflanzenreduktion auf. Der Ertragsverlust durch eine Pflanzenreduktion blieb deutlich unter dem erwarteten Wert.

Die Differenz zwischen erwartetem und eingetretenem Ertragsverlust wird als Kompensation bezeichnet. Es zeigte sich mit steigendem Anteil durchtrennter 
Rapsstängel eine erhöhte Kompensation. Bei einer Pflanzenreduktion von 70\% konnte eine Kompensation von 30\% beobachtet werden. Ableitend von den Ergebnissen der Analysen des TKG kann somit gefolgert werden, dass diese Ertragskomponente einen entscheidenden Faktor bei der Kompensation später Pflanzenverluste darstellt. Die Veränderung weiterer Ertragskomponenten, wie Anzahl Schoten pro Pflanze und Anzahl Körner pro Schote, konnten aus versuchstechnischen Gründen nicht untersucht werden. Denkbar wäre jedoch, dass auch diese Komponenten zur Kompensation beigetragen haben. Die Bildung neuer Seitentriebe, wie sie bei früher auftretenden Schädigungen zu beobachten ist, ist bei Schädigungen zu Beginn der Schotenbildung auszuschließen. SchUlz \& BoElCKE (1991) sowie TATCHELL (1983) haben in ihren Untersuchungen ebenfalls gezeigt, dass sehr späte Schädigungen von Ertragskomponenten durch eine Erhöhung der Einzelsamengewichte teilweise kompensiert werden können. In den Jahren 1999-2001 wurden in Schleswig-Holstein vergleichbare Untersuchungen von SCHLOTT \& SAUERMANN (2003) durchgeführt. In diesen Versuchen wurden bei $25-100 \%$ der Pflanzen pro Parzelle die Stängel im Bereich der untersten Verzweigung durchtrennt. Um Aussagen über das Kompensationsvermögen in Abhängigkeit des Zeitpunktes der Pflanzenreduktion machen zu können, wurden sechs verschiedene Behandlungstermine von Ende der Knospenbildung bis Schwaddruschreife gewählt. Entsprechend den Ergebnissen der Göttinger Feldversuche konnte mit steigender Pflanzenreduktion eine steigende Kompensation beobachtet werden. Auch die erreichten Werte sind mit denen der Göttinger Versuche vergleichbar. Die Kompensationsfähigkeit nimmt mit fortlaufender Pflanzenentwicklung stark ab. Ab dem Ende der Kornausbildung nähern sich die Ertragsverluste dem Anteil der entnommenen Pflanzen (SchlotT \& SAUERMANN, 2003). Ein abnehmendes Regenerationsvermögen mit fortschreitender Pflanzenentwicklung wird auch von SCHUlz \& BoelcKe (1989) sowie von MCGREGOR (1980) und WALKer (1983) berichtet. Ergebnisse aus eigenen Versuchen im Versuchsjahr 2003/04 konnten dies jedoch nicht bestätigen. Nach Entfernen von 50\% der Pflanzen einer Parzelle zu Beginn der Knospenbildung, im Knospenstadium, zu Beginn der Blüte und zur Vollblüte konnten keine Minderungen des Ertrages im Vergleich zur unbehandelten Kontrolle beobachtet werden. Anders als nach einer Pflanzenreduktion zu Beginn der Schotenbildung konnte jedoch kein Anstieg des TKG verzeichnet werden. Es ist daher davon auszugehen, dass die Pflanzenverluste durch vermehrte Ausbildung anderer Ertragskomponenten kompensiert wurden. Ähnliche Ergebnisse wiesen die 
Untersuchungen von SCHLOTT \& SAUERMANN (2003) vor. Lediglich nach Pflanzenreduktion $\mathrm{zu}$ Blühende und Beginn der Kornausbildung konnte ein ansteigendes TKG beobachtet werden. Da jedoch Pflanzenreduktionen zu früheren Terminen eine stärkere Kompensation hervorriefen, gehen die Autoren davon aus, dass zu diesen Terminen hauptsächlich die Ertragskomponente Schotenanzahl pro Pflanze kompensiert wurde.

Signifikante Unterschiede im Kompensationsvermögen zwischen den untersuchten Sorten Prince und Talent bzw. Maja konnten in den dreijährigen Feldversuchen nicht festgestellt werden. Die Liniensorte Prince wies jedoch ein tendenziell stärkeres Kompensationsvermögen als die Hybridsorten Talent und Maja auf. In den Untersuchungen von SCHLOTT \& SAUERMANN (2003) wird nicht auf Sortenunterschiede hinsichtlich des Kompensationsvermögens nach Reduktion von Ganzpflanzen eingegangen. Parallel durchgeführte Untersuchungen zur Regenerationsfähigkeit abgeknickter Pflanzen wiesen jedoch recht deutliche Unterschiede zwischen den Sorten Panther, Talent und Maja auf (SchlotT \& Sauermann, 2003). Da jede Sorte jedoch in nur einem Versuchsjahr angebaut wurde, ist ein Jahreseinfluss auf die sortenbedingten Unterschiede nicht auszuschließen.

\subsubsection{Befalls-Verlust-Relation für $V$. longisporum an Winterraps}

Zur Untersuchung der Schadwirkung von $V$. longisporum in Relation zur Befallshäufigkeit wurden unterschiedliche Mengen natürlich mit $V$. longisporum befallenen Rapsstrohs in den Parzellen ausgebracht. Die genaue Menge an reinem Pilzmaterial wurde jedoch vor Ausbringung nicht analysiert. Durch diese Bodenverseuchung konnten natürliche Infektionen sehr gut nachgestellt werden, da auch hier die Infektionen von Mikrosklerotien an Ernterückständen ausgehen. Wie die erzielten Befallshäufigkeiten in den Versuchsjahren 2002/03 und 2003/04 zeigten, konnte eine steigende Befallshäufigkeit mit ansteigender Menge an Inokulum erzielt werden. Im Versuchsjahr 2002/03 waren die erreichten Befallshäufigkeiten jedoch deutlich höher als im Versuchsjahr 2003/04.

In der Literatur wird mehrfach von einer positiven Korrelation zwischen Befallshäufigkeit und der Menge an bodenbürtigem Inokulum berichtet (ASHWORTH et al., 1972; Ashworth et al., 1979; Pullman \& De VAy, 1982a; NiCOT \& Rouse, 
1987b; Paplomatas et al., 1992; Heppner, 1995; XiaO \& SubbaraO, 1998). ASHWORTH et al. (1979) führen jedoch an, dass gleiche Mengen an Inokulum nicht immer zu denselben Befallshäufigkeiten führen, und dass die Ertragswirkung jahresabhängige Unterschiede aufweisen kann. Eine gebräuchliche Methode zur Quantifizierung der Menge an bodenbürtigem Inokulum stellt das Ausplattieren von Bodensuspensionen auf Selektivmedien dar. In der Literatur sind zahlreiche Angaben zu Entwicklung, Testung (Huisman \& Ashworth, 1974; ButTerfield \& DeVAY, 1977; NICOT \& RouSE, 1987a; HARRIS et al., 1993; GOUD et al., 2003; KABIR et al., 2004) und Anwendung verschiedener Medien (Pullman \& DeVAy, 1982; NiCOT \& Rouse, 1987b; PAPlomatas et al., 1992; KoIKE et al., 1994; Mol et al., 1995; SubBaraO \& HubBard, 1996; XiAO et al., 1998; XIAO \& SUBBARAO, 1998; STEINBACH et al., 2002) aufgeführt.

In der hier vorliegenden Arbeit wurde das im Rahmen eines UFOP-Monitorings zum Auftreten von $V$. longisporum auf Rapsstandorten in Deutschland (STEINBACH et al., 2002) verwendete Selektivmedium verwendet. Im ersten Versuchsjahr wurden beträchtlich höhere Mengen an Inokulum im Boden detektiert als im nachfolgenden Versuchsjahr. Mögliche Ursachen hierfür könnten zum einen in der längeren Lagerungsdauer des Inokulummaterials für das Versuchsjahr 2003/04, zum anderen in der unterschiedlichen Terminierung der Entnahme der Bodenproben liegen. In beiden Versuchsjahren wurde natürlich befallenes Stroh von einem Befallsstandort aus dem Jahr 2002 verwendet. Das Material für das Versuchsjahr 2003/04 wurde somit ein Jahr bei Raumtemperatur gelagert. Im Versuchsjahr 2002/03 wurden die Bodenproben bereits $\mathrm{zu}$ Vegetationsende im Oktober entnommen, während im darauf folgenden Versuchsjahr erst zu Beginn der Vegetationsperiode im April Bodenproben entnommen wurden. In der Arbeit von HEPPNER (1995) wurde die Inokulumkonzentration von $V$.dahliae in natürlich sowie in künstlich verseuchten Böden mit dem Plattengussverfahren und dem ELISA untersucht. Es zeigte sich, dass die Inokulumkonzentration bis Vegetationsende (Oktober/November) ansteigt, anschließend bis Vegetationsbeginn (Februar/März) wieder absinkt, bevor sie dann erneut ansteigt. Die maximale, im vorangegangenen Herbst erfasste Inokulumkonzentration wurde jedoch nicht wieder erreicht.

Sehr widersprüchlich war, dass in den nicht inokulierten Kontrollparzellen die höchsten Mengen an Verticillium-Inokulum detektiert wurden. Auch in den Untersuchungen von STEINBACH et al. (2002) wurden in Bodenproben von Feldern ohne bonitierten Befall 
hohe Mengen an Bodeninokulum durch Ausplattieren auf das genannte Selektivmedium detektiert. Eine Schwachstelle dieser Nachweismethode ist eine fehlende Differenzierung zwischen den verschiedenen Verticillium-Arten. Die Detektion erfolgt lediglich auf Grundlage der Ausbildung von Mikrosklerotien, die sich jedoch anhand der Koloniecharakteristika nicht genügend eindeutig den verschiedenen VerticilliumArten zuordnen lassen. Eine exakte Bestimmung der Menge an bodenbürtigem V. longisporum-Inokulum in den unterschiedlich stark inokulierten Parzellen ist aus dieser Sicht nicht möglich.

In der Arbeit von HEPPNER (1995) wurden verschiedene Medien zur Isolierung von V. dahliae aus Bodenproben getestet. Ein Pektatmedium, welches im Gegensatz zu dem in dieser Arbeit verwendeten Medium kein Bodenextrakt und eine veränderte Zusammensetzung von Nährstoffen enthielt, erwies sich als das am besten geeignete Medium. Ein dem in der vorliegenden Arbeit verwendeten vergleichbares Medium zeigte eine deutlich geringere Ausbeute an Pilzkolonien. Sowohl HEPPNER (1995) als auch STEINBACH et al. (2002) weisen darauf hin, dass in schwach verseuchten Böden eine genaue Quantifizierung des Bodeninokulums mit Hilfe des Plattengussverfahrens nicht möglich ist.

In den Feldversuchen haben jedoch neben der Inokulumkonzentration noch verschiedene abiotische Faktoren, wie Temperatur, Feuchte und Sortenwahl einen Einfluss auf die Ausbildung der Krankheit. Bei der Sortenwahl stehen dem Anbauer zurzeit noch keine resistenten Rapssorten zur Verfügung. Im Sortenspektrum gibt es jedoch unterschiedlich stark anfällige Sorten. Die im Versuchsjahr 2003/04 angebaute Sorte Wotan, die im aktuellen Anbau jedoch keine Bedeutung mehr hat, erwies sich in zweijährigen Untersuchungen als relativ anfällig (HEPPNER, 1995). Die im ersten Versuchsjahr angebaute Sorte Prince ist nach Züchterinformationen als mittel anfällig einzustufen. Genauere Untersuchungen hinsichtlich der Anfälligkeit verschiedener aktueller Winterrapssorten gegenüber $V$. longisporum sind allerdings noch nicht publiziert. In den hier beschriebenen Feldversuchen stellte sich die Sorte Wotan entgegen der Ergebnisse von HEPPNER (1995) als wenig anfällig dar. Im vorangegangenen Versuchsjahr wurden in der Sorte Prince deutlich höhere Befallshäufigkeiten erzielt. Wie bereits diskutiert, waren die Bodeninokulummengen im Versuchsjahr 2003/04 sehr gering und es wurde keine weitere Vergleichssorte angebaut, 
so dass auf Basis der vorliegenden Ergebnisse keine Aussage über die Anfälligkeit der Sorten gemacht werden kann.

Viele Autoren haben die Frage zum Einfluss der Temperatur auf Infektion und Symptomausprägung verschiedener Verticillium spp. bearbeitet. PEGG \& BRADY (2002) haben die Ergebnisse dieser Untersuchungen zusammengefasst. Mit steigenden Temperaturen können steigende Befallswerte beobachtet werden. Optimale Temperaturen für die Entwicklung von Verticillium spp. sind bei $20-25^{\circ} \mathrm{C}$ gegeben. Die Bildung von Mikrosklerotien im befallenen Pflanzengewebe hingegen zeigte ein Optimum bei $15-20^{\circ} \mathrm{C}$ (SOESANTO \& Termorshuizen, 2001). Untersuchungen an Baumwolle zeigten, dass Temperaturen von $38^{\circ} \mathrm{C}$ die Entwicklung von $V$. dahliae hindern (Pullman \& DeVAY, 1982b). Über den Einfluss der Feuchte auf Infektionen mit Verticillium spp. sind in der Literatur widersprüchliche Meinungen vertreten (GreEn, 1980; El-ZIK, 1985; CAPPAERT et al., 1992; GAUdreAult et al., 1992; XiaO et al., 1998; JEFFERSON \& GOSSEN, 2002; LÓPEZ-EsCUDERO \& BLANCO-LÓPEZ, 2005)

In den in Göttingen durchgeführten Feldversuchen waren im Versuchsjahr 2002/03 in den Monaten August bis Januar höhere Niederschlagsmengen als im Versuchsjahr 2003/04 zu verzeichnen. In den Monaten Februar bis Juli hingegen waren die Niederschlagsmengen im Versuchsjahr 2003/04 höher. Im ersten Versuchsjahr waren somit bis Vegetationsbeginn im Frühling relativ feuchte Bedingungen vorherrschend, gefolgt von trockeneren Bedingungen. Im Versuchsjahr 2003/04 waren bis Mai 2004 relativ geringe Niederschlagsmengen zu verzeichnen. Die Temperaturen waren in beiden Versuchsjahren weitestgehend vergleichbar. Die Wintermonate waren im Versuchsjahr 2002/03 kälter als im Versuchsjahr 2003/04, die Monate Mai-Juli hingegen waren im ersten Versuchjahr wärmer als im nachfolgenden. In beiden Versuchsjahren waren die mittleren Temperaturen nach der Aussaat geringer als $15^{\circ} \mathrm{C}$, bis November aber noch über der für eine Mikrosklerotienkeimung notwendigen Minimumtemperatur von $6^{\circ} \mathrm{C}$ (PEGG \& BRADY, 2002) jedoch kann die Bodentemperatur deutlich davon abweichen. Im Versuchsjahr 2002/03 waren die Temperaturbedingungen für die Entwicklung eines Verticillium-Befalls besser als im nachfolgenden Jahr. Die Feuchtigkeitsbedingungen hingegen waren schlechter, wenn man von einer Förderung des Krankheitsgeschehens unter feuchten Bedingungen ausgeht. Ausgehend von der Annahme, dass die Temperatur den größten Einfluss auf Infektion und Krankheitsverlauf hat (PEGG \& BRADY, 2002), könnten die höheren Befallshäufigkeiten 
im Versuchsjahr 2002/03 mit den für den Krankheitsverlauf besseren Witterungsbedingungen zu erklären sein.

Eine zentrale Frage dieser Arbeit war die Untersuchung der Schadwirkung von V. longisporum in Abhängigkeit der Befallshäufigkeit im Feld. Untersuchungen von ZEISE \& STEINBACH (2004) und ZEISE \& SEIDEL (1990) zur Ertragswirkung von V. longisporum an Einzelpflanzen haben eine deutliche Ertragsminderung ausgewiesen. ZEISE \& STEINBACH (2004) entnahmen vor der Ernte gesunde, halb abgestorbene und abgestorbene Pflanzen und ermittelten den Kornertrag sowie das TKG. In den Jahren 1985 bis 2004 konnten Ertragsverluste von 30-85\% in abgestorbenen und von 17-55\% in halb abgestorbenen Pflanzen ermittelt werden. Das TKG der Einzelpflanzen war in abgestorbenen Pflanzen um rund 20\% im Vergleich zu gesunden Pflanzen verringert. Auch hier war mit zunehmender Befallsstärke eine Verringerung des TKG zu verzeichnen. In künstlich inokulierten „rapid cycling“ Brassica Arten war der Einzelpflanzenertrag von Brassica napus um rund $60 \%$ im Vergleich zur Gesundkontrolle verringert. Das TKG zeigte keine signifikante Reaktion auf einen V. longisporum-Befall (ZEISE \& BUCHMÜLLER, 1997). Ergebnisse aus Einzelpflanzenuntersuchungen können jedoch nicht auf Feldergebnisse übertragen werden, da es im Feld zur Kompensation von Ertragsverlusten durch nicht befallene Pflanzen kommen kann (WALKER, 1983). Ein genaues Abbild eines befallenen Schlages kann somit nicht dargestellt werden.

Untersuchungen zur Schadwirkung von $V$. longisporum im Bestand sind in der Literatur nur spärlich zu finden. HoRNIG $(1986,1987)$ hat in seinen Untersuchungen TKGMinderungen von 2-25\% feststellen können. Für den Zeitraum 1984-1986 konnte er bei Befallshäufigkeiten von 3-98\% Ertragsverluste von 2-34\% beobachten. Diese Ertragsverluste wurden allerdings dem Krankheitsbild der krankhaften Abreife zugeordnet, die neben $V$. longisporum auch $P$. lingam einschließt. In künstlich mit V. longisporum infizierten Parzellenversuchen konnten GÜNZELMANN \& PAUL (1990) bei einer Befallshäufigkeit von $24 \%$ Ertragseinbußen von $10 \%$ verzeichnen. Sie berichten von Ertragsverlusten bis $25 \%$ auf stark verseuchten Flächen in der Praxis. In den eigenen Feldversuchen konnte bei Befallshäufigkeiten von 12-54\% in 2002/03 bzw. 9-34\% in 2003/04 keine signifikante Ertragsminderung im Mittel über jeweils vier Wiederholungen beobachtet werden. Auch auf TKG und Ölgehalt konnte kein negativer Effekt festgestellt werden. Im Jahr 2004/05 in Göttingen durchgeführte Sortenversuche 
zur Anfälligkeit gegen und Schadwirkung von $V$. longisporum zeigten ebenfalls bei sortenabhängigen Befallshäufigkeiten von bis zu 63\% keine Ertragsminderung im Vergleich zur Gesundkontrolle (EYNCK, 2005, persönliche Mitteilung). In der Arbeit von HEPPNER (1995) konnten erst ab einer Bodeninokulummenge von $240 \mu \mathrm{g} \mathrm{MS} / \mathrm{g}$ Boden statistisch abzusichernde Ertragsverluste in der Sorte Ceres von 20 bzw. 32,5\% erzielt werden. Die Befallshäufigkeit wurde in diesen Versuchen jedoch nicht aufgenommen, lediglich der Befallswert (3 bzw. 4). In der weniger anfälligen Sorte Express konnte bei der gleichen Bodeninokulummenge keine signifikante Ertragsminderung festgestellt werden. Bei dieser Sorte waren auch die Befallswerte mit rund 1,8 deutlich geringer als bei der Sorte Ceres (HEPPNER, 1995).

Wie die Untersuchungen von Zeise \& SeIDEL (1990) und ZEISE \& STEINBACH (2004) zeigten, ist neben der Befallshäufigkeit die Befallsstärke ein für die Schadwirkung entscheidender Faktor. Nur schwach befallene Pflanzen werden in der Ertragsbildung weniger stark beeinflusst als stark befallene Pflanzen. In den im Rahmen der hier vorliegenden Arbeit durchgeführten Feldversuchen waren die Befallsstärken auch in den hoch befallenen Parzellen sehr gering. Im Versuchsjahr 2002/03 wiesen in der mit $1200 \mathrm{~g}$ Inokulummaterial am stärksten infizierten Parzelle lediglich rund 10\% der Pflanzen einen starken Besatz mit Mikrosklerotien auf, im folgenden Versuchsjahr nur rund 5\% der Pflanzen. Die geringe Befallsstärke in beiden Versuchsjahren kann eine Ursache für die ausbleibende signifikante Ertragswirkung des Verticillium-Befalls darstellen.

Die Grundlage für Infektionen mit $V$. longisporum stellen die bodenbürtigen Mikrosklerotien dar. Ausgehend von den Mikrosklerotien wird ein Keimschlauch gebildet, aus dem Hyphen auswachsen, die die Hypodermis junger Wurzeln der Rapspflanzen direkt, ohne Ausbildung spezieller Penetrationsorgane, penetrieren (Fitzell et al., 1980). Untersuchungen von Mol (1995) zeigten, dass Wurzelexsudate für das Auskeimen der Mikrosklerotien von $V$. dahliae einen stimulierenden Faktor darstellen. Neuere Untersuchungen von EYNCK et al. (2005) sowie von ZHOU et al. (2006) zur Interaktion von $V$. longisporum und Raps zeigen, dass die ersten Interaktionen an den Wurzelhaaren stattfinden, die Penetration jedoch direkt an der Wurzel geschieht. Bevorzugte Infektionen über Wunden und Austrittsstellen von Sekundärwurzeln (AGRIOS, 1997) konnte für V. longisporum nicht beobachtet werden. Nachdem der Pilz in die Pflanze eingedrungen ist, besiedelt er das Xylem 
(Niederleitner et al., 1991; Pegg \& Brady, 2002). Für $V$. dahliae wurde eine Ausbreitung durch Konidien oder Hyphenwachstum in der Pflanze beobachtet. Im Verlauf der Pathogenese tritt der Pilz dann von dem Xylem in das Xylemparenchym über. Sichtbar wird die starke laterale Ausbreitung von $V$. longisporum in Raps aus den Xylemgefäßen in das Parenchym durch die starke Bildung von Mikrosklerotien unter der Stängelepidermis (NIEDERLEITNER et al., 1991). Die Mikrosklerotienbildung an Raps mit fortschreitender Seneszenz ist in der Literatur mehrfach beschrieben (GÜNZElMANN \& PAUl, 1990; Zeise \& Seidel, 1990; Niederleitner et al., 1991; Wolf \& Weinert, 2003; Zeise \& SteInBACH, 2004; Steinbach et al., 2005; Zhou et al., 2006). Es ist daher davon auszugehen, dass der Pilz zu diesem Zeitpunkt aufgrund ungünstiger Überlebensbedingungen in der Pflanze seine Überdauerungsformen produziert. Bei der durchgeführten Stoppelbonitur wurde der Befall der Pflanzen mit $V$. longisporum auf Basis der Bildung von Mikrosklerotien erhoben. Da die Stoppeln zur Bonitur nach der Ernte und somit nach der Abreife entnommen wurden, ist davon auszugehen, dass die Bildung von Mikrosklerotien das Befallsgeschehen ausreichend genau widerspiegelt. Wie die Ergebnisse der Stoppelbonitur in den Versuchsjahren 2002/03 und 2003/04 gezeigt haben, war im ersten Versuchsjahr der Anteil befallener Wurzeln höher als der Anteil befallener Haupttriebe und befallenen Stängelmarks. Mit ansteigender Inokulummenge konnte jedoch auch ein erhöhter Anteil befallener Haupttriebe und befallenen Stängelmarks beobachtet werden. Im folgenden Versuchsjahr war der Anteil befallener Wurzeln geringer als der befallener Haupttriebe und befallenen Stängelmarks. Ein deutlicher Anstieg im Anteil befallener Pflanzenteile mit ansteigender Inokulummenge war hier jedoch nicht zu verzeichnen. Die Ergebnisse der zwei Versuchsjahre lassen darauf schließen, dass Umwelt- oder Sortenfaktoren einen Einfluss auf die Ausbildung von Mikrosklerotien sowie die Verbreitung innerhalb der Pflanze haben. Die Witterungsbedingungen unterschieden sich in den Versuchsjahren deutlich voneinander, mit einem sehr viel wärmeren und trockeneren Sommer im Versuchsjahr 2002/03. Da in den beiden Versuchsjahren unterschiedliche Sorten angebaut wurden, wäre auch die Sortenwahl ein mögliches Kriterium für die Ausbildung von Mikrosklerotien.

Zur Untersuchung des Befallsverlaufes während der Vegetationsperiode wurden in regelmäßigen Abständen Pflanzenproben aus den unterschiedlich stark inokulierten Parzellen entnommen und mittels ELISA-Test auf Infektion mit $V$. longisporum 
untersucht. Die Methode der Detektion von Pathogenen auf immunologischer Basis wurde erstmals von EngVall \& Perlmann (1972) in der Humanmedizin angewendet. CLARK \& ADAMS (1977) verwendeten den ELISA erstmals in der Phytopathologie zum Nachweis von Pflanzenviren. In den darauf folgenden Jahren wurde der ELISA von CAsper \& Mendgen (1979) und Nachmias et al. (1979) zur Detektion pathogener Pilze (Verticillium lecanii bzw. Phoma tracheiphila) eingesetzt. Die Vorteile einer immunologischen Nachweismethode sind in der Spezifität, der Möglichkeit der Quantifizierung anhand von Standardreihen und in der hohen Empfindlichkeit dieser Verfahren zu sehen (MILLER \& MARTIN, 1988). In den vergangenen Jahren wurden mehrere ELISA-Methoden zur Detektion von Verticillium spp. entwickelt und angewendet (GERIK et al., 1987; SUNDARAM et al., 1991; VAN DE KOPPEL \& SCHOTS, 1994, 1995; CERNUSKO, 1995; HEPPNER, 1995; FORTNAGEL \& SCHLÖSSER, 1996; Cernusko \& Wolf, 1997; HePpNer \& Heitefuss, 1997).

In der hier vorliegenden Arbeit wurde der von CERNUSKO (1995) entwickelte ELISA eingesetzt. Die Antikörper wurden basierend auf einem aus Raps isolierten V. longisporum-Isolat durch Immunisierung von Kaninchen hergestellt. Wie die Ergebnisse zur Spezifität der Antikörper zeigten, wiesen $V$. longisporum-Isolate aus Raps die stärksten Signale auf. Während Isolate von V. albo-atrum, V. tricorpus und $V$. tenerum eine schwache Kreuzreaktivität aufwiesen, konnte bei weiteren pilzlichen Rapspathogenen keine Kreuzreaktivität beobachtet werden (CERNUSKO, 1995; Cennusko \& Wolf, 1997).

Die Ergebnisse der ELISA-Untersuchungen der Pflanzen aus den Feldversuchen in den Versuchsjahren 2002/03 und 2003/04 zeigten erst mit beginnender Abreife einen deutlichen Nachweis von $V$. longisporum in Wurzel- und Stängelmaterial, was sich mit den Ergebnissen von WOLF \& WEINERT (2003) und STEINBACH et al. (2005) deckt. Ein erster deutlicher serologischer Nachweis von $V$. longisporum im Pflanzenmaterial war in der hier vorliegenden Arbeit somit erst parallel zum Sichtbarwerden erster spezifischer Symptome zu Beginn der Abreife möglich.

Das Auftreten spezifischer Verticillium-Symptome an Raps erst mit beginnender Abreife wird auch von anderen Autoren beschrieben (GüNZELMANN \& PAUL, 1990; Zeise \& Seidel, 1990; Niederleitner et al., 1991; Wolf \& Weinert, 2003; Zeise \& STEINBACH, 2004; SteinBACH et al., 2005; ZHOU et al., 2006). An Blumenkohl konnten von KOIKE et al. (1994) erst mit Beginn der Bildung des Kohlkopfes erste Symptome im 
Feld beobachtet werden. Die Ursache des erst sehr späten Auftretens der Symptome an Raps liegt nach ZEISE \& SEIDEL (1990) und ZHOU et al. (2006) in den veränderten Stoffwechselprozessen zu Beginn der Blüte bzw. Abreife begründet. Der Übergang vom vegetativen zum generativen Wachstum hat nach ZHOU et al. (2006) einen entscheidenden Einfluss auf die Kolonisierung der Pflanze mit V. longisporum. Auch Untersuchungen des Pathosystems Arabidopsis thaliana und V.dahliae wies einen engen Zusammenhang zwischen der Blütephase der Pflanzen und der Symptomentwicklung auf (VERONESE et al., 2003). Entgegen der Beobachtungen im Feld können in Gewächshausversuchen mit künstlich inokulierten Pflanzen bereits zwei bis drei Wochen nach der Inokulation erste Symptome beobachtet werden (HEPPNER, 1995; ZEISE \& BUCHMÜLLER, 1997; KEUNECKE, 2005).

Aufgrund des erst sehr späten Auftretens von Symptomen stellt sich die Frage des Infektionszeitpunktes. Durch kontinuierliches Umtopfen symptomloser Rapspflanzen aus einem $V$. longisporum-verseuchten Boden in unverseuchten Boden konnte festgestellt werden, dass schon in sehr frühen Entwicklungsstadien Infektionen stattfinden (ZEISE \& SEIDEL, 1990). Auch in PCR-Untersuchungen künstlich inokulierter Gewächshauspflanzen konnte bereits zu BBCH 13 eine Besiedlung der Wurzeln mit $V$. longisporum nachgewiesen werden (ZHOU et al., 2006). Mit zunehmendem Pflanzenalter konnte in diesen Untersuchungen eine zunehmende Ausbreitung in der Pflanze beobachtet werden, jedoch erst mit Beginn der Blüte wurde auch in oberen Pflanzenteilen eine Besiedlung nachgewiesen. SVENSSON \& LERENIUS (1987) legten vor Winter gesammelte Laubblätter von Rapspflanzen aus künstlich inokulierten Parzellen in Feuchtekammern aus, und konnten dadurch einen Befall der noch sehr jungen Pflanzen nachweisen. Mit Hilfe der ELISA-Untersuchungen konnten auch in den Pflanzen der Göttinger Feldversuche bereits zu Vegetationsbeginn im Frühjahr geringe Mengen an Pilzbiomasse in Wurzeln detektiert werden, was auf eine latente Infektion hinweist.

Ein typisches Symptombild von Verticillium spp. ist das Auftreten von Welkeerscheinungen (PEGG \& BRADY, 2002). In den zweijährigen Feldversuchen konnten jedoch keine Welkeerscheinungen beobachtet werden. Auch in Untersuchungen von NIEDERLEITNER et al. (1991) blieben Welkesymptome nach Infektion von Rapspflanzen mit $V$. longisporum aus. Hervorgerufen werden die Welkeerscheinungen durch Besiedelung des Xylems durch ein Hyphengeflecht des 
Pathogens sowie durch Ablagerung amorphen Materials als Reaktion der Pflanze auf den Befall (NIEDERLEITNER et al., 1991). Wie Untersuchungen von KEUNECKE (2005) zeigten, rief ein $V$. longisporum-Befall an Winterraps nach künstlicher Inokulation im Gewächshaus jedoch keinen befallsinduzierten Wasserstress hervor. Rasterelektronenmikroskopische Untersuchungen von NIEDERLEITNER et al. (1991) zeigten, dass die Xylemgefäße von Rapspflanzen deutlich weniger stark mit Verticillium-Hyphen besetzt waren, als solche von Impatiens balsamina, was die ausbleibenden Welkeerscheinungen erklären könnte. Ebenso wie die fehlenden Welkesymptome traten die Stauchungseffekte, die in anderen Verticillium-Pathosystemen (PULlMAN \& DEVAY, 1982b; Koike et al., 1994; Xiao \& SubbaraO, 1998; Debode et al., 2005) sowie in Gewächshausversuchen auch an Raps beobachtet wurden (ZEISE, 1992; HEPPNER, 1995; ZEISE \& BUCHMÜLLER, 1997; KeUNECKE, 2005), in den Feldversuchen nicht auf. Aufgrund der ausbleibenden Welkeerscheinungen an mit $V$. longisporum befallenen Rapspflanzen stellt sich die Frage, ob der im Allgemeinen verwendete Begriff Rapswelke eine passende Bezeichnung für diese Krankheit darstellt.

Einen wichtigen Einflussfaktor für die Schadwirkung eines Verticillium-Befalls stellt der Zeitpunkt der Infektion bzw. der Symptomentwicklung dar (GUTIERREZ et al., 1983; AHLERS, 1987). In Untersuchungen von SVENSSON \& LERENIUS (1987) sowie von DAEBELER et al. (1988) führten frühe Infektionen von Rapspflanzen mit $V$. longisporum zu höheren Ertragsverlusten als Infektionen zu späteren Terminen. GuTIERREZ et al. (1983) und Pullman \& DeVay (1982b) beschreiben einen geringeren Ertragsverlust bei spät erkrankten Baumwollpflanzen im Vergleich zu früh erkrankten Pflanzen. Anhand der Ergebnisse der in Göttingen durchgeführten Feldversuche konnte ein Effekt des Infektionstermins auf die Schadwirkung jedoch nicht nachgewiesen werden. In beiden Versuchsjahren konnte erst mit beginnender Abreife ein Befall mit V. longisporum visuell sowie mit dem ELISA detektiert werden, der jedoch zu keinem signifikanten Ertragsverlust führte.

In verschiedenen Untersuchungen an Blumenkohl, Baumwolle und Kartoffeln konnte mit abnehmender Inokulumdichte im Boden eine verzögerte Krankheitsentwicklung beobachtet werden (Pullman \& DeVay, 1982a; Nicot \& Rouse, 1987b; XiaO \& SubBARAO, 1998). In den in Göttingen in den Versuchsjahren 2002/03 und 2003/04 durchgeführten Feldversuchen konnte dieser Zusammenhang nicht bestätigt werden. Die ELISA-Ergebnisse zeigten keine frühere Befallsentwicklung mit steigender 
Inokulummenge. Zwischen den Versuchsjahren konnten jedoch Unterschiede beobachtet werden. Im ersten Versuchsjahr waren eine frühere Befallsentwicklung und höhere Befallshäufigkeiten als im darauf folgenden Versuchsjahr zu verzeichnen. Ab dem Beginn der Abreife konnten stark ansteigende ELISA-Werte sowohl in Wurzel- als auch im Stängelmaterial erzielt werden. Die mit $300 \mathrm{~g}$ Inokulummaterial am niedrigsten inokulierte Variante wies jedoch zu BBCH 83 die höchsten ELISA-Werte auf. Erst zu BBCH 89 war in der hoch inokulierten Variante der höchste ELISA-Wert zu erzielen. Im Versuchsjahr 2003/04 war erst ab BBCH 83 ein deutlicher Anstieg der Netto-OD zu verzeichnen. Hier zeigte sich in den Untersuchungen des Wurzelmaterials bereits eine klare Abgrenzung der hoch inokulierten Variante zur niedrigen Inokulumstufe und zur Kontrolle. Im Stängelmaterial war erst zur Ernte ein deutlich höherer Netto-OD-Wert in der hoch inokulierten Variante nachzuweisen.

Das erst sehr späte Auftreten von Symptomen und die damit vermutlich einhergehende späte Besiedlung der Pflanze mit $V$. longisporum können somit eine Erklärung für die ausbleibende Ertragswirkung sein. Aus diesem Grund sollte man bei $V$. longisporum an Raps von einer Abreifekrankheit sprechen. Die ausbleibende Ertragswirkung in den Feldversuchen darf jedoch nicht als Entwarnung für die Praxis gelten. In den Versuchen waren der Befallsdruck und die erzielten Befallshäufigkeiten nur sehr gering. Bei starkem Befallsdruck durch hohe Mengen an bodenbürtigem Inokulum kann es durchaus zu Ertragsverlusten kommen. Durch eine weit gestellte Fruchtfolge sollte die Gefährdung von Verticillium-Infektionen minimiert werden, um eine Anreicherung von Mikrosklerotien im Boden zu verhindern. Aufgrund fehlender Bekämpfungsmöglichkeiten durch Fungizide war es im Gegensatz zu dem Pathogen S. sclerotiorum nicht möglich, eine wirtschaftliche Schadensschwelle für $V$. longisporum zu berechnen (TISCHNER, 1998).

\subsection{Wirtschaftlichkeit von Fungizidmaßnahmen zur Bekämpfung von S. sclerotiorum in Winterraps}

Der Einsatz von Fungiziden zur Bekämpfung von S. sclerotiorum im Winterraps zur Blüte wird in der Praxis oftmals routinemäßig durchgeführt, um hohe Ertragsverluste zu vermeiden (KROSTITZ, 1998). Wie Untersuchungen aus den Jahren 1980-1991 zeigten, sind jedoch ein Großteil dieser Behandlungen unwirtschaftlich (WAHMHOFF, 2000). 
In Anlehnung an die Untersuchungen von WAHMHOFF (2000) aus den Jahren 19811990 wurde die Wirtschaftlichkeit von Fungizidmaßnahmen der folgenden Jahre 19912003 im Hinblick auf die Bekämpfung von S. sclerotiorum anhand von Daten aus den offiziellen Feldversuchen der Pflanzenschutzdienste der Länder validiert.

Eine Schwierigkeit bei der Auswertung der Ertragswirkung und der Wirtschaftlichkeit von Fungizidapplikationen stellt die exakte Zuordnung zur Bekämpfung einzelner Pathogene dar. Durch ein relativ breites Wirkungsspektrum der Fungizide und das gleichzeitige Auftreten verschiedener Pathogene werden folglich mehrere Schaderreger gleichzeitig bekämpft. Der Ertragseffekt muss daher auf die gesamte Behandlung und nicht auf die Bekämpfung einzelner Schaderreger bezogen werden. Aus diesen Problemen ergibt sich die Tatsache, dass aufbauend auf solchen Daten nicht ohne weiteres, Befalls-Verlust-Beziehungen entwickelt werden können (KELBER, 1975; WAнмноғF, 2000). Etwas differenzierter ist die Situation bei einer Blütenbehandlung im Raps. Die Ertragswirkung einer Blütenbehandlung ist hauptsächlich der Bekämpfung des zu diesem Termin auftretenden Pathogens S. sclerotiorum zuzuordnen (WAHMHOFF, 2000).

Die Auswertung des vorliegenden Datensatzes wies deutliche Jahreseinflüsse im Auftreten von S. sclerotiorum mit Schwankungen in der Befallshäufigkeit zwischen $75,1 \%$ und $6,3 \%$ auf. Die Hauptursache für diese starke Schwankung ist in der jahresbedingten unterschiedlichen Witterung zu sehen. Wie bereits vorher diskutiert, ist das Auftreten von S. sclerotiorum stark von den Witterungsparametern Temperatur und Luftfeuchte abhängig. Es zeigte sich, dass das jahresabhängige Auftreten von S. sclerotiorum einen maßgeblichen Einfluss auf den durch eine Fungizidapplikation zur Vollblüte erzielten Mehrertrag hatte. Mit steigender Befallshäufigkeit konnte sowohl in den Jahren 1981-1990 (WAHMHOFF, 2000) als auch in den Jahren 1991-2003 eine höhere Ertragsdifferenz erzielt werden. Vergleichbare Ergebnisse aus dem norddeutschen Raum werden von KRÜGER und STOLTENBERG (1983), LindENBERG (2003) und LANDSCHREIBER (2004) berichtet. Im Mittel über die Jahre 1991-2003 belief sich der durch einen Fungizideinsatz zur Blüte erreichte Mehrertrag auf 2,41 dt/ha $(=5,70 \%)$. In den vorangegangenen Jahren 1981-1990 konnte durch eine Fungizidapplikation zur Blüte ein durchschnittlicher Mehrertrag von 2,96 dt/ha $(=8,3 \%)$ erzielt werden (WAHMHOFF, 2000). Die absolute Menge an Ertragszuwachs in den beiden aufgeführten Zeiträumen ist vergleichbar, jedoch ist in früheren Jahren der 
prozentuale Mehrertrag höher. Mögliche Ursache des geringeren prozentualen Mehrertrages kann in einem veränderten Sortenspektrum zu finden sein, mit einem höheren Ertragspotential der aktuelleren Sorten.

Eine vergleichende Betrachtung der Ertragswirkung von Fungizidapplikationen zu verschiedenen Behandlungsterminen und in unterschiedlicher Kombination weist deutlich höhere Mehrerträge durch Mehrfachbehandlungen als durch Einfachbehandlungen auf. Die Mehrfachbehandlungen, die eine Blütenbehandlung enthalten, erzielten einen etwas höheren Mehrertrag als eine Kombination aus Herbst- und Frühjahrsbehandlung. Bei den Einfachbehandlungen resultiert aus einer Frühjahrsbehandlung ein Mehrertrag von 6,8\%, etwa ein Prozent mehr als bei Blütenbehandlung. Die Spanne der Ertragsdifferenzen einer Blütenbehandlung ist jedoch mit rund $20 \mathrm{dt} / \mathrm{ha}$ von allen Behandlungen am größten. Dies spiegelt die starke Variabilität der Ertragswirkung aufgrund jahresbedingter Witterungseinflüsse wieder. Die Auswertung des Datensatzes aus den Jahren 1981 bis 1991 von WAHMHOFF (2000) ergab ebenfalls höhere Mehrerträge der Mehrfachbehandlungen im Vergleich zu Einfachbehandlungen. Bei den Einfachbehandlungen erwies sich die Blütenbehandlung jedoch als am effektivsten. In verschiedenen Versuchen konnte selbst ohne oder bei nur sehr geringem Auftreten von S. sclerotiorum ein deutlich positiver Ertragseffekt einer Fungizidapplikation zur Blüte beobachtet werden (HARTLEB et al., 1999; WOHLLEBEN, 2001; KRUSE, 2004). Diese Ertragssteigerung wird auf physiologische Effekt der Azolfungizide sowie eine erhöhte Schotenstabilität und dadurch geringere Ernteverluste zurückgeführt. Die deutlich höheren Ertragssteigerungen der Mehrfachbehandlungen sind vermutlich auf das breitere Spektrum der erfassten Pathogene sowie die ebenfalls erzielten pflanzenmorphologischen Veränderungen zurückzuführen.

Bei der Berechnung der Wirtschaftlichkeit einer Fungizidbehandlung müssen verschiedene Kostenfaktoren berücksichtigt werden. Neben den Kosten für das Fungizid fallen ebenso Kosten für Arbeitszeit und Maschinen an. Gerade bei Behandlungen zur Blüte im Rapsanbau müssen weiterhin Ertragsverluste, die durch Abknicken von Blütenständen bei einer Durchfahrt entstehen, berücksichtigt werden. Die Höhe dieser Ertragsverluste ist abhängig von verschiedenen Faktoren. Die verwendete Technik spielt eine entscheidende Rolle. Je größer und damit höher der Schlepper und die Spritze, umso geringer sind die Verletzungen der Pflanzen. Auch die Sortenwahl beeinflusst durch die unterschiedliche Höhe der verschiedenen Sorten die 
Durchfahrtsverluste. Oftmals werden in der Praxis speziell die Fahrgassen mit einer erhöhten Aufwandmenge an Wachstumsregulatoren behandelt, um durch eine geringere Pflanzenhöhe Verluste zu verringern. Der Zeitpunkt der Behandlung sollte möglichst so gelegt werden, dass die Pflanzen einen geringen Turgordruck aufweisen und die Pflanzenstängel somit weniger schnell abbrechen. In der Arbeit von KRÜGER \& StOltenberG (1983) wurden die Durchfahrtsverluste mit durchschnittlich 4\% angerechnet. Bei einer zu Grunde gelegten Ertragserwartung von $30 \mathrm{dt} / \mathrm{ha}$ entspricht dies einem Ertragsverlust von 1,2 dt/ha. In der hier vorliegenden Arbeit wurden die Durchfahrtsverluste von 2,6\% angerechnet. Im Mittel über die ausgewerteten Versuchsjahre entsprach dies einem Ertragsverlust von 1,17 dt/ha, was entsprechend dem Wert von KrÜGer \& Stoltenberg (1983) ist. Kolesch (1990) und LOR (1995) schätzen die Verluste durch eine Überfahrt zur Blüte mit bis zu 10\% ein. Spezielle Versuche zur Beurteilung und Quantifizierung von Ertragswirkungen einer Durchfahrt zur Blüte wurden bislang nicht durchgeführt. Bei der Entscheidungsfindung, ob eine Blütenbehandlung wirtschaftlich ist, stellen diese Verluste jedoch eine nicht zu unterschätzende Größe dar.

Für die Berechnung der Wirtschaftlichkeit der Fungizidapplikationen wurden die Gesamtkosten, die sich zusammensetzen aus Mittelkosten, Überfahrtskosten und Durchfahrtsverlusten (nur bei Blütenbehandlungen), dem Mehrertrag gegenübergestellt. Die Analyse der Daten der offiziellen Feldversuche der amtlichen Pflanzenschutzdienste der Länder aus den Jahren 1991-2003 zeigte, dass lediglich in 32,7\% der Fälle eine Fungizidapplikation zur Blüte wirtschaftlich war. Auch hier zeigt der Vergleich zu den Untersuchungen von WAHMHOFF (2000) aus den vorhergehenden Jahren keinen Unterschied. In den Jahren 1981-1990 waren nur 27\% der Fungizidbehandlungen im Winterraps wirtschaftlich.

Eine kombinierte Herbst- und Frühjahrsbehandlung war in den Jahren 1991-2003 mit 72,7\% die wirtschaftlichste Behandlung. Auch Einzelapplikationen im Herbst oder im Frühjahr waren mit deutlich über $50 \%$ und eine kombinierte Frühjahrs- und Blütenbehandlung mit ca. 43\% wirtschaftlicher als eine Einfachbehandlung zur Blüte. Die Gründe für eine bessere Wirtschaftlichkeit der Herbst- und Frühjahrsbehandlungen sowie der kombinierten Behandlungen sind wie bereits angesprochen zum einen in der Erfassung eines breiteren Spektrums an Pathogenen, sowie in der pflanzenmorphologischen Wirkung der Azole der Herbst- und Frühjahrsbehandlungen zu finden. 
Zum anderen stellen die Kosten der Behandlungen einen wichtigen Faktor dar. Die einfachen Herbst- und Frühjahrsbehandlungen haben mit 1,3 bzw. 2,3 dt/ha einen vergleichsweise geringen kostendeckenden Mehrertrag. Eine Blütenbehandlung müsste einen Mehrertrag von 3,3 dt/ha zur Deckung aller aufgewendeten Kosten erzielen. Der kostendeckende Mehrertrag der kombinierten Behandlungen reicht von 3,5 bis 7,2 dt/ha einer Dreifachbehandlung.

Ein weiteres Kriterium für die Wirtschaftlichkeit von Blütenbehandlungen stellt der bereits diskutierte Zusammenhang zwischen Befallshäufigkeit und Mehrertrag dar. Im analysierten Zeitraum waren starke Schwankungen der Befallshäufigkeit zu beobachten. Wie die Auswertung der vorliegenden Daten zeigte, gab es einen signifikanten positiven Zusammenhang zwischen Befallshäufigkeit und Anteil wirtschaftlicher Behandlungen in den einzelnen Jahren. In den Starkbefallsjahren war ein verhältnismäßig hoher Anteil der Fungizidapplikationen zur Blüte wirtschaftlich.

Nicht nur zwischen den verschiedenen Jahren sondern auch zwischen den verschiedenen Bundesländern, ist eine starke Variation in der Anzahl wirtschaftlicher Fungizidapplikationen zur Blüte zu sehen. KLUGE et al. (1999) erstellten auf Basis von Witterungsdaten und Anbauintensitäten eine Karte für die potentielle Befallsgefährdung durch S. sclerotiorum an Winterraps in Deutschland. Legt man lediglich die Witterungsdaten während der Blüte des Rapses zu Grunde, zählen hauptsächlich küstennahe Gebiete im nördlichen Mecklenburg-Vorpommern, Gebiete im nördlichen Niedersachsen, die Elbmarschgebiete Schleswig-Holsteins, Gebiete im östlichen sowie südlichen Sachsen sowie Gebiete in Südbayern zu den stark gefährdeten Regionen. Besonders gute Anbaubedingungen für Winterraps sind in den Küstenregionen sowie den Randlagen der Mittelgebirge aufgrund günstiger Witterungsbedingungen gegeben (PARKhomenko, 2003). Werden neben den klimatischen Faktoren auch die Anbauintensitäten von Winterraps zur regionalen Einschätzung der Befallsgefährdung hinzugezogen, so kristallisieren sich die Hauptanbaugebiete für Winterraps in Mecklenburg-Vorpommern, Teilen Schleswig-Holsteins sowie kleinere Gebiete in Thüringen, Hessen und im südlichen Niedersachsen als besonders stark gefährdete Anbauregionen heraus (KLUGE et al., 1999).

Mit 57\% und 50\% wiesen Niedersachsen und Sachsen den höchsten Anteil wirtschaftlicher Behandlungen aus, während in Bayern in keinem der ausgewerteten Versuche der kostendeckende Mehrertrag erreicht wurde. In Mecklenburg-Vorpommern 
und Schleswig-Holstein, in denen eine hohe Anbauintensität von Winterraps zu finden ist, und durch die Küstenlage besonders günstige Infektionsbedingungen herrschen, waren 35 bzw. 37\% aller ausgewerteten Behandlungen wirtschaftlich. Beim Vergleich der Wirtschaftlichkeit von Fungizidmaßnahmen in den unterschiedlichen Bundesländern darf man jedoch die Datengrundlage nicht außer Acht lassen. Aus Bayern lagen z. B. nur aus drei Versuchsjahren Daten vor. Aufgrund der starken jahresbedingten Variation der Befallshäufigkeiten können somit die Ergebnisse beeinflusst werden.

Ein weiterer Faktor, der die Wirtschaftlichkeit von Fungizidmaßnahmen beeinflusst, ist der Wirkungsgrad der eingesetzten Mittel. Durch eine Gegenüberstellung der Befallshäufigkeiten der unbehandelten Kontrollparzellen und der behandelten Parzellen wurde der Wirkungsgrad der Fungizidmaßnahmen des vorliegenden Datensatzes gegen S. sclerotiorum berechnet. Mit rund 62\% erzielte eine Behandlung zur Blüte einen sehr hohen Wirkungsgrad. Einen vergleichbaren Wirkungsgrad von 70\% resultierte aus den Untersuchungen von WAHMHOFF (2000). Kombinierte Behandlungen zur Blüte und im Frühjahr oder eine Dreifachbehandlung im Herbst, Frühjahr und zur Blüte erzielten mit 66,4 bzw. 82\% einen höheren Wirkungsgrad als eine alleinige Blütenbehandlung. Auch eine alleinige Herbstbehandlung sowie eine kombinierte Herbst-Frühjahrs-Behandlung erzielten mit rund 30\% einen unerwartet hohen Wirkungsgrad. Die unerwartet hohen Wirkungsgrade, besonders der Nicht-Blütenbehandlungen, sind jedoch nicht der direkten Sclerotinia-Bekämpfung anzurechnen, da erst zur Blüte Infektionen auftreten. Die physiologischen Effekte der Fungizidapplikationen haben möglicherweise zu einer höheren Widerstandsfähigkeit der Pflanzen geführt. In Mecklenburg-Vorpommern führten Folicur-Applikationen im Knospenstadium in den Starkbefallsjahren 1995 und 1996 zu Befallsreduktionen um 35 bis 60\% (STEINBACH \& BROSCHEWITZ, 1997). Die Autoren führen diesen Effekt auf eine Erhöhung der Pflanzenvitalität, mikroklimatische Veränderungen und eine mögliche Blühverzögerung zurück. Die Datengrundlage für die Berechnung des Wirkungsgrades einer Herbstbehandlung sowie der Mehrfachbehandlungen war mit 12 bis 84 Versuchen nur sehr gering, was eine Ungenauigkeit der Ergebnisse zur Folge haben kann. Für die Berechnung des Wirkungsgrades einer Blütenbehandlung lag mit 422 Versuchen eine deutlich größere Anzahl an Versuchen vor. 
Die Wirtschaftlichkeitsanalyse der Jahre 1991-2003 weist sehr deutlich das hohe Einsparungspotential bei der Blütenbehandlung zur Bekämpfung von S. sclerotiorum auf. Prognosemodelle stellen ein hilfreiches Werkzeug für einen gezielten und ökonomischen Pflanzenschutz dar. Vor allem in Jahren mit wenig Befall könnte durch Anwendung schwellenwertorientierter Prognosemodelle ein großer Anteil an Fungizidmaßnahmen eingespart werden.

\subsection{Wirtschaftliche Schadensschwellen für S. sclerotiorum an Winterraps}

Nach §2a des Pflanzenschutzgesetzes darf Pflanzenschutz nur nach guter fachlicher Praxis durchgeführt werden. Zur guten fachlichen Praxis gehört die Berücksichtigung der Grundsätze des Integrierten Pflanzenschutzes. Ein Grundsatz des Integrierten Pflanzenschutzes ist es, die Anwendung chemischer Pflanzenschutzmittel auf ein notwendiges Maß zu reduzieren. Das notwendige Maß ist per definitionem „...die Intensität der Anwendung von Pflanzenschutzmitteln, die notwendig ist, um die Wirtschaftlichkeit $\mathrm{zu}$ sichern, weil keine anderen praktikablen Abwehr- und Bekämpfungsmaßnahmen zur Verfügung stehen, und die gleichzeitig der Vorsorge im Verbraucher- und Umweltschutz Rechnung trägt“ (BMVEL, 2005). Die Anwendung von Schadensschwellen ist daher im Integrierten Pflanzenschutz ein zentrales Thema. Schadensschwellen stellen ein in Hinsicht auf die Optimierung von Behandlungszeitpunkten und zur Vermeidung unwirtschaftlicher Behandlungen geeignetes Werkzeug für den Integrierten Pflanzenschutz dar.

NUTTER et al. (1993) haben unterschiedliche Schwellenwerte, abhängig von der Befallshöhe, definiert (Abb. 4.1). Die Nachweisschwelle ist das geringste Befallslevel für den Nachweis eines Pathogens. Die Warnschwelle definiert ein Befallslevel, an dem der Anbauer sich auf eine Behandlung vorbereiten muss, während die Handlungsschwelle den Schwellenwert darstellt, bei dem eine Behandlung stattfinden muss, um zu vermeiden, dass der Befall die Schadensschwelle erreicht. Die Schadensschwelle wird definiert als das Befallsniveau, bei dem ein Verlust in Quantität oder Qualität durch das Pathogen verursacht wird. Die wirtschaftliche Schadensschwelle ist die Dichte eines Erregers, die einen Schaden in der Höhe der Kosten für eine Bekämpfung verursacht (NUTTER et al., 1993; HOFFMANN et al., 1994; BÖRNER, 1997; TISCHNER, 1998). Eine wirtschaftliche Schadensschwelle ist nicht feststehend, sondern richtet sich nach der Ertragserwartung und dem Erzeugerpreis 
sowie weiteren beeinflussenden Faktoren (HOFFMANN et al., 1994; NUTTER et al., 1993; TISCHNER, 1998).

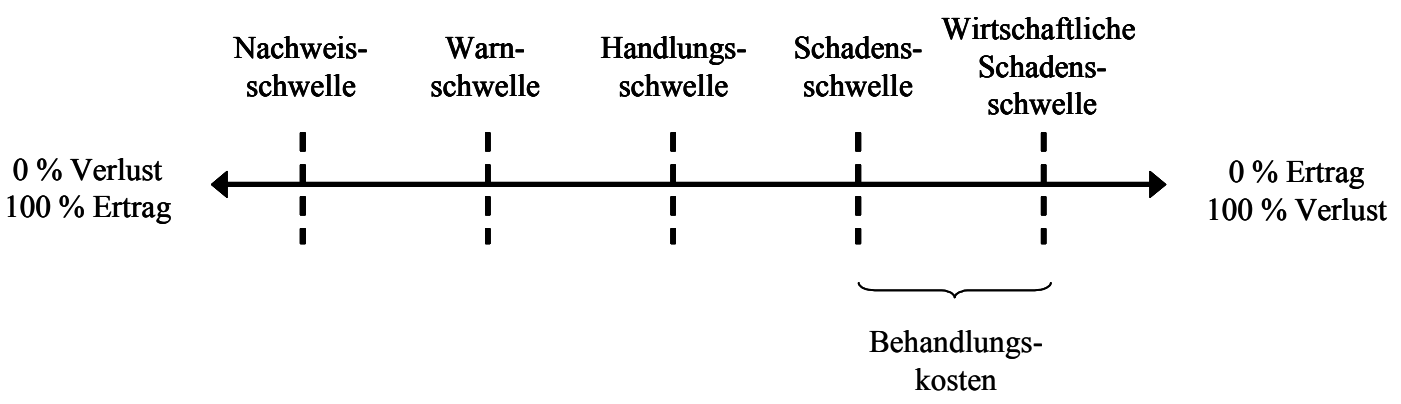

Abb. 4.1: Schwellenwert-Hierarchie nach NUTTER et al. (1993)

Nach TISCHNER (1998) ist eine Bekämpfungsmaßnahme noch vor Erreichen der wirtschaftlichen Schadensschwelle notwendig, um eine massenhafte Vermehrung des Pathogens zu verhindern. Da S. sclerotiorum jedoch ein monozyklisches Pathogen ist, kann eine Massenvermehrung nicht auftreten. Aufgrund dessen ist das von NuTTER et al. (1993) entworfene Schwellenwert-Konzept nicht ohne Einschränkungen auf S. sclerotiorum übertragbar.

In der vorliegenden Arbeit wurde die wirtschaftliche Schadensschwelle nach dem in Abb. 4.2 dargestellten Schema entwickelt. Die aus Befalls-Verlust-Relationen hervorgehende Regressionsgerade stellt die Berechnungsgrundlage für die wirtschaftliche Schadensschwelle dar (FREIER et al., 1994). Um die Schadensschwelle allgemein anwenden zu können, wurde der Ertrag als prozentuale und nicht als absolute Größe berechnet. Basierend auf dem Ertragsniveau unter Nichtbefall werden die Behandlungskosten in prozentualen Ertrag umgerechnet. Der Schnittpunkt der Behandlungskostengerade mit der Regressionsgeraden ergibt die Befallshäufigkeit, bei der eine Behandlung wirtschaftlich ist, und stellt somit die wirtschaftliche Schadensschwelle dar. 


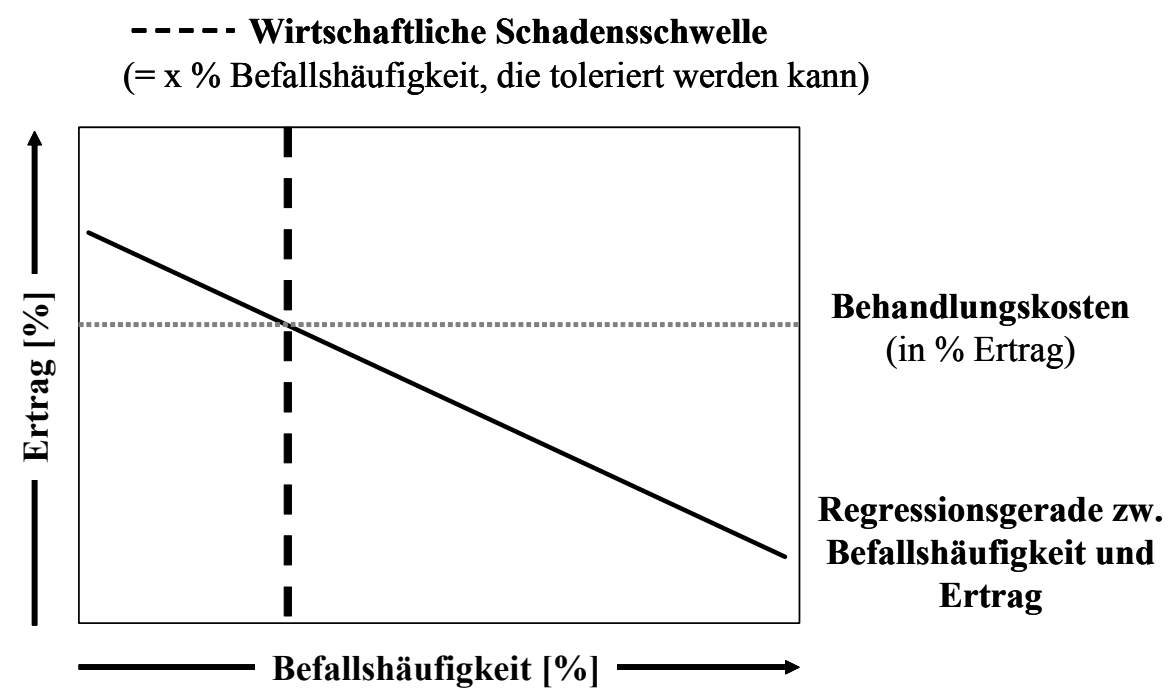

Abb. 4.2: Schematische Darstellung der Berechnung der wirtschaftlichen Schadensschwelle.

Die Schadwirkung eines Pathogens ist oftmals von verschiedenen Faktoren abhängig. Von Seiten der Wirtspflanze ist die Anfälligkeit ein sehr wichtiger Faktor, seitens des Pathogens die Virulenz verschiedener Populationen. Des Weiteren spielen auch pflanzenbauliche Aspekte eine Rolle, wie z. B. Bestandesdichte oder Aussaattermin (FrEIER et al., 1994). Wie die in den Jahren 2001-2005 durchgeführten Feldversuche gezeigt haben, hatten die Faktoren Sorte und Inokulationstermin einen Einfluss auf die Schadwirkung von S. sclerotiorum. In der Arbeit von FREIER et al. (1994) wird das Ertragsniveau als weitere mögliche Einflussgröße auf die Befalls-Schadens-Relation angeführt. Abhängig von Pathogen und Wirtspflanze kann es mit steigendem Ertragsniveau zu stärkerer oder geringerer Schadwirkung kommen. In der vorliegenden Arbeit wurde der Faktor Ertragsniveau nicht gesondert behandelt. Unter der Annahme, dass das Ertragsniveau keinen Einfluss auf die Befalls-Schadens-Relation hat, spielt es bei der Berechnung der wirtschaftlichen Schadensschwelle jedoch eine wichtige Rolle.

In der vorliegenden Arbeit wurden Schadensschwellen für zwei verschiedene Sorten (-typen) und zwei verschiedene Infektionstermine erstellt. Wie die Ergebnisse zeigten, ist die wirtschaftliche Schadensschwelle der Hybridsorte sowohl bei einem frühen als auch bei dem späten Inokulationstermin höher als bei der Liniensorte. Die Liniensorte reagiert somit sensibler auf Sclerotinia-Befall als die Hybridsorte, was sich in der geringeren wirtschaftlichen Schadensschwelle niederschlägt. Mit steigender Ertragserwartung werden die Unterschiede zwischen den Sorten größer. Innerhalb der Sorten 
sind jeweils höhere wirtschaftliche Schadensschwellen nach Inokulationen zu BBCH 71 als nach Inokulation zu BBCH 61-65 zu verzeichnen. Obwohl die Befalls-VerlustRelationen keine signifikanten Unterschiede zwischen den Sorten und den Inokulationsterminen zeigten, sind sehr große Unterschiede in den wirtschaftlichen Schadensschwellen vorhanden. Während diese für Ertragserwartungen von 30-50 dt/ha bei einer frühen Inokulation zwischen 25 und 13\% für die Hybridsorte und zwischen 16 und 5\% für die Liniensorte liegt, ist sie nach einer späten Inokulation mit $37-23 \%$ bzw. $29-12 \%$ deutlich höher.

In der von AHLERS \& HINDORF (1987) entwickelten Negativprognose wird ein Grenzwert von 10\% Befallshäufigkeit als Schwellenwert für eine Bekämpfungsmaßnahme eingesetzt. Ergebnisse über die Wirtschaftlichkeit dieses Modells sind jedoch nicht verfügbar. Ableitend aus Fungizidversuchen zur Bekämpfung von S. sclerotiorum im Winterraps erarbeiteten KRÜGER \& STOLTENBERG (1983) eine wirtschaftliche Schadensschwelle für dieses Pathogen unter Verwendung des Fungizides Ronilan (Wirkstoff Vinclozolin). Für einen durchschnittlichen Ertrag von $30 \mathrm{dt} /$ ha und einen kostendeckendem Mehrertrag von 2,6 dt (=8\%) ergab sich eine wirtschaftliche Schadensschwelle von 15,5\%. Überträgt man dieses Ergebnis aus den frühen achtziger Jahren auf die heutigen Gegebenheiten mit einem um rund $10 \mathrm{dt} / \mathrm{ha}$ höheren Ertragsniveau, so ist die Schadensschwelle mit denen der vorliegenden Arbeit zu vergleichen. Eine regelmäßige Überprüfung und Validierung von Schadensschwellen ist notwendig (WALKER, 1983), vor allem in Hinblick auf ein wechselndes Sortenspektrum, sich ändernde technische Voraussetzungen und auch sich verändernden wirtschaftlichen Gegebenheiten.

Eine praktische Anwendung finden die erarbeiteten wirtschaftlichen Schadensschwellen in dem Prognosemodell SkleroPro (Koch \& vON Tiedemann, 2005a, b). In dieses Modell wurde die Schadensschwelle des frühen Inokulationtermins der Hybridsorte integriert. Eine retrospektive Anwendung des Modells zeigte, dass bei Integration der geringeren Schadensschwelle der Liniensorte zu viele falsch positive Bekämpfungsentscheidungen empfohlen wurden. Aufgrund der hohen Anzahl falsch positiver Empfehlungen sank die Wirtschaftlichkeit des Modells.

Die aus Inokulationen zu BBCH 71 abgeleiteten Schadensschwellen gehen nicht in das Prognosemodell SkleroPro ein, da sie für eine Fungizidbehandlung in der Praxis eine nur sehr untergeordnete Rolle spielen. Basierend auf technischen Voraussetzungen ist 
das Zeitfenster für eine Behandlung auf die Blüte des Rapses beschränkt, da Überfahrten während der Schotenbildung zu deutlich höheren Durchfahrtsverlusten führen würden.

\subsection{Artspezifischer in vitro-Nachweis von $V$. longisporum}

Im Rahmen eines sich immer weiter ausdehnenden Rapsanbaus tritt das Fruchtfolgepathogen $V$. longisporum immer häufiger auf. Die Symptome im Feld sind erst mit Auftreten von Mikrosklerotien spezifisch diesem Erreger zuzuordnen. Die frühen Symptome wie halbseitige Vergilbung der Blätter und streifenförmige Verbräunungen am Stängel sind nur sehr unspezifisch und können ebenfalls durch natürliche Seneszens oder andere Pathogene hervorgerufen werden (SVENSSON \& LeReniUs, 1987; PAUL, 2003). Eine sichere Diagnose im Feld ist somit erst mit Bildung der Mikrosklerotien mit beginnender Abreife möglich. Labormethoden bieten eine Möglichkeit, Pathogene bereits vor der Ausbildung spezifischer Symptome zu detektieren. Methoden die hierfür angewendet werden sind z. B. der ELISA oder PCRbasierte Diagnosesysteme. Im ELISA werden auf immunologischer Basis bestimmte Antigene des Pathogens detektiert. Wie vorhergehend diskutiert, wurde ein ELISA-Test zum Nachweis von $V$. longisporum in Rapspflanzen im Verlauf der Vegetationsperiode eingesetzt. Allerdings konnte erst parallel zum Sichtbarwerden erster Symptome im Feld ein deutlicher Nachweis mit dem ELISA erbracht werden. Es besteht jedoch weiterhin die Frage, ob der ausbleibende Nachweis zu frühen Entwicklungsstadien des Rapses auf fehlende Infektionen oder auf $\mathrm{zu}$ geringe Mengen an Antigenen in der Pflanze zurückzuführen ist. In der PCR werden bestimmte DNA-Sequenzen selektiv amplifiziert. Theoretisch kann mit der PCR ein einzelnes Molekül nachgewiesen werden (HENSON \& FRENCH, 1993), was demnach eine Diagnose schon in sehr frühen Stadien des Krankheitsverlaufes ermöglicht. Die PCR stellt somit eine sensitivere Detektionsmethode als der ELISA dar.

Im Rahmen dieser Arbeit sollten artspezifische Primer für den spezifischen PCRNachweis von $V$. longisporum entwickelt werden. Mit Hilfe der PCR soll es ermöglicht werden, bereits sehr geringe Mengen des Pathogens schon zu Beginn der Infektion nachzuweisen. Die Artspezifität des Nachweises ist ein wichtiger Faktor dieser Untersuchungen, basierend auf der Unsicherheit der Abgrenzung von $V$. longisporum zu V. dahliae. 
Ursprünglich wurde die an Raps vorkommende Verticillium-Art als $V$. dahliae klassifiziert. STARK (1961) konnte von befallenem Meerrettich erstmals ein $V$. dahliaeIsolat isolieren, dessen Konidien mit 8,2 $\mu \mathrm{m}$ etwa doppelt so lang wie die Konidien anderer $V$. dahliae-Isolate waren. Aufgrund des Unterschieds in der Konidienlänge wurde dieses Isolat als $V$. dahliae var. longisporum klassifiziert. Untersuchungen von Ingram (1968), TyPAS \& HeAle (1977), TyPAS \& HeAle (1980) und JACKSON \& HeALE (1985) zeigten, dass es sich bei den langsporigen $V$. dahliae-Isolaten um diploide Organismen handelte.

Auch die aus Raps stammenden Verticillium-Isolate weisen langsporige Konidien auf. In vergleichenden Untersuchungen an Isolaten von $V$. longisporum, $V$. dahliae und V. albo-atrum zur Mikrosklerotiencharakteristik, Konidienlänge, Ploidie, Aktivität extrazellulärer Polyphenoloxidasen, Unterschiede in RAPD-PCR Bandenmustern sowie der Pathogenität an Raps konnten KARAPAPA et al. (1997) eine deutliche Abgrenzung der $V$. longisporum-Isolate zu den $V$. dahliae-Isolaten beobachten. Basierend auf diesen Untersuchungen wurde vorgeschlagen, $V$. longisporum als neue Spezies anzuerkennen, wie es schon vorher von MORTON et al. (1995b) aufgrund von Sequenzunterschieden in Teilen der ribosomalen RNA vorgeschlagen wurde.

Auf Basis molekulargenetischer Untersuchungen konnten eine Vielzahl von Autoren deutliche Unterschiede zwischen $V$. longisporum und $V$. dahliae feststellen (OKOLI et al., 1994; KoIKe et al., 1995; Morton et al., 1995a; SubBaraO et al., 1995; MeSSNER et al., 1996; KoIKe et al., 1997; PAPLOMATAS \& LAMPROPOUlOS, 1997; TYPAS, 1997; KARAPAPA \& TYPAS, 2001; STEVENTON et al., 2002a; ZEISE \& VON TIEDEMANN, 2002a; COLlins et al. 2003; FAHLESON et al., 2003; Collins et al., 2005). Auch die von KARAPAPA et al. (1997) gefundenen morphologischen und Virulenzunterschiede konnten von verschiedenen Autoren bestätigt werden (SUBBARAO et al., 1995; ZEISE \& von TiedemanN, 2001; Zeise \& von TiedemanN, 2002b). Neben den mit 7-8 $\mu \mathrm{m}$ nahezu doppelt so langen Konidien wie die Konidien von $V$. dahliae mit rund $4 \mu \mathrm{m}$ (STARK, 1961; KARAPAPA et al., 1997; ZEISE \& VON TIEDEMANN, 2001; STEVENTON et al., 2002a), bildet $V$. longisporum gestreckte, unregelmäßige Mikrosklerotien, während $V$. dahliae kugelförmig und kompakte Mikrosklerotien bildet (KARAPAPA et al., 1997; ZEISE \& VON TIEDEMANN, 2001). Weitere Unterschiede sind in der Bildung dunklen Myzels auf Czapek-Dox-Agar sowie in einer einheitlich dunklen Koloniefarbe zu finden (ZEISE \& VON TIEDEMANN, 2001). In den Virulenztestungen von ZEISE \& VON 
TIEDEMANN (2002b) verschiedener $V$. dahliae-Isolate, die den VegetativenKompatibilitäts-Gruppen (VCG) 2B, 2B*, 4A und 4B angehören, sowie verschiedener V. longisporum-Isolate an Brassica spp., Leguminosen, Lein, Tomaten, Erdbeeren und Kartoffeln, konnten den verschiedenen VCGs der $V$. dahliae-Isolate und $V$. longisporum unterschiedliche Wirtspflanzengruppen zugeordnet werden. Die Aggressivität der $V$. longisporum-Isolate konnte sehr streng auf die Brassica spp. eingegrenzt werden, wobei die Aggressivität an Raps am stärksten war. Isolate der VCGs 4B, 2B und 2B* waren dagegen nur in sehr geringem Maße pathogen an Brassica spp..

Nach Collins et al. (2003) und ZEISE \& VON TIEDEMANN (2002a) können die langsporigen $V$. dahliae-Isolate ( $V$. longisporum) in zwei Gruppen unterteilt werden. ColLINS et al. (2003) unterscheiden eine $\alpha$ - und eine $\beta$-Gruppe basierend auf AFLPUntersuchungen. ZEISE \& VON TIEDEMANN (2002a) unterscheiden eine lsp- und eine 1sp*-Gruppe voneinander, basierend auf RAPD-PCR-Analysen. Diese beiden Gruppen weisen ebenfalls Unterschiede in Virulenz und Morphologie auf (ZEISE \& VON Tiedemann, 2001). Nach Barbara \& Clewes (2003) können die $\alpha$ - und lsp-Gruppe sowie die $\beta$ - und 1sp*-Gruppe als Synonyme angesehen werden. Die Mehrheit der untersuchten $V$. longisporum-Isolate waren der $\alpha$ - bzw. lsp-Gruppe zugehörig (ZEISE \& von Tiedemann, 2002; Collins et al., 2003). Das von STARK (1961) erstmals publizierte langsporige $V$. dahliae-Isolat aus Meerrettich ist in die $\beta$ - bzw. lsp*-Gruppe einzuordnen (ZEISE \& VON TIEDEMANN, 2002a; COLLINS et al., 2003).

Aufgrund des diploiden Genoms von $V$. longisporum ist davon auszugehen, dass es sich um eine interspezifische Hybride handelt. Basierend auf ähnlicher Mikrosklerotiencharakteristika, homologer Banden von $V$. longisporum und einem aus Luzerne stammendem $V$. albo-atrum-Isolat im RAPD-PCR-Profil und 42\% taxonomischer Ähnlichkeit zu $V$. dahliae folgern KARAPAPA et al. (1997), dass V. longisporum eine Hybride aus $V$. dahliae und $V$. albo-atrum ist. Untersuchungen des Cytochrom b, SSU rRNA und ITS-Sequenzen von FAHLESON et al. (2004) weisen ebenfalls eine enge Verbindung von $V$. longisporum zu $V$. albo-atrum und $V$. dahliae auf. In RFLPAnalysen von MORTON et al. (1995a) trat lediglich ein unterschiedliches Nukleotid in den ITS-Bereichen des rRNA-Gens haploider $V$. dahliae-Isolate zu $V$. albo-atrum auf. Zwischen den haploiden und diploiden $V$. dahliae-Isolaten hingegen konnten sechs Transitionen bzw. Transversionen beobachtet werden. In Anlehnung an die für durch interspezifische Hybridisierung entstandenen Pflanzen (Brassica Hybriden) verwendete 
Bezeichnung, die einen ungleichen Chromosomensatz beider Eltern tragen, schlagen CoLlins et al. (2003) vor, den Begriff amphihaploid anstatt von ,near-diploid“ oder diploid für $V$. longisporum zu verwenden.

BARbara \& Clewes (2003) bezweifeln die Entstehung von $V$. longisporum aus $V$. dahliae und V. albo-atrum. Sie vermuten, dass eine haploide, molekulargenetisch V. albo-atrum ähnliche Spezies einen Elternteil darstellt, der sich jedoch von den eigentlichen $V$. albo-atrum-Isolaten deutlich unterscheidet. Den Beitrag von $V$. dahliae, als zweiten Elternteil, stellen sie nicht in Frage. Weitere Untersuchungen von BARBARA et al. (2005) unterstützen diese These. Sie verwendeten Mikrosatelliten-Marker zur Charakterisierung von $V$. albo-atrum sowie $V$. dahliae- und $V$. longisporum-Isolaten. Die Annahme, dass die diploiden Isolate jeweils eine $V$. dahliae und eine $V$. alboatrum-Bande aufweisen, wurde jedoch nicht bestätigt.

In Untersuchungen der SSU rRNA-Bereiche verschiedener Verticillium spp. konnten KARAPAPA \& TYPAS (2001) spezifisch für $V$. longisporum-Isolate eine Insertion mit einer Größe von 839 bp finden, welche sie in die Intron-Gruppe I einordneten. Ausgehend von diesem Ergebnis nehmen KARAPAPA \& TYPAS (2001) an, dass es sich um eine evolutionäre Divergenz handelt, die sich möglicherweise auf die Anpassung an Brassica-Arten als Wirtspflanzen zurückführen lässt. Anhand eigener PCRUntersuchungen mit von der Intron-Sequenz abgeleiteten Primern konnten diese Ergebnisse jedoch nicht bestätigt werden. Neben drei $V$. longisporum-Isolaten konnten auch in dem $V$. dahliae-Isolat $\mathrm{Vd} 76, V$. albo-atrum, V.tricorpus sowie in $S$. sclerotiorum, A. alternata und $F$. oxysporum ein Amplifikat generiert werden.

Verschiedene PCR-Fingerprint-Methoden sowie RAPD-Analysen wurden verwendet, um $V$. longisporum-spezifische Banden zu generieren. LI et al. (1993, 1999) setzten RAPD-Analysen bereits erfolgreich für die Entwicklung spezifischer Primer für den Nachweis von $V$. dahliae in Kartoffeln ein. Im Rahmen der vorliegenden Arbeit wurde unter anderem der RAPD-Primer OPA-13 eingesetzt, der bereits in der Arbeit von KARAPAPA et al. (1997) zur molekularen Charakterisierung von $V$. longisporum eingesetzt wurde. Den verwendeten RAPD-Primer A-06 setzten KOIKE et al. (1996) bereits zur Differenzierung verschiedener $V$. dahliae- und $V$. albo-atrum-Isolate ein. ZEISE \& VON TIEDEMANN (2002a) setzten diese beiden RAPD-Primer A-06 und OPA-13 zur Differenzierung zwischen verschiedenen VCGs von $V$. dahliae und $V$. longisporum ein. In allen drei Arbeiten konnten mit Hilfe der eingesetzten Primer A-06 und OPA-13 
Bandenmuster erzielt werden, die eine Abgrenzung von $V$. dahliae zu $V$. longisporum ermöglichten. Auch in der vorliegenden Arbeit konnten polymorphe Bandenmuster von $V$. longisporum und $V$. dahliae mit Hilfe der RAPD-Primer sowie mit ERIC-, VNTRund BOX-Primern erzielt werden. Insgesamt 23 distinkte Banden wurden extrahiert und weiter bearbeitet. Es konnten neun Amplifikate kloniert werden, von denen jedoch nur zwei, pVlE5-23 und pVlO2/3-6, eine V. longisporum-spezifische Hybridisierung aufwiesen. Alle weiteren Sonden wiesen auch bei $V$. dahliae Signale auf.

Die Sonde pVlE5-23 basiert auf einer distinkten Bande aus einer ERIC-PCR, die Sonde pVlO2/3-6 aus einer PCR mit dem RAPD-Primer OPA-13. Aus den Ergebnissen der Sequenzierungsanalysen dieser beiden Sonden konnten schließlich artspezifische Primer auf Basis der Sonde pV1O2/3-6 abgeleitet werden. Mit Hilfe dieser Primer konnten bei $V$. longisporum-Isolaten sowie bei dem $V$. dahliae-Isolat Vd 76 eine spezifische Bande bei 140 bp amplifiziert werden. Auch das Isolat V1 32, welches von ZEISE \& VON Tiedemann (2002a) in die lsp*-Gruppe (entsprechend der $\beta$-Gruppe bei Collins et al., 2003) eingeordnet wurde, wies die für V. longisporum spezifische Bande auf. Das Isolat Vd 76 wurde aus Baumwolle isoliert. Dieses Isolat wurde bereits in den Untersuchungen von CERNUSKO (1995) zur Entwicklung eines ELISA-Tests zum Nachweis von $V$. dahliae in Raps eingesetzt. Mit Hilfe der Silberfärbung und der Esterasenfärbung konnte dieses Isolat zusammen mit weiteren $V$. dahliae-Isolaten aus Baumwolle deutlich von $V$. dahliae-Isolaten aus Raps abgegrenzt werden (CERNUSKO, 1995). Pathogenitätstests wurden mit dem Isolat Vd 76 jedoch nicht durchgeführt. Eigene, im Rahmen dieser Arbeit nicht aufgeführte Untersuchungen dieses Isolats mit den RAPD-Primern A-06 und OPA-13 wiesen jedoch homologe Bandenmuster zu einer Vielzahl von $V$. longisporum-Isolaten auf. Ebenfalls unerwartet war das Ausbleiben der spezifischen Bande bei den beiden V. longisporum-Isolaten V1 82 und V1 83. Nach Untersuchungen von ZEISE \& VON TIEDEMANN (2001, 2002a, b) hinsichtlich Virulenz, morphologischer und physiologischer Eigenschaften sowie genetischer Ähnlichkeiten wiesen die beiden Isolate keine größeren Unterschiede $\mathrm{zu}$ anderen $V$. longisporumIsolaten auf. In eigenen hier nicht aufgeführten Untersuchungen wies das Isolat V1 82 unter Verwendung der beiden RAPD-Primer A-06 und OPA-13, ERIC- und VNTRPrimern abweichende Bandenmuster zu anderen $V$. longisporum-Isolaten auf. Das Isolat V1 83 wurde nicht weiter untersucht. Zur Klärung der PCR-Ergebnisse und der 
genetischen Einordnung der drei Isolate V1 82, V1 83 und Vd 76 sind weitere Untersuchungen notwendig.

Aufgrund der fehlenden Kreuzreaktionen zu anderen Verticillium spp. sowie anderen Pilzen zeigte sich das Primerpaar pV1O2/3-6 als geeignet für den artspezifischen in vitro-Nachweis von $V$. longisporum. Die Nachweisgrenze für das genannte Primerpaar wurde bei einer DNA-Menge von 61 pg erreicht. Diese Menge entspricht einer Anzahl von 10.000 Kopien unter der Annahme einer Genomgröße von 57 x $10^{6}$ bp (COLLINS et al., 2003) und dem Vorliegen einer „single copy sequence“. LI et al. (1999) konnten in ihrem $V$. dahliae-spezifischem PCR-System eine Nachweisgrenze von 50-500 Kopien des amplifizierten Fragments erzielen. Die Sensitivität der von CARDER et al. (1994) entwickelten Primer zum Nachweis von $V$. albo-atrum und $V$. dahliae lag bei weniger als 1 pg gereinigter DNA, was einer Anzahl von 45 Kopien entspricht bzw. 200 pg Gesamt-DNA aus infiziertem Pflanzenmaterial. Aus den Angaben der Autoren geht jedoch nicht hervor, ob es sich bei dem amplifizierten Fragment um eine ,single-copy sequence“" oder eine mehrfach im Genom auftretende Sequenz handelt. Der Vergleich der Nachweisgrenzen der genannten Arbeiten mit der des Primerpaares pV1O2/3-6 zeigt deutlich, dass eine weitere Bearbeitung nötig ist, um geringere Mengen an Pilz-DNA nachweisen zu können.

Die Anwendung einer PCR-Methode zur spezifischen Detektion verschiedener Verticillium spp. ist in der Literatur mehrfach beschrieben. Für den Nachweis von $V$.dahliae, $V$. albo-atrum und $V$. tricorpus in Kartoffeln und in Boden entwickelten MAHUKU et al. (1999) eine PCR-Methode. LI et al. (1994) konnten in ihren Untersuchungen PCR-Primer entwickeln, mit denen sie $V$. dahliae von $V$. albo-atrum und $V$. tricorpus differenzieren konnten. Die Primer wurden mit einer Vielzahl an $V$. dahliae-Isolaten getestet, unter denen jedoch kein Isolat aus Raps oder einer anderen Brassica-Art vertreten war. Es ist daher ungewiss, ob mit Hilfe dieser Primer auch eine Differenzierung zwischen $V$. dahliae und $V$. longisporum möglich wäre. In Untersuchungen von CARDER et al. (1994) wurden vier Primerpaare zur Differenzierung verschiedener RFLP-Gruppen von $V$. albo-atrum und $V$. dahliae eingesetzt. Mit einem Primerpaar konnten sowohl $V$. longisporum- als auch $V$. dahliae-Isolate detektiert werden, wobei $V$. longisporum-Isolate eine um ca. 1000 bp größere Bande produzierten. Für einen in planta-Nachweis eignet sich dieses Primerpaar jedoch nicht, da es neben pilzlicher DNA auch pflanzliche DNA amplifiziert. Basierend auf der Sequenz des 
nuklearen ribosomalen RNA-Gen Komplexes entwickelten PRAMATEFTAKI et al. (2000) Primer, die in der ,intergenic spacer region“ binden. Mehrere V. albo-atrum, V. dahliae und $V$. longisporum-Isolate wurden mit den Primern analysiert, jedoch konnte anhand des Amplikons nicht zwischen $V$. dahliae und $V$. longisporum differenziert werden. STEVENTON et al. (2002a) entwickelten artspezifische Primer für den in vitro-Nachweis von $V$. longisporum. Mit diesen Primern konnten in $87 \mathrm{~V}$. longisporum-Isolaten eine spezifische Bande von 340 bp erzielt werden, die bei Isolaten anderer Verticillium spp. sowie bei DNA-Extrakten aus Pflanzenmaterial nicht auftraten. In den Untersuchungen von ZHOU et al. (2005) wurden diese Primer zum artspezifischen Nachweis in Raps eingesetzt. Mit Hilfe der PCR konnte bereits zu BBCH 13, noch vor Sichtbarwerden erster Symptome, eine Infektion der Pflanzen mit $V$. longisporum nachgewiesen werden. Die im Rahmen der vorliegenden Arbeit entwickelten artspezifischen Primer wurden am Institut für Pflanzenpathologie und Pflanzenschutz in Göttingen in ersten Untersuchungen zur Diagnose von $V$. longisporum in „rapid cycling“ Raps eingesetzt. Die Ergebnisse wiesen keine Kreuzreaktionen mit extrahierter pflanzlicher DNA aus Blättern, Stängeln und Wurzeln auf. In DNA-Extrakten aus mit $V$. longisporum infizierten Pflanzen konnte 33 dpi die spezifische Bande in Wurzel- und Stängelmaterial amplifiziert werden. Auch eine parallele Amplifikation von pflanzlicher und pilzlicher DNA wies keine Wechselwirkungen auf (RIEDIGER \& DUNKER, 2005, nicht veröffentlicht). Diese ersten Ergebnisse der in planta-Diagnose weisen auf eine gute Eignung des Primerpaares in Hinsicht auf eine diagnostische PCR hin.

Basierend auf dem Ansatz einer kompetitiven PCR wurden durch Mitführen eines internen Standards in verschiedenen Untersuchungen quantitative PCR-Analysen durchgeführt (Hu et al., 1993; MouKHAMEDOV et al., 1994; RoBB et al., 1994; HEINZ et al., 1998; DAN et al., 2001). Eine quantitative PCR zum Nachweis von V. longisporum an Raps ist bis jetzt noch nicht beschrieben.

Der Vergleich verschiedener Methoden zum Nachweis und zur Quantifizierung von Verticillium spp. ergab vergleichbare Ergebnisse in PCR-Analysen und durch Auslegen von Pflanzenmaterial auf Selektivmedien (Hu et al., 1993; MAHUKU et al., 1999). Der Vorteil der PCR ist in der Sensitivität und der Schnelligkeit der Durchführung zu sehen (HENSON \& FRENCH, 1993). Bei Auslegen befallenen Pflanzenmaterials ist mit mehreren Wochen Inkubationszeit zu rechnen, während eine PCR an einem Tag durchgeführt werden kann. Weiterhin bietet die PCR die Möglichkeit, durch Einsetzen 
spezifischer Primer, verschiedene Spezies voneinander $\mathrm{zu}$ unterscheiden. Die Untersuchungen von RoBB et al. (1993) zeigen als einen weiteren Vorteil der PCRbasierten Diagnosemethoden die genauere Differenzierung einzelner Isolate voneinander. Mit Hilfe einer PCR mit spezifischen Primern konnte ein V. albo-atrumIsolat, welches morphologische Unterschiede zu Referenzisolaten aufwies, in eine neue Untergruppe eingeordnet werden (RoBB et al., 1993).

Die Real-time-PCR stellt neben der kompetitiven PCR eine weitere, modernere Methode für die quantitative Diagnostik dar. Diese Methode der Quantifizierung wird immer verbreiteter auch in der Pflanzenpathologie angewendet. VANDERMARK \& BARKER (2003) setzten die Real-time-PCR zum quantitativen Nachweis von Aphanomyces euteiches in Luzerne und Erbsen und BATES et al. (2001) zum Nachweis von Pyrenophora spp. an Gerstensaatgut ein. Auch zum Nachweis und zur Quantifizierung von Bakterien (DELANOY et al., 2003) oder Viren (SALM \& GEIDER, 2004) stellt die Real-time PCR eine geeignete Methode dar.

Mit den im Rahmen dieser Arbeit entwickelten spezifischen Primern ist eine Grundlage für die Entwicklung einer Real-time PCR für $V$. longisporum in Winterraps geschaffen. Weiterführende Optimierungen sind jedoch notwendig, um die Sensitivität der Primer $\mathrm{zu}$ erhöhen sowie den sicheren in planta-Nachweis zu ermöglichen, und eine dem ELISA überlegene Detektionsmethode darzustellen.

Mit Hilfe einer Real-time PCR wäre es möglich, den Befallsverlauf schon in sehr frühen Stadien zu untersuchen, und damit die Frage nach der Ursache der ausbleibenden Detektion des Pilzes in Pflanzenmaterial vor dem Frühjahr, die sich im Rahmen der durchgeführten ELISA-Untersuchungen stellte, zu beantworten. 


\section{Zusammenfassung}

Durch die Intensivierung des Rapsanbaus ist es zu einer deutlichen Zunahme der Fruchtfolgekrankheiten $S$. sclerotiorum und $V$. longisporum gekommen. Zur Bekämpfung von $V$. longisporum stehen dem Anbauer zurzeit noch keine resistenten Sorten oder Fungizide zur Verfügung. Hingegen werden zur Bekämpfung von S. sclerotiorum seit vielen Jahren prophylaktische Fungizidapplikationen durchgeführt.

Wie die Auswertung eines Datensatzes von 1036 Fungizidbehandlungen aus 163 Versuchen der amtlichen Pflanzenschutzdienste der Länder aus dem Zeitraum 19912003 zeigte, konnte durch eine Blütenbehandlung ein durchschnittlicher Mehrertrag von $2,41 \mathrm{dt} / \mathrm{ha}$ erzielt werden. Nur in 33\% der ausgewerteten Versuche konnte jedoch der durchschnittliche kostendeckende Mehrertrag von 3,32 dt/ha erzielt werden.

Im Rahmen dieser Arbeit wurden in mehrjährigen Feldversuchen Befalls-VerlustRelationen für S. sclerotiorum und V. longisporum erarbeitet, um die Schadwirkung dieser beiden Pathogene $\mathrm{zu}$ untersuchen. Im Gegensatz $\mathrm{zu}$ vielen anderen Untersuchungen, in denen verschiedene Befallshäufigkeiten durch Anwendung von Fungiziden auf Befallsflächen eingestellt wurden, wurden die Versuche in dieser Arbeit auf befallsfreien Flächen angelegt und verschiedene Befallshäufigkeiten durch künstliche Inokulation eingestellt.

Die Schadwirkung von S. sclerotiorum wurde in Abhängigkeit verschiedener Faktoren untersucht. Neben dem Inokulationstermin wurden die agronomischen Parameter Aussaattermin, Bestandesdichte und Sorte variiert. Alle Versuche wurden mit einer Hybrid- und einer Liniensorte angelegt, um erste Hinweise auf mögliche Sorteneffekte zu erlangen.

Die Ergebnisse der Feldversuche ergaben mit zunehmendem Pflanzenalter eine tendenziell erhöhte Anfälligkeit sowohl der Hybrid- als auch der Liniensorte. Die Hybridsorte Talent wies eine geringere Anfälligkeit als die Liniensorte Prince auf. Die im dritten Versuchsjahr angebaute Hybride Maja hingegen zeigte eine höhere Anfälligkeit als die Liniensorte Prince. Auch in dem Sortenversuch des Versuchsjahres 2004/05 konnten Unterschiede in der Anfälligkeit der untersuchten Sorten beobachtet werden, die sich jedoch in nur einem Fall statistisch absichern ließen. Auch die Schadwirkung in den verschiedenen Sorten wies zum Teil große Unterschiede auf. 
Aufgrund des geringen Datenumfanges aus nur einem Versuchsjahr konnten sich diese Unterschiede jedoch statistisch nicht absichern lassen.

Die Ergebnisse aus den Sclerotinia-Feldversuchen wiesen bei Inokulation zu Beginn der Schotenbildung eine geringere Schadwirkung als nach einer Inokulation zur Vollblüte auf. Ein Vergleich der Regressionsgeraden wies jedoch keine signifikanten Unterschiede auf. Die Parameter Aussaattermin und Bestandesdichte wiesen keinen signifikanten Einfluss auf die Schadwirkung auf.

Neben dem Ertrag wurden auch der Einfluss eines S. sclerotiorum-Befalls auf die Parameter TKG und Ölgehalt untersucht. Mit steigender Befallshäufigkeit konnte eine zunehmende Minderung des TKG verzeichnet werden. Die Wirkung von S. sclerotiorum auf den Ölgehalt stellte sich in den verschiedenen Feldversuchen unterschiedlich dar. Allgemein war jedoch nur ein geringer Einfluss auf diesen Qualitätsparameter zu beobachten. Während für die Parameter Aussaattermin und Bestandesdichte kein signifikanter Einfluss auf das TKG und den Ölgehalt nachgewiesen werden konnte, zeigten Sorte und Inokulationstermin signifikante Unterschiede auf.

In einem weiteren Feldversuch wurde die Kompensationsfähigkeit von Winterraps nach späten Pflanzenverlusten untersucht. Zu Beginn der Schotenbildung wurden bei bis zu $70 \%$ der Pflanzen einer Parzelle die Haupttriebe durchtrennt. Eine Analyse der Ertragsergebnisse wies eine Kompensation der Pflanzenverluste von bis zu 30\% durch eine Erhöhung des TKG auf. Signifikante Unterschiede zwischen den Sorten konnten dabei nicht festgestellt werden.

Aus den Ergebnissen der Feldversuche und der Wirtschaftlichkeitsuntersuchungen wurden wirtschaftliche Schadensschwellen für S. sclerotiorum in Abhängigkeit von Ertragserwartung, Sorte und Inokulationstermin entwickelt. Sowohl bei der Hybrid- als auch der Liniensorte sind die Schadensschwellen einer Infektion zu BBCH 71 deutlich höher als nach einer Infektion zur Vollblüte. Obwohl die Schadwirkung zwischen Hybrid- und Liniensorte keinen signifikanten Unterschied aufwies, ist die Schadensschwelle der Liniensorte deutlich geringer als die der Hybridsorte. Für Ertragserwartungen von 30-50 dt/ha variieren sie für die Hybridsorte zwischen 25 und $13 \% \mathrm{zu}$ tolerierenden Befall und für die Liniensorte von 16 bis 5\% Befallshäufigkeit. 
Praktische Anwendung finden die wirtschaftlichen Schadensschwellen in dem neuen Prognosemodell SkleroPro.

Zur Untersuchung der Schadwirkung von $V$. longisporum konnten durch Ausbringung unterschiedlicher Mengen natürlich befallenen Rapsstrohs vor der Aussaat unterschiedlich abgestufte Befallshäufigkeiten eingestellt werden. Mit 50\% Befallshäufigkeit im Versuchsjahr 2002/03 bzw. 34\% im Versuchsjahr 2003/04 konnte jedoch kein Befall aus stark befallenen Gebieten simuliert werden. Auch die Befallsstärke war nur sehr gering. Nur ein geringer Anteil der befallenen Pflanzen wies einen starken Besatz mit Mikrosklerotien auf. In beiden Versuchsjahren konnte kein ertragsmindernder Effekt von $V$. longisporum festgestellt werden. Auch TKG und Ölgehalt wiesen keine Beeinflussung auf.

Durch ELISA-Untersuchungen von im Verlauf der Vegetation regelmäßig entnommenen Pflanzenproben wurde der Befallsverlauf von $V$. longisporum in den Pflanzen untersucht. Erst mit beginnender Abreife konnte der Pilz deutlich im Pflanzenmaterial nachgewiesen werden. Mit zunehmender Inokulummenge konnte eine ebenfalls steigende Menge an Pilzmaterial in den Pflanzen zur Ernte detektiert werden.

Im Rahmen der molekularbiologischen Untersuchungen sollten aufgrund der unsicheren Diagnose von $V$. longisporum und der erst sehr späten Symptomentwicklung Primer für einen artspezifischen Nachweis dieses Pathogens entwickelt werden. Basierend auf Unterschieden in den Bandenmustern verschiedener DNA-Fingerprint-Analysen zwischen $V$. dahliae und $V$. longisporum konnte ein artspezifisches Amplifikat selektiert werden von dessen Sequenz Primer abgeleitet wurden. In vitro-Untersuchungen haben gezeigt, dass mit Hilfe dieser Primer ein spezifischer Nachweis von $V$. longisporum möglich ist. In Isolaten von $V$. dahliae, $V$. albo-atrum, $V$. tricorpus sowie in anderen Pilzarten konnte das spezifische Fragment von 140 bp nicht amplifiziert werden. Diese Primer sollen nach der Entwicklung einer quantitativen Real-time PCR die Grundlage für weitere Studien zum Befallsverlauf von $V$. longisporum bilden. 


\subsection{Summary}

The increasing area of rapeseed cultivation in Germany has caused a significant spread of soil borne diseases such as Sclerotinia sclerotiorum and Verticillium longisporum. At present there are no fungicides for control of $V$. longisporum available to the growers. In contrast, preventive fungicide applications at flowering stage are common practice in agriculture to control Sclerotinia stem rot.

Analysis of a dataset from 1036 fungicide treatments in 163 field trials of the state extension services from 1991 to2003 revealed an average yield benefit of $2.41 \mathrm{dt} / \mathrm{ha}$ for fungicide sprays at bloom. In only one third of all analysed fungicide treatments the cost effective yield gain of $3.32 \mathrm{dt} / \mathrm{ha}$ was achieved.

Within the scope of this project disease/yield loss relations were investigated in field trials during four growing seasons (2001-2005) for $V$. longisporum and S. sclerotiorum. The Sclerotinia field trials were conducted on sites without natural soil infestation.

Yield effects of Sclerotinia stem rot were studied by artificially adjusting different levels of disease incidence with the tooth pick inoculation technique. Further factors in the field trials were date of inoculation, sowing time, plant density and cultivar. Each field trial was conducted with a hybrid and a line cultivar in order to examine cultivar responses to Sclerotinia infection.

Rapeseed plants tended to become more susceptible with advancing plant development. The hybrid cultivar 'Talent' was less susceptible than the line cultivar 'Prince'. The hybrid cultivar 'Maja', grown in the third experimental year instead of 'Talent', showed a higher susceptibility than the cultivar 'Prince'. In 2004/05, differences in the susceptibility between seven cultivars were only slight and not statistically significant. The same applied for the effects on yield which showed a high variation between the different cultivars, with no statistical significance.

For both cultivar types the results of the field trials show that crop loss resulting from infections during full bloom is higher than from infections at beginning of pod formation. Statistical analysis showed no significant differences of the damage effects between the two inoculation dates. Sowing date and seeding density showed no significant effects on crop loss. 
Apart from the effect of $S$. sclerotiorum on yield the effect on thousand seed weight (TSW) and oil content was investigated. With increasing disease incidence a decrease in TSW was found. The results of the field trials showed no consistent effect on the oil content. The overall effect of Sclerotinia stem rot on this quality parameter was low. In contrast to cultivar and time of inoculation, sowing date and plant density had no significant effect on TSW and oil content.

The results of the field trial dealing with the compensation potential of winter oilseed rape for late plant losses revealed a compensation of up to $30 \%$ enabled by increasing TSW. No significant differences were observed between the cultivars.

Based on the results of the field trials and the validation of the cost-effectiveness of fungicide applications against $S$. sclerotiorum economic damage thresholds were developed depending on yield expectation, cultivar and time of infection. For both cultivar types the economic damage thresholds following late infections (at beginning of pod ripening) were clearly higher than following early infections (at flowering stage). Although no significant differences between the two cultivars in yield effects to S. sclerotiorum infections were observed, the economic damage threshold for the line cultivar 'Prince' was significantly lower than that of the hybrid cultivars. With yield expectations at 30-50 dt/ha the damage thresholds for the hybrid cultivar varied between 25 and $13 \%$ of tolerable disease incidence, whereas for the line cultivar the threshold varied between 16 and 5\% of tolerable disease incidence. The economic damage thresholds were implemented into the new forecasting model SkleroPro.

Yield effects of $V$. longisporum were derived from different disease incidences adjusted by contaminating the soil with different amounts of naturally infested rapeseed straw prior to sowing. In the experimental year $2002 / 03$, disease incidences up to $50 \%$ and in 2003/04 disease incidences up to $34 \%$ were achieved. However, only few infected plants showed an intense colonisation with microsclerotia. In both experimental years no effect on yield, TSW and oil content was observed at the given levels of V. longisporum infections.

The spread of $V$. longisporum within roots and shoots was investigated by ELISA on plants sampled during the whole growing season in the field. Not until maturity V. longisporum was detectable in plant material at elevated levels. With increasing 
amount of inoculum an increasing amount of fungal biomass and of disease symptoms was detected in plants before harvest.

Alternatively a molecular genetic approach for developing a PCR assay based on species specific primers was undertaken for an early and reliable detection of $V$. longisporum. Based on differences between $V$. dahliae and $V$. longisporum in the banding pattern of several DNA-fingerprintings, a specific fragment was extracted and sequenced for designing primers. In vitro a specific detection of $V$. longisporum was possible and no cross reaction occurred with $V$. dahliae, $V$. albo-atrum and $V$. tricorpus isolates or other fungal DNA with the specific fragment of $140 \mathrm{bp}$. 


\section{Literaturverzeichnis}

Abawi, G. S., Grogan, R. G. (1975): Source of primary inoculum and effects of temperature and moisture on infection of beans by Whetzelinia sclerotiorum. Phytopathology 65: 300-309

AdAms, P. B., TATE, C. J. (1976): Mycelial germination of sclerotia of Sclerotinia sclerotiorum on soil. Plant Disease Reporter 60: 515-518

Agrios, G. N. (1997): Plant Pathology. 4. Aufl., Academic Press, New York

AHLERS, D. (1987): Untersuchungen über den Erreger der krankhaften Abreife an Winterraps. Gesunde Pflanzen 39: 375-383

Ahlers, D. (1989): Integrierter Pflanzenschutz bei Pilzkrankheiten in Winterraps. Gesunde Pflanzen 41: 306-311

Ahlers, D., Hindorf, H. (1987): Epidemiologische Untersuchungen über den Schaderreger der Weißstängeligkeit Sclerotinia sclerotiorum im Hinblick auf eine Prognose. Nachrichtenblatt des Deutschen Pflanzenschutzdienstes 39: 113-119

AlSTRÖM, S. (2000): Root-colonizing fungi from oilseed rape and their inhibition of Verticillium dahliae. Journal of Phytopathology 148: 417-423

Amelung, D., Schulz, R.-R., Daebeler, F. (1996): Einfluss der Fruchtfolge auf Rapskrankheiten. Raps 14: 52-56

Andersson, B., Bengtsson, A. (1989): The influence of row spacing, seed rate and sowing time on overwintering and yield in winter oilseed rape (Brassica napus). Swedish Journal of Agricultural Research 19: 129-134

Angadi, S. V., Cutforth, H. W., McConkey, B. G., GAn, Y. (2003): Yield adjustment by canola grown at different plant populations under semiarid conditions. Crop Science 43: 1358-1366

ANONYM (2004): Beschreibende Sortenliste 2004, Getreide, Mais, Ölfrüchte, Leguminosen (großkörnig), Hackfrüchte (außer Kartoffeln). Landbuchverlag, Hannover

Ashworth, L. J. Jr., Huisman, O. C., Harper, D. M., StromberG, L. K., Bassett, D. M. (1979): Verticillium wilt disease of cotton: Influence of inoculum density in the field. Phytopathology 69: 483-489 
Ashworth, L. J. JR., McCutcheon, O. D., George, A. G. (1972): Verticillium alboatrum: the quantitative relationship between inoculum density and infection of cotton. Phytopathology 62: 901-903

Atallah, Z. K., Johnson, D. A. (2004): Development of Sclerotinia stem rot in potato fields in South-Central Washington. Plant Disease 88: 419-423

Barbara, D. J., Clewes, E. (2003): Plant pathogenic Verticillium species: how many of them are there? Molecular Plant Pathology 4: 297-305

Barbara, D. J., Morton, A., Miller, N. J. (2005): Isolation of microsatellite markers from an interspecific hybrid isolate of the fungal plant pathogen Verticillium dahliae. Molecular Ecology Notes 5: 854-856

Barbetti, M. J., Khangura, R. K. (1999): Managing black leg in the disease-prone environment of western Australia. Proceedings of the $10^{\text {th }}$ International Rapeseed Congress, Canberra, Australia

Bates, J. A., TAylor, E. J. A., Kenyon, D. M., Thomas, J. E. (2001): The application of real-time PCR to the identification, detection and quantification of Pyrenophora species in barley seed. Molecular Plant Pathology 2: 49-57

BIRnBOIM, H. C. (1983): A rapid alkaline extraction method for the isolation of plasmid DNA. Methods in Enzymology 100, 243-255

BMVEL (2005): Grundsätze für die Durchführung der guten fachlichen Praxis im Pflanzenschutz.

BockeY, D. (2003): Der Biodieselmarkt wächst. Raps 21: 81-84

Bom, M., Boland, G. J. (2000): Evaluation of disease forecasting variables for sclerotinia stem rot (Sclerotinia sclerotiorum) in canola. Canadian Journal of Plant Science 80: 889-898

BÖRNER, H. (1997): Pflanzenkrankheiten und Pflanzenschutz. 7. Auflage, Verlag Eugen Ulmer, Stuttgart

Brown, J., McCaffrey, J. P., Harmon, B. L., Davis, J. B., Brown, A. P., Erickson, D. A. (1999): Effect of late season insect infestation on yield, yield components and oil quality of Brassica napus, B. rapa, B. juncea and Sinapis alba in the Pacific 
Northwest region of the United States. Journal of Agricultural Science, Cambridge 132: $281-288$

BRUNS, J. B. (1996): Untersuchungen zur wetterbasierten Befallssimulation und Verlustprognose von Echtem Mehltau (Erysiphe graminis D. C. f. sp. tritici Marchal) an Winterweisen. Dissertation, Georg-August Universität Göttingen

Butterfield, E. J., DeVAy, J. E. (1977): Reassessment of soil assays for Verticillium dahliae. Phytopathology 67: 1073-1078

Buzzell, R. I., Welacky, T. W., ANDERSON, T. R. (1993): Soybean cultivar reaction and row width effect on Sclerotinia stem rot. Canadian Journal of Plant Science 73: $1169-1175$

CAmpbell, C. L., Madden, L. V. (1990): Introduction to plant disease epidemiology. John Wiley \& Sons, New York

Cappaert, M. R., Powelson, M. L., Christensen, N. W. (1992): Effect of soil moisture status on symptom expression of potato early dying. Phytopathology 82 : 1138

Carder, J. H., Morton, A., Tabrett, A. M., Barbara, D. J. (1994): Detection and Differentiation by PCR of subspecific groups within two Verticillium species causing vascular wilts in herbaceous hosts. In: Schots, A., Dewey, F. M. und Oliver, R. P. (eds.): Modern assays for plant pathogenic fungi: identification, detection and quantification. CAB International, Wallingford, UK, pp. 91-97

CASPER, R., MENDGEN, K. (1979): Quantitative serological estimation of a hypoparasite: detection of Verticillium lecanii in yellow rust infected wheat leaves by ELISA. Journal of Phytopathology 94: 89-91

CERnusko, R. (1995): Entwicklung und Erprobung enzymatischer und immunologischer Nachweismethoden für Verticillium dahliae Kleb. im Raps (Brassica napus). Dissertation, Georg-August Universität Göttingen

Cernusko, R., Wolf, G. A. (1997): Immunological methods for the detection of Verticillium dahliae in oilseed rape. In Dehne, H.-W., Adam, G., Diekmann, M., Frahm, J., Mauler-MachniK, A., Van Halteren, P. (eds.): Diagnosis and identification of plant pathogens. Kluwer Academic Publishers, Dordrecht, Boston, London 
Christen, O., SiEBLING, K. (1999): Vorfruchtwert von Raps. Raps 17: 65-67

Chun, S., KaO, L. B., Lockwood, J. L., Isleib, T. G. (1987): Laboratory and field assessment of resistance in soybean to stem rot caused by Sclerotinia sclerotiorum. Plant Disease 71: 811-815

Clarke, J. M., Clarke, F. R., Simpson, G. M. (1978): Effects of method and rate of seeding on yield of Brassica napus. Canadian Journal of Plant Science 58: 549-550

Clark, M. F., Adams, A. N. (1977): Characterisitcs of the micro plate method of enzyme-linked immunosorbent assay for the detection of plant viruses. Journal of General Virology 34: 475-483

Collins, A., Mercado-Blanco, J., Jiménez-Díaz, R. M., Olivares, C., Clewes, E., BARBARA, D. J. (2005): Correlation of molecular markers and biological properties in Verticillium dahliae and the possible origins of some isolates. Plant Pathology 54: $549-557$

Collins, A., Okoli, A. A. N., Morton, A., Parry, D., Edwards, S. G., Barbara, D. J. (2003): Isolates of Verticillium dahliae pathogenic to crucifers are of at least three distinct molecular types. Phytopathology 93, 364-376

Daebeler, F., Amelung, D., Engel, K. H. (1985): Zur Verwechslungsmöglichkeit der durch Phoma lingam (Tode ex Fr.) Desm. verursachten Wurzelhalsfäule mit Rhizoctonia solani K. und Verticillium dahliae Kleb. Nachrichtenblatt Pflanzenschutzdienst DDR 39: 180-181

Daebeler, F., Amelung, D., Zeise, K. (1988): Verticillium-Welke an Winterraps Auftreten und Bedeutung. Nachrichtenblatt Pflanzenschutzdienst DDR 42: 71-73

Dan, H., Ali-Khan, S. T., RobB, J. (2001): Use of quantitative PCR diagnostics to identify tolerance and resistance to Verticillium dahliae in potato. Plant Disease 85: 700-705

Danielson, G. A., Nelson, B. D., Helms, T. C. (2004): Effect of Sclerotinia stem rot on yield of soybean inoculated at different growth stages. Plant Disease 88: 297300

Debode, J., DeclercQ, B., HöFte, M. (2005): Identification of cauliflower cultivars that differ in susceptibility to Verticillium longisporum using different inoculation methods. Journal of Phytopathology 153: 257-263 
Degenhardt, D. F., Kondra, Z. P. (1981): The influence of seeding date and seeding rate on seed yield and growth characters of five genotypes of Brassica napus. Canadian Journal of Plant Science 61: 185-190

Delanoy, M., Salmon, M., Kummert, J., Frison, E., Lepoivre, P. (2003): Development of Real-time PCR for the rapid detection of episomal Banana streak virus (BSV). Plant Disease 87: 33-38

EL-ZIK, K. M. (1985): Integrated control of Verticillium wilt of cotton. Plant Disease 69: $1025-1032$

Engvall, E., Perlmann, P. (1972): Enzyme-linked immunosorbent assay. III. Quantitation of specific antibodies by enzyme-labelled anti-immunoglobulin in antigen-coated tubes. Journal of Immunology 109: 129-135

Eynck, C., Koopmann, B., Grunewaldt-Stöcker, G., von Tiedemann, A. (2005): Interaction of Verticillium longisporum and Verticillium dahliae with oilseed rape - root infection and systemic spread. Proceedings of the $9^{\text {th }}$ International Verticillium Symposium 2005, Monterey, USA

FACHAGENTUR NACHWACHSENDE ROHSTOFFE (2005): http://www.fnr.de/

Fahleson, J., Hu, Q., DiXelius, C. (2004). Phylogenetic analysis of Verticillium species based on nuclear and mitochondrial sequences. Archives of Microbiology 181: 435-442

Fahleson, J., Lagercrantz, U., Uh, Q., Steventon, L. A., Dixelius, C. (2003): Estimation of genetic variation among Verticillium isolates using AFLP analysis. European Journal of Plant Pathology 109: 361-371

Fitzell, R., Evans, G., FAHY, P. C. (1980): Studies on the colonization of plant roots by Verticillium dahliae Klebahn with use of immunofluorescent staining. Australian Journal of Botany 28: 357-368

Fortnagel, B., Schlösser, E. (1996): Polyclonal antibodies against Verticillium dahliae Kleb. from oilseed rape via immunized hens. Zeitschrift für Pflanzenkrankheiten und Pflanzenschutz 103: 582-589

Freier, B., Pallutt, B., Hommes, M. (1994): Zur Anwendung von flexiblen Schwellenwerten im integrierten Pflanzenschutz. Nachrichtenblatt des Deutschen Pflanzenschutzdienstes 46: 170-175 
Friesland, H. (2000): Agrarmeteorologisches Verfahren zur Prognose von Rapskrebs. Raps 18: 14-17

Garbe, V. (1999): Krankheiten im Winterraps in Europa. Wo steht der integrierte Pflanzenschutz? Raps 17: 68-71

Gaudreault, S. M., Powelson, M. L., Christensen, N. W. (1992): Effect of soil water matric potential on potato plant growth and root infection in Verticillium dahliae infested soil. Phytopathology 82: 1138

GeISLER, G. (1988): Pflanzenbau. 2. Auflage, Paul Parey Verlag, Berlin, Hamburg

Gerik, J. S., Lommel, S. A., Huisman, O. C. (1987): A specific serological staining procedure for Verticillium dahliae in cotton root tissue. Phytopathology 77: 261265

Goud, J.-K. C., Termorshuizen, A. J., Gams, W. (2003): Morphology of Verticillium dahliae and $V$. tricorpus on semi-selective media used for the detection of $V$. dahliae in soil. Mycological Research 107: 822-830

GRAU, C. R., RADKE, V. L. (1984): Effects of cultivars and cultural practices on Sclerotinia stem rot of soybean. Plant Disease 68: 56-58

GREEN, R. J. JR. (1980): Soil factors affecting survival of microsclerotia of Verticillium dahliae. Phytopathology 70: 353-355

GünzelmanN, H., Paul, V. H. (1990): Zum Auftreten und zur Bedeutung der Verticillium-Welke an Raps in der Bundesrepublik Deutschland in 1989. Raps 8: $23-25$

Gutierrez, A. P., DeVay, J. E., Pullman, G. S., Friebertshauser, G. E. (1983): A model of Verticillium wilt in relation to cotton growth and development. Phytopathology 73: 89-95

HAAS, J. H., BOLWYN, B. (1972): Ecology and epidemiology of Sclerotinia wilt of white beans in Ontario. Canadian Journal of Plant Science 52: 525-533

Hall, R., Peters, R. D., Assabgui, R. A. (1993): Occurrence and impact of blackleg on oilseed rape in Ontario. Canadian Journal of Plant Pathology 15: 305-313

HANAHAN, D. (1983): Studies on transformation of Escherichia coli with plasmid. Journal of Molecular Biology 166: 557-580 
Harris, D. C., YANG, J. R., Ridout, M. S. (1993): The detection and estimation of Verticillium dahliae in naturally infested soil. Plant Pathology 42: 238-250

Hartleb, H., WolfF, C., RÜCKer, P. (1999): Fungizideinsatz im Winterraps - eine schwierige Entscheidung. Raps 17: 72-75

Heale, J. B., KarapapA, V. K. (1999): The verticillium threat to Canada's major oilseed crop: canola. Canadian Journal of Plant Pathology 21: 1-7

Heath, D. D., Iwama, G. K., Devlin, R. H. (1993): PCR primed with VNTR core sequences yields species specific patterns and hypervariable probes. Nucleic Acids Research 21: 5782-5785

Heinz, R., Lee, S. W., SAParno, A., Nazar, R. N., RobB, J. (1998): Cyclical systemic colonization in Verticillium-infected tomato. Physiological and Molecular Plant Pathology 52: 385-396

Henson, J. M., French, R. (1993): The polymerase chain reaction and plant disease diagnosis. Annual Review of Phytopathology 31: 81-109

HEPPNER, C. (1995): Nachweis von Verticillium dahliae Kleb. im Boden mit Plattengussverfahren und ELISA (Enzyme-linked immunosorbent assay) sowie Untersuchungen zur Auswirkungen des Inokulums auf den Befall von Winterraps (Brassica napus ssp. oleifera Metzg.). Dissertation, Georg-August Universität Göttingen

HePPNER, C., Heitefuss, R. (1997): Development of an enzyme-linked immunosorbent assay (ELISA) for Verticillium dahliae detection in soil. In DEHNE, H.-W., ADAM, G., Diekmann, M., Frahm, J., Mauler-Machnik, A., van Halteren, P. (eds.): Diagnosis and identification of plant pathogens. Kluwer Academic Publishers, Dordrecht, Boston, London

Heran, A., McCartney, H. A., LI, Q. (1999): The effect of petal characteristics, inoculum density and environmental factors on infection of oilseed rape by Sclerotinia sclerotiorum. Proceedings of the $10^{\text {th }}$ International Rapeseed Congress, Canberra, Australia

Hoffmann, G. M., Nienhaus, F., Poehling, H.-M., Schönbeck, F., Weltzien, H. C., Wilbert, H. (1994): Lehrbuch der Phytomedizin. 3. Auflage, Blackwell Wissenschafts-Verlag, Berlin 
Honermeier, B., Behle-Schalk, L., Gaudchau, M. (2002): Vorfruchtwirkung von Winterraps. Raps 20: 108-110

HoRNig, H. (1986): Krankhafte Abreife - Spätschäden durch Phoma lingam und/oder Verticillium dahliae? Raps 4: 83-85

HoRnIG, H. (1987): Weiter Untersuchungen und Erkenntnisse zur Krankhaften Abreife. Raps 5: 27-29

Hu, B., Chen, F., LI, Q., Wu, X., Hou, S., FeI, W., WANG, X. (1999): Effect of cultural control on rapeseed stem rot (Sclerotinia sclerotiorum) in Brassica napus. Proceedings of the $10^{\text {th }}$ International Rapeseed Congress, Canberra, Australia

Hu, X., NAZAR, R. N., RoBB, J. (1993): Quantification of Verticillium biomass in wilt disease development. Physiological and Molecular Plant Pathology 42: 23-36

HuAng, H. C. (1985): Factors affection myceliogenic germination of sclerotia of Sclerotinia sclerotiorum. Phytopathology 75: 433-437

Huang, H. C., Dueck, J. (1980): Wilt of sunflower from infection by mycelialgerminating sclerotia of Sclerotinia sclerotiorum. Canadian Journal of Plant Pathology 2: 47-52

HuAng, H. C., Hoes, J. A. (1980): Importance of plant spacing and sclerotial position to development of Sclerotinia wilt of sunflower. Plant Disease 64: 81-84

Hudyncia, J., Shew, H. D., Cody, B. R., Cubeta, M. A. (2000): Evaluation of wounds as a factor for infection of cabbage by ascospores of Sclerotinia sclerotiorum. Plant Disease 84: 316-320

Huisman, O. C., Ashworth, L. J. JR. (1974): Quantitative Assessment of Verticillium albo-atrum in field soils: procedural and substrate improvements. Phytopathology 64: $1043-1044$

INGRAM, R. (1968): Verticillium dahliae Kleb. var. longisporum Stark: a stable diploid. Transactions of the British Mycological Society 51: 339-341

Inoue, H., Nojima, H., OKayama, H. (1990): High efficiency transformation of Escherichia coli with plasmids. Gene 96: 23-28

JaCKSOn, C. W., HeAle, J. B. (1985): Relationship between DNA content and spore volume in sixteen isolates of Verticillium lecanii and two new diploids of $V$. 
dahliae $(=V$. dahliae var. longisporum Stark). Journal of General Microbiology 131: $3229-3236$

JamauX, I., Gelie, B., Lamarque, C. (1995): Early stages of infection of rapeseed petals and leaves by Sclerotinia sclerotiorum revealed by scanning electron microscopy. Plant Pathology 44: 22-30

JAMES, W. C. (1974): Assessment of plant diseases and losses. Annual Review of Phytopathology 12: 27-48

JEFFERSON, P. G., Gossen, B. D. (2002): Irrigation increases Verticillium wilt incidence in a susceptible Alfalfa cultivar. Plant Disease 86: 588-592

JIANG, L. (2001): A mutant with apetalous flowers in oilseed rape (Brassica napus): Mode of inheritance and influence on crop physiology and Sclerotinia infection. Dissertation, Georg-August Universität Göttingen

KABIR, Z., BHAT, R. G., SubBARAO, K. V. (2004): Comparison of media for recovery of Verticillium dahliae from soil. Plant Disease 88: 49-55

Karapapa, V. K., Bainbridge, B. W., Heale, J. B. (1997): Morphological and molecular characterization of Verticillium longisporum comb. nov., pathogenic to oilseed rape. Mycological Research 101: 1281-1294

KARAPAPA, V. K., TYPAS, M. A. (2001): Molecular characterization of the host-adapted pathogen Verticillium longisporum on the basis of a Group-I intron found in the nuclear SSU-rRNA gene. Current Microbiology 42: 217-224

KELBER, E. (1975): Möglichkeiten der Entwicklung von Befalls-Verlust-Relationen für Pflanzenkrankheiten aus Sekundärdaten. Dissertation, Justus-Liebig-Universität Gießen

KEUNECKE, H. (2005): Einfluss von Verticillium longisporum auf die Wurzel- und Sprossentwicklung von Winterraps unter Berücksichtigung von Fungizidapplikationen. Masterarbeit, Georg-August-Universität Göttingen

KIM, C.-H., MacKenzIE, D. R. (1987): Empirical models for predicting yield loss caused by a single disease. In: TENG, P. S.: Crop loss assessment and pest management. The American Phytopathological Society, St. Paul, Minnesota, pp. 126-132 
Klein-GebBincK, H. W., Woods, D. L. (2002): Yield loss assessment in canola: effects of brown girdling root rot and maggot damage on single plant yield. Plant Disease 86: $1005-1010$

Kluge, E., Enzian, S., Gutsche, V. (1999): Befallsatlas - Atlas der potentiellen Befallsgefährdung durch wichtige Schadorganismen im Ackerbau Deutschlands. BBA Braunschweig, Saphir Verlag, Ribbesbüttel

Koch, S., Von Tiedemann, A. (2005a): Den Spritztermin richtig absichern. DLGMitteilungen 3: 44-46

Koch, S., von Tiedemann, A. (2005b): Mit SkleroPro auf der sicheren Seite. Neue Strategien im Pflanzenschutz. Land \& Forst Schriftenreihe Pflanzenschutz, 28-30

Koike, M., Fujita, M., NagaO, H., Ohshima, S. (1996): Random amplified polymorphic DNA analysis of Japanese isolates of Verticillium dahliae and $V$. albo-atrum. Plant Disease 80: 1224-1227

Koike, M., Nagao, H., Dobinson, K., RobB, J. (1997): Genetic relatedness between Japanese and Canadian isolates of Verticillium spp. based on random amplification of polymorphic DNA. Proceedings of the $7^{\text {th }}$ International Verticillium Symposium. Cape Sounion, Athens, Greece, pp. 19-24

Koike, M., Watanabe, M., NagaO, H., Ohshima, S. (1995): Molecular analysis of Japanese isolates of Verticillium dahliae and V. albo-atrum. Letters in Applied Microbiology 21: 75-78

Koike, S. T., Subbarao, K. V., Davis, R. M., Gordon, T. R., Hubbard, J. C. (1994): Verticillium wilt of cauliflower in California. Plant Disease 78: 1116-1121

KOLESCH, H. (1990): Wann lohnt sich eine Krankheitsbekämpfung im Winterraps. Raps 8: $15-19$

KÖPPL, H., ScHMIDT, H. (1993): Erprobung eines Sclerotinia-Warndienstes. Raps 11: 66-69

Kora, C., McDonald, M. R., Boland, G. J. (2005): Lateral clipping of canopy influences the microclimate and development of apothecia of Sclerotinia sclerotiorum in carrots. Plant Disease 89: 549-557

KrostitZ, J. (1998): Weißstängeligkeit - Wie ernst ist sie zu nehmen? Raps 16: 52-56 
KRÜGER W. (1986): Verticillium dahliae Kleb. Raps 4: 14-19

KRÜGER, W. (1973): Maßnahmen zur Bekämpfung des Rapskrebses verursacht durch Sclerotinia sclerotiorum (Lib.) de Bary. Phytopathologische Zeitschrift 77: 125137

KRÜGER, W. (1982): Die Wurzelhals- und Stengelfäule des Rapses, verursacht durch Phoma lingam (stat. Gen. Leptosphaeria maculans), eine schwer bekämpfbare Krankheit. Zeitschrift für Pflanzenkrankheiten und Pflanzenschutz 89: 489-507

KRÜGeR, W., StOltenberG, J. (1983): Bekämpfung von Rapskrankheiten II. Maßnahmen zur Befallsverringerung von Sclerotinia sclerotiorum unter Berücksichtigung ökonomischer Faktoren. Phytopathologische Zeitschrift 108: $114-126$

KRUSE, T. (2004): Epidemiologie, Bedeutung und integrierte Bekämpfungsmöglichkeiten von Leptosphaeria maculans (Phoma lingam) sowie weiterer pilzlicher Krankheitserreger im schleswig-holsteinischen Winterrapsanbau (Brassica napus L. var. napus). Dissertation, Christian-Albrechts-Universität Kiel

Kurle, J. E., Grau, C. R., Oplinger, E. S., Mengistu, A. (2001): Tillage, crop sequence, and cultivar effects on Sclerotinia stem rot incidence and yield in soybean. Agronomy Journal 93: 973-982

LAMEY, A. (1998): Disease losses. Proceedings of the Sclerotinia Workshop, Fargo, North Dakota

LANDSCHREIBER, M. (2004): Weißstängeligkeit - Nach wie vor eine ernst zu nehmende Krankheit! Raps 22: 12-15

Leach, J. E., Darby, R. J., Williams, I. H., Fitt, B. D. L., RaWlinson, C. J. (1994): Factors affecting growth and yield of winter oilseed rape (Brassica napus), 19851989. Journal of Agricultural Science, Cambridge 122: 405-413

Leach, J. E., Stevenson, H. J., Rainbow, A. J., Mullen, L. A. (1999): Effects of high plant populations on the growth and yield of winter oilseed rape (Brassica napus). Journal of Agricultural Science, Cambridge 132: 173-180

Li, K.-N., German, T. L., Rouse, D. I. (1993): A unique RAPD fragment for Verticillium dahliae and its application to the specific detection of the pathogen. Phytopatholgoy 83: 1370 
Li, K.-N., Rouse, D. I., Eyestone, E. J., German, T. L. (1999): The generation of specific DNA primers using random amplified polymorphic DNA and its application to Verticillium dahliae. Mycological Research 103: 1361-1368

LI, K.-N., Rouse, D. I., GERMAN, T. L. (1994): PCR primers that allow intergeneric differentiation of ascomycetes and their application to Verticillium spp. Applied and Environmental Microbiology 60: 4324-4331

Li, Y., Chen, J., Bennett, R., Kiddle, G., Wallsgrove, R., Huang, Y., He, Y. (1999): Breeding, inheritance, and biochemical studies on Brassica napus cv. Zhongyou 821: tolerance to Sclerotinia sclerotiorum (stem rot). Proceedings of the $10^{\text {th }}$ International Rapeseed Congress, Canberra, Australia

LindENBERG, H. (2003): Fungizid- und Wachstumsreglereinsatz im Frühjahr. Raps 21: $60-65$

LIS, J. T., SCHLEIF, R. (1975): Size fractionation of double-stranded DNA by precipitation with polyethylene glycol. Nucleic Acid Research 2: 383-389

Liu, S., Wang, H., Zhang, J., Fitt, B. D. L., Xu, Z., Evans, N., Liu, Y., Yang, W., GuO, X. (2005): In vitro mutation and selection of doubled-haploid Brassica napus lines with improved resistance to Sclerotinia sclerotiorum. Plant Cell Reports 24: 133-144

Lobo JNR, M., Lopes, C. A., Silva, W. L. C. (2000): Sclerotinia rot losses in processing tomatoes grown under centre pivot irrigation in central Brazil. Plant Pathology 49: $51-56$

LÓPEZ-Escudero, F. J., BlanCO-LÓPEZ, M. A. (2005): Effects of drip irrigation on population of Verticillium dahliae in olive orchard. Journal of Phytopathology 153: 238-239

LOR, H.-J. W. (1995): Ist der Einsatz von Fungiziden in Raps noch wirtschaftlich? Raps 13: $62-63$

LuMSDEN, R. D. (1979): Histology and physiology of pathogenesis in plant diseases caused by Sclerotinia species. Phytopathology 69: 890-896

MAdDen, L. V. (1983): Measuring and modeling crop losses at the field level. Phytopathology 73: 1591-1596 
Madden, L. V., Nutter JR., F. W. (1995): Modeling crop losses at the field scale. Canadian Journal of Plant Pathology 17: 124-137

Madden, L. V., Pennypacker, S. P., Antle, C. E., Kingsolver, C. H. (1981): A loss model for crops. Phytopathology 71, 685-689

Mahuku, G. S., Platt, H. W., Maxwell, P. (1999): Comparison of polymerase chain reaction based methods with plating on media to detect and identify Verticillium wilt pathogens of potato. Canadian Journal of Plant Pathology 21: 125-131

McCartney, H. A., Doughty, K. J., Norton, G., Booth, E. J., Kightley, S. P. J., Landon, G., West, G., Walker, K. C., Thomas, J. E. (1999): A study of the effect of disease on seed quality parameters of oilseed rape. Proceedings of the $10^{\text {th }}$ International Rapeseed Congress, Canberra, Australia

MCGREgOR, D. I. (1980): The nature of hail injury to rapeseed. Canadian Journal of Plant Science 60: 1441-1449

MCGREGOR, D. I. (1987): Effect of plant density on development and yield of rapeseed and its significance to recovery from hail injury. Canadian Journal of Plant Science 67: $43-51$

Mendham, N. J., Shipway, P. A., Scott, R. K. (1981a): The effects of delayed sowing and weather on growth, development and yield of winter oil-seed rape (Brassica napus). Journal of Agricultural Science, Cambridge 96: 389-416

Mendham, N. J., Shipway, P. A., Scott, R. K. (1981b): The effects of seed size, autumn nitrogen and plant population density on the response to delayed sowing in winter oil-seed rape (Brassica napus). Journal of agricultural Science, Cambridge 96: 417-428

Messner, R. Schweigkofler, W., Ibl, M., Berg, G., Prillinger, H. (1996): Molecular characterization of the plant pathogen Verticillium dahliae Kleb. using RAPD-PCR and sequencing of the 18SrRNA-gene. Journal of Phytopathology 144: $347-354$

Miller, S. A., Martin, R. R. (1988): Molecular diagnosis of plant disease. Annual Review of Phytopathology 26: 409-432 
MoL, L. (1995): Effect of plant roots on the germination of microsclerotia of Verticillium dahliae. II Quantitative analysis of the luring effect of crops. European Journal of Plant Pathology 101: 679-685

Mol, L., Scholte, K., Vos, J. (1995): Effects of crop rotation and removal of crop debris on the soil population of two isolates of Verticillium dahliae. Plant Pathology 44: 1070-1074

Möller, E. M., Bahnweg, G., Sandermann, H., Geiger, H. H. (1992): A simple and efficient protocol fort the isolation of high molecular weight DNA from filamentous fungi, fruit bodies, and infected plant tissues. Nucleic Acids Research 20: 6115-6116.

Morton, A., Carder, J. H., Barbara, D. J. (1995a): Sequences of the internal transcribed spacers of the ribosomal RNA genes and relationships between isolates of Verticillium alboatrum and V. dahliae. Plant Pathology 44: 183-190

Morton, A., Tabrett, A. M., Carder, J. H., Barbara, D. J. (1995b): Sub-repeat sequences in the ribosomal RNA intergenic regions of Verticillium alboatrum and V. dahliae. Mycological Research 99: 257-266

Moukhamedov, R., Hu, X., NaZAR, R. N., RobB, J. (1994): Use of polymerase chain reaction-amplified ribosomal intergenic sequences for the diagnosis of Verticillium tricorpus. Phytopathology 84: 256-259

Mullins, E., Quinlan, C., Jones, P. (1999): Isolation of mutants exhibiting altered resistance to Sclerotinia sclerotiorum from small M2 populations of an oilseed rape (Brassica napus) variety. European Journal of Plant Pathology 105: 465-475

Murray, M. G., Thompson, W. F. (1980): Rapid isolation of high molecular weight plant DNA. Nucleic Acids Research 8: 4321-4325

Nachmias, A., BAR-Joseph, M., Solel, Z., BARASh, T. (1979): Diagnosis of mal secco disease in lemon by enzyme-linked immunosorbent assay. Phytopathology 69: 559591

Nicot, P. C., Rouse, D. I. (1987a): Precision and bias of three quantitative soil assays for Verticillium dahliae. Phytopathology 77: 875-881 
Nicot, P. C., Rouse, D. I. (1987b): Relationship between soil inoculum density of Verticillium dahliae and systemic colonization of potato stems in commercial fields over time. Phytopathology 77, 1346-1355

Niederleitner, S., Zinkernagel, V., Bartscherer, H.-C. (1991): Untersuchungen zur Pathogenese von Verticillium dahliae an Impatiens balsamina und Brassica napus. Zeitschrift für Pflanzenkrankheiten und Pflanzenschutz 98: 484-489

Nordin, K., Sigvald, R., Svensson, C. (1992): Forecasting the incidence of Sclerotinia stem rot on spring-sown rapeseed. Zeitschrift für Pflanzenkrankheiten und Pflanzenschutz 99: 245-255

Nutter, F. W. JR., Teng, P. S., Royer, M. H. (1993): Terms and concepts for yield, crop loss, and disease thresholds. Plant Disease 77: 211-215

Okoli, C. A. N., Carder, J. H., Barbara, D. J. (1994): Restriction fragment length polymorphisms (RFLPs) and the relationships of some host-adapted isolates of Verticillium dahliae. Plant Pathology 43: 33-40

Paplomatas, E. J., Bassett, D. M., Broome, J. C., DeVay, J. E. (1992): Incidence of Verticillium wilt and yield losses of cotton cultivars (Gossypium hirsutum) based on soil inoculum density of Verticillium dahliae. Phytopathology 82: 1417-1420

PAPlomatas, E. J., LAMPROPOUlos, C. J. (1997): Molecular characterization of Verticillium spp. by random amplified polymorphic DNA analysis. Proceedings of the $7^{\text {th }}$ International Verticillium Symposium. Cape Sounion, Athens, Greece, pp. $48-52$

PARKHOMENKO, S. (2003): Ein Vergleich der weltweit wichtigsten Anbauregionen für Ölsaaten. Endbericht für die Union zur Förderung von Öl- und Proteinpflanzen e.V.http://www.ufop.de/downloads/Weltoelsaaten_deutsch.pdf

Paul, V. H. (2003): Raps - Krankheiten, Schädlinge, Schadpflanzen, 3. Aufl. Verlag Th. Mann, Gelsenkirchen-Buer

Pedras, M. S. C., Ahiahonu, P. W. K. (2004): Phytotoxin production and phytoalexin elicitation by the phytopathogenic fungus Sclerotinia sclerotiorum. Journal of Chemical Ecology 30: 2163-2179

PegG, G. F., Brady, B. L. (2002): Verticillium wilts. CABI-Publishing, Oxon, New York 
Pope, S. J., VArney, P. L., Sweet, J. B. (1989): Susceptibility of cultivars of oilseed rape to Sclerotinia sclerotiorum and the effect of infection on yield. Aspects of applied biology 23: 451-456

Pramateftaki, P. V., Antoniou, P. P., Typas, M. A. (2000): The complete DNA sequence of the nuclear ribosomal RNA gene complex of Verticillium dahliae: Intraspecific heterogeneity within the intergenic spacer region. Fungal Genetics and Biology 29: 19-27

Pullman, G. S., De VAy, J. E. (1982a): Epidemiology of Verticillium wilt of cotton: A relationship between inoculum density and disease progression. Phytopathology 72: $549-554$

Pullman, G. S., DeVAy, J. E. (1982b): Epidemiology of Verticillium wilt of cotton: Effects of disease development on plant phenology and lint yield. Phytopathology 72: $554-559$

Reuter, L. B. (2003): Der Rapsmarkt auf einen Blick. Raps 21: 192-193

REWERTS, T. (2003): Entwicklung und Validierung von Methoden zum Screening der Anfälligkeit von Winterraps gegenüber Sclerotinia sclerotiorum. Masterarbeit, Georg-August-Universität Göttingen

RobB, J., Hu, X., Platt, H., NAZAR, R. (1994): PCR-based assays for the detection and quantification of Verticillium species in potato. In: Schots, A., Dewey, F. M. und Oliver, R. P. (eds.) Modern assays for plant pathogenic fungi: identification, detection and quantification. CAB International, Wallingford, UK, pp. 83-90

Robb, J., Moukhamedov, R., Hu, X., Platt, H., Nazar, R. N. (1993): Putative subgroups of Verticillium albo-atrum distinguishable by PCR-based assays. Physiological and Molecular Plant Pathology 43: 423-436

SAH, D. N., MACKENZIE, D. R. (1987): Methods of generating different levels of disease epidemics in loss experiments. In TENG, P. S.: Crop loss assessment and pest management. The American Phytopathological Society, St. Paul, Minnesota, pp. 90-96

SAlm, H., GeIDER, K. (2004): Real-time PCR for detection and quantification of Erwinia amylovora, the causal agent of fireblight. Plant Pathology 53: 602-610 
SAmbroOK, J., Fritsch, E. F., Maniatis, T. (1989): Molecular cloning: a laboratory manual. Cold Spring Habor Laboratory Press, New York

SCARisbrick, D. H., Daniels, R. W., Noor RaWi, A. B. (1982): The effect of varying seed rate on the yield and yield components of oil-seed rape (Brassica napus). Journal of agricultural Science, Cambridge 99: 561-568

SchlotT, W., SAUERMANN, W. (2003): Regenerationsfähigkeit von Winterrapsbeständen. Raps 21: 176-182

SCHUlZ, R.-R., BoElCKE, B. (1989): Zum Regenerationsvermögen von Winterraps. Archiv für Phytopathologie und Pflanzenschutz 25: 285-291

Schulz, R.-R., Boelcke, B. (1991): Regenerations- und Kompensationsvermögen von Winterraps. Raps 9: 43-45

Sedun, F. S., Seguin-Swartz, G., Rakow, G. F. W. (1989): Genetic variation in reaction to Sclerotinia stem rot in Brassica species. Canadian Journal of Plant Science 69: 229-232

Seidel, D., Daebler, F., Amelung, D., Engel, K.-H., Lücke, W. (1984): Auftreten, Schadwirkung und Bekämpfung von Phoma lingam an Winterraps. Nachrichtenblatt Pflschutzdienst DDR 38: 120-123

Shane, W. W., TEnG, P. S. (1987): Generating the database for disease-loss modeling. In: Teng, P. S.: Crop loss assessment and pest management. The American Phytopathological Society, St. Paul, Minnesota, pp. 82-89

SHI, S, LiU, L., WU, J., ZHOU, Y. (2003): In vitro screening stem rot resistant (tolerant) materials in Brassica napus L. Proceedings of the $11^{\text {th }}$ International Rapeseed Congress, Copenhagen, Denmark

Shivpuri, A., Sharma, K. B., ChHipA, H. P. (1999): Some studies on the stem rot disease (Sclerotinia sclerotiorum) of rapeseed/mustard in Rajasthan, India. Proceedings of the $10^{\text {th }}$ International Rapeseed Congress, Canberra, Australia

Sidlauskas, G., Bernotas, S. (2003): Some factors affecting seed yield of spring oilseed rape (Brassica napus L.). Agronomy Research 1: 229-243

Soesanto, L., TERMORSHUIZEN, A. J. (2001): Effect of temperature on the formation of microsclerotia of Verticillium dahliae. Journal of Phytopathology 149: 685-691 
STARK, C. (1961): Das Auftreten der Verticillium-Tracheomykosen in Hamburger Gartenbaukulturen. Gartenbauwissenschaft 26: 493-528

STATISTISCHES BUNDESAMT (2005): http://www.destatis.de/basis/d/forst/forsttab5.php

SteinBach, P., Broschewitz, B. (1997): Ertragssicherung durch Krankheitskontrolle und/oder Wachstumsregulierung? Raps 15: 62-66

Steinbach, P., Kreye, H., Wolf, G. A. (2005): Bundesweites „VerticilliumMonitoring“. Bewertung von Diagnosesicherheit und Risikofaktoren. Raps 23: 2026

Steinbach, P., Von Tiedemann, A., EDNer, I. M., 2002. Quantifizierung des bodenbürtigen Inokulums von Verticillium dahliae auf Rapsstandorten in Deutschland. UFOP-Monitoring Verticillium 2000/2001

Stelfox, D., Williams, J. R., Soehngen, U., Topping, R. C. (1978): Transport of Sclerotinia sclerotiorum ascospores by rapeseed pollen in Alberta. Plant Disease Reporter 62: 576-579

Steventon, L. A., Fahleson, J., Hu, Q., Dixelius, C. (2002a): Identification of the causal agent of Verticillium wilt of winter oilseed rape in Sweden, V. longisporum. Mycological Research 106: 570-578

Steventon, L., A., Happstadius, I., OKori, P., DiXelius, C. (2002b): Development of a rapid technique for the evaluation of the response of Brassica napus to Verticillium wilt. Plant Disease 86: 854-858

Subbarao, K. V., Chassot, A., Gordon, T. R., Hubbard, J. C., Bonello, P., Mullin, R., Oкамото, D., Davis, R. M., Koike, S. T. (1995): Genetic relationships and cross pathogenicities of Verticillium dahliae isolates from cauliflower and other crops. Phytopathology 85: 1105-1112

SubbaraO, K. V., HubBard, J. C. (1996): Interactive effects of broccoli residue and temperature on Verticillium dahliae microsclerotia in soil and on wilt in cauliflower. Phytopathology 86: 1303-1310

Sundaram, S., Plasencia, J., Banttari, E. E. (1991): Enzyme-linked immunosorbent assay for detection of Verticillium spp. using antisera produced to $V$. dahliae from potato. Phytopathology 81: 1485-1489 
Svensson, C., LeRENIUS, C. (1987): An investigation on the effect of Verticillium wilt (Verticillium dahliae Kleb.) on oilseed rape. Bulletin SROP 10: 30-34

TARTOF, K. D., HoBBS, C. A. (1987): Improved media for growing plasmid and cosmid clones. Bethesda Res. Lab. Focus 9, 12

TATChELl, G. M. (1983): Compensation in spring-sown oil-seed rape (Brassica napus L.) plants in response to injury to their flower buds and pods. Journal of agricultural Science, Cambridge 101: 565-573

TAYLOR, A. J., SMITH, C. J. (1992): Effect of sowing date and seeding rate on yield and yield components of irrigated canola (Brassica napus L.) grown on a red-brown earth in South-East Australia. Australian Journal of Agricultural Research 43: $1629-1641$

Tischner, H. (1998): Entscheidungs- und Prognosesysteme im Pflanzenschutz. Gesunde Pflanzen 50: 237-245

Turkington, T. K., Clayton, G. W., Harker, K. N. (2001): The impact of fall versus spring seeding on Sclerotinia stem rot and black spot of canola. Canadian Journal of Plant Pathology 23: 190

Turkington, T. K., Morrall, R. A. A. (1993): Use of petal infestation to forecast Sclerotinia stem rot of canola: the influence of inoculum variation over the flowering period and canopy density. Phytopathology 83: 682-689

Twengström, E., Sigvald, R., Svensson, C., Yuen, J. (1998): Forecasting Sclerotinia stem rot in spring sown oilseed rape. Crop Protection 17: 405-411

TyPAS, M. A. (1997): Molecular Characterization of Verticillium species. Proceedings of the $7^{\text {th }}$ International Verticillium Symposium. Cape Sounion, Athens, Greece, pp. $32-40$

Typas, M. A., Heale, J. B. (1977): Analysis of ploidy levels in strains of Verticillium using a Coulter counter. Journal of General Microbiology101: 177-180

Typas, M. A., Heale, J. B. (1980): DNA content of germination spores individual hyphal cells and resting structure cells of Verticillium spp. measured by microdensitometry. Journal of General Microbiology 121: 231-242

UFOP (2005a): http://www.ufop.de/1622.php 
UFOP (2005b): http://www.ufop.de/1675.php

VAN DE KopPel, M. M., SchOts, A. (1994): A double (monoclonal) antibody sandwich ELISA for the detection of Verticillium species in roses. In: SCHOTS, A., DEWEY, F. M. und Oliver, R. P. (eds.) Modern assays for plant pathogenic fungi: identification, detection and quantification. CAB International, Wallingford, UK, pp. 99-105

VAN DE Koppel, M. M., SchOts, A. (1995): Monoclonal antibody-based doubleantibody sandwich-ELISA for detection of Verticillium spp. in ornamentals. Phytopathology 85: 608-612

VANDERMARK, G. J., BARKer, B. M. (2003): Quantifying the relationship between disease severity and the amount of Aphanomyces euteiches detected in roots of alfalfa and pea with a Real-time PCR assay. Archives of Phytopathology and Plant Protection 36: 81-93

Veronese, P., Narasimhan, M. L., Stevenson, R. A., Zhu, J.-K., Weller, S. C., SubbaraO, K. V., Bressan, R. A. (2003): Identification of a locus controlling Verticillium disease symptom response in Arabidopsis thaliana. The Plant Journal 35: $574-587$

Versalovic, J., Schneider, M., de Bruijn, F. J., Lupski, J. R. (1994): Genomic fingerprinting of bacteria using repetitive sequence-based polymerase chain reaction. Methods in molecular and cellular biology 5: 25-40

Vietinghoff, J., DAebeler, F. (1986): Neuere Gesichtspunkte bei der Handhabung des Bekämpfungsrichtwertes für den Rapsglanzkäfer. Nachrichtenblatt Pflanzenschutzdienst DDR 40: 58-61

Vogelstein, B., GILlESPIE, D. (1979): Preparative and analytical purification of DNA from agarose. Proceedings of the National Academy of Sciences USA 76: 615-619

von Tiedemann, A., Hedke, K., Mögling, R. (2000): Biologische Bekämpfung der Sclerotinia-Weißstängeligkeit. Raps 18: 10-13

Vuong, T. D., Hoffman, D. D., Diers, B. W., Miller, J. F., Steadman, J. R., HARTMAn, G. L. (2004): Evaluation of soybean, dry bean, and sunflower for resistance to Sclerotinia sclerotiorum. Crop Science 44: 777-783 
WAнмноғF, W. (2000): Integrierter Rapsanbau. Initiativen zum Umweltschutz 16, Deutsche Bundesstiftung Umwelt, Erich Schmidt Verlag, Berlin

WALKER, P. T. (1983): Crop losses: The need to quantify the effects of pests, diseases and weeds on agricultural production. Agriculture, Ecosystems and Environment 9: 119-158

Wang, H., LiU, G., Zheng, Y., WAnG, X., YAnG, Q. (1999): Breeding of a Brassica napus cultivar Zhongshuang No. 9 with high-resistance to Sclerotinia sclerotiorum and dynamics of its important defense enzyme activity. Proceedings of the $11^{\text {th }}$ International Rapeseed Congress, Copenhagen, Denmark

Weingart, H., VöLKSCH, B. (1997): Genetic fingerprinting of Pseudomonas syringae pathovars using ERIC-, REP-, and IS50-PCR. Journal of Phytopathology 145:339345.

Weiss, A., KerR, E. D., Steadman, J. R. (1980): Temperature and moisture influences on development of white mold disease (Sclerotinia sclerotiorum) on Great Northern Beans. Plant Disease 64: 757-759

WERNER, B. (1996): Das Göttinger Schadensschwellenmodell zur gezielten Unkrautbekämpfung im Winterraps; Überprüfung, Weiterentwicklung und Einführung in die landwirtschaftliche Praxis. Dissertation, Georg-August Universität Göttingen

Werner, B., DE Mol, F., GerowitT, B. (2002): Unkraut mit der Maus erwischen. DLGMitteilungen 9: 52-56

Williams, I. H., FreE, J. B. (1979): Compensation of oil-seed rape (Brassica napus L.) plants after damage to their buds and pods. Journal of Agricultural Science, Cambridge 92: 53.59

Williams, J. R., Stelfox, D. (1979): Dispersal of ascospores of Sclerotinia sclerotiorum in relation to Sclerotinia stem rot of rapeseed. Plant Disease Reporter 63: $395-399$

Wohlleben, S. (2001): Epidemie- und Schadensdynamik von pilzlichen Krankheitserregern (Leptosphaeria maculans, Sclerotinia sclerotiorum, Verticillium dahliae) an Winterraps (Brassica napus L. var. napus) in SchleswigHolstein. Dissertation, Christian-Albrechts-Universität Kiel 
Wolf, G. A., Weinert, J. (2003): Problemschläge früh erkennen. DLG-Mitteilungen 7: $48-50$

XiaO, C. L., SubbaraO, K. V. (1998): Relationship between Verticillium dahliae inoculum density and wilt incidence, severity, and growth of cauliflower. Phytopathology 88: 1108-1115

XiaO, C. L., SubbaraO, K. V., Schulbach, K. F., Koike, S. T. (1998): Effects of crop rotation and irrigation on Verticillium dahliae microsclerotia in soil and wilt in cauliflower. Phytopathology 88: 1046-1055

Young, C. S., Clarkson, J. P., Smith, J. A., Watling, M., Phelps, K., Whipps, J. M. (2004): Environmental conditions influencing Sclerotinia sclerotiorum infection and disease development in lettuce. Plant Pathology 53: 387-397

YousAf, M., AHMAD, A., JAHANGIR, M., NASEEB, T. (2002): Effect of different sowing dates on the growth and yield of canola (Sarson) varieties. Asian Journal of Plant Sciences 1: 634-635

ZEISE, K. (1992): Gewächshaustest zur Resistenzprüfung von Winterraps (Brassica napus L. var. oleifera Metzger) gegen den Erreger der Rapswelke Verticillium dahliae Kleb. Nachrichtenblatt Deutscher Pflanzenschutzdienste 44: 125-128

ZeISE, K., BUCHMÜLLER, M. (1997): Studies on the susceptibility to Verticillium dahliae KLEB. var. longisporum STARK of six related Brassica species. Zeitschrift für Pflanzenkrankheiten und Pflanzenschutz 104: 501-505

ZEISE, K., SEIDEL, D. (1990): Zur Entwicklung und Schadwirkung der VerticilliumWelkekrankheit am Winterraps. Raps 8: 20-22

Zeise, K., Steinbach, P. (2004): Schwarze Rapswurzeln und der Vormarsch der Verticillium-Rapswelke. Raps 22: 170-174

ZEISE, K., VON TIEDEMANN, A. (2001): Morphological and physiological differentiation among vegetative compatibility groups of Verticillium dahliae in relation to $V$. longisporum. Journal of Phytopathology 149: 469-475

Zeise, K., Von Tiedemann, A. (2002a): Application of RAPD-PCR for virulence type analysis within Verticillium dahliae and V. longisporum. Journal of Phytopathology 150: $557-563$ 
ZEISE, K., VON TIEDEMANN, A. (2002b): Host spezialization among vegetative compatibility groups of Verticillium dahliae in relation to Verticillium longisporum. Journal of Phytopathology 150: 112-119

Zhao, J., Peltier, A. J., Meng, J., Osborn, T. C., Grau, C. R. (2004): Evaluation of Sclerotinia stem rot resistance in oilseed Brassica napus using a petiole inoculation technique under greenhouse conditions. Plant Disease 88: 1033-1039

Zhou, Y., Fitt, B. D. L., Welham, S. J., Gladders, P., Sansford, C. E., West, J. S. (1999): Effects of severity and timing of stem canker (Leptosphaeria maculans) symptoms on yield of winter oilseed rape (Brassica napus) in the UK. European Journal of Plant Pathology 105: 715-728

Zhou, L., Hu, Q., Johansson, A., Dixelius, C. (2006): Verticillium longisporum and V. dahliae: infection and disease in Brassica napus. Plant Pathology 55: 137-144. 


\section{Anhang}

Tab. A1a: Acker- und pflanzenbauliche Maßnahmen im Versuchsjahr 2001/02:

$\begin{array}{ll}\begin{array}{l}\text { Sorten: } \\ \text { Bodenbearbeitung: }\end{array} & \text { Prince, Talent } \\ \text { Saatbettbereitung: } & \text { 22.08.01: Pflug mit Packer } \\ \text { Aussaat } & \\ \text { früh: } & 09.08 .01+21.08 .01: \text { Kreiselegge + Walze } \\ \text { normal: } & 21.08 .01 \\ \text { Düngung } & \\ \text { Gesamt } N: & 212,4 \mathrm{~kg} \mathrm{~N} / \mathrm{ha} \\ \text { Schwefel: } & 41 \mathrm{~kg} \mathrm{~S} / \mathrm{ha} \\ \text { Pflanzenschutz } & \\ \text { Saatgutbeizung: } & \text { Chinook } \\ \text { Herbizide: } & 30.08 .01: 21 / \mathrm{ha} \text { Butisan Top } \\ \text { Wachstumsregler: } & 16.10 .01: 11 / \mathrm{ha} \text { Caramba; } 023.04 .02: 11 / \mathrm{ha} \text { Moddus } \\ \text { Insektizide: } & 16.10 .01: 0,11 / \mathrm{ha} \text { Karate } \\ \text { Scheiteln: } & 17 .-25.06 .02 \\ \text { Ernte: } & 28.07 .02\end{array}$

Tab. A1bAcker- und pflanzenbauliche Maßnahmen im Versuchsjahr 2002/03:
Sorten:
Prince, Talent
Bodenbearbeitung: 14.08.02: Pflug mit Packer
Saatbettbereitung: $\quad$ 15.08.02: Kombination BBG; 26.08.02: Kreiselegge + Walze Aussaat:
früh:
16.08 .02
normal:
26.08.02 (Verticillium Versuch: 23.08.02)
Düngung
Gesamt N:
$226,1 \mathrm{~kg} \mathrm{~N} / \mathrm{ha}$
Schwefel:
$41 \mathrm{~kg} \mathrm{~S} / \mathrm{ha}$
Pflanzenschutz
Saatgutbeizung:
Chinook
Herbizide:
29.08.02: 2,5 1/ha Brasan bzw. Butisan Top; 19.09.02: 1 1/ha Galant super
Wachstumsregler: $\quad$ 24.10.02: 1,5 1/ha Caramba; 22.04.03: 0,75 1/ha Moddus
Insektizide:
19.09.02: 0,1 1/ha Karate; 28.03 + 22.04.03: $150 \mathrm{~g} /$ ha Karate WG
Fungizide:
Verticillium-Versuch: 07.05.03: 0,5 kg/ha Cantus
Scheiteln:
10./11.06.03
Ernte:
16./17.07.03 
Tab. A1c: Acker- und pflanzenbauliche Maßnahmen im Versuchsjahr 2003/04:

Sorten: $\quad$ Prince, Maja, Wotan

Bodenbearbeitung: 31.07.03: Pflug mit Packer

Saatbettbereitung: 01.08.03: Väderstatt Carrier; 25.08.03: Kreiselegge + Walze Aussaat

früh: $\quad 14.08 .03$

normal: $\quad 25 . / 26.08 .03$

Düngung

Gesamt N: $\quad 268,4 \mathrm{~kg} \mathrm{~N} / \mathrm{ha}$

Schwefel: $\quad 41 \mathrm{~kg} \mathrm{~S} / \mathrm{ha}$

Pflanzenschutz

Saatgutbeizung: Chinook

Herbizide:

28. 08. bzw. 15.09.03: 2,5 1/ha Brasan bzw. 2 1/ha Butisan Top; 29.03.04: 0,6 1/ha Agil

Wachstumsregler: $\quad$ 20.10.03: 1,5 1/ha Caramba; 17.03.04: 1,2 1/ha Folicur; 01.04.04: $0,71 /$ ha Folicur

Insektizide: $\quad$ 20.10.03: $0,1 \mathrm{~kg} / \mathrm{ha}$ Karate $\mathrm{WG}$; 17.03.04: $75 \mathrm{ml} / \mathrm{ha}$ Karate Zeon; 29.03.04: $100 \mathrm{ml} / \mathrm{ha}$ Fastac SC

Scheiteln: $\quad$ 16.-18.06.04

Ernte: $\quad 01.08 .04$

Tab. A1d: Acker- und pflanzenbauliche Maßnahmen im Versuchsjahr 2004/05:

Sorten: $\quad$ Smart, Trabant, Talent, Elektra, Oase, Maja, Viking, Prince

Bodenbearbeitung: 06.08.04: Pflug mit Packer

Saatbettbereitung: 06.08.04: Väderstatt Carrier; 02.09.04: Kreiselegge + Walze

Aussaat:

03.09.2004 (Prince nachgesät am 15.09.2004)

Düngung

Gesamt N:

Schwefel:

$214,3 \mathrm{~kg} \mathrm{~N} / \mathrm{ha}$

$41 \mathrm{~kg} / \mathrm{ha}$

Pflanzenschutz

Saatgutbeizung:

Herbizide:

Chinook

03.09.04: 1,7 1/ha Brasan + 0,5 1/ha Butisan; 26.10.04: 1 1/ha Fusilade

Wachstumsregler: $\quad$ 26.10.04: 1,25 1/ha Caramba; 04.04.05: 0,7 1/ha Folicur

Insektizide: $\quad$ 26.10.04: 0,1 1/ha Fastac SC; 24.03.05: 0,1 1/ha Fastac SC;

04.04.05: $75 \mathrm{ml} / \mathrm{ha}$ Karate Zeon

Scheiteln: $\quad 22 . / 23.06 .05$

Ernte: $\quad 01.08 .05$ 


\begin{tabular}{|c|c|c|c|c|c|c|c|c|c|c|c|c|c|c|c|c|c|c|c|c|c|c|c|c|}
\hline 气̊ํํ & s. & & & $\begin{array}{l}m \\
\overbrace{n}^{2}\end{array}$ & $\begin{array}{l}\hat{\partial} \\
\dot{\partial}\end{array}$ & & & $\left|\begin{array}{l}\infty \\
\infty \\
2 \\
\dot{\lambda}\end{array}\right|$ & & $\begin{array}{l}+ \\
\stackrel{+}{2} \\
\dot{m}\end{array}$ & $\begin{array}{l}\vec{z} \\
\vec{g}\end{array}$ & & & 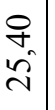 & & & & & & & & 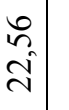 & & \\
\hline క్్ & 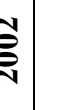 & & & $\frac{m}{m}$ & $\mid \begin{array}{l}\infty \\
0 \\
\infty \\
\infty \\
d\end{array}$ & & $\stackrel{n}{\infty}$ & $\left|\begin{array}{l}\infty \\
0 \\
2 \\
i \\
\lambda\end{array}\right|$ & & $\begin{array}{l}\infty \\
2 \\
\\
\tilde{m}\end{array}$ & & & & 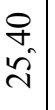 & $\begin{array}{l}3 \\
\infty \\
\\
\end{array}$ & & $\begin{array}{l}8 \\
\text { : }\end{array}$ & & & & & & & \\
\hline 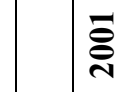 & 5 & & 忍 & & $\begin{array}{l}\delta \\
\partial \\
\partial \hat{i}\end{array}$ & & $\stackrel{2}{\infty}$ & $\left|\begin{array}{c}\delta \\
-m \\
m\end{array}\right|$ & & $\overrightarrow{\hat{m}}$ & & $\left|\begin{array}{c}n \\
\tilde{n} \\
n\end{array}\right|$ & & 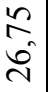 & $\begin{array}{l}\Omega \\
\Omega \\
\end{array}$ & & \begin{tabular}{l|l}
$\mathbb{a}$ & $i$ \\
$n$ &
\end{tabular} & 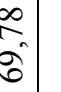 & & & & & & $\stackrel{\infty}{=}$ \\
\hline ఫ్ & $\begin{array}{l}\hat{\mathbf{v}} \\
\mathrm{i}\end{array}$ & & $\underset{f}{\stackrel{f}{a}}$ & & $\begin{array}{l}0 \\
\infty \\
\infty \\
i \\
i\end{array}$ & & & $\mid \begin{array}{l}0 \\
0 \\
0 \\
\dot{m}\end{array}$ & $\mid \begin{array}{l}\& \\
\dot{ \pm}\end{array}$ & $\mid \begin{array}{l}\infty \\
\infty \\
2 \\
\tilde{m}\end{array}$ & & & & 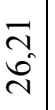 & & & 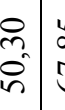 & 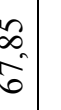 & & $\stackrel{0}{\circ}$ & & & & $\stackrel{\beth}{=}$ \\
\hline $\bar{\Xi}$ & & & $\begin{array}{l}\text { in } \\
i n\end{array}$ & & $\stackrel{0}{\stackrel{i}{i}}$ & & & $\mid \begin{array}{l}\vec{m} \\
\vec{m}\end{array}$ & $\mid \begin{array}{l}\& \\
\dot{ \pm}\end{array}$ & $\mid \begin{array}{l}n \\
\infty \\
\infty \\
\infty\end{array}$ & & & & 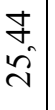 & & & 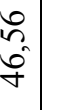 & & & $\vec{m}$ & & & & {$\left[\begin{array}{l}6 \\
0 \\
\hdashline\end{array}\right.$} \\
\hline 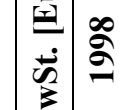 & $\begin{array}{c}0 \\
0 \\
0 \\
0 \\
6\end{array}$ & & & & 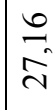 & & $\frac{n}{\infty}$ & 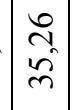 & & 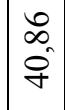 & & & 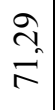 & 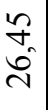 & & & 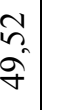 & & & & & & & $\begin{array}{l}\overbrace{0}^{\infty} \\
\stackrel{0}{0}\end{array}$ \\
\hline 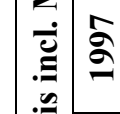 & $=\left[\begin{array}{l}\infty \\
0 \\
0\end{array}\right.$ & $\begin{array}{l}n \\
m \\
m \\
m\end{array}$ & & & & $\stackrel{2}{2}$ & $\stackrel{2}{\infty}$ & $\mid \begin{array}{c} \pm \\
\tilde{n} \\
\tilde{m} \\
\tilde{m}\end{array}$ & & $\begin{array}{l}q \\
q \\
q \\
q\end{array}$ & & & $\begin{array}{l}\hat{n} \\
\text { ه్ }\end{array}$ & $\begin{array}{l}\vec{s} \\
\stackrel{\sim}{\sim}\end{array}$ & & & $\frac{\infty}{B^{\prime}}$ & & & & & $\begin{array}{l}\dot{+} \\
\text { a } \\
\dot{m}\end{array}$ & & \\
\hline 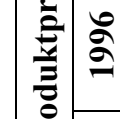 & & & & & & $\begin{array}{l}\tilde{N} \\
\infty \\
-\end{array}$ & & $\mid \begin{array}{c}\tilde{m} \\
\stackrel{2}{*} \\
\stackrel{m}{*}\end{array}$ & & $\begin{array}{l}\tilde{z} \\
\tilde{m} \\
\tilde{m}\end{array}$ & & & & 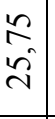 & & & & & & & & & & \\
\hline 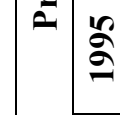 & है & & $\begin{array}{l}\tilde{\delta} \\
\dot{f}\end{array}$ & & & & & $\mid \begin{array}{l}0 \\
0 \\
0 \\
0\end{array}$ & & 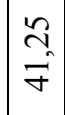 & & & & \begin{tabular}{l}
0 \\
\multirow{2}{*}{} \\
î.
\end{tabular} & & & & & 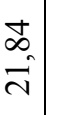 & & & & & \\
\hline I & 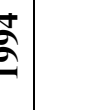 & & & & & & & $\mid \begin{array}{c}m \\
\mathfrak{n} \\
m\end{array}$ & & $\begin{array}{l}\hat{0} \\
\hat{n}\end{array}$ & & & & 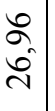 & & & & & $\begin{array}{l}\text { I. } \\
\text { i. }\end{array}$ & & & & & \\
\hline$\tilde{\sigma}$ & 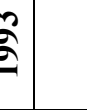 & & & & & & & $\mid \begin{array}{l}0 \\
0 \\
i \\
i \\
i\end{array}$ & & $\mid \begin{array}{l}n \\
\vdots \\
0 \\
0\end{array}$ & & & & 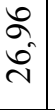 & & & & & $\begin{array}{l}\text { î } \\
\text { ते }\end{array}$ & & & 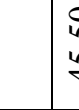 & & \\
\hline ริ & है & & & & & $\begin{array}{l}5 \\
6 \\
-0\end{array}$ & & $\begin{array}{l}2 \\
\tilde{n} \\
\tilde{m}\end{array}$ & & $\begin{array}{l}\overrightarrow{\hat{n}} \\
\tilde{n} \\
\tilde{n}\end{array}$ & & & & 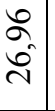 & & 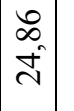 & & & & & & 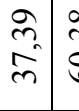 & & \\
\hline $\bar{\partial}$ & 5 & & & & & & & & & 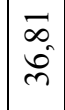 & & & & 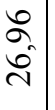 & & & & & & & \begin{tabular}{l} 
ঃ. \\
\multirow{\gamma}{*}{}
\end{tabular} & $\begin{array}{c}\hat{2} \\
\hat{\infty} \\
\tilde{m}\end{array}$ & & \\
\hline 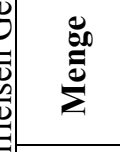 & $=$ & $=$ & $=$ & $\stackrel{\infty 00}{=}$ & $=$ & $=$ & $\stackrel{000}{=}$ & $=$ & $=$ & $=$ & $=$ & $=$ & $\exists$ & $\exists$ & $\exists$ & $=$ & $=7$ & $=:$ & $=$ & $=$ & $\exists$ & $=$ & 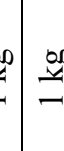 & $=$ \\
\hline 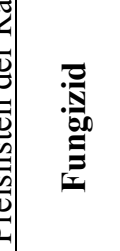 & 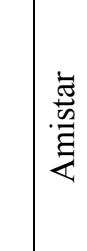 & $\begin{array}{l}\overline{\vec{a}} \\
\overline{0} \\
\stackrel{0}{0}\end{array}$ & U & 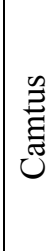 & 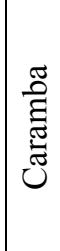 & 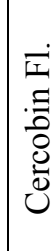 & $\begin{array}{l}3 \\
0 \\
0 \\
\bar{z} \\
0 \\
0\end{array}$ & $\mid \begin{array}{l}\dot{L} \\
\vec{w} \\
\tilde{D} \\
\dot{\vec{U}} \\
\tilde{D}\end{array}$ & 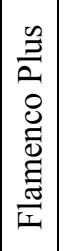 & 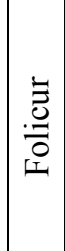 & 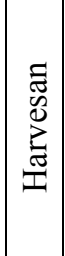 & $\left|\begin{array}{l}: \stackrel{9}{0} \\
\frac{\pi}{0} \\
0\end{array}\right|$ & 总 & 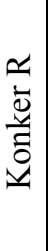 & $\begin{array}{c}8 \\
\vdots \\
7 \\
\end{array}$ & 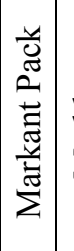 & 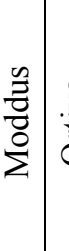 & 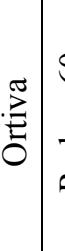 & 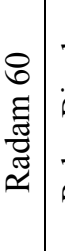 & 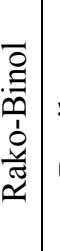 & 离 & 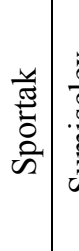 & $\frac{5}{2}$ & 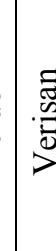 \\
\hline
\end{tabular}




\begin{tabular}{|c|c|c|c|c|c|c|c|}
\hline 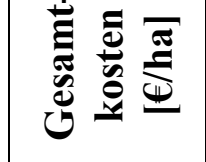 & హิ & $\stackrel{n}{n}$ & $\frac{\Re}{\infty}$ & $\begin{array}{l}\mathbb{J} \\
\infty \\
\infty\end{array}$ & مֵ & $\frac{\bar{a}}{a}$ & $\stackrel{n}{r}$ \\
\hline 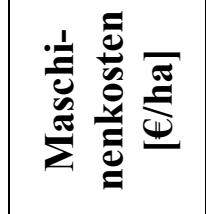 & $\begin{array}{l}\vec{a} \\
\text { i }\end{array}$ & $\frac{m}{m}$ & $\underset{\dot{\sigma}}{\stackrel{q}{\prime}}$ & $\hat{m}$ & $\stackrel{\infty}{\sim}$ & 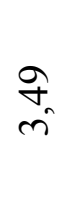 & \begin{tabular}{l}
\multirow{U}{*}{} \\
¿
\end{tabular} \\
\hline 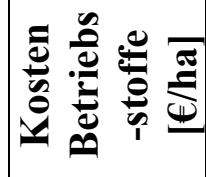 & $\begin{array}{l}\dot{\sigma} \\
\sigma\end{array}$ & $\stackrel{0}{=}$ & 点 & $\stackrel{+}{\text { m }}$ & $\stackrel{\infty}{0}$ & $\stackrel{\infty}{n}$ & $\widetilde{\beth}$ \\
\hline 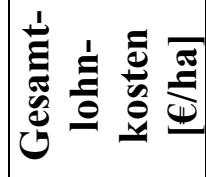 & $\begin{array}{l}0 \\
\text { n } \\
\text { no }\end{array}$ & $\bar{n}$ & $\begin{array}{l}\text { वे } \\
\text { ते }\end{array}$ & $\hat{a}$ & $\frac{m}{m}$ & $\frac{0}{m}$ & $\begin{array}{l}\overline{6} \\
\text { i }\end{array}$ \\
\hline 息 & $\begin{array}{l}0 \\
\text { n. } \\
0\end{array}$ & గn & ก้ & $\tilde{n}^{n}$ & $\tilde{n}_{0}^{n}$ & $\overline{\tilde{n}}$ & กี \\
\hline 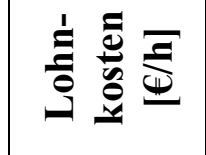 & $\begin{array}{l}\circ \\
\infty \\
-\end{array}$ & $\begin{array}{l}0 \\
\text { m. } \\
\infty\end{array}$ & $\begin{array}{l}n \\
0 \\
a\end{array}$ & 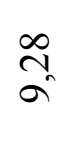 & $\hat{\sigma}$ & $\begin{array}{l}8 \\
0 \\
0\end{array}$ & $\stackrel{\stackrel{\sim}{\circ}}{\circ}$ \\
\hline 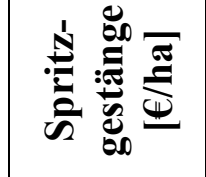 & ' & 1 & ' & 1 & I & ' & గn \\
\hline 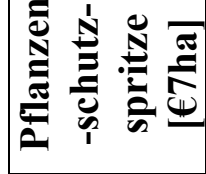 & $\underset{\sigma}{\stackrel{N}{\sigma}}$ & $\hat{\sigma}$ & $\hat{\sigma}$ & $\hat{\sigma}$ & $\hat{\sigma}$ & 8 & ?̊ \\
\hline 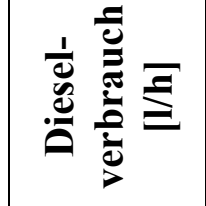 & $\begin{array}{l}\text { กે } \\
0\end{array}$ & $\begin{array}{l}\text { กે } \\
\stackrel{0}{ }\end{array}$ & $\begin{array}{l}\text { กૂ } \\
\stackrel{0}{ }\end{array}$ & $\begin{array}{l}\text { గે } \\
\stackrel{0}{ }\end{array}$ & $\begin{array}{l}\text { กิ } \\
\stackrel{0}{ }\end{array}$ & $\begin{array}{l}\text { సે } \\
\text { o }\end{array}$ & $\frac{P}{a}$ \\
\hline 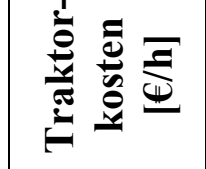 & $\begin{array}{l}\infty \\
\sigma\end{array}$ & 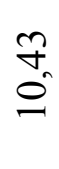 & $\begin{array}{l}\tilde{\sigma} \\
\hat{\sigma}\end{array}$ & $\begin{array}{l}n \\
0 \\
0\end{array}$ & $\begin{array}{l}\hat{b} \\
\infty\end{array}$ & Nֶ & $\begin{array}{l}+ \\
n \\
0\end{array}$ \\
\hline 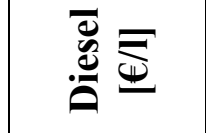 & $\bar{n}$ & $\begin{array}{l}0 \\
\text { n్ } \\
0\end{array}$ & $\stackrel{\sigma}{0}_{0}$ & $\vec{\sigma}_{0}$ & $\tilde{n}^{m}$ & $\begin{array}{l}n \\
0 \\
0\end{array}$ & ñ \\
\hline 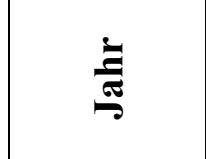 & $\begin{array}{l}\bar{\alpha} \\
\text { ळे }\end{array}$ & $\begin{array}{l}\text { ลี } \\
\text { ลे }\end{array}$ & $\stackrel{\partial}{\stackrel{\partial}{\partial}}$ & $\begin{array}{l}\hat{\sigma} \\
\hat{\sigma} \\
\sigma\end{array}$ & $\begin{array}{l}\delta \\
\delta \\
\sigma\end{array}$ & హ) & 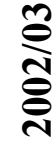 \\
\hline
\end{tabular}




\begin{tabular}{|c|c|c|c|c|c|c|c|c|c|c|c|c|c|c|}
\hline \multirow{13}{*}{ 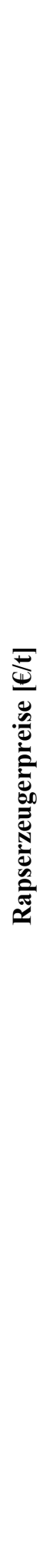 } & 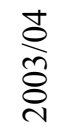 & 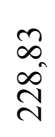 & $\begin{array}{l}\hat{\hat{a}} \\
\text { ते }\end{array}$ & 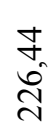 & $\begin{array}{l}2 \\
6 \\
\tilde{d}\end{array}$ & ' & & ' & ' & , & ' & , & ' & $\begin{array}{l}\mathbb{R} \\
\hat{\Xi} \\
\hat{N}\end{array}$ \\
\hline & $\begin{array}{l}\text { 今̊ } \\
\text { ठे }\end{array}$ & & 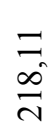 & $\begin{array}{l}\text { a } \\
\text { d̃ }\end{array}$ & तે & $\begin{array}{l}f \\
\text { f } \\
\text { ond }\end{array}$ & \begin{tabular}{l} 
య \\
\multirow{w}{*}{}
\end{tabular} & 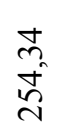 & 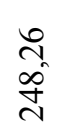 & $\begin{array}{l}\overrightarrow{\vec{\sigma}} \\
\overrightarrow{\mathrm{d}}\end{array}$ & 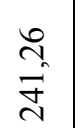 & $\begin{array}{l}\otimes \\
\stackrel{0}{-} \\
\stackrel{+}{+}\end{array}$ & 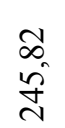 & $\frac{ \pm}{\Delta}$ \\
\hline & $\begin{array}{l}\widetilde{\delta} \\
\stackrel{0}{\circ}\end{array}$ & $\stackrel{\circ}{\stackrel{\text { సิ }}{2}}$ & $\begin{array}{l}\stackrel{8}{0} \\
\text { तิ }\end{array}$ & $\begin{array}{l}\text { D. } \\
\text { ते }\end{array}$ & $\begin{array}{l}\frac{8}{N} \\
\stackrel{1}{N}\end{array}$ & $\begin{array}{l}\text { त् } \\
\text { ה్ }\end{array}$ & $\begin{array}{l}0 \\
\text { s. }\end{array}$ & $\begin{array}{l}\text { ฉ } \\
\text { ते }\end{array}$ & $\begin{array}{l}\infty \\
\text { त्र }\end{array}$ & $\begin{array}{l}\stackrel{\circ}{\circ} \\
\stackrel{\infty}{\sim}\end{array}$ & , & , & , & 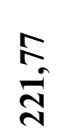 \\
\hline & $\begin{array}{l}\bar{\partial} \\
\text { ڤे } \\
\text { d }\end{array}$ & $\begin{array}{l}\infty \\
\stackrel{0}{i} \\
\end{array}$ & $\begin{array}{l}R \\
\stackrel{1}{E}\end{array}$ & $\begin{array}{c}0 \\
0 \\
\infty \\
\infty \\
\infty \\
-1\end{array}$ & $\begin{array}{l}\stackrel{R}{2} \\
\infty \\
\infty \\
\infty\end{array}$ & 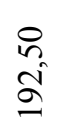 & $\begin{array}{l}q \\
\stackrel{9}{\alpha} \\
\stackrel{2}{a}\end{array}$ & $\begin{array}{l}\text { ָิ } \\
\text { న్ }\end{array}$ & $\begin{array}{l}0 \\
m \\
\infty \\
\infty \\
\infty\end{array}$ & $\begin{array}{l}\stackrel{8}{0} \\
\infty \\
\infty \\
\infty\end{array}$ & $\begin{array}{l}\stackrel{8}{ } \\
\stackrel{i}{\Omega}\end{array}$ & $\begin{array}{l}\stackrel{\circ}{\circ} \\
\stackrel{2}{\circ}\end{array}$ & 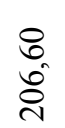 & $\begin{array}{l}\hat{0} \\
\infty \\
\infty\end{array}$ \\
\hline & @ & $\begin{array}{l}R \\
0 \\
\text { ô }\end{array}$ & $\begin{array}{l}8 \\
\dot{\sigma} \\
\dot{g}\end{array}$ & $\begin{array}{l}\stackrel{0}{1} \\
\text { In }\end{array}$ & $\begin{array}{l}8 \\
6 \\
6 \\
\end{array}$ & 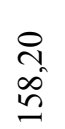 & $\begin{array}{l}0 \\
0 \\
0\end{array}$ & $\begin{array}{l}8 \\
\infty \\
\infty \\
n\end{array}$ & 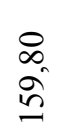 & $\begin{array}{l}8 \\
\dot{0} \\
\dot{0}\end{array}$ & $\begin{array}{l}8 \\
\stackrel{0}{0} \\
\vdots\end{array}$ & $\begin{array}{c}0 \\
0 \\
\infty \\
\infty\end{array}$ & $\stackrel{\circ}{\stackrel{0}{c}}$ & $\begin{array}{l}\stackrel{0}{0} \\
\stackrel{0}{0}\end{array}$ \\
\hline & $\begin{array}{l}\stackrel{\alpha}{\infty} \\
\stackrel{\alpha}{\sigma}\end{array}$ & , & $\begin{array}{l}8 \\
\stackrel{8}{0}\end{array}$ & $\begin{array}{l}R \\
\stackrel{m}{d}\end{array}$ & $\begin{array}{l}\stackrel{\circ}{.} \\
\text { ठें }\end{array}$ & $\begin{array}{l}\stackrel{R}{\vec{\sim}} \\
\vec{\sim}\end{array}$ & $\begin{array}{l}8 \\
\stackrel{0}{\sim} \\
\stackrel{\sim}{N}\end{array}$ & $\begin{array}{l}\stackrel{R}{0} \\
\stackrel{0}{\sim}\end{array}$ & $\begin{array}{c}\stackrel{1}{-} \\
\stackrel{-}{-}\end{array}$ & \begin{tabular}{l} 
तิ \\
\multirow{5}{0}{}
\end{tabular} & 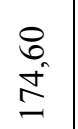 & $\begin{array}{l}8 \\
\stackrel{8}{\Xi}\end{array}$ & $\begin{array}{l}\circ \\
\stackrel{0}{0}\end{array}$ & $\begin{array}{l}\overrightarrow{0} \\
\stackrel{0}{\sigma}\end{array}$ \\
\hline & 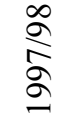 & ' & $\begin{array}{l}8 \\
8 \\
\hat{i}\end{array}$ & $\frac{O}{\mathrm{~d}}$ & $\begin{array}{l}8 \\
\stackrel{\sim}{\sim}\end{array}$ & $\begin{array}{l}\infty \\
\infty \\
\infty \\
\text { di }\end{array}$ & $\begin{array}{l}\text { in } \\
\infty \\
\text { in }\end{array}$ & $\begin{array}{l}\stackrel{0}{n} \\
\stackrel{+}{+}\end{array}$ & $\begin{array}{l}\text { D } \\
\infty \\
\infty \\
\end{array}$ & 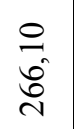 & $\begin{array}{l}\text { ते } \\
\stackrel{\sim}{\mathrm{d}}\end{array}$ & 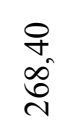 & $\begin{array}{l}8 \\
\text { i } \\
\end{array}$ & $\begin{array}{l}\mathbb{J} \\
\tilde{J}\end{array}$ \\
\hline & $\begin{array}{l}\hat{\sigma} \\
\stackrel{\circ}{\sigma} \\
\text { a }\end{array}$ & ' & 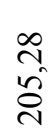 & $\stackrel{\beth}{\stackrel{\sim}{\circ}}$ & $\begin{array}{l}\overrightarrow{\vec{\alpha}} \\
\hat{\mathrm{v}}\end{array}$ & 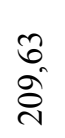 & $\begin{array}{l}n \\
\stackrel{n}{\circ} \\
\stackrel{\sim}{N}\end{array}$ & $\begin{array}{l}\tilde{N} \\
\underset{N}{N}\end{array}$ & $\begin{array}{l}\stackrel{\Xi}{\circ} \\
\stackrel{\sim}{N}\end{array}$ & $\begin{array}{l}0 \\
\stackrel{\tilde{a}}{\mathbf{d}}\end{array}$ & $\begin{array}{l}\text { z } \\
\text { aे } \\
\text { a }\end{array}$ & $\begin{array}{l}\vec{m} \\
\text { ते }\end{array}$ & $\begin{array}{l}\text { ڤे } \\
\text { ते }\end{array}$ & $\begin{array}{l}\text { त్ } \\
\stackrel{\sim}{\sim}\end{array}$ \\
\hline & 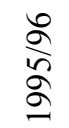 & & 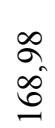 & 点 & $\frac{7}{5}$ & \begin{tabular}{l}
0 \\
\multirow{2}{*}{} \\
\multirow{2}{*}{}
\end{tabular} & 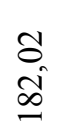 & $\begin{array}{l}8 \\
0 \\
\infty \\
0\end{array}$ & $\stackrel{m}{\stackrel{m}{\infty}}$ & $\begin{array}{l}\infty \\
\infty \\
\infty \\
\infty \\
0\end{array}$ & $\begin{array}{l}\vec{m} \\
\approx \\
\approx\end{array}$ & 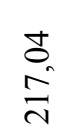 & $\begin{array}{l}8 \\
\frac{B}{0}\end{array}$ & $\begin{array}{l}\hat{\alpha} \\
\bar{\infty}\end{array}$ \\
\hline & $\begin{array}{l}\frac{n}{\alpha} \\
\frac{\alpha}{\alpha} \\
\sigma\end{array}$ & & 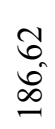 & $\begin{array}{l}\hat{\lambda} \\
\tilde{\Omega}\end{array}$ & 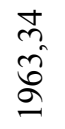 & $\frac{9}{\vec{D}}$ & $\begin{array}{l}\stackrel{m}{2} \\
\stackrel{\sim}{0}\end{array}$ & $\stackrel{\mathcal{F}}{\vec{\sim}}$ & $\frac{7}{8}$ & $\begin{array}{l}\text { o } \\
\stackrel{d}{\vec{N}}\end{array}$ & $\begin{array}{l}\tilde{S} \\
\infty \\
\infty \\
\stackrel{0}{0}\end{array}$ & $\begin{array}{l}\hat{0} \\
\dot{+} \\
-0\end{array}$ & $\begin{array}{l}\hat{\hat{d}} \\
\stackrel{0}{0}\end{array}$ & 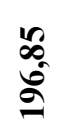 \\
\hline & 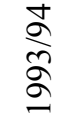 & $\begin{array}{l}\bar{\alpha} \\
\hat{\sigma}\end{array}$ & 尺̊ & $\begin{array}{l}\hat{\hat{\theta}} \\
\hat{\varepsilon}\end{array}$ & $\begin{array}{l}\bar{m} \\
\stackrel{i}{I}\end{array}$ & $\begin{array}{l}\Delta \\
0 \\
\infty \\
\stackrel{0}{0}\end{array}$ & $\begin{array}{l}\text { g } \\
\text { o }\end{array}$ & $\begin{array}{l}\infty \\
\stackrel{\sim}{N} \\
\stackrel{\sim}{N}\end{array}$ & $\begin{array}{l}\text { n. } \\
\text { ते }\end{array}$ & $\stackrel{\stackrel{ }{\vec{d}}}{\stackrel{\vec{d}}{2}}$ & . & , & , & 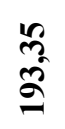 \\
\hline & 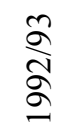 & & $\begin{array}{l}\overline{6} \\
\therefore \\
\dot{q}\end{array}$ & $\begin{array}{l}\hat{0} \\
\dot{m}\end{array}$ & $\begin{array}{l}\cong \\
\vec{\Xi}\end{array}$ & $\begin{array}{l}\stackrel{\infty}{\underset{J}{ \pm}} \\
\end{array}$ & 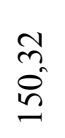 & $\begin{array}{l}\stackrel{\infty}{d} \\
\stackrel{n}{n}\end{array}$ & $\frac{2}{\stackrel{5}{0}}$ & $\begin{array}{l}\hat{E} \\
\hat{g} \\
\underline{I}\end{array}$ & $\begin{array}{l}\tilde{s} \\
\stackrel{-}{\Xi}\end{array}$ & $\begin{array}{c}\bar{m} \\
\stackrel{I}{I} \\
\underline{I}\end{array}$ & ' & $\begin{array}{l}7 \\
6 \\
6\end{array}$ \\
\hline & $\begin{array}{l}\sigma \\
\sigma \\
\sigma \\
\sigma\end{array}$ & & & & & $\begin{array}{l}\vec{d} \\
\stackrel{0}{m} \\
\text { m. }\end{array}$ & $\begin{array}{l}\infty \\
\stackrel{0}{0} \\
\stackrel{d}{0}\end{array}$ & \begin{tabular}{l}
0 \\
N \\
\multirow{j}{m}{}
\end{tabular} & $\frac{\partial}{\stackrel{0}{0}}$ & $\begin{array}{l}\infty \\
\stackrel{2}{2} \\
\dot{\sigma}\end{array}$ & $\begin{array}{l}n \\
\hat{n} \\
\tilde{n}\end{array}$ & \begin{tabular}{l}
$\infty$ \\
$n$ \\
\multirow{m}{\infty}{} \\
$m$
\end{tabular} & $\underset{m}{\infty}$ & $\begin{array}{l}\text { fे } \\
\text { 今े }\end{array}$ \\
\hline & & $\bar{\Xi}$ & 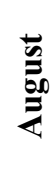 & 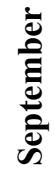 & 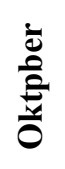 & 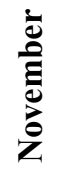 & 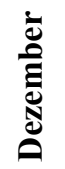 & 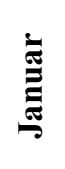 & 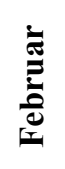 & 漓 & $\overline{\bar{z}}$ & $\dot{\bar{\pi}}$ & $\ddot{\Xi}$ & 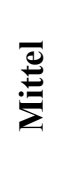 \\
\hline
\end{tabular}




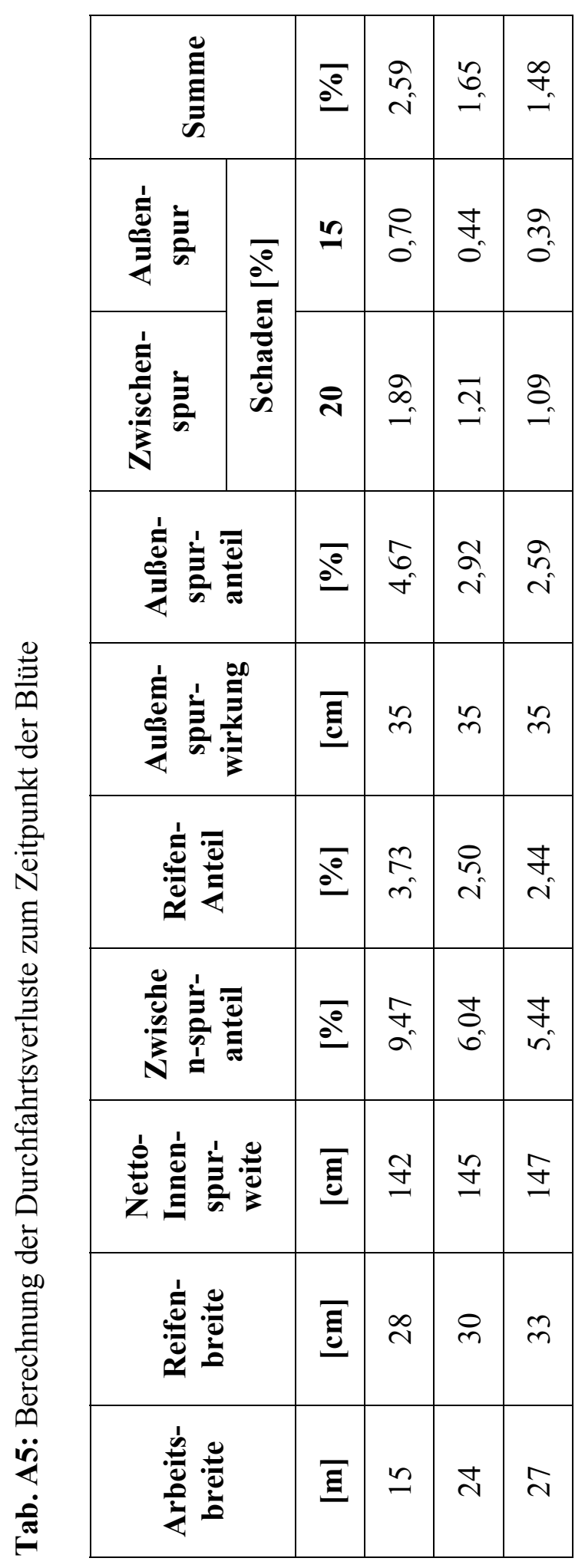


Tab. A6: Wirkung von S. sclerotiorum auf den Ertrag in Abhängigkeit von Jahr, Sortentyp und Inokulationstermin Die Signifikanz der Regression wurde mit dem Durbin-Watson-Test überprüft.

\begin{tabular}{|c|c|c|c|c|}
\hline Jahr & Sortentyp & $\begin{array}{c}\text { Inokulations- } \\
\text { termin } \\
{[\mathbf{B B C H}]}\end{array}$ & $\mathbf{b}$ & $\mathbf{r}^{\mathbf{2}}$ \\
\hline $2001 / 02$ & Hybride & $61-65$ & $-0,14$ & $0,00^{\mathrm{ns}}$ \\
\hline $2001 / 02$ & Hybride & 71 & 0,87 & $0,03^{\mathrm{ns}}$ \\
\hline $2002 / 03$ & Hybride & $61-65$ & $-0,69$ & $0,05^{\mathrm{ns}}$ \\
\hline $2002 / 03$ & Hybride & 71 & $-0,66$ & $0,14^{* *}$ \\
\hline $2003 / 04$ & Hybride & $61-65$ & $-0,33$ & $0,11^{*}$ \\
\hline $2003 / 04$ & Hybride & 71 & $-0,28$ & $0,50^{* * *}$ \\
\hline $2001 / 02$ & Linie & $61-65$ & $-0,66$ & $0,11^{*}$ \\
\hline $2001 / 02$ & Linie & 71 & $-0,98$ & $0,29^{* * *}$ \\
\hline $2002 / 03$ & Linie & $61-65$ & $-0,27$ & $0,09^{*}$ \\
\hline $2002 / 03$ & Linie & 71 & $-0,19$ & $0,07^{\mathrm{ns}}$ \\
\hline $2003 / 04$ & Linie & $61-65$ & $-0,79$ & $0,39^{* * *}$ \\
\hline $2003 / 04$ & Linie & 71 & $-0,49$ & $0,46^{* * *}$ \\
\hline
\end{tabular}

$\mathrm{b}=$ Regressionskoeffizient; $\mathrm{r}^{2}=$ Bestimmtheitsma $\beta$

Tab. A7: Wirkung von S. sclerotiorum auf das TKG in Abhängigkeit von Jahr, Sortentyp und Inokulationstermin Die Signifikanz der Regression wurde mit dem Durbin-Watson-Test überprüft.

\begin{tabular}{|c|c|c|c|c|}
\hline Jahr & Sortentyp & $\begin{array}{c}\text { Inokulations- } \\
\text { termin } \\
{[\mathbf{B B C H}]}\end{array}$ & $\mathbf{b}$ & $\mathbf{r}^{\mathbf{2}}$ \\
\hline $2001 / 02$ & Hybride & $61-65$ & 0,14 & $0,03^{\mathrm{ns}}$ \\
\hline $2001 / 02$ & Hybride & 71 & $-0,62$ & $0,19^{* *}$ \\
\hline $2002 / 03$ & Hybride & $61-65$ & 0,27 & $0,11^{*}$ \\
\hline $2002 / 03$ & Hybride & 71 & $-0,13$ & $0,06^{\mathrm{ns}}$ \\
\hline $2003 / 04$ & Hybride & $61-65$ & $-0,54$ & $0,37^{* *}$ \\
\hline $2003 / 04$ & Hybride & 71 & $-0,10$ & $0,01^{\mathrm{ns}}$ \\
\hline $2001 / 02$ & Linie & $61-65$ & 0,17 & $0,06^{\mathrm{ns}}$ \\
\hline $2001 / 02$ & Linie & 71 & $-0,24$ & $0,08^{\mathrm{ns}}$ \\
\hline $2002 / 03$ & Linie & $61-65$ & 0,02 & $0,01^{\mathrm{ns}}$ \\
\hline $2002 / 03$ & Linie & 71 & $-0,09$ & $0,09^{*}$ \\
\hline $2003 / 04$ & Linie & $61-65$ & 0,13 & $0,02^{\mathrm{ns}}$ \\
\hline $2003 / 04$ & Linie & 71 & $-0,41$ & $0,51^{* *}$ \\
\hline
\end{tabular}

$\mathrm{b}=$ Regressionskoeffizient; $\mathrm{r}^{2}=$ Bestimmtheitsmaß 
Tab. A8: Wirkung von S. sclerotiorum auf den Ölgehalt in Abhängigkeit von Jahr, Sortentyp und Inokulationstermin Die Signifikanz der Regression wurde mit dem Durbin-Watson-Test überprüft.

\begin{tabular}{|c|c|c|c|c|}
\hline Jahr & Sortentyp & $\begin{array}{c}\text { Inokulations- } \\
\text { termin } \\
{[\mathbf{B B C H}]}\end{array}$ & $\mathbf{b}$ & $\mathbf{r}^{\mathbf{2}}$ \\
\hline $2001 / 02$ & Hybride & $61-65$ & $-0,20$ & $0,11^{*}$ \\
\hline $2001 / 02$ & Hybride & 71 & 0,15 & $0,04^{\mathrm{ns}}$ \\
\hline $2002 / 03$ & Hybride & $61-65$ & 0,12 & $0,05^{\mathrm{ns}}$ \\
\hline $2002 / 03$ & Hybride & 71 & $-0,05$ & $0,05^{\mathrm{ns}}$ \\
\hline $2003 / 04$ & Hybride & $61-65$ & $-0,24$ & $0,34^{* * *}$ \\
\hline $2003 / 04$ & Hybride & 71 & $-0,01$ & $0,01^{\mathrm{ns}}$ \\
\hline $2001 / 02$ & Linie & $61-65$ & $-0,02$ & $0,00^{\mathrm{ns}}$ \\
\hline $2001 / 02$ & Linie & 71 & $-0,02$ & $0,00^{\mathrm{ns}}$ \\
\hline $2002 / 03$ & Linie & $61-65$ & $-0,01$ & $0,00^{\mathrm{ns}}$ \\
\hline $2002 / 03$ & Linie & 71 & $-0,09$ & $0,24^{* * *}$ \\
\hline $2003 / 04$ & Linie & $61-65$ & $-0,04$ & $0,02^{\mathrm{ns}}$ \\
\hline $2003 / 04$ & Linie & 71 & $-0,06$ & $0,04^{\mathrm{ns}}$ \\
\hline
\end{tabular}

$\mathrm{b}=$ Regressionskoeffizient $\mathrm{r}^{2}=$ Bestimmtheitsma $\beta$

Tab. A9: Ertrag, TKG und Ölgehalt der Kontrollparzellen der verschiedenen Aussaatvarianten für Hybrid- und Liniensorten in den drei Versuchsjahren. Unterschiedliche Buchstaben kennzeichnen signifikante Unterschiede (Tukey-Test, $\mathrm{p} \leq$ $0,05)$.

\begin{tabular}{|c|c|c|c|c|c|c|c|c|c|}
\hline \multirow{2}{*}{ Variante } & \multicolumn{3}{|c|}{ Ertrag } & \multicolumn{3}{|c|}{ TKG } & \multicolumn{3}{|c|}{ Ölgehalt } \\
\hline & $01 / 02$ & $02 / 03$ & $03 / 04$ & $01 / 02$ & $02 / 03$ & $03 / 04$ & $01 / 02$ & $02 / 03$ & $03 / 04$ \\
\hline \multirow{2}{*}{ H fh } & 43,13 & 44,73 & 47,96 & 4,26 & 4,19 & 3,14 & 42,82 & 41,68 & 41,21 \\
\hline & $a b$ & $\mathrm{a}$ & $\mathrm{a}$ & b & $\mathrm{b}$ & $\mathrm{a}$ & $\mathrm{a}$ & $\mathrm{a}$ & $\mathrm{a}$ \\
\hline \multirow{2}{*}{ H fg } & 41,98 & 44,35 & 43,79 & 4,25 & 4,17 & 3,49 & 43,11 & 41,61 & 42,74 \\
\hline & $a b$ & $\mathrm{a}$ & $\mathrm{a}$ & $a b$ & $\mathrm{~b}$ & $\mathrm{a}$ & $a b$ & $\mathrm{a}$ & $\mathrm{a}$ \\
\hline \multirow{2}{*}{ H nh } & 47,12 & 48,02 & 42,75 & 4,24 & 4,09 & 3,49 & 43,76 & 40,58 & 41,12 \\
\hline & $\mathrm{b}$ & a & $\mathrm{a}$ & $a b$ & b & a & $a b$ & $\mathrm{a}$ & a \\
\hline \multirow{2}{*}{ H ng } & 39,40 & 45,36 & 39,85 & 4,20 & 4,14 & 3,41 & 43,47 & 40,55 & 42,49 \\
\hline & $a b$ & $\mathrm{a}$ & $\mathrm{a}$ & $a b$ & $\mathrm{~b}$ & $\mathrm{a}$ & $a b$ & $\mathrm{a}$ & $\mathrm{a}$ \\
\hline \multirow{2}{*}{ L f fh } & 36,33 & 44,76 & 44,35 & 4,02 & 3,84 & 3,52 & 44,38 & 40,90 & 42,02 \\
\hline & $\mathrm{a}$ & $\mathrm{a}$ & $\mathrm{a}$ & $a b$ & $\mathrm{a}$ & $\mathrm{a}$ & $a b$ & $\mathrm{a}$ & $\mathrm{a}$ \\
\hline \multirow{2}{*}{ L fg } & 34,98 & 46,65 & 41,89 & 4,00 & 3,86 & 3,33 & 44,10 & 42,12 & 43,63 \\
\hline & $\mathrm{a}$ & $\mathrm{a}$ & $\mathrm{a}$ & $\mathrm{a}$ & $\mathrm{a}$ & $\mathrm{a}$ & $a b$ & $\mathrm{a}$ & $\mathrm{a}$ \\
\hline \multirow{2}{*}{ L nh } & 34,74 & 43,31 & 42,46 & 4,07 & 3,82 & 3,27 & 44,89 & 41,33 & 43,68 \\
\hline & a & $\mathrm{a}$ & $\mathrm{a}$ & $a b$ & $\mathrm{a}$ & $\mathrm{a}$ & b & $\mathrm{a}$ & $\mathrm{a}$ \\
\hline \multirow{2}{*}{ L ng } & 35,94 & 43,03 & 39,44 & 4,09 & 3,79 & 3,36 & 44,53 & 40,89 & 41,89 \\
\hline & $\mathrm{a}$ & $\mathrm{a}$ & $\mathrm{a}$ & $a b$ & $\mathrm{a}$ & $\mathrm{a}$ & $\mathrm{ab}$ & $\mathrm{a}$ & $\mathrm{a}$ \\
\hline
\end{tabular}

Abkürzungen: $\mathrm{H}=$ Hybride, $\mathrm{L}=$ Liniensorte; $\mathrm{f}=$ frühe Aussaat, $\mathrm{n}=$ normale Aussaat; $\mathrm{h}=$ hohe Aussaatdichte, $\mathrm{g}=$ geringe Aussaatdichte 
Tab. A10: Einfluss von S. sclerotiorum auf den Relativertrag in Abhängigkeit von Jahr, Sortentyp, Aussaattermin und Bestandesdichte. Die Signifikanz der Regression wurde mit dem Durbin-Watson-Test überprüft.

\begin{tabular}{|c|c|c|c|c|c|}
\hline Jahr & Sortentyp & $\begin{array}{c}\text { Aussaat- } \\
\text { termin }\end{array}$ & $\begin{array}{c}\text { Bestandes- } \\
\text { dichte } \\
{\left[\mathrm{Pfl} . / \mathbf{m}^{2}\right]}\end{array}$ & b & $\mathbf{r}^{2}$ \\
\hline $2001 / 02$ & Hybride & früh & 50 & $-0,93$ & $0,18^{* *}$ \\
\hline $2001 / 02$ & Hybride & früh & 35 & 0,13 & $0,00^{\mathrm{ns}}$ \\
\hline $2001 / 02$ & Hybride & normal & 50 & $-0,41$ & $0,01^{\mathrm{ns}}$ \\
\hline $2001 / 02$ & Hybride & normal & 35 & 0,004 & $0,00^{\mathrm{ns}}$ \\
\hline $2002 / 03$ & Hybride & früh & 50 & $-0,67$ & $0,27^{* * *}$ \\
\hline $2002 / 03$ & Hybride & früh & 35 & $-0,47$ & $0,19^{* *}$ \\
\hline $2002 / 03$ & Hybride & normal & 50 & 0,31 & $0,02^{\text {ns }}$ \\
\hline $2002 / 03$ & Hybride & normal & 35 & $-0,30$ & $0,03^{\mathrm{ns}}$ \\
\hline $2003 / 04$ & Hybride & früh & 50 & $-0,67$ & $0,24^{* *}$ \\
\hline $2003 / 04$ & Hybride & früh & 35 & 0,38 & $0,03^{\text {ns }}$ \\
\hline $2003 / 04$ & Hybride & normal & 50 & $-0,51$ & $0,40^{* * *}$ \\
\hline $2003 / 04$ & Hybride & normal & 35 & $-0,85$ & $0,18^{* *}$ \\
\hline $2001 / 02$ & Linie & früh & 60 & $-0,76$ & $0,15^{*}$ \\
\hline $2001 / 02$ & Linie & früh & 45 & $-0,15$ & $0,01^{\mathrm{ns}}$ \\
\hline $2001 / 02$ & Linie & normal & 60 & $-0,93$ & $0,17^{*}$ \\
\hline $2001 / 02$ & Linie & normal & 45 & $-0,86$ & $0,35^{* * *}$ \\
\hline $2002 / 03$ & Linie & früh & 60 & $-0,50$ & $0,38^{* * *}$ \\
\hline $2002 / 03$ & Linie & früh & 45 & $-0,44$ & $0,73^{* * *}$ \\
\hline $2002 / 03$ & Linie & normal & 60 & $-0,26$ & $0,24^{* *}$ \\
\hline $2002 / 03$ & Linie & normal & 45 & $-0,49$ & $0,63^{* * *}$ \\
\hline $2003 / 04$ & Linie & früh & 60 & $-0,90$ & $0,40^{* * *}$ \\
\hline $2003 / 04$ & Linie & früh & 45 & $-0,78$ & $0,41^{* * *}$ \\
\hline $2003 / 04$ & Linie & normal & 60 & $-0,72$ & $0,58^{* * *}$ \\
\hline $2003 / 04$ & Linie & normal & 45 & $-0,71$ & $0,21^{* *}$ \\
\hline
\end{tabular}


Tab. A11: Einfluss von S. sclerotiorum auf das relative TKG in Abhängigkeit von Jahr, Sortentyp, Aussaattermin und Bestandesdichte. Die Signifikanz der Regression wurde mit dem Durbin-Watson-Test überprüft.

\begin{tabular}{|c|c|c|c|c|c|}
\hline Jahr & Sortentyp & $\begin{array}{c}\text { Aussaat- } \\
\text { termin }\end{array}$ & $\begin{array}{c}\text { Bestandes- } \\
\text { dichte } \\
{\left[\mathrm{Pfl} . / \mathrm{m}^{2}\right]}\end{array}$ & b & $\mathbf{r}^{2}$ \\
\hline $2001 / 02$ & Hybride & früh & 50 & 0,18 & $0,04^{\mathrm{ns}}$ \\
\hline $2001 / 02$ & Hybride & früh & 35 & 0,23 & $0,00^{\text {ns }}$ \\
\hline $2001 / 02$ & Hybride & normal & 50 & $-0,04$ & $0,00^{\mathrm{ns}}$ \\
\hline $2001 / 02$ & Hybride & normal & 35 & 0,06 & $0,01^{\mathrm{ns}}$ \\
\hline $2002 / 03$ & Hybride & früh & 50 & $-0,001$ & $0,00^{\text {ns }}$ \\
\hline $2002 / 03$ & Hybride & früh & 35 & $-0,03$ & $0,02^{\mathrm{ns}}$ \\
\hline $2002 / 03$ & Hybride & normal & 50 & $-0,03$ & $0,00^{\text {ns }}$ \\
\hline $2002 / 03$ & Hybride & normal & 35 & 0,13 & $0,08^{\mathrm{ns}}$ \\
\hline $2003 / 04$ & Hybride & früh & 50 & $-0,07$ & $0,01^{\mathrm{ns}}$ \\
\hline $2003 / 04$ & Hybride & früh & 35 & $-0,49$ & $0,34^{* * *}$ \\
\hline $2003 / 04$ & Hybride & normal & 50 & $-0,64$ & $0,28^{* * *}$ \\
\hline $2003 / 04$ & Hybride & normal & 35 & 0,02 & $0,00^{\text {ns }}$ \\
\hline $2001 / 02$ & Linie & früh & 60 & 0,03 & $0,01^{\mathrm{ns}}$ \\
\hline $2001 / 02$ & Linie & früh & 45 & $-0,09$ & $0,04^{\text {ns }}$ \\
\hline $2001 / 02$ & Linie & normal & 60 & 0,12 & $0,12^{*}$ \\
\hline $2001 / 02$ & Linie & normal & 45 & $-0,21$ & $0,16^{*}$ \\
\hline $2002 / 03$ & Linie & früh & 60 & 0,05 & $0,02^{\text {ns }}$ \\
\hline $2002 / 03$ & Linie & früh & 45 & $-0,01$ & $0,00^{\text {ns }}$ \\
\hline $2002 / 03$ & Linie & normal & 60 & $-0,04$ & $0,02^{\text {ns }}$ \\
\hline $2002 / 03$ & Linie & normal & 45 & $-0,10$ & $0,27^{* * *}$ \\
\hline $2003 / 04$ & Linie & früh & 60 & $-0,25$ & $0,09^{\text {ns }}$ \\
\hline $2003 / 04$ & Linie & früh & 45 & $-0,02$ & $0,02^{\text {ns }}$ \\
\hline $2003 / 04$ & Linie & normal & 60 & 0,02 & $0,01^{\mathrm{ns}}$ \\
\hline $2003 / 04$ & Linie & normal & 45 & $-0,31$ & $0,09^{\mathrm{ns}}$ \\
\hline
\end{tabular}


Tab. A12: Einfluss von S. sclerotiorum auf den relativen Ölgehalt in Abhängigkeit von Jahr, Sortentyp, Aussaattermin und Bestandesdichte. Die Signifikanz der Regression wurde mit dem Durbin-Watson-Test überprüft.

\begin{tabular}{|c|c|c|c|c|c|}
\hline Jahr & Sortentyp & $\begin{array}{c}\text { Aussaat- } \\
\text { termin }\end{array}$ & $\begin{array}{c}\text { Bestandes- } \\
\text { dichte } \\
{\left[\mathrm{Pfl} . / \mathbf{m}^{2}\right]} \\
\end{array}$ & b & $\mathbf{r}^{2}$ \\
\hline $2001 / 02$ & Hybride & früh & 50 & 0,39 & $0,29^{* * *}$ \\
\hline $2001 / 02$ & Hybride & früh & 35 & $-0,59$ & $0,01^{\mathrm{ns}}$ \\
\hline $2001 / 02$ & Hybride & normal & 50 & 0,09 & $0,04^{\mathrm{ns}}$ \\
\hline $2001 / 02$ & Hybride & normal & 35 & 0,004 & $0,00^{\text {ns }}$ \\
\hline $2002 / 03$ & Hybride & früh & 50 & 0,05 & $0,03^{\text {ns }}$ \\
\hline $2002 / 03$ & Hybride & früh & 35 & $-0,03$ & $0,02^{\text {ns }}$ \\
\hline $2002 / 03$ & Hybride & normal & 50 & $-0,09$ & $0,01^{\mathrm{ns}}$ \\
\hline $2002 / 03$ & Hybride & normal & 35 & 0,14 & $0,06^{\mathrm{ns}}$ \\
\hline $2003 / 04$ & Hybride & früh & 50 & 0,03 & $0,00^{\text {ns }}$ \\
\hline $2003 / 04$ & Hybride & früh & 35 & $-0,21$ & $0,11^{\mathrm{ns}}$ \\
\hline $2003 / 04$ & Hybride & normal & 50 & $-0,09$ & $0,03^{\text {ns }}$ \\
\hline $2003 / 04$ & Hybride & normal & 35 & 0,21 & $0,21^{* *}$ \\
\hline $2001 / 02$ & Linie & früh & 60 & 0,06 & $0,03^{\mathrm{ns}}$ \\
\hline $2001 / 02$ & Linie & früh & 45 & 0,07 & $0,11^{\mathrm{ns}}$ \\
\hline $2001 / 02$ & Linie & normal & 60 & 0,03 & $0,03^{\text {ns }}$ \\
\hline $2001 / 02$ & Linie & normal & 45 & 0,14 & $0,23^{* *}$ \\
\hline $2002 / 03$ & Linie & früh & 60 & 0,01 & $0,00^{\text {ns }}$ \\
\hline $2002 / 03$ & Linie & früh & 45 & $-0,11$ & $0,12^{\text {ns }}$ \\
\hline $2002 / 03$ & Linie & normal & 60 & $-0,02$ & $0,00^{\mathrm{ns}}$ \\
\hline $2002 / 03$ & Linie & normal & 45 & $-0,05$ & $0,13^{*}$ \\
\hline $2003 / 04$ & Linie & früh & 60 & 0,01 & $0,00^{\text {ns }}$ \\
\hline $2003 / 04$ & Linie & früh & 45 & $-0,04$ & $0,05^{\text {ns }}$ \\
\hline $2003 / 04$ & Linie & normal & 60 & $-0,01$ & $0,00^{\text {ns }}$ \\
\hline $2003 / 04$ & Linie & normal & 45 & $-0,20$ & $0,16^{*}$ \\
\hline
\end{tabular}


Tab. A13: Einfluss einer Pflanzenreduktion zu BBCH 71 auf Ertrag und TKG in Abhängigkeit des Sortentyps und des Versuchsjahres. Die Signifikanz der Regression wurde mit dem Durbin-Watson-Test überprüft.

\begin{tabular}{|c|c|c|c|c|c|}
\hline \multirow{2}{*}{ Versuchsjahr } & \multirow{2}{*}{ Sortentyp* } & \multicolumn{2}{|c|}{ Ertrag } & \multicolumn{2}{|c|}{ TKG } \\
\cline { 2 - 6 } & & $\mathbf{b}$ & $\mathbf{r}^{\mathbf{2}}$ & $\mathbf{b}$ & $\mathbf{r}^{\mathbf{2}}$ \\
\hline \multirow{2}{*}{$2001 / 02$} & $\mathrm{H}$ & $-0,80$ & $0,66^{* * *}$ & 0,10 & $0,13^{* *}$ \\
\cline { 2 - 6 } & $\mathrm{L}$ & $-0,70$ & $0,73^{* * *}$ & 0,16 & $0,44^{* * *}$ \\
\hline \multirow{2}{*}{$2002 / 03$} & $\mathrm{H}$ & $-0,57$ & $0,33^{* * *}$ & 0,18 & $0,39^{* * *}$ \\
\cline { 2 - 6 } & $\mathrm{L}$ & $-0,67$ & $0,42^{* * *}$ & 0,14 & $0,41^{* * *}$ \\
\hline \multirow{2}{*}{$2003 / 04$} & $\mathrm{H}$ & $-0,60$ & $0,73^{* * *}$ & 0,11 & $0,20^{* *}$ \\
\cline { 2 - 6 } & $\mathrm{L}$ & $-0,50$ & $0,59^{* * *}$ & 0,26 & $0,12^{* *}$ \\
\hline
\end{tabular}

* $\mathrm{H}=$ Hybridsorte, $\mathrm{L}=$ Liniensorte

Tab. A14: Wirtschaftlichkeit von Fungizidapplikationen zur Blüte in Winterraps in Abhängigkeit vom Versuchsjahr. Basierend auf Daten aus den offiziellen Feldversuchen der Pflanzenschutzdienste der Länder aus den Jahren 1991-2003.

\begin{tabular}{|c|c|c|c|c|}
\hline Jahr & $\begin{array}{c}\text { Anzahl } \\
\text { Versuche }\end{array}$ & $\begin{array}{c}\text { Befallshäufigkeit } \\
{[\mathbf{\%}]}\end{array}$ & $\begin{array}{c}\text { Mehrertrag } \\
{[\mathbf{d t} / \mathbf{h a}]}\end{array}$ & $\begin{array}{c}\text { Wirtschaftliche } \\
\text { Behandlungen [\%] }\end{array}$ \\
\hline 1991 & 7 & 24,33 & 2,87 & 57,14 \\
\hline 1992 & 37 & 11,71 & 1,27 & 10,81 \\
\hline 1993 & 46 & 7,48 & 2,57 & 30,43 \\
\hline 1994 & 34 & 6,33 & 0,52 & 0,00 \\
\hline 1995 & 47 & 75,06 & 4,26 & 63,83 \\
\hline 1996 & 51 & 65,22 & 2,13 & 31,37 \\
\hline 1997 & 42 & 35,07 & 2,54 & 47,62 \\
\hline 1998 & 57 & 19,17 & 2,66 & 33,33 \\
\hline 1999 & 53 & 7,23 & 2,41 & 24,53 \\
\hline 2000 & 62 & 12,06 & 2,61 & 33,87 \\
\hline 2001 & 48 & 25,50 & 2,96 & 43,75 \\
\hline 2002 & 29 & 16,19 & 2,91 & 44,83 \\
\hline 2003 & 41 & 13,72 & 1,23 & 17,07 \\
\hline Mittel & $\mathbf{5 5 4}$ & $\mathbf{2 4 , 5 4}$ & $\mathbf{2 , 3 8}$ & $\mathbf{3 3 , 7 4}$ \\
\hline
\end{tabular}



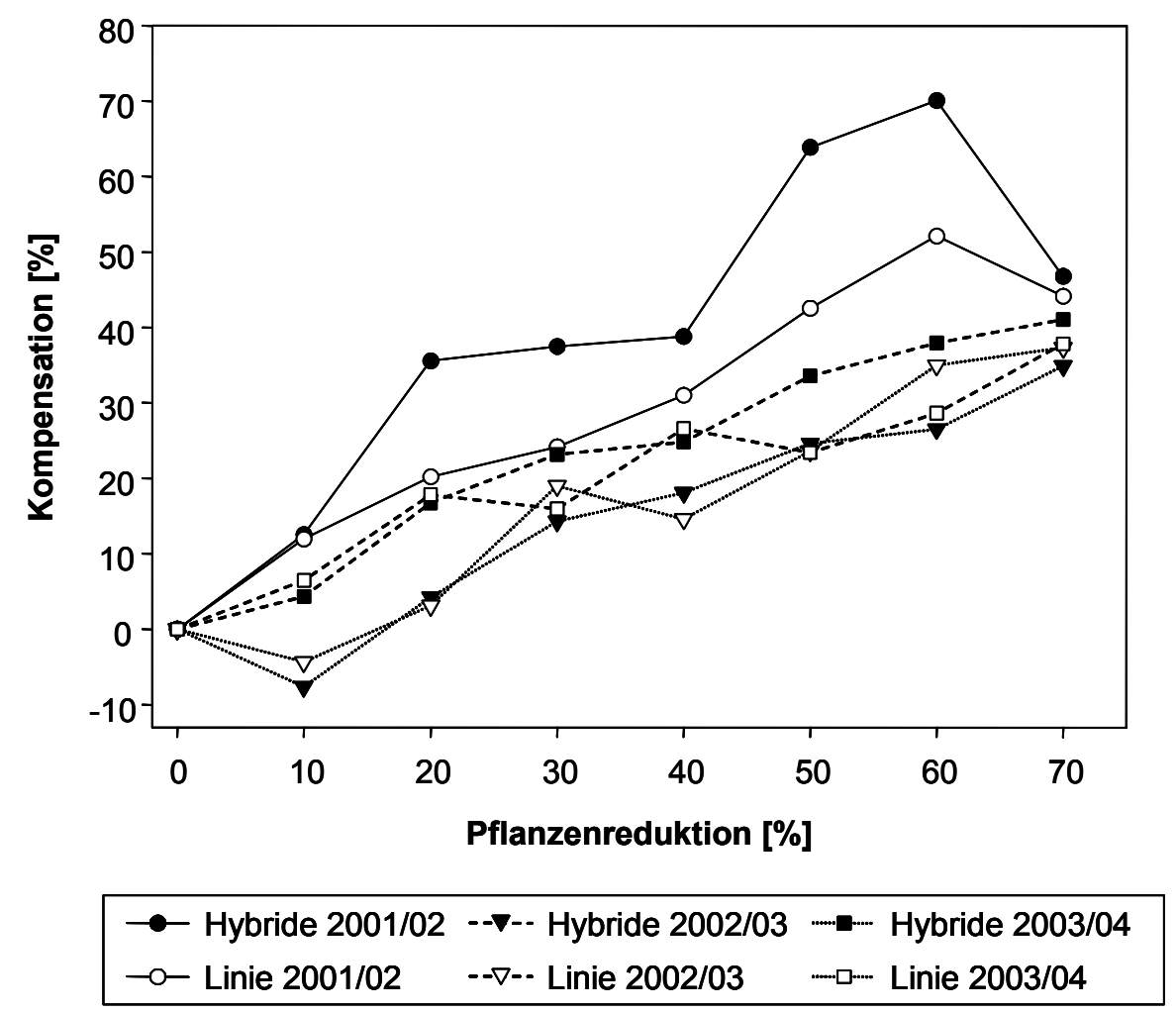

Abb. A1: Kompensation später Pflanzenverluste in Abhängigkeit der Pflanzenreduktion von Hybrid- und Liniensorte in den Versuchsjahren 2001/02 bis 2003/04 an den Standorten „Dragoneranger“, „Große Lage“ und „Große Breite“ in Göttingen-Weende. Sorten: Liniensorte Prince in 2001/02-2003/04, Hybridsorte Talent in 2001/02 und 2002/03 und Maja in 2003/04.
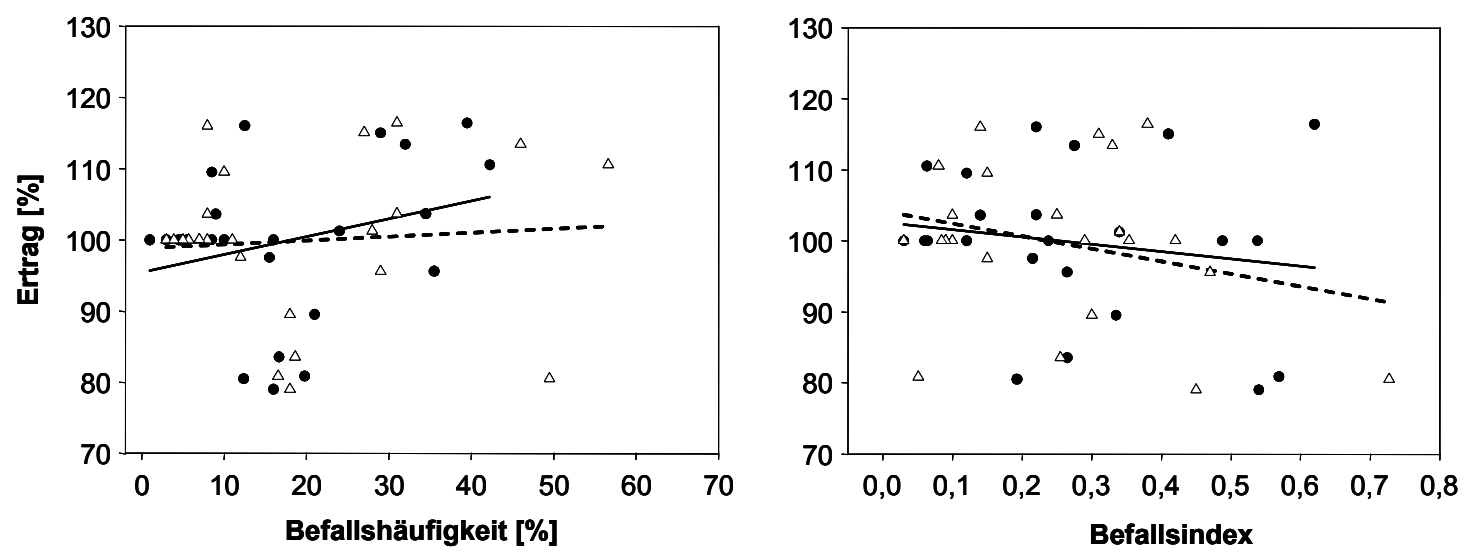

$$
\begin{array}{ll}
\text { • Stängel } & -\triangle \text {. Wurzel } \\
y=95,46+0,25 x & y=98,79+0,06 x \\
r^{2}=0,08 \mathrm{~ns} & r^{2}=0,01 \mathrm{~ns}
\end{array}
$$

\begin{tabular}{|ll|}
\hline • Stängel & $-\Delta$. Wurzel \\
$y=102,59-10,26 x$ & $y=104,23-17,77 x$ \\
$r^{2}=0,03$ ns & $r^{2}=0,08$ ns \\
\hline
\end{tabular}

Abb. A2: Regression zwischen Ertrag und Verticillium-Befallshäufigkeit bzw. Befallsindex getrennt nach Stängel und Wurzel als Mittel über die Versuchsjahre 2002/03 und 2003/04 an den Standorten "Große Breite“ und „Große Lage“ in Göttingen-Weende. Die Signifikanz der Regression wurde mit dem Durbin-WatsonTest überprüft. 


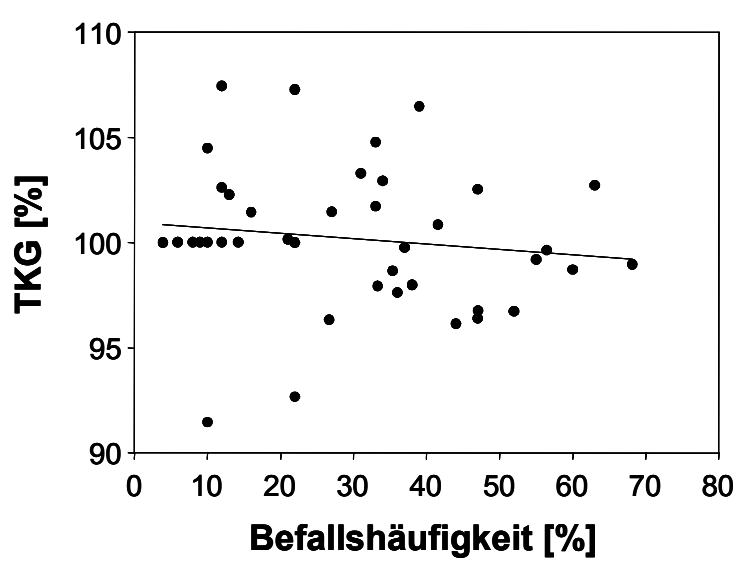

$y=100,96-0,03 x ; r^{2}=0,02^{\text {ns }}$

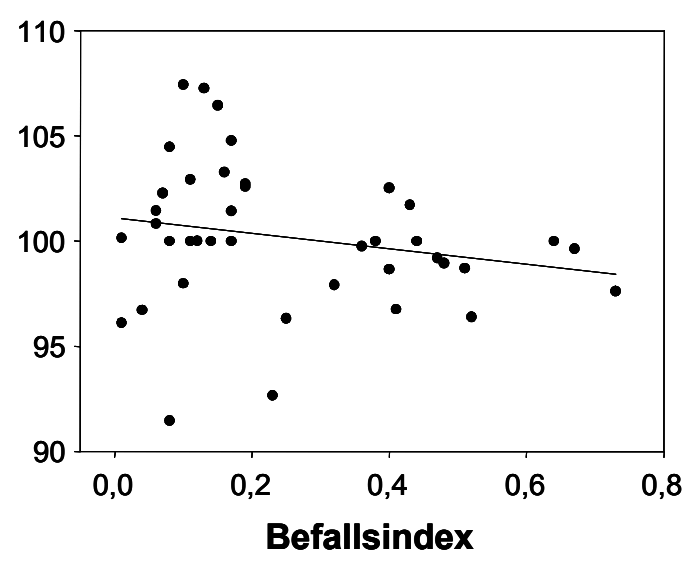

$\mathrm{y}=101,17-3,70 \mathrm{x} ; \mathrm{r}^{2}=0,05^{\mathrm{ns}}$

Abb. A3: Regression zwischen TKG und Verticillium-Befallshäufigkeit bzw. Befallsindex als Mittel über die Versuchsjahre 2002/03 und 2003/04 an den Standorten „Große Breite“ und „Große Lage“ in Göttingen-Weende. Die Signifikanz der Regression wurde mit dem Durbin-Watson-Test überprüft.

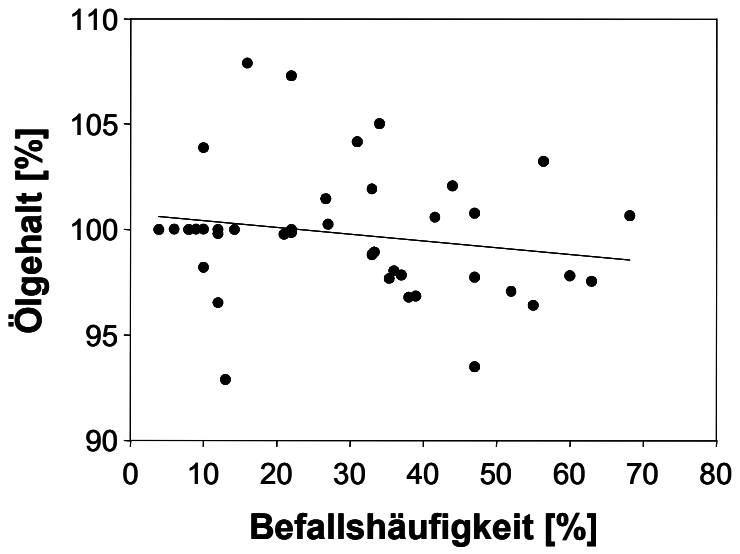

$y=100,74-0,03 x ; r^{2}=0,03^{\text {ns }}$

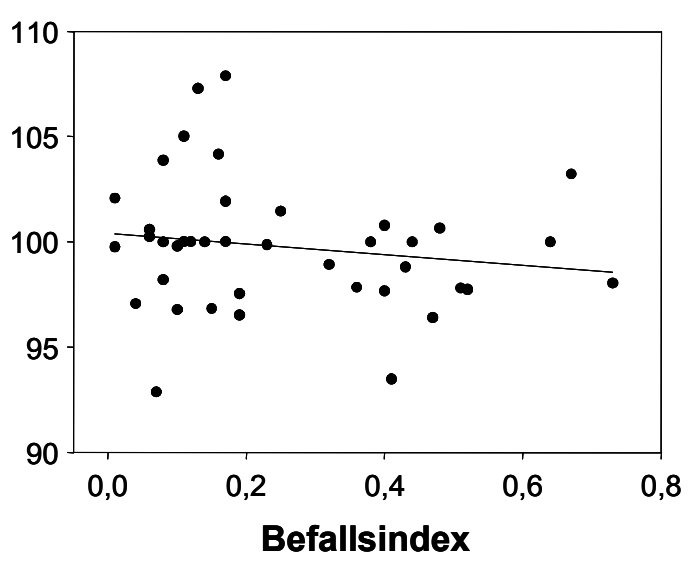

$y=100,42-2,53 x ; r^{2}=0,03^{\text {ns }}$

Abb. A4: Regression zwischen Ölgehalt in Relation zur nicht inokulierten Kontrolle und Verticillium-Befallshäufigkeit bzw. Befallsindex als Mittel über die Versuchsjahre 2002/03 und 2003/04 an den Standorten „Große Breite“ und „Große Lage“ in Göttingen-Weende. Die Signifikanz der Regression wurde mit dem DurbinWatson-Test überprüft. 


\section{Danksagung}

Mein ganz besonderer Dank gilt Herrn Prof. Dr. A. von Tiedemann für die Betreuung, die Gespräche, Diskussionen und Anregungen sowie die in jeder Hinsicht gewährte Freiheit und Unterstützung bei der Durchführung dieser Arbeit.

Bei Herrn Prof. Dr. P. Karlovsky bedanke ich mich für die bereitwillige Übernahme des Korreferats.

Herrn Dr. Birger Koopmann gebührt mein ganz besonderer Dank für die große Unterstützung bei praktischen und geistigen Arbeiten sowie für die immer gewährte Hilfsbereitschaft bei jeglichen Problemen.

Bei Herrn Prof. Dr. G. A. Wolf bedanke ich mich für die Überlassung der Antiseren und bei Herrn Dr. C. Möllers, Institut für Pflanzenbau und Pflanzenzüchtung für die Bereitstellung des Geräts zur Ölgehaltbestimmung.

Bei den Mitgliedern unserer „Sclerotinia-Arbeitsgruppe“ Isabel Müller, Michaela Meyer und Simone Koch sowie bei Evelin Vorbeck und Dagmar Tacke möchte ich mich ganz besonders herzlich für die große technische Unterstützung und Hilfe sowie für ihre Freundschaft bedanken.

Allen fleißigen Helfern sowie allen Hiwis, möchte ich ganz besonders herzlich für die riesige Hilfsbereitschaft und Unterstützung sowie ihren unermüdlichen Einsatz bei der Inokulation, auch wenn es ,ganz schön doll geregnet“ hat, danken.

Der Gewächshaus-Truppe Hubertus Reintke, Eugen Hodyl und Frank Gremmes danke ich für die freundliche Unterstützung bei der Anlage und Durchführung der Feld- und Gewächshausversuche.

Bei allen weiteren Mitarbeitern der Arbeitsgruppe bedanke ich mich ganz herzlichen für die freundliche Atmosphäre und die große Hilfsbereitschaft während meiner Promotionszeit. Bei Frau Bode bedanke ich mich ganz herzlich für die Hilfe und Unterstützung bei allen administrativen Problemen.

Den teilnehmenden Pflanzenschutzdiensten der Länder und der Bundesanstalt danke ich für die Überlassung der Daten aus den Feldversuchen.

Der Deutschen Bundesstiftung Umwelt (DBU) danke ich für die Finanzierung dieser Arbeit.

Zum Schluss gilt mein ganz besonderer Dank meinen Eltern und Freunden für die immer gewährte Unterstützung und das Verständnis und dafür, dass ich mich immer auf sie verlassen kann. 
Name: $\quad$ Sarah Dunker

Geburtsdatum: $\quad 03.02 .1978$ in Helmstedt

Schulausbildung:

1984-1988 Grundschule Hoiersdorf

$1988-1990 \quad$ Orientierungsstufe Eichendorff-Schule Schöningen

$1990-1997$ Gymnasium Anna-Sophianeum Schöningen

Abschluss: Abitur

\section{Hochschulausbildung:}

1997 - 1999 Grundstudium Agrarwissenschaften an der Georg-August Universität Göttingen

1999 - $2002 \quad$ Hauptstudium Agrarwissenschaften an der Georg-August Universität Göttingen, Fachrichtung Pflanzenproduktion

03-06/2001 Auslandsstudium, Kings College Aberdeen, Schottland

2001 - $2002 \quad$ Masterarbeit am Institut für Pflanzenpathologie und Pflanzenschutz der Georg-August Universität Göttingen

20.01.2002 Abschluss M. sc. agr.: „Untersuchungen zu Entwicklung und Ausmaß der durch Rhizoctonia solani (Kühn) verursachten Späten Rübenfäule mit Hilfe serologischer und enzymatischer Nachweisverfahren“"

2002 - $2005 \quad$ Anfertigung einer Dissertation am Institut für Pflanzenpathologie und Pflanzenschutz der Georg-August Universität Göttingen

\section{Praktika:}

03-04/1998 Landwirtschaftskammer Braunschweig

08-10/1998 FAL Braunschweig-Völkenrode

07-10/1999 Betriebspraktikum Betrieb Fromme, Scheppau

09-09/2000 Saatzucht Dieckmann, Sülbeck

\section{Berufliche Tätigkeit:}

03/2002-04/2005 Wissenschaftliche Mitarbeiterin Institut für Pflanzenpathologie und Pflanzenschutz, Universität Göttingen

seit 05/2005 Wissenschaftliche Mitarbeiterin Dienstleistungszentrum Rheinhessen-Nahe-Hunsrück, Bad Kreuznach 


\section{Eidesstattliche Erklärung}

Hiermit erkläre ich eidesstattlich, dass diese Dissertation selbständig und ohne unerlaubte Hilfe angefertigt wurde.

Göttingen, Dezember 2005 